\title{
RE-ENGAGING THE SPIRIT
}

MADISON DOZZI-PERRY 



\section{RE-ENGAGING THE SPIRIT:}

Engaging Traditional Anishinabek Healing Beliefs into an Architecture

For Addiction WellBeing Centres

Madison Dozzi-Perry

Bachelor of Architectural Science

Ryerson University, Toronto, Ontario, Canada, 2016

A Design Thesis|Project

Presented to Ryerson University

In partial fulfillment of the

requirements for the degree of

Master of Architecture

in the program of

Architecture

Toronto, Ontario, Canada, 2016

๑) Madison Dozzi-Perry 2016 


\section{AUTHOR'S DECLARATION}

I hereby declare that I am the sole author of this thesis. This is a true copy of the thesis, including any required final revisions, as accepted by my examiners.

I authorize Ryerson University to lend this thesis to other institutions or individuals for the purpose of scholarly research.

I further authorize Ryerson University to reproduce this thesis by photocopying or by other means, in total or in part, at the request of other institutions or individuals for the purpose of scholarly research.

I understand that my thesis may be made electronically available to the public

Madison Dozzi-Perry 


\section{ACKNOWLEDGMENTS}

I would like to start off by thanking my classmates for always setting the standards high, providing great critiques, fun distractions and good friends. I would like to thank my supervisor, Dr. Leila Farah, for always pushing me to work harder and explore further. As well, my committee members, Scott Sorli and Vincent Hui who were always providing me with insightful and thought provoking critiques.

I would like to thank local contact, my support from the north, and the Anishinabek community members and interviewees that shared their culture and wisdom with me. Thank you for allowing me to learn and grow and providing the greatest asset to my thesis.

I would like to thank my family as a whole, from aunt and uncles to cousins to grandparents, who all rooted for my success since day one. I would like to thank my brothers and my stepparents and in particular my mom. She suffered through every all-nighter and stress fest I had with love, patience and food! Her strength and love is one of the most admirable and influential assets I've had throughout my life, allowing me to flourish and get to the finish line.

Lastly, I would like to thank my dad. As long as I can remember, I have aspired to be, not only the architect and businessman he is, but the person he is. His ability to put a smile on your face in every situation is a skill I hope to have one day. His financial, professional and emotional support has been the greatest and most educational part of this journey. There aren't enough words to express my gratitude.

So, as my dad always says, you're finished this chapter of your life, now onto the next one. 


\section{ABSTRACT}

Current design practices for addiction treatment facilities reflect that of the western perspective on health, providing sterile, monolithic and cold environments. The quest for cleanliness, static and conditioned spaces robs the user of the richness of an engaging experience, isolating them into a sealed box. We further numb and anesthetize patients, disembodying them from the world and hindering their abilities to achieve physical, mental, emotional and spiritual awareness. This disengagement of the natural, human and spiritual realms proliferates the problems facing people with addiction. This thesis proposes an engagement of Anishinabek healing and wellbeing principles to inform the design of addiction healing spaces that stimulate the users, re-engages and enhances one's awareness and understanding of one's self, other beings and place in the world. By incorporating these principles into design, architecture can begin to re-engage the mind, the body, the heart and the soul of people suffering from addiction wellbeing issues. 


\section{TABLE OF CONTENTS}

RE-ENGAGING THE SPIRIT

Authors Declaration

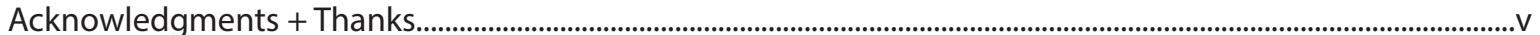

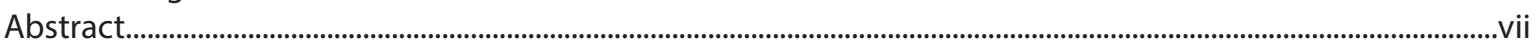

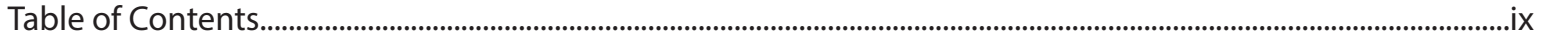

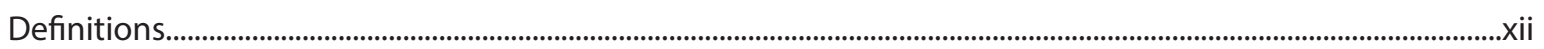

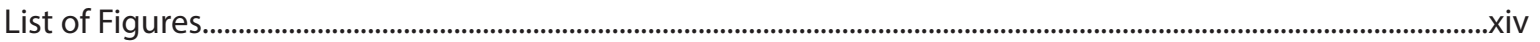

$1.0 \quad$ INTRODUCTION

$2.0 \quad$ METHODOLOGY + SOURCES

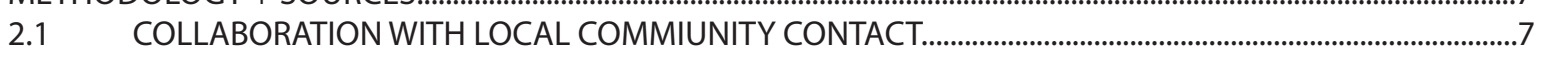

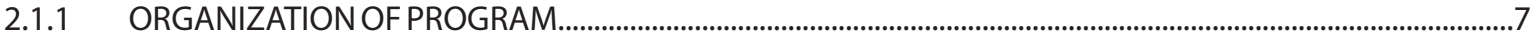

2.1 .2 DEVELOPMENT OF SPATIAL REQUIREMENTS ................................................................................................

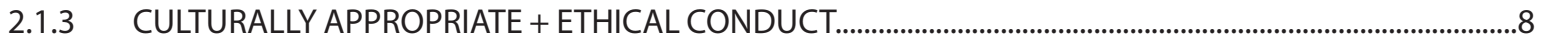

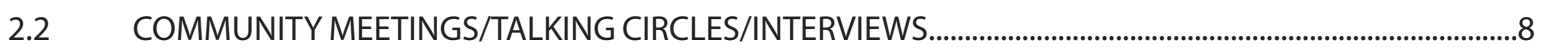

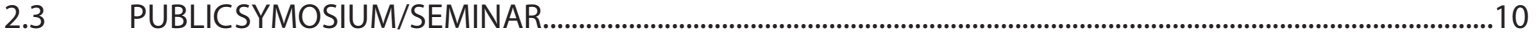

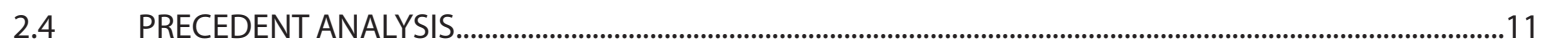

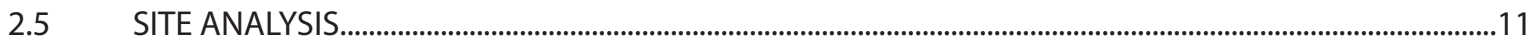

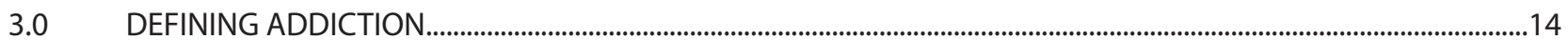

3.1 ADDICTED SOCIETY + ADDICTED MINDS: THE JOURNEY TO THE MODERN CRISIS..............................14

3.2 SCIENTIFIC REVOLUTION AND MODERN TECHNOLOGY.............................................................................16

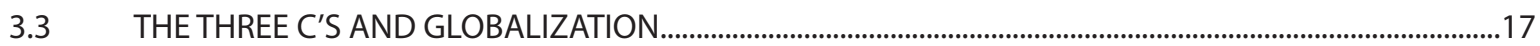

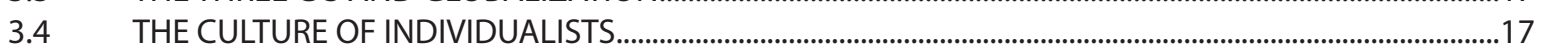

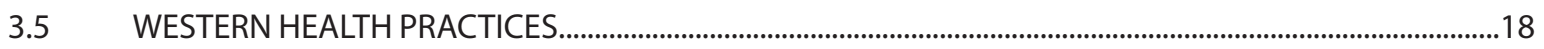

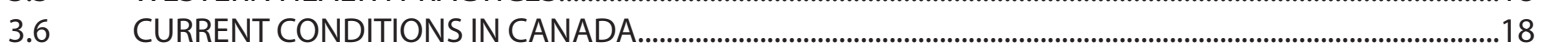

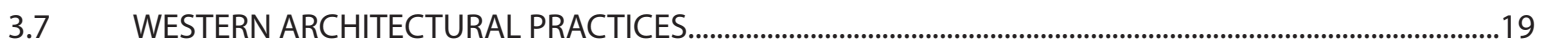

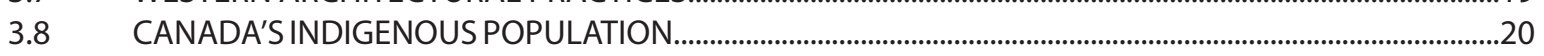

3.9 THE EVOLUTION OF THE OFFICIAL VIEW OF ADDICTION

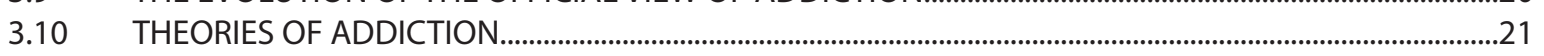

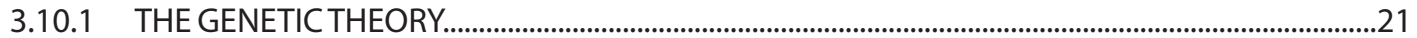

3.10.2 THE EXPOSURETHEORY...........................................................................................................................2

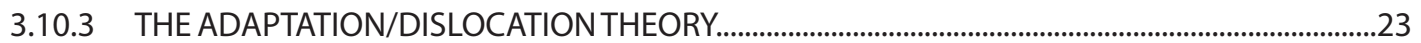

3.11 THE RIPPLE EFFECT: CO-OCCURING MENTAL HEALTH DISORDERS...........................................................23

3.12 PERSPECTIVES ON THE PROLIFERATION OF ADDICTION IN INDIGENOUS COMMUNITIES.................23

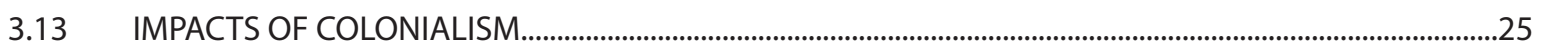

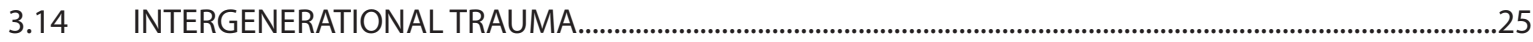

3.15 LACK OF INFRASTRUCTURE + SOCIAL DEGRADATION 


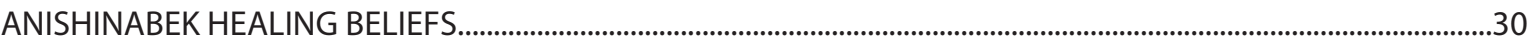

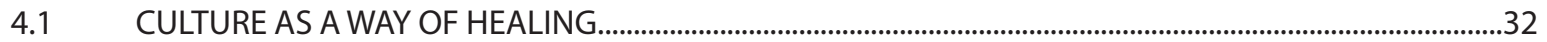

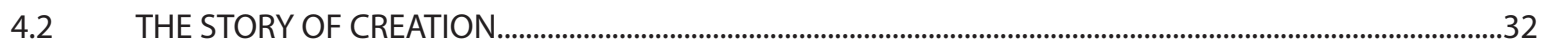

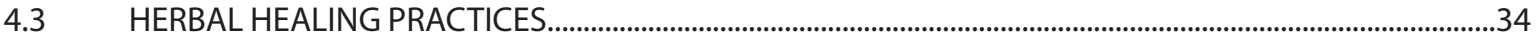

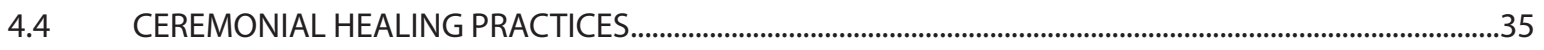

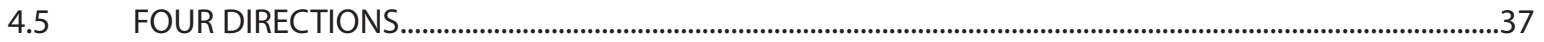

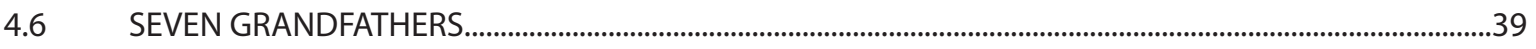

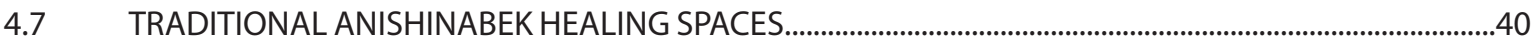

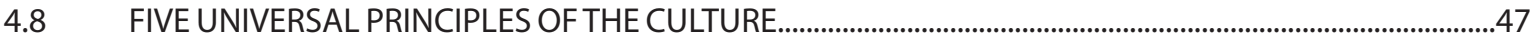

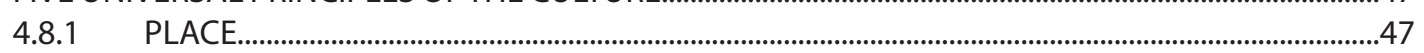

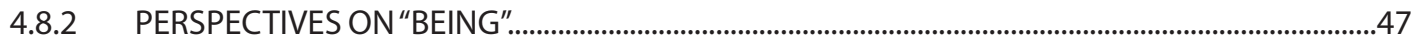

INTERRELATED WORLD

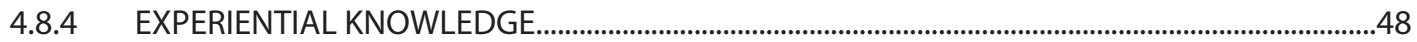

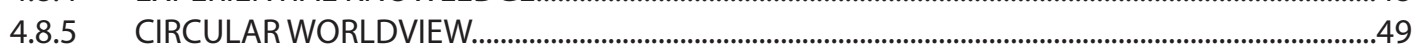

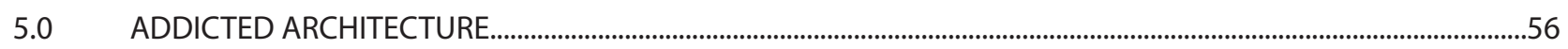

6.1 THE EVOLUTION OF ADDICTION TREATMENT FACILITIES IN NORTH AMERICA.......................................56

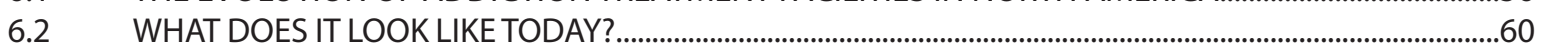

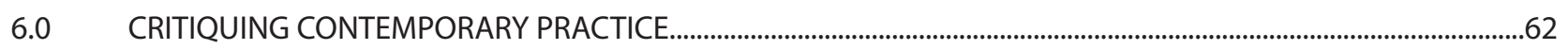

7.1 CENTRE FOR ADDICTION AND MENTAL HEALTH

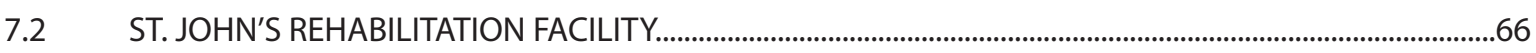

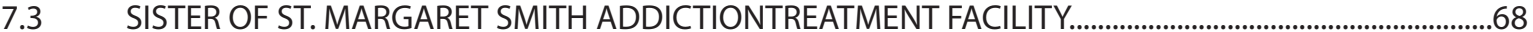

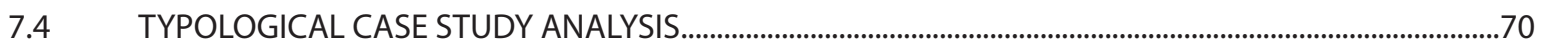

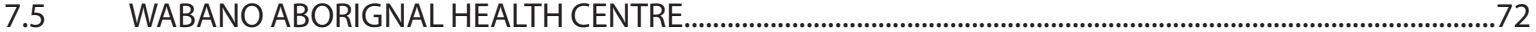

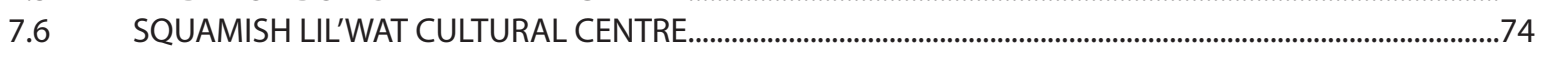

7.7 THE CENTRE FOR NATIVE CHILD AND FAMILY WELLBEING .........................................................................

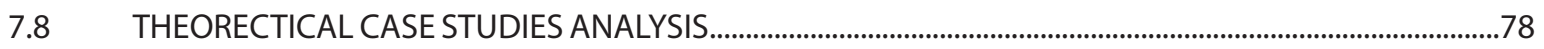

7.0 ARCHITECTURAL HEALING

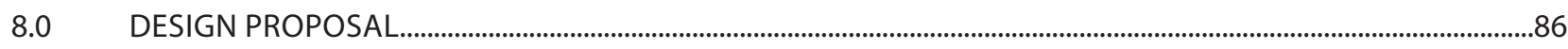

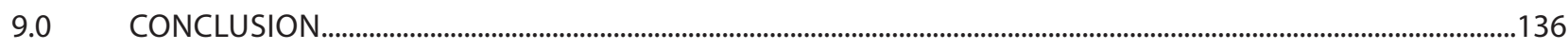

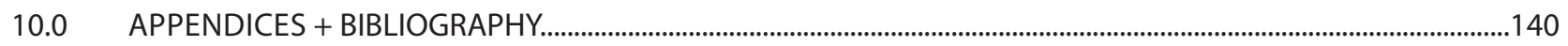




\title{
DEFINITIONS + CONTEXT
}

\author{
RE-ENGAGING THE SPIRIT
}

\section{INDIGENOUS}

"Originating or occurring naturally in a particular place; native." [1] Historically, in Canada, the terms native, Aboriginal or Indian have been used, however, it has been recognized that these terms can be offensive and associated with the assimilation and colonization by the Europeans. Therefore, this thesis will be using the word indigenous when referencing the First Peoples. The thesis acknowledges the vast complexities and differences among indigenous people globally, however when referring to "indigenous" the thesis is focusing on North American indigenous groups, particularly within Canada.

\section{ANISHINABEK}

"Anishinaabe or more properly Anishinaabeg or Anishinabek (which is the plural form of the word) is a collective term that refers to the Ojibway, Odawa and Algonkin Peoples, who all share closely, related Algonquian languages." [2]

When discussing Anishinabek the thesis and research recognizes the vast groups and geographies that fall under Anishinabek, but has particularly conducted research with the Anishinabek of Manitoulin Island.

\section{TRADITIONAL}

"The transmission of customs or beliefs from generation to generation, or the fact of being passed on in this way." [3]

This thesis uses the terms tradition and/or traditional in the context of Indigenous and Anishinabek people, their customs, beliefs and practices within North America, Canada and Northern Ontario.

\section{ADDICTION}

When referring to addiction, this thesis recognizes the adaptation-dislocation theory of addiction. This view does not solely focus on and reduce addiction to alcohol and drug use as addictive substances. Therefore, this broadens the understanding of addiction. [8] In this theory, addiction is depicted as a way of adapting to the "increasingly dominant and onerous aspects of the modern world" along with the concept of intergenerational trauma.[9] This theory acknowledges the lack of wellbeing that history and current societal systems have provided to human beings and the earth, from the systems that are in place to the built environment around us that reflect and enforce these systems.[10] This thesis does not claim that genetic and biological factors are not relevant in the manifestation of addiction, however, it focuses on the environmental factors that contribute to the manifestation of addiction.

\section{BEING}

"Being" can be defined as "existence" or "the nature or essence of a person." [11] In typical western perspectives and semantics, personhood is defined by being a human. "Person: a human being regarded as an individual."[12] This definition of person or personhood does not align with the Anishinabek perception of person or being, which states that any and all elements are beings and personhood does not have a direct correlation to the concept of being. [13] For example, a tree in a western sense is a natural object and in an Anishinabek sense is a non-human being. Therefore, when referring to beings in this thesis, it is recognizing the latter definition, as all elements and forces recognized as beings.

\section{ENVIRONMENT}

Environment is "the surroundings or conditions in which a person, animal, or plant lives or operates" [14] When referring to the word 'environment' this thesis is referring to the physical, emotional, mental and spiritual conditions and surroundings. If we refer to the definition for "Beings", we see that in this thesis, personhood and beings are not tied and when referring to the environment it includes all beings in its definition, unless otherwise stated. 


\section{HEALING}

This thesis defines healing as the journey to wellbeing, wellbeing as defined in this thesis. To heal is to be balanced and to recognize the ailment, not mask it with drugs or superficial treatments. In the Anishinabek traditions, culture and way of life is the dominant healing tool. The practices, social dynamics and connections to other beings [animate and inanimate] define the healing process. This thesis recognizes the non-linearity, complexity and the interwoven aspects of healing that overlap in all realms of life and acknowledges healing as an active agent in day to day living

\section{MENTAL HEATH}

Mental health is defined, in the Western, North American context, as "a person's condition with regard to their psychological and emotional wellbeing." [4] It is recog nized by many agencies across Canada that achieving good mental health requires a balance between the emotional, spiritual, economic, physical, mental and social aspects of one's life. The term mental health covers a large range of conditions, such as depression addiction, bipolar disorder, and anxiety. [5] This thesi focuses on mental health treatment for addiction and the co-occurring disorders that often accompany it.

\section{WELLBEING}

The term wellbeing, when discussed in this thesis, re fers to the Anishinabek concept of health. It focuses on the balance between earth, body, mind and spirit and shares some commonalities with the conception of mental health in Western Canadian culture such as finding the balance in all realms of one's life. In Anishinabek, the closest term for health or wellbeing is "mnaamodzawin," meaning a "good, holistic way of life."[6] There is no distinction between different types of health they all are one and the same. [7]

\section{NATURE/LANDSCAPE}

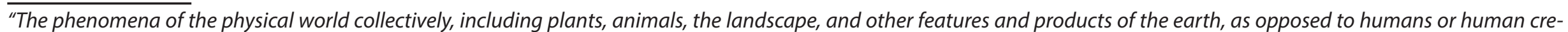

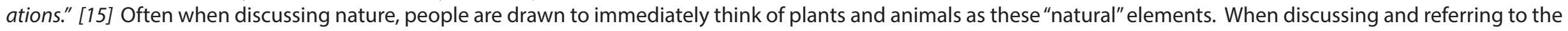

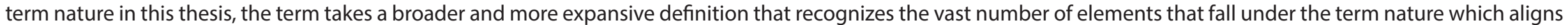

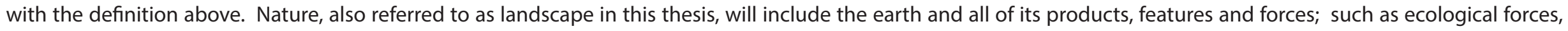
gravitational forces, all weather phenomenon, geology and geological forces, and will also include any cosmological products, features and forces.

[1] "Definition of Indigenous in English." Oxford Dictionaries. Oxford University Press. Web. <http://www.oxforddictionaries.com/definition/english/indigenous>.

[2] "Anishinaabe Indigenous Peoples."Intercontinental Cry: A Publication of the Centre of World Indigenous Studies. CWIS: Centre for World Indigenous Studies, Oct. 2011. Web. <https://intercontinentalcry.org/indigenous-peoples/anishinaabe/>.

[3] "Definition of "Tradition" in English::" Oxford Dictionaries. Oxford University Press, n.d. Web. <http://www.oxforddictionaries.com/definition/english/tradition>.

[4] "Your Mental Health - Centre for Addiction and Mental Health." Centre for Addiction and Mental Health. University of Toronto. Web.

$<$ http://www.cmha.ca/mental-health/your-mental-health/>.

[5] "About Mental Health and Mental Health Problems." Centre for Addiction and Mental Health. University of Toronto. Web. <http://www.camh.ca/en/hospital/visiting_camh/rights_and_policies/Pages/challenges_choices_aboutmhprob.aspx>.

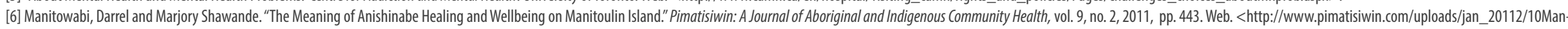
itowabiShawande.pdf $>$

[7] Manitowabi, Darrel and Marjory Shawande. "The Meaning of Anishinabe Healing and Wellbeing on Manitoulin Island." Pimatisiwin: A Journal of Aboriginal and Indigenous Community Health, vol. 9, no. 2, 2011, pp. 441-55. Web.

[8] Alexander, Bruce. "The Rise and Fall of the Official View of Addiction." Bruce K. Alexander. Simon Fraser University, Burnbay, British Columbia, July, 2014. Web.

<http://www.brucekalexander.com/articles-speeches/277-rise-and-fall-of-the-official-view-of-addiction-6>.

[9] Alexander, Bruce. "The Rise and Fall of the Official View of Addiction." Bruce K. Alexander. Simon Fraser University, Burnbay, British Columbia, July, 2014. Web.

[10] Alexander, Bruce. “The Rise and Fall of the Official View of Addiction." Bruce K. Alexander. Simon Fraser University, Burnbay, British Columbia, July, 2014. Web.

[11] "Definition of Being in English." Oxford Dictionary. Oxford University Press. Web. <http://www.oxforddictionaries.com/us/definition/american_english/being?q=being\%2B $>$.

[12] "Definition of Person in English." Oxford Dictionary. Oxford University Press. Web. <http://www.oxforddictionaries.com/us/definition/american_english/person>.

[13] Norton-Smith, Thomas M. The Dance of Person and Place: One Interpretation of American Indian Philosophy. State U of New York, Albany, NY, 2010, pp. 85-86.

[14] "Definition of Environment in English." Oxford Dictionary. Oxford University Press. Web. <http://www.oxforddictionaries.com/us/definition/american_english/environment>.

[15] "Definition of Nature in English." Oxford Dictionary. Oxford University Press. Web. <http://www.oxforddictionaries.com/us/definition/american_english/nature>. 


\section{RE-ENGAGING THE SPIRIT}

Figure 1. Image from Photographer Eric Pickersgrill Removed Series, pg. 15.

Source: http://www.removed.social//lwxiphis5oh03erg0bb6pxyrtibb0

Figure 2. March of Science (Paleo Future) by Alexander Leydenfrost in 1952, pg 16. Source: March of Science Alexander Leydenfrost, http://www.p10designstudio.com/ the-new-industrial-revolution/

Figure 3. The Ford Assembly Line in Highland Park Michigan in $1913 \mathrm{pg} 16$. Source: https://www.college.columbia.edu/core/content/ford-assembly-line-1913

Figure 4. The Dislocation Theory of Addiction from Bruce Alexander redrawn by Author $\mathrm{pg} 22$. Source: Oreo Diagram by Bruce Alexander, Redrawn by Author . http://www.brucekalexander. com/articles-speeches/277-rise-and-fall-of-the-official-view-of-addiction-6

Figure 5. 0jibwe First Nation Water Trail, pg 31.

Source: http://www.crystalinks.com/ojibwa.html

Figure 6. Western vs. Canadian Indigenous World View Adapted and Redrawn by Author, pg 33. Source: http://www.roamingthemind.com/snake-medicine-how-shamanism-heals

Figure 7. Western versus Canadian Aboriginal Healing Process by Author, $\mathrm{pg} 33$.

Figure 8. Pow Wow Ceremony, pg. 35.

Source: http://www.manitoulin.ca/2015/09/09/mchigeeng-powwow-cele-

brates-28-years-of-honoring-traditions/

Figure 9. Anishinabek Art: Healing the Earth by Janice Toulouse, pg. 36

Source: http://janicetoulouse.weebly.com/new-paintings.html

Figure 10. Smudging Ceremony, pg. 36

Source: http://powwow-power.com/smudging/

Figure 11. Medicine Wheel Graphic by Author, pg. 38.

Figure 12. Sweat Lodge Analysis by author Overlaid on Peter Nabokov drawing, pg. 40.

Figure 13. Indigenous Sweat Lodge, pg. 41.

Source: http://indianbowlproject.org/ojibwe-culture/

Figure 14. Longhouse Analysis by author Overlaid on Long House drawing, pg. 42. Source: http://shortstreet.net/NA/nalonghous.htm

Figure 15. Long House Canadian Indigenous Architecture, pg. 43. Source: https://en.wikipedia.org/wiki/Wyandot_people

\section{Figure 16. Landscape by Author, pg. 45}

Figure 17. Comparison between Western Health + Canadian Indigenous s Health with lin showing where current addiction treatment lies drawn by Author, pg. 46 .
Figure 18. The Seventh Direction - Well Being + Balance drawn by Author, pg. 50 . Source: Nabokov, Peter, and Robert Easton. Native American Architecture. Oxford University Press, New York, NY, 1989, pp. 72

Figure 19. The Evolution of Addiction Treatment and Addiction Treatment Spaces by Author pg. 56-57

Figure 19a. Indigenous Talking Circle, pg. 56-57

Source: http://qualcosadaltro.blogspot.ca/2013/03/aborigeni-saggezza-e-conoscenza.html

Figure 19b. Start of Temperance Movement, pg. 56-57

Source: http://www.riverwashbooks.com/si/HIS3074.html

Figure 19c. Centre for Addiction and Mental Health 1850, pg. 56-57

Source: http://www.camh.ca/en/hospital/about_camh/_AMH_redevelopment/history_of_ queen_street_site/Pages/history_of_queen_street_site.aspx

Figure 19d. Keeley Institutes Opening Across North America, pg. 56-57 Source: https://www.cardcow.com/166941/keeley-institute-white-plains-new-york/

Figure 19e. Halfway House Movement, pg. 56-57

Source: http://www.blogto.com/city/2014/03/what_kingston_road_used_to_look_like_ in toronto/

Figure 19f. 1956 Canadian Addiction and Mental Health Center, pg. 56-57

Source: $h$ tttp://www.camh.ca/en/hospital/about_camh/CAMH_redevelopment/history_of_ queen_street_site/Pages/Historical_Chronology.aspx

Figure 19g. Award Winning St. John's Rehab, pg. 56-57

Source: http://sunnybrook.ca/content/?page=st-johns-rehab-address-map-directions-parking

Figure 19h. CAMH Urban Village Design Proposal, pg. 56-57

Source: http://www.camh.ca/en/hospital/about_camh/CAMH_redevelopment/history_of queen_street_site/Pages/Historical_Chronology.aspx

Figure 20. Sqaumish Lil'Wat Cultural Centre, pg. 63 Source: https://sicc.ca/

Figure 21. St. John's Rehab, pg. 63

Sourcehttp://www.montgomerysisam.com/projects/st-john\%E2\%80\%99s-rehab-hospital

Figure 22. Wabano Health Centre, pg. 63

Source: http://vaniernow.blogspot.ca/2013/07/photos-of-week-wabano-centre-for.htm

Figure 23. Sisters of St. Margaret Addictions Treatment Facility, pg. 63

Source: http://www.archdaily.com/109414/sister-margaret-smith-addictions-treatment-centre-montgomery-sisam-architects

Figure 24. Center for Addiction and Mental Health, pg. 63

Source: http://www.montgomerysisam.com/projects/centre-addiction-and-mental-health-phase-1b
Figure 25. Native's Child and Family Services, pg. 63

Source: http://www.archdaily.com/120391/native-child-and-family-services-of-toronto-levitt-goodman-architects

Figure 26-30. Centre for Addiction and Mental Health, pg. 64-65 Source: http://kmai.com/projects/the-centre-for-addiction-mental-health-phase-1a

Figure 31-35. St. John's Rehab, pg 66-67

Source: http://www.montgomerysisam.com/projects/st-john\%E2\%80\%99s-rehab-hospital

Figure 36-40. Sister of St. Margaret Smith Treatment Facility, pg. 68-69

Source: http://www.montgomerysisam.com/projects/sister-margaret-smith-addictions-treat ment-centre

Figure 41-45. Wabano Health Centre, pg. 72-73

Source: http://pamfitzgeraldottawa.blogspot.ca/2014_01_01_archive.htm

Figure 42-44. Squamish Lil'Wat Cultural Centre, pg. 74-75

Source: http://www.formline.ca/SQUAMISH-LIL-WAT-CULTURAL-CENTRE

Figure 45-47. Centre for Native Child and Family Well-Being, pg. 76-77 Source: http://lga-ap.com/project/ncfs30college 78-79

Figure 48. Architectural Design Strategies Through an Anishinabek Perspective by Author, pg. 85

Figure 49. The Harmony of Healing by Author, pg. 85

Figure 50. View Approaching Site from the Parking Lot + Road by Author, pg. 89

Figure 51. Site Plan by Author, pg. 91

Figure 52. Site Section by Author, pg. 92-93

Figure 53. Underground Level Floor Plan by Author, pg. 94

Figure 54. Ground Level Floor Plan by Author, pg. 95

Figure 55. Level Two Floor Plan by Author, pg. 96

Figure 56. Level Three Floor Plan by Author, pg. 97

Figure 57. Permeability Diagram by Author, pg. 98

Figure 57. Permeability Diagram by Author, pg. 99

Figure 58. NW View of Design Proposal by Author, pg. 98-99

Figure 59. View from Ramp to Enter Site/Building by Author, pg. 100

Figure 60. Progression into the Building by Author, pg. 101 
Figure 61. Site Rock Erosion and Formation Analysis by Author, pg. 102

Figure 62. Entering the Building - "In between "by Author, pg. 104

Figure 63. Overlapping Planes + Spaces by Author, pg. 105

Figure 64. Layers of Time, by Author pg. 105

Figure 65. Emerging Elements by Author, pg. 105

Figure 66. Section through Main Entrance + Café by Author, pg. 106

Figure 67. Framing Views and Connections to the Landscape, by Author pg. 107

Figure 68. View from Stairs down to Café by Author, pg. 108

Figure 69. View to Intake Hall and Administrative Offices by Author, pg. 109

Figure 70. Intake + Administration Reception by Author, pg. 110

Figure 71. Administrative Office by Author, pg. 111

Figure 72. Transition to Atrium/Gymnasium by Author pg. 111

Figure73. Longitudinal Section of Administrative space + Atrium - Summer by Author pg. 112-113

Figure74. Longitudinal Section of Administrative space + Atrium - Rainfall by Author, pg. 114-115

Figure75. Longitudinal Section of Administrative space + Atrium - Winter by Author, pg. 116-117

Figure 76. View in Atrium towards Gathering Space by Author, pg. 118

Figure 77. View from Outdoor Gathering Space by Author, pg. 120

Figure 78. View in Atrium by Author, pg. 121

Figure 79. Interactive Elements by Author, pg. 122

Figure 80. Ecological Features by Author, pg. 122

Figure 81. Extending the Landscape by Author, pg. 122

Figure 82. Level Two Management Office Level by Author, pg. 123

Figure 83. View from Residential Street To Main Building by Author, pg. 124

Figure 84. Semi Covered Multi-Use Space by Author, pg. 125
Figure 85. View North on Residential Street by Author, pg. 125

Figure 86. View North from Boardwalk by Author, pg. 125

Figure 87. Residential Site Plan by Author, pg. 126

Figure 88. Residential Street Plan by Author, pg. 127

Figure 89. Residential Plan-Zoomed by Author, pg. 128

Figure 90-91. Zoomed in Aftercare Care Unit Floor Plan by Author, pg. 129

Figure 92. View Approach Residential Street by Author, pg. 130

Figure 93. Main Entrance to Residential Unit by Author, pg. 131

Figure 94. View of Residential Dining + Kitchen by Author, pg. 132

Figure 95. View of Residential Living Room by Author, pg. 132

Figure 96. View of Entering the Residential Unit by Author, pg. 132

Figure 97. View of Residential Bedroom Hall by Author, pg. 133

Figure 98. View of Residential Bedroom Hall by Author - Closed Louvres by Author, pg. 133

Figure 99. Section through Residential Bedrooms + Hall by Author, pg. 135

Figure 100-101. Photographs of Site, pg. 141

Source: https://ssl.panoramio.com/photo/34548845

Figure 102. Site Photos- Winter by Author, pg. 142-143

Figure 103. Site Photos- Summer by Author, pg. 144-145

Figure 104. Context Photos- Winter by Author, pg. 144-145

Figure105. Site Sections through marsh and uphill by Author, pg. 146-147

Figure106. Preliminary Site Sketches by Author, pg.148

Figure 107. Healing Treatment Program developed by Collaborator and Community Council drawn by Author, pg. 150

Figure 108. Site Key Functional Relationships by Author, pg. 151

Figure 109. Preliminary Building Key Functional Relationships by Author, 151

Figure 110. Preliminary Building Spatial Requirements by Author, pg. 152

Figure 111. Photographs of Spatial Relationship Development Exercise by Author, pg. 153
Figure 112. Milestone 3: View towards ramp entrance by Author, pg. 154

Figure 113. Milestone 3: Administrative Entrance Foyer by Author, pg. 154

Figure 114. Milestone 3: Hall to Atrium Space by Author, pg. 155

Figure 115. Milestone 3: Hall to Administration \#2 + Intake by Author, pg. 155

Figure 116. Milestone 3: Second Administrative Space by Author, pg. 155

Figure 117. Milestone 3: Atmospheric Site View by Author, pg. 154

Figure 118. Milestone 3: Atmospheric Site View 2 by Author, pg. 157

Figure 119. Milestone 3: Middle Ground - Inside + Out View by Author, pg. 158 
INTRODUCTION 
"In a decaying society, art, if it is truthful, must also reflect decay and unless it wants to break faith with its social function, art must show the world as changeable and help change it."

\section{$1.0 \quad$ INTRODUCTION}

As humans we crave connection, it is engraved into our biological makeup,[1] a connection to anything, through any means. This is why we see such success in technological forums, such as Facebook, Instagram or Snapchat. These vessels of communication provide a digital environment which allows for a type of connection that, perhaps, our environments are currently not providing. However, these means of connection, from a perspective of authenticity, face-to-face relationships and experiential capacity building, are hindering humans and their relations to other beings. They further, physically, emotionally, spiritually and mentally remove people from the world, from other people and from themselves, providing an escape from the neglectful and impoverished environments of their daily lives. This escape, quest and thirst humans feel for a connection and a meaningful purpose, leads its way to an impoverished society, plagued with the proliferation of physical, mental, psychological and emotional disorders. [2] Addiction is a manifestation of the need to escape or numb and is one of the largest mental health problems in North America.[3] Now, more than ever, we are seeing addiction in every aspects of life, from drugs, alcohol, food, internet, sex, tanning, hording, technology, work, religion, money, exercise and so on. "Addiction is an extreme example of an existential challenge we all wrestle with every day: accepting reality as it is... addiction is all about escapism, avoidance and denial. Addicts run from reality, and, in some cases, have been running all their lives. The addict cannot tolerate reality and its vicissitudes. Neither internal reality or external reality." [4]

As stated by Ernst Fischer, in the opening quote, "art must also reflect decay and unless it wants to break faith with its social function, art must show the world as changeable and help change it." [5] Architecture is both a science and an art, it is the bridge between these two fields which have seemed to be at odds for centuries in western philosophy and epistemology.[6] However, in reality, art and science both attempt to do the same thing, "find order within chaos."[7] Ernst Fischer continues to argue that, art [or architecture], struggles in our capitalist society to be art, to be free of the monetary, leisure and luxury aspects that capitalism traps art in and attempts to control it.[8] As architects, we directly and indirectly contribute to these problems of addiction and proliferate capitalist ideals through architecture. We are the creators of these spaces, of the built environment in which our addicted society lives. In particular, our current design practices for addiction treatment facilities follow suit with the rest of our western societal practices and further produce spaces that disembody its users who are already suffering with these serious conditions. Though it is not the architect's sole responsibility to remedy these failures, as repair cannot be done without a drastic shift in our societal perspectives as a whole, it is one profession that has a strong role in how societies are shaped. As architects, how do we begin to address this phenomenon, where our capitalist society does not let architecture be an art or science and reduces its social function to economic efficiencies and individual interests? It may seem like a daunting task, but out of all of the arts, architecture has the most potential to make an impact.

This thesis explores how architecture can create healing spaces that break away from the economic and capitalist confines of our North American, western society that shape our current architectural practices. The thesis explores how the traditional Canadian Indigenous Anishinabek culture and healing beliefs can be incorporated architecturally through the design of a Community and Residential Wellbeing Addiction Wellbeing Facility. The term 'addiction wellbeing' verus 'addiction treatment' is used becuase healing requires an overall wellbeing of an individual, family, community and earth. The facility will be both a community centre and residential treatment that provides a transition place for people who have previously undergone detoxification programs, yet, are not ready to re-enter the community without support. This thesis does not posit to revert to the past ways of living of the Anishinabek. It proposes an intersection between indigenous Anishinabek healing beliefs and principles and contemporary western treatment programs and facilities, through the exploration of how it can be manifested through architecture. 
[1] Cook, Gareth. "Why We Are Wired to Connect." Scientific American Global RSS. Scientific American Online, 22 0ct. 2013. Web. <http://www.scientificamerican.com/article/why-we-are-wired-to-connect/>.

[2] Alexander, Bruce. "The Rise and Fall of the Official View of Addiction." Bruce K. Alexander. Simon Fraser University, Burnbay, British Columbia, July 2014. Web. <http://www.brucekalexander.com/articles-speeches/277-rise-and-fall-of-the-official-view-of-addiction-6> [3] Alexander, Bruce. "The Rise and Fall of the Official View of Addiction." Bruce K. Alexander. Simon Fraser University, Burnbay, British Columbia, July 2014. Web.

[4] Diamonds, Stephen A. “Avoidance, Sobriety and Reality: The Psychology of Addiction." Psychology Today. Sussex Publishers, Feb. 2010. Web. <https://www.psychologytoday.com/blog/evil-deeds/201002/avoidance-sobriety-and-reality-the-psychology-addiction> [5] Fischer, Ernst, John Berger, and Anna Bostock. The Necessity of Art. Verso, London, England 2010, pp. 48.

6] Moore, Charles W. "Architecture: Art and Science."Journal of Architectural Education (1947-1974), vol. 19, no. 4, 1965., pp. 53-56. Web. <http://www.jstor.org.ezproxy.lib.ryerson.ca/stable/1424258?pq-origsite=summon\&seq=1\#page scan tab_contents >

[7] Moore, Charles W. “Architecture: Art and Science." Journal of Architectural Education (1947-1974), vol. 19, no. 4, 1965., pp. 53-56. Web. [8] Alexander, Dominic. "Ernst Fischer, The Necessity of Art: A Marxist Approach." Counterfire. University of Cambridge, 23 July 2010. Web. $<$ <htp://www.counterfire.org/articles/book-reviews/6012-ernst-fischer-the-necessity-of-art-a-marxist-approach> 
METHODOLOGY + SOURCES 


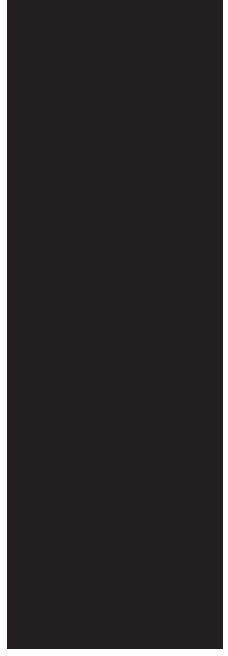

\subsection{METHODOLOGY + SOURCES}

A literature review was conducted to gain knowledge on different perspectives from three subjects; architecture, the North American Indigenous culture, with a specific focus on Canadian Indigenous groups, particularly the Anishinabek culture, and addiction theories and treatments. Literatures that overlapped these fields and/or were specific to the Anishinabek culture or the geographical area of the site were of specific focus and relevance, as well as scholarly research that originated from Northern Ontario or the surrounding communities. The literature included books, academic journals, government documents, scholarly articles, websites, university dissertations and theses and videos (interviews and documentaries). The research was sourced from the fields of architectural, psychology, sociology, biology, and anthropology. With the exception of some classical and seminal texts or when referencing precedent theories, research sourced stayed within the past 30 years. The research has acknowledged the differences that exist between the United States and Canada, between east, central and western Canada and between individual indigenous communities. This is why different research methods have been employed, including consultations with Northern Ontario Anishinabek community members and talking circles held with the Anishinabek community where the project is proposed, interviews, precedent studies, site analysis and attending symposiums and seminars on Canadian Indigenous issues.

I would like to note that prior to the development of this thesis I have worked on numerous architectural projects within a Northern Ontario Indigenous context. This is mentioned only to recognize past experience and knowledge working within this setting and within this culture. The firm I work at often works with indigenous communities on architectural projects, therefore, my experience, though not extensive, extends beyond the realm of this thesis.

I would like to recognize that I am aware that possible criticisms might be directed my way, as I am a non-indigenous person studying the Anishinabek culture. I would like to make it clear that I am not speaking for or on behalf of anyone other than myself. I understand the sensitivity and politics of cross-cultural research and ensured that throughout all of my research work I understood that I was an outsider who was privileged to be given the opportunity to engage with the culture. The research I have conducted is from my viewpoint as a non-indigenous, architecturally trained individual. I do not claim that my findings and conclusions are applicable to all Anishinabek groups. My research conclusions represent my interpretation of the knowledge shared with me through community meetings and interviews, literature research and my own education and personal experiences and is my interpretation of the relationship between the Anishinabek culture, addiction and architecture's role. 
The project taken on for this thesis required the expertise and external consultation with a third party who works in the Indigenous Anishinabek Community in which the project is situated, is a registered Social worker, works in Native human services and has been working on an Indigenous model for residential Mental Health and Addictions Treatment. Constant communication and collaboration was required in order to understand and develop the program, determine base level spatial and functional requirements and to ensure culturally and ethically appropriate conduct was adhered to. The collaborator also provided a medium in which I could keep the members of the community informed and aware of the project. Frequent emails, phone calls and face to face meetings were held in order to maintain contact and flow of information. Due to the geographical distance from the site/community, visits were held every few months.

\subsubsection{ORGANIZATION OF PROGRAM}

The project was born out of a strong need in the area over the past couple of years. Upon its recognition, many precedent treatment programs were analyzed to form an appropriate model for the facility by the council. The program consists of a four pillar model that incorporates, education, therapeutic intervention, the Anishinabek culture and a wilderness program. The program is composed of two parts; the residential treatment program that focuses on in-patient care, called "The Four Directions" program which focuses on youth from 13-19 and "The Seven Grandfathers" program for people from 19-30 years old. Each program has 3 phases that incorporate the four pillars model. Each program plan is to be design specifically on the patients' needs and progress. The first phase of the Four Directions program is an off-site "Wilderness Stabilization" program which removes patients from the triggers of daily life and allows them the chance to re-balance and focus on healing and wellbeing in a natural setting. This occurs at an off-site location where patients live in the wilderness for an extended period of time. The second phase consists of residential treatment. This phase of treatment determines the needs, program and spatial requirements of the building proposal in this thesis. The duration of this phase can last anywhere from six months to a year, depending on the patient. The residents will live in an apartment/dorm style setting, while attending school, working or volunteering in the community. This space will be in linked with multiple community spaces that allow a gradual and soft re-integration of patients back into the community. The final phase will consist of the outpatient aftercare. In conjunction with family and community members, the program would work to help transition and reintegrate the patient back into the community. The "Seven Grandfathers" program will be conducted similarly to the "Four Directions," however after the wilderness stabilization phase, patients will enter a residential aftercare facility, which is located in close proximity to the "Four Directions" program site, yet provides more independent living space and apartments for patients, while still providing consistency and support. The final phase of the "Seven Grandfathers" program is to help re-integrate patients back into the community, help set them up with job referrals and work with the families to help support the patient achieve wellbeing. This program was not developed by the author. All credit is given to the Collaborator and his team on the development of the program. I am unable to disclose name the source due to ethics guidelines by Ryerson University and the Ethics Board of the community, as it would reveal the community and the third party collaborators. I would just like to re-state that this program was not created by the author but the third parties involved, full credit is to be given to them.

\subsubsection{DEVELOPMENT OF SPATIAL REQUIREMENTS}

The development of the spatial requirements and spatial relationships was done in conjunction with the collaborator and the author. A preliminary spatial requirement was given to me from my collaborator which outlined the functions, required equipment and activities of the space and number of occupants. From there, I conducted a spatial analysis in order to determine the physical spatial requirements needs with a $30 \%$ baseline circulation factor added to the overall spatial requirements. These numbers provided the absolute minimum requirements needed for the facility in order for it to function efficiently. Upon this spatial analysis, the collaborator was invited to meet to discuss the functional relationship requirements of the spaces. The goal of this meeting was to allow the collaborator (the "client") and I (the "designer") to work together, combining both of our expertise to develop the preliminary spatial relationships of the facility. This was done by using physical color-coded, scaled, square pieces of paper that represented the spatial requirements of each space and allowed for each member of the meeting to engage with and to use as a tool to brainstorm the functional preliminary relationships. It allowed for multiple variations of the relationships to be discussed without the rigidity and finality of typical mediums. The result of this meeting provided a baseline for the spatial relationships; however, this process did not consider the author's research on the culture and its healing beliefs and practices. This stage provided more of the contemporary western perspectives, though, due to the collaborator's knowledge and experiences and studies of indigenous culture, there was a degree of influence, however, the space planning and efficiency of design and relationships between spaces was conducted to learn from the expertise of the collaborator in the field of mental health/addiction and social work, was more focused on efficiency of space and economic feasibility. Once again, these numbers only provided a guideline for the design of the facility and 
were adjusted based off of the research and design iterations that were conducted throughout the process of the thesis.

\subsubsection{CULTURALLY APPROPRIATE + ETHICAL CONDUCT:}

Due to the nature of this thesis, the process of obtaining ethical approval was extensive. This was due to the fact that this thesis engages, not only with the Indigenous Anishinabek culture, but also with individuals from the Anishinabek community. I submitted two ethics applications; one to Ryerson University and the other to the Ethics governing body of the community who both gave ethical approval and permission to conduct research on the culture and with members of the community. This required outlining all purposes and ways of conducting and facilitating research during the thesis. As a result of the ethics approval from both boards, throughout the thesis, I am unable to provide names of community participants, interviewees, the location of the project in which the site is situated or any other third party contributors to the process. The thesis collaborator provided cultural insight on the practices and culturally appropriate ways in which to adhere to Anishinabek customs. Some of these included, ways of approaching and handling myself in meetings, providing refreshments and food for meetings, providing sacred tobacco to Elders, how to make first point of conduct through email or through phone, certain language and semantics to use while conversing with community members or conducting meetings, etc. The guidance and insight from my collaborator was absolutely essential and invaluable to the success of this thesis and I would like to once again thank him for all he has done.

\subsection{COMMUNITY MEETINGS/TALKING CIRCLES/NTERVIEWS}

Community engagement was a crucial part of this thesis. The intention of the meetings was to engage community members in a dialogue about architecture, addiction, healing and the Anishinabek culture, have a reciprocal relationship of sharing knowledge, inform the community of the thesis and allow them the opportunity to comment and to affirm that my literature review and research conclusions I had made were in fact accurate depictions of the culture and were not misrepresenting the community.

The rationale for conducting research involving human participants from the Indigenous community was that it provided beneficial outcomes for the research and the community through a collaborative and participatory framework of research. Due to exploration of the design of a facility for addiction treatment, which is also needed in the community and is in the process of achieving funding, mutual benefits for both I, the investigator and the community occurred, as we shared knowledge about architecture, addiction, Indigenous beliefs on healing and how it can be manifested architecturally. This pedagogical process expanded the knowledge of all parties involved and extended the boundaries of knowledge and further promote capacity building. Due to my belief that Indigenous people are the knowledge holders and are the experts in their culture, I believe in a true and open exchange of information where these community members have the possibility to share their culture with me if they choose to.

Recruitment was conducted through an external third party from the community. № specific requirement, inclusion or exclusion criteria was mandated. Any community member who is interested in contributing their beliefs and opinions on the topics being discussed and project will be invited. The recruitment for participants for the meetings was done through posters, brochures, emailing and word of mouth. My collaborator from the community who I was working with assisted in gathering participants, organizing a location and set up and any requirements needed for the meetings. From here, community circles and an open discussion group was held for participants to share their beliefs on traditional Anishinabek healing and culture. At the beginning of each meeting, an oral statement was announced re-stating the outline of the consent form and the purpose of the meeting in terms of the thesis. Participants were also asked to sign a written consent form that outlined the same conditions and procedures as the oral consent did. If someone did not consent to the use of the knowledge they share in the thesis research, they were advised to inform the investigator, and it was to be excluded from the thesis.

The attendance for the meeting was 10 participants. At the beginning of the meeting, an introduction was given of me, my experience and the outline thesis. A brief summary of the goals of the meetings were outlined. At the beginning of the meeting, I made it a point to say that I am there to listen and learn from them, they are the ones that are controlling the meeting and can share as much or as little as they want with me. I also made it clear that the style of the meeting was open-forum and free discussion, anyone can jump in at any point. From there I opened the floor up for anyone who wished to speak or had any comments or questions. I then began to give a more in depth overview of the thesis and my research findings. The first goal of the meeting was to explain the research I had conducted and ensure the interpretation of my research was accurately depicting the community and the Anishinabek culture. This was done through the use of visual graphics and bullet points which I explained my understanding 
and the participants affirmed them, elaborated on them or corrected my understanding. The second goal of the meeting was to discuss the built environment, particularly the architectural spaces in their community. The intention of this discussion was to draw connections between the culture and architecture and how current architecture fails or contradicts the culture. The discussion led to some very insightful comments and perspectives on space, materiality and the concept of separation and isolation. At this meeting, preliminary design images were shared with the participants to share my preliminary architectura representations and gestures of how to incorporate these ideas. From here, further elaborations on ideas and concepts were discussed in terms of how architecture can engage with the culture. See Chapter 5 for a summary of the research findings and further analysis from the community meetings and interviews.

Interviews were conducted to gain essential qualitative, one-on-one, data from members of the Anishinabek culture of their experiences, views and feelings about the culture, addiction, wellbeing and the built environment. A similar process as the community meetings was conducted, where recruitments were done through the third party collaborator, through emails and phone calls. Prior to meeting, I contacted the interviewee to provide an overview of the thesis and the goals of the interviews in order to fully inform them of my intentions, as well as to set up a meeting time and place for the interviews. Upon meeting, the interviewee was given a written consent form to read and sign and was also given an oral statement for consent. The meetings were conducted in a semi-structured format. Prior to the interview a guide was developed to provide a framework of topics and questions to be covered. However, it was encouraged throughout the process to go off the guide and follow the interviewee, where their responses go and to further elaborate and ask follow up questions to ensure I fully understood. The interviews were an opportunity to gain more detailed information from the advanced knowledge of the interviewee on the culture and addiction treatment. In total 3 interviews were held; two that focused mainly on gaining knowledge and insight into the Anishinabek culture and one which focused on the addiction treatment program.

As mentioned, community engagement was a key part of this thesis and has benefitted it at multiple levels. One of the main reasons for working with community members and conducting interviews with people of Anishinabek descent was to have a reciprocation of knowledge, keeping the community informed of what I was doing and getting first-hand knowledge from members of the community. This knowledge has been invaluable in the process and has been gathered through interviews and community meetings/talking circles. I have compiled the knowledge from both methods in the following section of the thesis.

Prior to my community meetings and interviews I had compiled my research on Anishinabek and North American Indigenous cultures. As one of the goals was to ensure the data I collected and my interpretation of it was accurate and reflective of the culture, I shared my findings and received affirmative responses and corrections back on my research. My greatest concern for the process was how to share with the community members architecture's ability to explore Anishinabek concepts beyond literal and symbolic representations of the culture through built form, while speaking in a language that allows people, who don't have an educational background in architecture, to understand certain architectural concepts and philosophies. However, each community member was extremely insightful about built space and how architecture has failed and achieved certain concepts, regarding healing, addiction or the culture, or has the potential to. Looking back after better understanding the culture, their wisdom of built form directly corresponds to many aspects of the culture. I have broken down the discussions into four categories to help extrapolate the ideas out of the meetings and interviews.

\subsubsection{THE PROBLEM WITH BUILDINGS}

Among the discussion with community members and interviewees, many problems regarding current architectural practices, particularly in the context of Anishinabek culture, way of thought and healing were raised. The critiques were very insightful, not only in terms of architecture, but also in terms of gaining a better understanding of the culture. The critiques can be defined by four main categories: Isolation and Separation, Materiality, Permission and Balance.

Isolation and Separation was a concern that was raised the most. The critiques included the separation from both animate and inanimate objects, such as other people and the natural world. One member of the community meeting raised the point that 'to have a roof over our heads is very unnatural. It cuts off the connection to Father Sky and further restricts our spiritual connection.' (Community Meeting Participant) The same goes for the traditional hermetically sealed wall in modern architecture. 'Buildings are designed to protect you from the elements...but the elements are not necessarily bad.' (Community Meeting Participant) The solidity and finality of its separation between interior and exterior or between individuals allows for the isolation of objects and creates a strong literal and figurative distinctions between them, ie. my space versus your space or inside versus outside. This idea then creates a sense of segregation and privatization in all realms of life, promoting ideas of division and disconnection. An interviewee raised 
the point that' You have no idea where you are in a building particularly in relation to outside or the sun.' (Interview \#1 Participant) The definitive boundaries that buildings create need to move to soft, gradual and slow boundaries that do not pose sharp barriers and distinctions between interior and exterior. In particular, they separate people from the sun which was a very practical tool. 'There was no watch or GPS and therefore the sun and the four directions of the medicine wheel are very important, as they orient you in space.'(Interview \#1 Participant) When you separate yourself from these elements than you lose your reference to place, your orientation, which roots people to their surroundings.

Materiality was another concern raised by participants. Its artificiality and banality in texture, strips character from the built space and does not showcase materials honestly, as it has been drastically manipulated and manufactured. Though not all elements of a building need to be texturized, raw or natural, the balance between gypsum board or concrete and wood or earth is disproportionally unbalanced. Materials hold a lot of meaning in the culture, as they represent place. Traditionally, materiality was determined by surplus of place. Materials were not manufactured and transported. Therefore, built forms were a representation of place because they literally grew out of it. For example, one community member explained that'rocks are extremely important to the culture and symbolic of creation as a whole. They symbolize the oldest living relative and are considered the "grandfather"' (Community Meeting Participant). This showcases the importance of materials to place, meaning, history and spirituality.

"Permission to take" is a concept that is missing in Western cultures and globally in the construction business. This idea does not represent the concept of not touching nature. It represents a reciprocal relationship between humans and the landscape. It represents a respect for creation,'asking permission to put a building somewhere, asking permission to remove trees in return for something else that will benefit the earth.'(Community Meeting Participant) The relation with land then becomes stronger, filled with respect and reciprocity. Decisions then become made with a conscious awareness of the earth and its ability to accept and receive. One community member pointed out that' many of the standard housing developments provided by government agencies have slowly collapsed into the earth. '(Community Meeting Participant) The soils were not ready and settled over time causing the building to collapse', showing that the relation and respect for the land was not present and the earth was not ready for the building.' (Community Meeting Participant) As previously mentioned, there is a misconception that many indigenous cultures believe in not taking anything from the earth. This, for the most part, is not true. Humans survive off the land and they have since the beginning of time. One interviewee points out that in Robert Kimemer's, Braiding Sweetgrass, the participant explained his theory that' $h u m a n s$ need to use nature in order for it grow and continue, its needs a disturbance.' (Interview \#1 Participant)The question is what is your gift in return? What is the scale of impact on the land? On the ecosystem? Does the contribution of the building balance what was taken from it? These are the questions that are the concern. However, they are hard to measure as results can often be intangible. Building is not considered a negative thing, if it is done for the greater good and with the intent to give back. Building can be a teaching and learning tool for people that contribute to the greater good. Reciprocity is the goal. This speaks to a larger concept of the expansive view of persons and beings. Respect for all objects, animate and inanimate is strong in the culture and speaks to ideals of how one builds and what one builds for people and the planet. It speaks to the greater idea of how people should treat each other, how to get along and understand others throughout our lives.

Balance is an important concept to the Anishinabek culture, particularly when referring to healing and wellbeing. "Balance and harmony doesn't necessarily mean everything is good" (Interview \#1 Participant). Good cannot exist without bad. The dichotomy of the relationship is what allows us to find balance and harmony. You need death to have life, you need to know wrong to do right, bad to do good, light to have dark. Finding this balance is central to how to get along with the world. For example, in the Medicine Wheel, East represents life, new beginnings, while west represents death, the ending. There are many stories of how the west and east battle each other. This represents the balance and harmony that needs to be found between these dualities. This is why in the culture; dawn is the best time of day to talk to the Creator. This is because 'dawn is the collapsing of time and space. It is not night or day, one or other. It is a balance' (Interview \#1 Participant). Therefore, the idea of contrast to represent dichotomies is a strong teaching tool in the Anishinabek culture. Elements of each dichotomy are amplified by its opposite and one can begin to acknowledge the differences in order to find balance.

Throughout my thesis development, I took every opportunity to attend public events, seminars or symposiums on addiction, mental health and the Canadian Indigenous culture. This was to further immerse myself into the research and attend events where the forums were both directly and indirectly related to one of the main topics of the thesis, particularly events where I could obtain firsthand knowledge from indigenous people. I attended two symposium/seminar events, Colonialism in Context on March 15, 2016 at Ryerson University and Soup and Substance - Truth and Reconciliation Commission 2015 Report on 
October 7, 2015 at Ryerson University. At each event speakers were of Indigenous background and had expert and experiential knowledge in indigenous studies for youth, mental health and addiction, infrastructure, women's issues and the Truth and Reconciliation Commission. These events provided an opportunity to further observe and understand the culture and ask questions regarding my thesis.

\subsection{PRECEDENT ANALYSIS}

Precedent analyses were conducted under two categories; precedents that focused on addiction treatment facilities within the Ontario context; and theoretical concepts which focused on projects where the Canadian indigenous culture was interpreted into architectural projects. The precedent analysis provided inspiration and an opportunity to critique contemporary practice through the lens of the thesis problem statement and research questions. Certain questions were asked in order to determine if the project fit within the criteria of each analysis category. Some of these questions included the buildings location, typology, program, client, scale, social and cultural impacts, intentions or functions. With the exception of one, each project is situated in an Ontario context, of all six precedents, four investigate and incorporated indigenous culture, issues or communities, five look at health and wellbeing and all deal with issues of community development. Analysis was conducted at the scale of each individual precedent critiques and common themes of the projects as a whole were developed under each precedent category. See chapter 7 for Precedent Critiques.

\subsection{SITE ANALYSIS}

The site location was chosen by the community council who is developing this project in the community. Therefore, site selection was not undertaken by the author. Site and context analysis was conducted through many mediums, including, multiple site visits in winter, summer, fall and spring, where the site was photographically and graphically documented and assisted in understanding the place through an experiential approach. These were done through a series of hikes throughout the site and surrounding area, site specific visits, community visits, where I visited local attractions, restaurants, and health and community facilities. Please note, I am unable to identify the location of the site or any information of the specific community in which it is situated. This is due to ethics guidelines and stipulations. 
DEFINING ADDICTION 
"...society needed more and more addictions to feed our cravings. If we try to stop, we go into withdrawal, unable to find any way to distract ourselves from responsibility, unable to avoid the consequences of our choices."

\subsection{DEFINING ADDICTION}

It seems as if addiction is spreading throughout Canada, North America and many other countries across the globe. We have become an addicted society. "Dislocation and addiction are, however, mass produced by free-market society, which is a form of hyper-capitalism that any regime can impose."[1] Many throughout the country have become dislocated from reality, from each other, from what it means to be human. People pass through their lives unaware of the happenings around them, neglecting any responsibility that they have as an individual, as a human race and that they may have for our surroundings and the global condition. It is an addiction to ease, efficiency, comfort and speed. Dr. David Ley, an American clinical psychologist, professor and novelist of the The Myth of Sex Addiction, states that:

"...society needed more and more addictions to feed our cravings. If we try to stop, we go into withdrawal, unable to find any way to distract ourselves from responsibility, unable to avoid the consequences of our choices. Every time a new technology surfaces, we use it to the point of self-destruction, and then label it as addictive to try to regain some control over our use of the technology. We use the concept of addiction more every day, despite our growing knowledge that it is destroying our culture, our legal system, our ability to hold ourselves responsible." [2]

We have become addicted to neglect, to lack of responsibility and to our individualist mentalities as it allows us to remove ourselves from all the tragedies we see in the world. But why has this epidemic been so neglected?

It is important to note that there is no single consensus on the determinants and causes that foster addiction in an individual, as well as there is no single consensus on what the definition of addiction is. [3] The thesis examines three different theories of addiction in order to set the framework and context of which theory the thesis intends to focus and to help grasp the understanding of addiction and why its proliferation has been such a neglected problem in society. The three dominant theories this thesis explores are; the genetic theory, the exposure theory and the adaption-dislocation theory. This thesis will first examine societal paradigms that have occurred over the past century that have contributed to our society's current condition and how they have contributed to the formation of a society that proliferates addiction.

\subsection{ADDICTED SOCIETY + ADDICTED MINDS: THE JOURNEY TO THE MODERN CRISIS}

It seems as if there is a rise in the number of people suffering from different types of addiction. It is not to say that people thousands of years ago did not suffer from addiction, yet, now it is more common than ever and comes in so many more forms. [4] It is important to understand what led to this current condition in the world, particularly westernized countries, where most are wealthy, social and governments systems are stable and have some of the highest standards of living in the world, yet many of these countries suffer from high rates of mental health issues. By understanding the factors that cause this epidemic, we can begin to identify ways in which the problem can be remedied. So, the question is, how did we get here? 


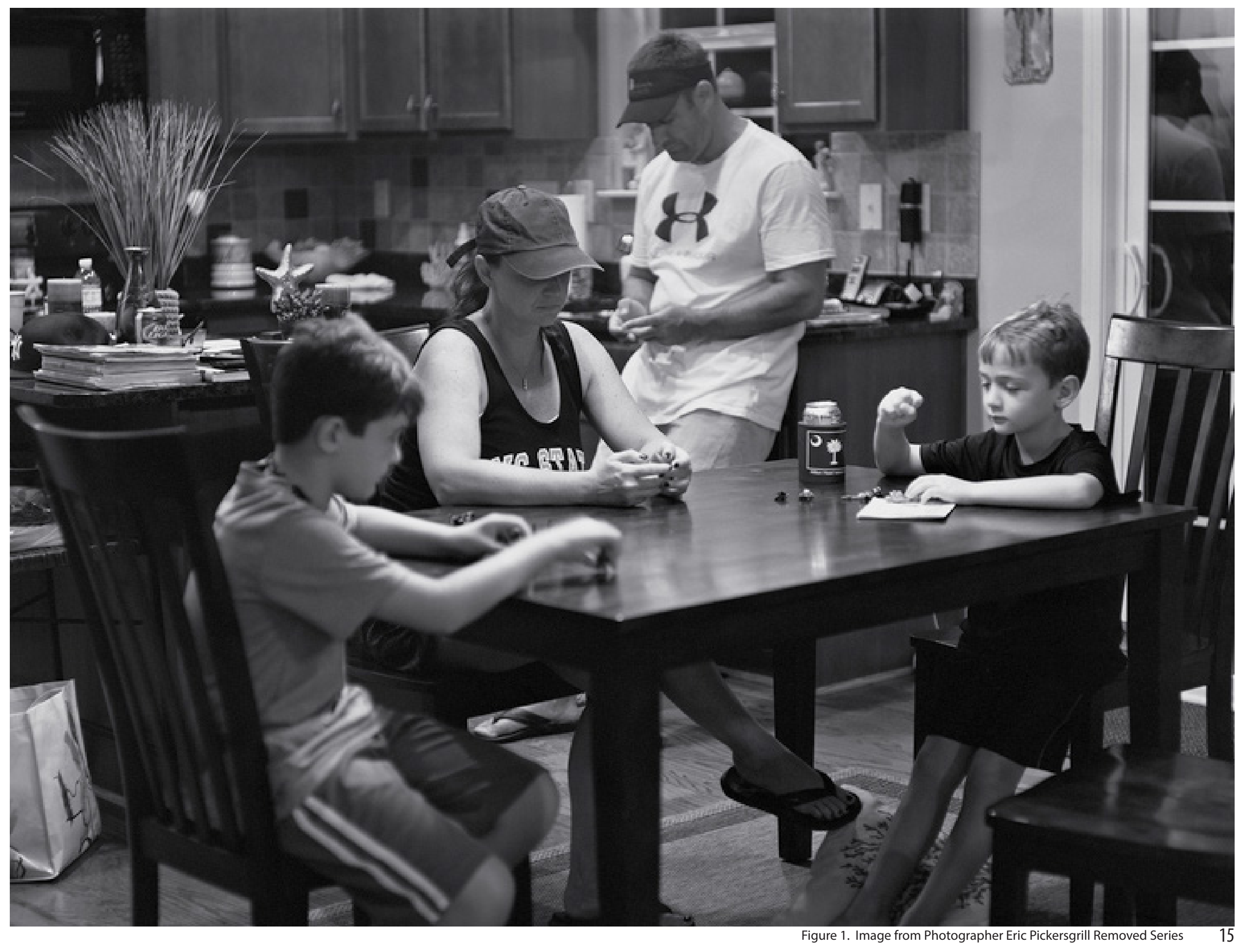




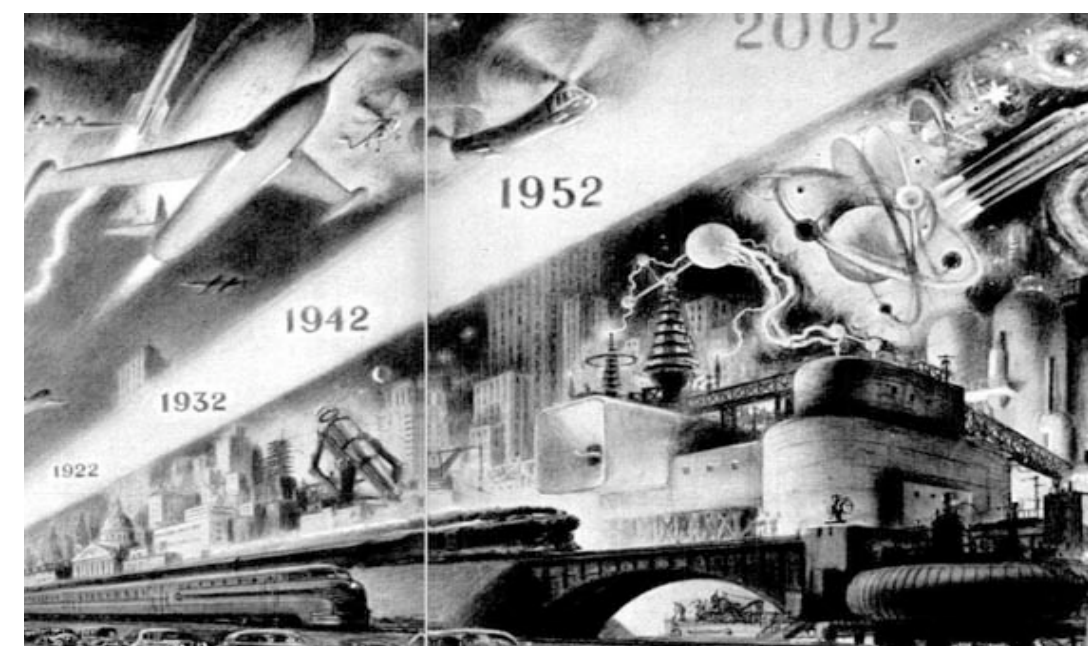

Figure 2. March of Science (Paleo Future) by Alexander Leydenfrost in 1952

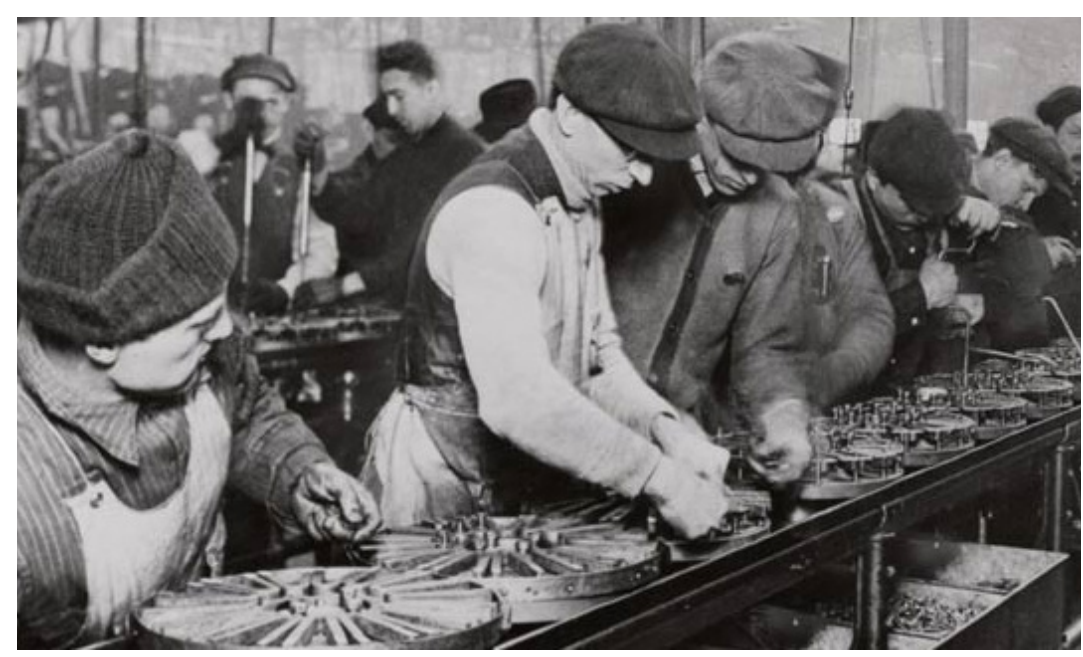

Figure 3. The Ford Assembly Line in Highland Park Michigan in 1913

3.2 SCIENTIFIC REVOLUTION AND MODERN TECHNOLOGY

Though it would be naiive to claim that the scientific revolution is solely responsible for the current state of our society and that it is the starting point of its rapid evolution to its current condition, it does remain evident that upon the breakthrough of the scientific revolution and all the way to the current modern technological age, we have somehow lost our way, in terms of the wellbeing needs of humans. Our visions have been blurred and in some cases we have been blinded by the ease, efficiency and comfort that modern technology provides to us. Though this statement may appear as if it is blame or a condemnation on technology, it is not. It is on the human. Humans have made these decisions without serious reflection and analysis of the consequences and have agency over the application of technologies. However, even with the time, reflection and the thought that was needed prior to the implementation of these new systems and technologies had been executed, the scientific revolution brought forth a new way of seeing the world. The world was then seen through a technological lens, where assets quantifiability and calculability are of the highest value. In Questions Concerning Technology, philosopher Martin Heidegger states that:

It remains true, nonetheless, that man in the technological age is, in a particularly striking way, challenged forth into revealing. That revealing concerns nature, above all, as the chief storehouse of the standing energy reserve. Accordingly, man's ordering attitude and behavior display themselves first in the rise of modern physics as an exact science. Modern science's way of representing pursues and entraps nature as a calculable coherence of forces. [5]

In Heidegger's statement he is exposing the contradiction that man faces, between technology's way of revealing and man's attitude towards the environment. The problem he is posing is the contradiction between revealing nature and the way in which modern society approaches nature through exact measurements and science. As well, Heidegger is not solely talking of nature in terms of one's typical conception of the natural, as plants and animals that one may conventionally think of, but in a much broader context, a context which includes the climate, the weather, earths gravitational forces, human beings, physical and intellectual energies and so on. These are the forces or "energies" that make the world and the universe. He argues that upon the rise of "modern physics" and modern science, everything in our world, from the human perspective, has become a potential resource, a means to an end, solely to serve human needs. This shift in way of thought was the first step in which we lost touch with what it means to be human in a world of other beings. It is also a shift towards a way of thought that values propositional and prescriptive knowledge, knowledge that is factual, directive and declarative. [6] Where our "justified to be true" beliefs are portrayed as facts of science, governments and legal systems. [7] As previously mentioned, we cannot look at the scientific revolution in isolation and place sole responsibility on it for the consequences of our current global condition. Its accompaniment with health, political and economic epidemics and paradigms further propagated its spread. In Architecture, Modernity, Crisis, Timothy Hyde states that: 
The arrival of novel scientific and philosophical thought in parallel with the political crises of the age of revolutions initiated a relationship that has unfolded in a succession

of historical episodes in which collapse, disaster, impossibility or failure have accompanied the development of economic, scientific and cultural forms of modernity. [8]

Our society has become stuck in this "reality" of life. We live in a world dominated by technologies and systems thinking. We no longer have the time, let alone the desire or capacity, to see the world out of this scientific context. Now, western societies biggest challenge is to discover how to grasp the world through a holistic spiritual, emotional, mental and physical means of understanding in an environment that is conditioned to see it as measurable and quantifiable.

\subsection{THE THREE C'S AND GLOBALIZATION}

The scientific revolution provided the platform for the rise of the "Three C's"; Consumerism, Consumption and Capitalism along with the globalization of the world. [9] These phenomena further disembodied us from traditional human ways of being and knowing. The introduction of money and its symbolic worth, shifted the focus to profits and acquiring assets. The act of making and taking for individual monetary means versus creating and sharing for collective interests was perpetuated throughout Western societies. [10] Furthermore, globalization, which was proliferated at an exponential rate by technology, the digital age and the irresponsible and hazardous actions of humans, dislocated us from our realities and the consequences of our actions became irrelevant, whether they directly affect our next door neighbor or a starving family on the other side of the world. [11] Actions then become disconnected from people and less value is placed on thought before action. For example, the diversity of people and cultures is being eradicated by the globalization and the market economy. It is no longer as easy to recognize place in our world, as it has been commodified by western global corporations and this is afforded by the proliferation of technologies. Jerry Mander, in The Absence of the Sacred, states that:

Because of technologies geographical scale, its cost, the astounding power of its imagery and its ability to homogenize thought, behavior and culture, large corporations found television uniquely efficient for ingraining a way of life that served (and still serves) their interests. [12]

Our assumptions of technology's beneficence combined with our pastsivity to its advance has permitted certain technological forms to expand their scale of impact and to interlock and merge with one another. [13]

Now that the smartphone has entered the world, it is now easier than ever for corporations to sell their mantras. The earth has now become a means of making money, following the paradigm that resulted from the scientific revolution, by seeing all in our world as a resource, therefore, global corporations are slowly homogenizing our world in the name of profit with no care for the economic, political, cultural and social genocide that they are creating within communities and cultures. We have lost touch with the concept of action and consequences, as the digitized and globalized condition of our world has allowed us to. We are also losing our identities, as individuals, as communities, as nations and as places. Time no longer exists for others, for community, for shared and collective interests, it barely exists for ourselves. The stresses of day to day living consume too much time and cost too much money.

Our societal constructs today predicate that we must exploit, compete and acquire. This societal fabric is not one that allows us to meet our basic human needs. The increasingly hierarchical constructs of our western society create environments that contradict and challenge us from achieving wellbeing. The ability to share and feel a sense of belonging becomes difficult when monetary motives and individual interest create competitive mindsets and perspectives that separate us from one another rather than bring us together. The stratification of society would allow people to view each other as peers, as equals, relationships to bond over collective interest and fluidity between groups would occur. $[14,15,16]$

\section{$3.4 \quad$ THECULTURE OFINDIVIDUALSTS}

Today, there is a bombardment of Facebook updates of what someone had for dinner, a collection of a hundred Instagram "selfies" posted and people who cannot even stop to help someone else in need because their face is buried in their phone. We have been led to a culture of individualist, egotist and narcissist. Private interests are valued in favor of collective and there is little value on community and the 
shared society. A quote from Aristotle states that, "He who is unable to live in society, or who has no need because he is sufficient for himself, must be either beast or a god." [17] This quote recognizes that as early as 4th century B.C., the concpet of society and community support was essential to survival. Though these traits and characteristics existed back then, it was recognized that they are unattainabel and/ or unhealthy. Aristotle's statement resonates the idea that, as a human species, it is essential for us to work together and rely on one another. This concept is also echoed in a statement by Karl Marx on the Thefts of the Woods in Rheinische Zeitung, "The representation of private interest...abolishes all natural and spiritual distinctions by enthroning in their stead the immoral, irrational and soulless abstraction of a particular material object and a particular consciousness which is slavishly subordinated to this object." [18] Though he is referring to a natural element, the forest, western society tends to forget that humans are part of the natural world and when members of society seclude themselves from it and from each other, their sense of collective and community is further diminished, they neglect their role in the world and the consequences their our actions.

There is also a huge irony that exists in the western culture, professing its value of individual identity and priding itself in its individualist perspectives. The reality is that individualism has been commodified and mass produced. Individuals are being tricked and sucked into this illusion and are part of the globalized society. Erich Fromm, in The Art of Loving, states that:

Most people are not even aware of their need to conform. They live under the illusion that they follow their own ideas and inclinations that they are individualist, that they have arrived at their opinions as a result of their own thinking and that it just happens that their ideas are the same as those of the majority. [19]

Western society is homogenized set of individualists who look after theirindividualist interests. Our specific attitudes and views are being turned into niche markets and capitalized on.

\subsection{WESTERN HEALTH PRACTICES}

Western health practices have followed in tandem with the new perspectives that the scientific revolution, globalization, the three C's and individualist ideals have brought forth. Humans and human health is now a commodity, a means to make profit, to do research, a device to enhance pharmaceutical consumptions and endorsements. Dr. Bernard Lown, a professor of Cardiology at Harvard, developer of the defibrillator and author of The Lost Art of Healing states that, "The practice of medicine has increasingly shifted to a scientific paradigm which approaches the patient as a biomedical being. Medical students are selected based on their achievements in pre-medical science courses, not their affinity for the humanities nor their readiness to serve people." [20] He further goes on to state that:

This trend is reinforced and accelerated by the billions of dollars poured by the government into medical research. The physician most gifted in obtaining grant funding is promoted in academe. Advance is unthinkable without a thick bibliography and success in obtaining grant support. Prestige no longer belongs to a beloved family physician nor to an astute bedside clinician, but is the prize for those who breach the scientific frontier. Not only contemporary philosophic notions of illness, but powerful economic incentives reinforce these views. The shift from a patient-focused health care system to one based on disease, relates to lucrative fiscal rewards for the practitioners of scientific based medicine. [21]

Addiction cannot be reduced to a science, as it is not quantifiable, it lies in the realm of the human spirit. [22] This is why we have not seen any succesfuls drugs or strict prescribed therapy tactics that try to heal an addicted individual and this is why addiction is such a large problem in western cultures. It is about one's overall wellbeing and if that is being fulfilled in all realms of one's life we can begin to see success in battling addiction. [23]

\subsection{CURRENT CONDITIONS IN CANADA}

In Canada, in a given year, 1 in every 5 Canadians will experience a mental health or addiction problem. [24] Seventy percent of people facing addiction problems have their onset during childhood or adolescence, with young people, between the ages of 15 to 24, most at risk for these disorders than any other age group. [25] According to the 2012 Canadian Community Health Survey, 21.6\% of Canadians met the criteria for experiencing substance abuse in their lifetime. Of this $21.6 \%, 30 \%$ perceived their mental health as good or healthy. It also revealed that 1 in 6 Canadians have reported needing mental care in the last 12 months, which included individuals with and without known mental health or substance issues. As well, substance abuse rates are highest among youth. The survey excluded people under the age of 
15 years old, people on-reserve or in indigenous communities, people who are part of the Canadian Armed Forces and people who are institutionalized, ie, jails, hospitals, treatment facilities nursing homes. $[26,27,28]$

These exclusions pose a challenge to truly quantify the problem of addiction and mental health in the country, as some of the most vulnerable groups are excluded. As well, the criteria for what classifies as substance abuse or addiction is limited to drugs and alcohol. This reflects how our society views addiction, as a substance driven issue and also fails to neglect the growing numbers of types and varieties of addictions that we are seeing emerge from our society, including money addiction, internet addiction, porn addictions, and fitness addictions and so on. Therefore, many surveys and reports that are released do not, just as this one doesn't, paint a true picture of the problem, not only in Canada but across the globe.

\subsection{WESTERN ARCHITECTURAL PRACTICES}

The "origins of architecture in human culture have been closely related to the idea of ritual." [29] Architecture used to be an act of "place-making activities for the deployment of rites, passages or significant moments in society," [30] which was shared with family, friends, community, tribes, villages, cities and so on. Architecture was a spiritual event, shared by the community, shared with others and with the contribution of others. This was a representation of our culture at the time. Once there was value in the capacity and spirit of nature, community and the individual. Our western society has shifted away from these ideals and principles, and these cultural epidemics, previously mentioned, have seeped their way into architecture, and the profession has followed suit without confrontation. The concept of architecture as an event, a passage, a ritual, a spiritual act has been eradicated. [31] It has been held hostage by capitalism, globalism, technology, individualism and addiction. Architects are now constrained to conform to these ideals, or to challenge them.

Yet, it appears to be a hard task to challenge these ideas with the condition of our profession and its evolution into the reliance on economic and technologically heavy mediums of producing. The way in which architects work and produce design further disconnects them from the user and the user's experience. The architect's tools are their mediums of abstraction and this makes it easier to remove ourselves as designers, creating another barrier for the architect when trying to design spaces that re-engage its users. According to Henri Lefebvre's Conceptual Triad, in The Production of Space, the production of space needs to depart from a Cartesian way of producing and thinking. [32] He argues that:

"We may be sure that representations of space have a practical impact, that they intervene in and modify spatial textures which are informed by effective knowledge and ideology. Representations of space must therefore have a substantial role and a specific influence in the production of space. Their intervention occurs by way of construction - in other words, by way of architecture, conceived of not as the building of a particular structure, palace or monument, but rather as a project embedded in a spatial context and a texture which call for 'rep." [33]

His critique of space challenges the typical and current architectural practices we see in western society. He believes that current practices of production of space fail to fully integrate all realms of the true productions of space, which he defines in his conceptual triad. Lefebvre's conceptual triad consists of three realms of space production: spatial practice - how one uses and creates meaning in spaces by use and activities during the everyday influences by the specific conditions of place and social formations; representational space - how spaces are connected with history, memory and meaning, the images and symbols associated with its inhabitants, its connections to past events activities and traditions; and representations of space- this is where the architect, engineers, urbanists and social scientists lie. Where space is abstracted and interpreted by others and represent by detached representations, models, images, drawings, diagrams. [34, 35, 36]

"Within the spatial practice of modern society, the architect ensconces himself in his own space. He has a representation of this space, one which is bound to graphic elements - to sheets of paper, plans, elevations, perspective views of façades, modules, and so on. This conceived space is thought by those who make use of it to be true, despite the fact-or perhaps because of the fact - that it is geometrical: because it is a medium of objects, an object in itself, and a locus of the objectification of plans. Its distant ancestor is the linear perspective developed as early as the Renaissance: a fixed observer, an immobile perceptual field, a stable visual world." [37] 
As a result, we often get container architecture, devoid of life, meaning and human function. It is the incorporation, in the profession of architecture and the design process and development, of Lefebvre's "conceived" space that is greatly lacking, particularly how one experiences and uses space on a daily basis through daily activities.

Contemporary western architectural practices also tends to produce space that favors individual and privatized lifestyles. Most spaces are separated by function and activity, into sealed and confined boxes that restrict one's ability to dynamically engage with them, and in turn, restrict the ability for architecture, the resident and the location to work together and create a vibrant and engaging sense of place. Even when public space is provided through architectural intervention it is stripped of its vibrancy and social function due to technological mediums of communication and connection. "[The] sense of public space has been dematerialized by the various media and communication technologies; it has physically and materially also been threatened by the economics and social privatization processes."[38] This condition has led an urban, suburban and rural environment that consists of "...closed defended islands with blank and windowless facades surrounded by wastelands of parking lots and fast moving traffic." [39] Though this may not described exactly the rural condition, it does hint at notions of separation and the domination of cars in our society and built environment, that exist in a rural setting.

It seems obvious that the users experience and daily use of space are vital contributors in the production of sustainable and healthy designs in the profession. However, the epidemic our culture faces still clouds our views of what a healthy space is, as it works within the framework of the western society and its pressures of day-to-day life and living. These are the tensions that lie in the architectural profession, though architects are not the only ones who feel it. However, as a profession that is strongly influential and whose responsibility to society that is exponential, their actions have lager repercussions than most. The tensions that lie between our current societal values, practices and mentalities and between true and positive ideals of morals, ethics and sustainability that we one once had, are butting heads, and the production of healing spaces seems to become impossible.

\subsection{CANADA'S INDIGENOUS POPULATION}

After over half of a century of suppression, neglect, abuse and cultural genocide, the Indigenous population in Canada make up approximately 4.3\% of the overall Canadian population. [40] However, with a majority of this 4.3\% in their youth, this means that the population is young and growing fast, increasing 20\% between 2006 and 2011 compared to non-aboriginal population increasing only 5.2\%.[41] The indigenous population in Canada have a disproportionately high ratio of addiction and substance disorders versus non-indigenous. Approximately $75 \%$ of people from Canadian Indigenous communities feel that alcohol use is a problem in their community, 33\% state it's a problem in their own home and 25\% claim they have a personal problem with alcohol. [42] Along with alcohol abuse and other substance abuse, Indigenous people face suicide rates among youth that are 5-6x greater than non-indigenous youth and experience twice the national average of major depression and other mental disorders. [43] These statistics along with the skewed and misguided understanding of addiction and its causes, lead to racial profiling and discrimination against the indigenous population, with some reports over the years having stated that the Canadian indigenous population has a genetic predisposition to becoming addicted. This statement could not be more inaccurate.

The misconstrued views and lack of education that the Canadian and North American society has about health, addiction, the Canadian indigenous population and how our societal constructs impact and shape our health, ways of thinking and the world we live in needs to be changed. We can no longer live with blindfolds on. Education of the nation's population is vital. We must educate the population about addiction and what causes it and we must also expand the criteria that determines what an addiction is, extending beyond drugs and alcohol. As a country must also acknowledge the apparent connection between society, social circumstances and overall wellbeing. We must redefine and reorganize how our societies work, as currently, we are working against our basic human needs that will allow our society to be happy and healthy.

\subsection{THE EVOLUTION OF THE OFFICIAL VIEW OF ADDICTION}

The word addiction has a long lineage in the English language, with its etymology rooting back to the Latin word addictus; to deliver, to devote, sacrifice, sell out.[44] Its origins lie beyond the bounds of moral indecency and medical conditions that we see today. The manipulation of the word addiction started to take place in the 18th century when the word was taken by the medical community and moralists interests groups who transformed its meaning in accordance with their own objectives. "The temperance movement began appropriating the word "addiction" in the name of a moral failure at about the same time that the medical profession began appropriating it as the name of a disease." [45] This new definition portrayed addiction through the lens of alcohol and drugs use, and nothing out side of it. Religious groups 
claimed it as a fault of moral deficiency and the medical profession claimed it as a fault of biological factors. [46] Since then, the view and definition of addiction has changed little to none. Its lack of evolution hides behind the high-tech developments of neuroscience, posing itself as progress.[47] These two contributing factors have determined the definition of addiction that society is fed today in the media, in politics, in medicine and in religion. This official view, according to psychologist Bruce Alexander, can be broken down into six different elements or misconceptions which are conveyed to the general public:

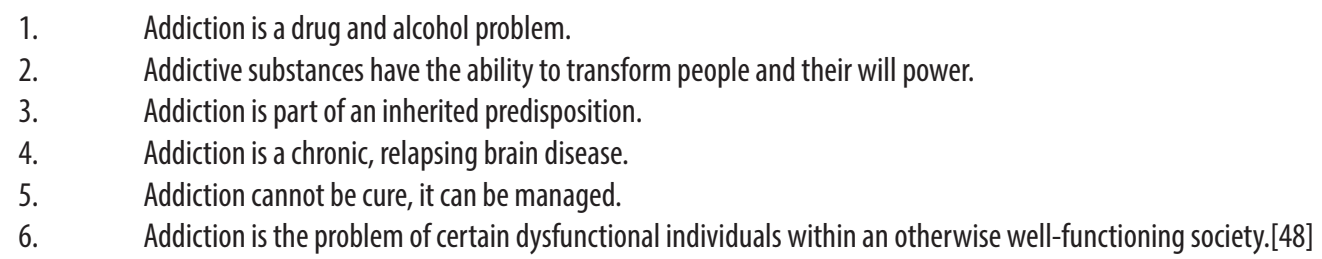

These views are supported by the strong faith that society has in the scientific and medical fields. The western culture believes them to be true and factual and the medical field will find a pharmaceutical drug to rehabilitate the problem. Though this view is the dominant understanding of addiction in society, many do view addiction through different lenses; therefore, it is false to argue that every individual maintains this perspective. Overtime, and through the constant debate between nature versus nurture, theories of addiction and the causes of it have risen. Focusing on three major theories this thesis examines the genetic and exposure theory, which lie in the realms of this "official view of addiction" portrayed in society, and a third theory, the adaptation-dislocation theory, which begins to look beyond this narrowed and reductionist view and challenges the Official View of Addiction.

\subsection{THEORIES OF ADDICTION}

Most theories of addiction stem from the nature versus nurture debate, one that provides and oversimplified view of the problem. It is an "unbalanced false dichotomy" [49] that states that nature is 'deterministic and coded into one's DNA, therefore, addiction is incurable, rooted in biology and cannot be changed and don't waste resources trying to.' [50] On the other end of the spectrum lies nurture, representing the social science aspect of the debate, stating that humans are free from biology and genes play no role in determining who you are and how you perceive the world. Both ends of the spectrum are false as it is virtually impossible to understand how biology works out of the context of environment.[51] Yet, still today, in terms of defining addiction, society tends to rely heavily on the medicalize theories, where biology and genes are the driving determinants and medicalized treatment is favored.

\subsubsection{THE GENETIC THEORY}

The genetic theory of addiction claims that addiction is an inherited predisposition, strongly influenced by genetic factors.[52] It claims that family history plays a vital role in determining if one will struggle with addiction and that there is a high increase of one becoming addicted if it is in their genetic lineage.[53] This theory falls under the Official view of addiction. Its studies focus mainly on drug and alcohol use and the scientific and medical conditions of an addicted person. Though the science does not exclude other environmental and sociocultural factors, it states that genetics and biology play the largest role in determining if one becomes an addict.[54,55,56]

\subsubsection{THE EXPOSURETHEORY}

The exposure theory of addiction (or the metabolic theory) claims that addiction is a result of a repeated exposure of a substance into the body that changes the cellular response, which will lead the body to become addicted to it.[57] This theory consists of two models: the biological model and the conditioning model. The biological model states that the addictive result is due to certain biological factors of the individual. [58] The conditioning model, or Pavlovian model, states that anyone can be conditioned to become addicted to any substance by repeated use and abuse which rewires the brain and creates stimulation to the brain that creates a connection of pleasure or ecstasy with these substances or acts and, in turn, increases the persons need for the substance, creating a behavioral pattern in the individual. [59] This theory also lies closely within the bounds of the Official View, it is scientific and biological in nature, though the conditioned model of the exposure theory begins to acknowledge that addiction is not 
necessarily a biological predisposition, it still focuses of scientific and quantifiable means of analysis and measurement.

These theories of addiction prove themselves to be myths and misconceptions, particularly because society and the general public are not given all the facts about studies on addiction. According to Dr. Gabor Mate, "most diseases are not determined by genetics." [60] Science does not say that genetics determines addiction and there has been no addiction genome has been found. [61] He further goes on to state that, "in reality, nothing is really addictive." [62] It's not so much about the substance but about the susceptibility of a person, and genes do not determine this susceptibility. As previously mentioned, it is virtually impossible to understand how biology works out of the context of environment. [63] This is because genes are shaped by the environment of a human as early as when they are in the mother's womb. One's genes and one's environment work closely and are interrelated. They cannot be separated and understood without the other. In a study done by psychologist, Dr. Gabor Mate, he examines how childhood influences effect gene expression which plays a role how we respond to our environments. This is called the epigenetic effect. [64] It's gene expression and how cells read those genes. [65] This epigenetic effect can activate or deactivate genes as a result of environmental conditions. In Mate's study, it shows that those who had experienced child abuse were more likely to become addicted later in life.[66] Therefore, the relationship between genes and environment is reciprocal. Biology and development is shaped by the psychological and social environment of a person. [67] This is also called Neural Darwinism, a theory deeply researched by biologist Gerald Edelman in the 1970's, where he mapped out how the body's complex adaptive system formed from the feedback relationship between genes and environment/experiences.[68,69]

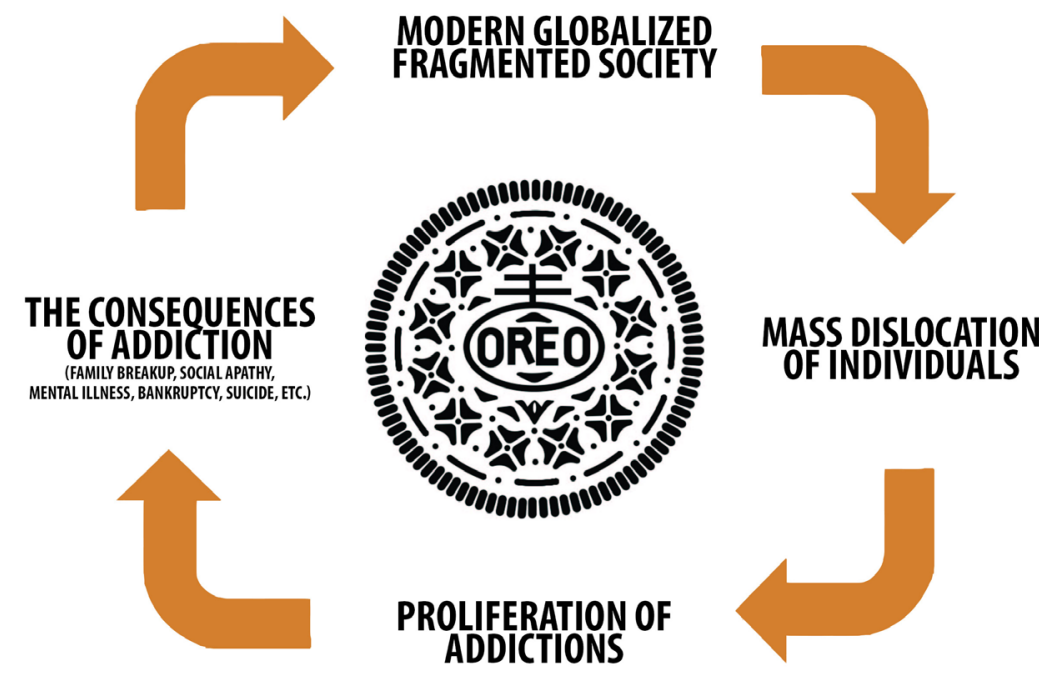

Figure 4. The Dislocation Theory of Addiction from Bruce Alexander redrawn byAuthor 


\subsubsection{THE ADAPTATION/DISLOCATION THEORY}

The adaptation-dislocation theory begins to acknowledge the complexity and reciprocal relationship between genes and the environment. The adaptation-dislocation theory of addiction is "non-medical and non-moralistic" and therefore does not fit with the official view of addiction.[70] This view is not grounded in the scientific realm of research, but more in the social. To start, this view does not solely focus on and reduce addiction to alcohol and drug use as addictive substances, therefore, broadening the understanding of addiction. [71] In this theory, addiction is depicted as a way of adapting to the "increasingly dominant and onerous aspects of the modern world - in particular, social fragmentation and individual dislocation."[72] It states that adaptation is an evolutionary process and can become excessive and harmful in some instances. [73] This is one of those instances. The causes for the need to adapt are not looked at in isolation either. Society and the greater population are examined through a holistic approach. It mainly focuses on the idea of fragmentation, an epidemic that has flooded the globe since the time of Christopher Columbus, resulting in our globalized world. [74] The traditional individual, family, community, city and global dynamics have been crushed. The modern age has fragmented our traditional societies that have been around for thousands of years, in a fraction of its existence. Though we believe we live in a connected world, according to Alexander, modern dislocation, a social fragmentation of beings, both physically, mentally, emotionally and spiritually, has helped to perpetuate the problems of addiction in a vicious cycle.[75] This theory acknowledges the lack of wellbeing that society is providing to human beings, from the systems that are in place to the built environment around us that reflects and enforces those systems. As a society we are dislocated from our traditional ways of life, our traditional connection to people, place and self. As a result, we are turning to addictive behaviors to adapt, to escape. This is the theory in which this thesis and research aligns itself with. Addiction is not an ailment of biological, medical or scientific means; it is an ailment of an impoverished society, resulting in impoverished minds, bodies, hearts and souls. [76]

\subsection{THE RIPPLE EFFECT: CO-OCCURING MENTAL HEALTH DISORDERS}

Many people who suffer from addiction also suffer from co-occurring mental health issues. The five most common disorders to coincide with addiction are anti-social personality disorders, anxiety disorders, post-traumatic stress disorder and depression. [77] When we examine addiction through the lens of the official view or through the genetic or exposure theories, these co-occurring disorders seem as though they are results of one with addiction, a symptom and consequence, that reflect the traits of the disease. When we look at addiction through the theory of adaptation or dislocation, the co-occurring mental disorders further reinforce the concept that addiction is an issue of wellbeing, not something that can be reduced to science. The ripple effect of an unbalanced, unhealthy individual spreads into all aspects of their life. Mental disorders are also an adaption, an escape from the overall problems facing our current society. It is a mechanism the body is implementing to protect itself or to notify itself that there is something wrong. [78] These other mental health problems that often go along with addiction are often treated with prescribed drugs, which come with a long list of side effects. [79] These drugs often do more harm than good, and tend to mask the problem, does not heal the root of it and brings more negative side effects to the individual.

This is why throughout the thesis, I continually refer to addiction and mental health and/or wellbeing together. It is difficult to separate these issues or neglect them, as they are often the result of the same source. Therefore, this thesis considers the treatment and condition of addiction, as well as its common, co-occurring disorders.

\subsection{PERSPECTIVES ON THE PROLIFERATION OF ADDICTION IN INDIGENOUS COMMUNITIES}

Many Canadians are unaware of the injustice that took place in our country over the past 500 years. The assault on the basic human rights, the genocide of indigenous people and destruction of the culture across Canada is potentially the most horrific event to happen in Canadian history. If we begin to acknowledge and understand the conditions and experiences that many indigenous people faced we can begin to understand addiction in a new light that aligns with the adaptation-dislocation theory and can begin to acknowledge the theories validity. We must learn from the past to move forward in the future.

\subsection{IMPACTS OF COLONIALISM}

The Indigenous population in Canada consists of three main groups; the First Nations, the Metis and the Inuit. [80] Though there are many aspects of the culture and beliefs that all three of these groups share, each group has its own distinct characteristics and differences. Therefore, for this thesis, I will focus on the traditions of the Anishinabek people, as this is the dominant population in Ontario. This thesis does not claim that any of the following historic events, their consequences or any overarching beliefs are exclusive to the Anishinabek and recognizes that they may be applicable to other indigenous groups in Canada. 
Indigenous people have been inhabiting and growing their culture in Canada for thousands of years. Over these years, they have developed a complex self-governed society where each tribe had their own character and ways of practicing their culture, not all Indigenous throughout Canada were the same. [81] Each developed their own tools, oral traditions, medicines, shelters, transportation methods, clothing, food and religious practices. [82] Each tribe learned to adapt and thrive to the variety harsh climates across Canada. This greatly influenced their settlement patterns, leading to two main types of settlements; nomadic settlements, who seasonally migrated based on the natural cycles of the land, plants and animals; and permanent settlements, who stayed in one place a lived off the local land by farming, hunting fishing and gathering. [83]

In the 1500's European explorers began to arrive on the eastern shores of Canada, drawn by the rich fishing and wealth of resources and settlers from many countries began to make contact and create a trading system for these resources. [84] This created a new network and system of competition, where the British and the French claimed power throughout most of Northern America, slowly moving further inland and conquering indigenous territories. [85,86] Indigenous tribes began to sign a multitude of treaties with the European settlers, trading land and resources for protection and alliance. [87] 0 ver the next 500 years, more and more settlers came and took control of the land and the people.

The origins of alcohol abuse in Canadian history dates back to the early 17th century, when Europeans introduced liquor as part of the fur trade and before the arrival of colonist, violence and drunkenness was virtually non-existent in indigenous communities. [88] As well, the arrival of settlers disrupted the traditional diet of the communities, where food was eaten for convenience and the use of tobacco, which was, and still is, an extremely sacred herb, was turned into a commercial good. [89]

The arrival of Europeans brought even more drastic and detrimental consequences beyond the introduction of alcohol and new food systems. Europeans introduced and propagated the belief that indigenous people were savages, needing to be saved and whites were a superior species. This is what lead to the Indian Act (1876), Act of Gradual Enfranchisement of Indians (1869), the Sterilization Act (1928) and many others that had the sole purpose of controlling, assimilating and eradicating the culture, language, beliefs system, customs and all spiritual traditions. [90] People were punished and beaten when caught practicing any aspects of their culture, they were forced to relocate, have their land and resources taken away, leading many to starve, and even have their children removed from their homes. [91]

A Residential School system was set in place to take children from a very young age away from their families into a school, run by the government or the Catholic Church, in order to assimilate them to the Canadian-European ways of life. The intent was to remove the "savage" from each child and assimilate them into the Europeans life and culture. [92] Children were taught that they were sinful, disgusting, dirty and immoral and suffered from severe abuse in all aspect of their life. [93] Psychological and emotional abuse that included humiliation and degradation, public shaming and taught to believe that men are superior to women and whites are superior to indigenous; physical and sexual abuse that include forced abortions, severe torture, morbid sexual assault and starvation. [94] With the last residential school closing in 1998, some indigenous families had up to five generations of children institutionalized in these schools. [95]

Over the past, 20 years, Canada and the government, has started to recognize and make changes in how to deal with and approach Canadian Indigenous issues and history. In July of 2015, the final report of the Truth and Reconciliation Commission of Canada was released. The act was created by the Indian Residential Schools Settlement Agreement calling for a recognition of the horrendous history and abuse against the Canadian Indigenous population, in particular from the implementation of the residential school system. [96] It does not call for the shaming or blame onto Canada and non-indigenous people, it calls for action and reconciliation. However, words are no longer enough and no longer constitute as action. "It requires a new vision, based on mutual respect be developed. It also requires an understanding that the most harmful impacts of residential schools have been the loss of pride and self-respect of Aboriginal people, and the lack of respect that non-Aboriginal people have been raised to have for their Aboriginal neighbors."[97] In The Comeback by John Raulston, he outlines how the indigenous population of Canada is on the verge of a comeback. With the rapidly growing, young indigenous population, the growing knowledge, respect and drive of this population and the implementation of the Truth and Reconciliation Commission, the future is looking up and towards a positive, social, economic, and political role for the Canadian indigenous population. [98] The culture is re-gaining its voice on a national scale and determined to flourish once again. 


\subsection{INTERGENERATIONAL TRAUMA}

Intergenerational trauma is defined as "the transmission of historical oppression and its negative consequences across generations." [99] This also aligns with the indigenous beliefs that all things are interconnected; the past, present and future; the individual, family community, nation and the earth. When this infinite web of relationship is disrupted or disconnected it affects the greater whole of the web. The invasion of Europeans and the implementation of the Residential school system, which impacted the populations children, at a stage which is the most fundamental part of health and growth in one's life, provided this disruption on a massive scale. [100] Much of the Canadian Indigenous population lost its culture and ways of living and the children came out of the school system traumatized (emotionally, physically, mentally and spiritually), with no relationship skills and were undereducated. These repercussions are still seen through the generations today. [101]

\subsection{LACK OF INFRASTRUCTURE + SOCIAL DEGRADATION}

Currently, the conditions of indigenous communities across Canada is very diverse, ranging from self-sufficient communities to communities with conditions equivalent to slums in third world countries and everything in between. The majority of communities face problems with lack of infrastructure, both physical and administrative, lack of funding, poor housing conditions, poor economic conditions and racial discrimination. [102] As previously mentioned, the wellbeing of indigenous communites today is still deeply impacted by the consequences and repercussion of the atrocities faced in the recent, 500 year, history, with addiction, suicide, depression, sexual and domestic abuse rates drastically higher than non-indigenous Canadians.

[1] Alexander, Bruce K. The Globalisation of Addiction: A Study in Poverty of the Spirit. Oxford University Press, Vancouver, BC, 2008, pp 4

[2] Ley, David J., PhD. “The Addictive Society." Psychology Today. Sussex Publishers, 24 Aug. 2011. Web.

$<$ https://www.psychologytoday.com/blog/women-who-stray/201108/the-addictive-society>.

[3] Ph.D., By Marc Lewis, By Mark D. Griffiths Ph.D., By Adi Jaffe Ph.D., and By Suzanne Degges-White Ph.D. “Addiction." Psychology Today. Sussex Publishers. Web. <https://www.psychologytoday.com/basics/addiction>.

[4] Alexander, Bruce. "The Rise and Fall of the Official View of Addiction." Bruce K. Alexander. Simon Fraser University, Burnbay, British Columbia. Bruce Alexander. July 2014. Web. <http://www.brucekalexander.com/articles-speeches/277-rise-and-fallof-the-official-view-of-addiction-6>.

[5] Heidegger, Martin. The Questions Concerning Technology and Other Essays. Harper Collins, New York, NY, 1982, pp. 10. [6]Thrift, Nigel. Knowing Capitalism. Sage Publications, London, England 2005, pp. 6-7.

[7] Creller, Aaron B. Making space for knowing: A Capacious Alternative to Propositional Knowledge. ProQuest Dissertations Publishing, Manoa, Hawaii, 2014, pp. 3, 6, 23, 30.

[8] Hyde, Timothy. "Architecture, Modernity, Crisis." Journal of Architectural Education, vol. 69, no. 1, 2015, pp. 2.

[9] Cohen, Floris H. The Scientific Revolution: A Historiographical Inquiry. The University of Chicago Press, Chicago,ll, 1994, pp. 216-225, 446 .

[10] Mander, Jerry. In the Absence of the Sacred: The Failure of Technology and the Survival of the Indian Nations. Sierra Club, San Francisco, CA, 1992, pp.3.

[11] Mander, Jerry. In the Absence of the Sacred: The Failure of Technology and the Survival of the Indian Nations. Sierra Club, San Francisco, CA, 1992, pp.3.

[12] Mander, Jerry. In the Absence of the Sacred: The Failure of Technology and the Survival of the Indian Nations. Sierra Club, San Francisco, $C A, 1992, \mathrm{pp} .3$

[13] Mander, Jerry. In the Absence of the Sacred: The Failure of Technology and the Survival of the Indian Nations. Sierra Club, San Francisco, CA, 1992, pp.51.

14] Maté, Gabor. In the Realm of Hungry Ghosts: Close Encounters with Addiction. North Atlantic Publishing, Berkeley, CA, 2010, pp. 260-66.

[15] Mander, Jerry. In the Absence of the Sacred: The Failure of Technology and the Survival of the Indian Nations. Sierra Club, San
Francisco, 1992

[16] Mate, Gabor in "Zeitgeist: Moving Forward-Natural Law." Prod. Peter Joseph. Perf. Gabor Mate. Netflix. Gentle Machines Productions, 2011. Web. <http://www.zeitgeistmovingforward.com/>.

[17] Aristotle, Benjamin Jowett, and HW. C. Davis. Aristotle's Politics. Batoche Books, Kitchener, ON, 1999, pp. 6. Web.

$<$ https://socserv2.socsci.mcmaster.ca/econ/ugcm/3ll3/aristotle/Politics.pdf>

[18] Linebaugh, Peter. "Karl Marx, The Theft of Wood, and Working-Class Composition: A Contribution to the Current Debate." Social Justice, vol. 40, no. 1-2, 2014, pp. 137.

[19] Fromm, Erich, and Ruth Nanda. Anshen. The Art of Loving. Harper \& Row, New York, NY, 1956, pp. 14

[20] Lown, Bernard. "Commodification of Health Care." Physicians for a National Health Program Newsletter. PHNP Newsletter, Spring 2007,pp. 41.<http://www.pnhp.org/PDF_files/spring2007newsletter_lown.pdf>.

[21] Lown, Bernard. "Commodification of Health Care." Physicians for a National Health Program Newsletter. PHNP Newsletter Spring 2007,pp. 41. <http://www.pnhp.org/PDF_files/spring2007newsletter_lown.pdf>.

[22] Mate, Gabor in "Zeitgeist: Moving Forward-Natural Law." Prod. Peter Joseph. Perf. Gabor Mate. Netflix. Gentle Machines Productions, 2011. Web.

[23] Mate, Gabor in "Zeitgeist: Moving Forward-Natural Law." Prod. Peter Joseph. Perf. Gabor Mate. Netflix. Gentle Machines Productions, 2011. Web.

[24] "Facts about Mental IIIness - Canadian Mental Health Association." Canadian Mental Health Association. Canadian Menta Health Association. Web. <http://www.cmha.ca/media/fast-facts-about-mental-illness/>.

[25] “Facts about Mental IIIness - Canadian Mental Health Association." Canadian Mental Health Association. Canadian Menta Health Association. Web.

<http://www.cmha.ca/media/fast-facts-about-menta-illness/>.

[26] ] Canadian Community Health Survey: Mental Health, 2012." Statistics Canada. Government of Canada, 18 Sept. 2013. Web. $<$ http://www.statcan.gc.ca/daily-quotidien/130918/dq130918a-eng.htm>.

[27] Adam Sunderland And Leanne C. Findlay. “Perceived Need for Mental Health Care in Canada: Results from the 2012 Canadian Community Health Survey-Mental Health." Statistics Canada Health Reports. vol. 24, no.9, Government of Canada, Ottawa, Sept. 2013, pp. 3-9. Web. <http://www.statcan.gc.ca/pub/82-003-x/2013009/article/11863-eng.htm>

[28] Pearson, Caryn, Teresa Janz, and Jennifer Ali. "Mental and Substance Use Disorders in Canada." Statistics Canada. Govern- 
ment of Canada, 0ttawa, Sept. 2013. Web. <http://www.statcan.gc.ca/pub/82-003-x/2013009/article/11863-eng.htm>. [29] Perez-Gomez, Alberto. "Architecture as a Performing Art- the End of the Master Builder?" Architecture: Norway. Arkitektur N Magazine, 25 May, 2015. Web. <http://architecturenorway.no/questions/histories/perez-gomez-performance/>

[30] Perez-Gomez, Alberto. "Architecture as a Performing Art- the End of the Master Builder?" Architecture: Norway. Arkitektur N Magazine, 25 May, 2015. Web.

[31] Perez-Gomez, Alberto. "Architecture as a Performing Art- the End of the Master Builder?" Architecture: Norway. Arkitektur N Magazine, 25 May, 2015. Web.

[32] Stanek, Lukasz. "Space as an Abstraction"Space, Difference, Everyday Life: Reading Henri Lefebvre edited by Kanishka GoonewardenaStefan Kipfer, Richard Milgrom, Christian Schmid, Routledge Publishing, New York, 2008, pp. 71. Web. <http://www. mom.arq.ufmg.br/mom/babel/textos/lefebure_space_everyday.pdf>

[33] Henri Lefebvre, The Production of Space, trans. Donald Nicholson-Smith, Blackwell, Oxford, UK, 1991, pp. 42.

[34] Hill, Johnathan. "Building a Drawing and Drawing a Building." Nordic Journal of Architectural Research, vol. 15, no. 4, 2002, pp. 15-20. Nordisk Arkitekturforskning. SINTEF Academic Press, Norway, 2013. Web. <arkitekturforskning.net/na/article/ download/325/283>.

[35] Henri Lefebure, The Production of Space, trans. Donald Nicholson-Smith, Blackwell Publishing, Oxford, UK, 1991.

[36] Stanek, Lukasz. "Space as an Abstraction"Space, Difference, Everyday Life: Reading Henri Lefebure edited by Kanishka Goonewardena, Stefan Kipfer, Richard Milgrom, Christian Schmid, Routledge Publishing, New York, 2008. Web. <http://www.mom. arq.ufmg.br/mom/babel/textos/lefebure_space_everyday.pdf>.

[37] Henri Lefebvre, The Production of Space, trans. Donald Nicholson-Smith, Blackwell Publishing, Oxford, 1991, pp. 361.

[38] Borden, lain. The Urban Condition: Space, Community and Self in the Contemporary Metropolis, vol. 212, EMAP Architecture, Rotterdam, NL, 2000. pp 89. Web.

$<$ https://ryerson.summon.serialssolutions.com/search?s.q=+Architecture\%3A+Art+and+-

Science+Charles+W.+Moore\&spellcheck=true\#!!/search?ho=t\&fvf=|sFullText,true,,$\& \mid=$ en\&q=The\%20Urban\%20Condi-

tion:\%20Space, $\% 20$ Community, $\% 20$ and $\% 20$ Self\%20in\%20the\%20Contemporary\%20Metropolis>.

[39] Borden, lain. The Urban Condition: Space, Community and Self in the Contemporary Metropolis, vol. 212, EMAP Architecture, Rotterdam, NL, 2000, pp. 95. Web.

[40] "Aboriginal Peoples in Canada: First Nations People, Métis and Inuit." Statistics Canada. Government of Canada, Ottawa, 23 Dec. 2015. Web. <https://www12.statcan.gc.ca/nhs-enm/2011/as-sa/99-011-x/99-011-x2011001-eng.ffm>.

[41] "Aboriginal Peoples in Canada: First Nations People, Métis and Inuit." Statistics Canada. Government of Canada, Ottawa, 23 Dec. 2015. Web.

[42] Mussell, Bill, and Sarah Hamid-Balma, eds. "Aboriginal People." Visions Journal. Here to Help: BC Partners for Mental Health and Addiction Information, vol.5, no.1, Summer 2008, Vancouver, British Columbia, pp. 7. Web. < http://www.heretohelp. bc.ca/visions/aboriginal-people-vol5>.

[43] Mussell, Bill, and Sarah Hamid-Balma, eds. "Aboriginal People." Visions Journal. Here to Help: BC Partners for Mental Health and Addiction Information, vol.5, no.1, Summer 2008, Vancouver, British Columbia, pp. 7. Web.

44] Harper, Douglas. "Addict." Online Etymology Dictionary. Web. <http://www.etymonline.com/index.php?term=addict>.

[45] Alexander, Bruce. "The Rise and Fall of the Official View of Addiction." Bruce K. Alexander. Simon Fraser University, Burnbay, British Columbia. Bruce Alexander. July 2014. Web.

$<$ http://www.brucekalexander.com/articles-speeches/277-rise-and-fall-of-the-official-view-of-addiction-6>.

[46] Alexander, Bruce. "The Rise and Fall of the Official View of Addiction." Bruce K. Alexander. Simon Fraser University, Burnbay, British Columbia. Bruce Alexander. July 2014. Web.

[47] Alexander, Bruce. "The Rise and Fall of the Official View of Addiction." Bruce K. Alexander. Simon Fraser University, Burnbay,

British Columbia. Bruce Alexander. July 2014 . Web.
[48] Alexander, Bruce. "The Rise and Fall of the Official View of Addiction." Bruce K. Alexander. Simon Fraser University, Burnbay, British Columbia. Bruce Alexander. July 2014. Web.

[49] Sapolsky, Robert in "Zeitgeist: Moving Forward--Natural Law.. Prod. Peter Joseph. Perf. Robert Sapolsky. Netflix. Gentle Machines Productions, 2011. Web.

[50] Sapolsky, Robert in "Zeitgeist: Moving Forward--Natural Law." Prod. Peter Joseph. Perf. Robert Sapolsky. Netflix. Gentle Machines Productions, 2011. Web.

[51] Sapolsky, Robert in "Zeitgeist: Moving Forward--Natural Law." Prod. Peter Joseph. Perf. Robert Sapolsky. Netflix. Gentle Machines Productions, 2011. Web.

[52] Heyman, Gene M. Addiction: A Disorder of Choice. Harvard UP, Cambridge, Mass., 2009, pp.91-96.

53] Heyman, Gene M. Addiction: A Disorder of Choice. Harvard UP, Cambridge, Mass., 2009, pp.91-96.

54] Rasmussen, Sandra. Addiction Treatment: Theory and Practice. SAGE Publications, London, UK, 2000, pp. 27.

[55] "Genetics of Addiction." Addictions and Recovery. N.p., 1 Mar. 2016. Web. <http://www.addictionsandrecovery.org/is-addiction-a-disease.htm>.

[56] Heyman, Gene M. Addiction: A Disorder of Choice. Harvard UP, Cambridge, Mass., 2009, pp.91-96.

[57] Courtwright, David. “The Prepared Mind: Marie Nyswander, Methadone Maintenance, and the Metabolic Theory of Addiction." Addiction. Carfax Publishing, Jacksonville, Florida vol. 92, n0.3, 1997, pp. 257-65. Web. <http://journals2.scholarsportal. info.ezproxy.lib.ryerson.ca/details/09652140/v92i0003/257_tpmmnmatmtoa.xml>.

[58] "Theories of Addiction." SparkNotes. Barnes and Noble. Web.

<http://www.sparknotes.com/health/addiction/section2.rhtml>.

[59] West, Robert, and Ainsley Hardy. Theory of Addiction. Blackwell Pub./Addiction Press, Sussex, England, 2006, pp.117-118. [60] Mate, Gabor in "Zeitgeist: Moving Forward-Natural Law." Prod. Peter Joseph. Perf. Gabor Mate. Netflix. Gentle Machines Productions, 2011. Web.

[61] Mate, Gabor in "Zeitgeist: Moving Forward-Natural Law." Prod. Peter Joseph. Perf. Gabor Mate. Netflix. Gentle Machines Productions, 2011. Web.

[62] Mate, Gabor in "Zeitgeist: Moving Forward-Natural Law." Prod. Peter Joseph. Perf. Gabor Mate. Netflix. Gentle Machines Productions, 2011. Web.

[63] Sapolsky, Robert in "Zeitgeist: Moving Forward--Natural Law." Prod. Peter Joseph. Perf. Robert Sapolsky. Netflix. Gentle Machines Productions, 2011. Web.

[64] Mate, Gabor in "Zeitgeist: Moving Forward-Natural Law." Prod. Peter Joseph. Perf. Gabor Mate. Netflix. Gentle Machines Productions, 2011. Web.

[65] Sapolsky, Robert in "Zeitgeist: Moving Forward--Natural Law." Prod. Peter Joseph. Perf. Robert Sapolsky. Netflix. Gentle Machines Productions, 2011. Web.

[66] Mate, Gabor in "Zeitgeist: Moving Forward-Natural Law." Prod. Peter Joseph. Perf. Gabor Mate. Netflix. Gentle Machines Productions, 2011. Web.

[67] Sapolsky, Robert in "Zeitgeist: Moving Forward--Natural Law." Prod. Peter Joseph. Perf. Robert Sapolsky. Netflix. Gentle Machines Productions, 2011. Web.

[68] Edelman, Gerald M. Neural Darwinism: The Theory of Neuronal Group Selection. Basic Books, New York,NY, 1987.

[69]Mate, Gabor in "Zeitgeist: Moving Forward-Natural Law." Prod. Peter Joseph. Perf. Gabor Mate. Netflix. Gentle Machines Productions, 2011. Web

[70] Mate, Gabor in "Zeitgeist: Moving Forward-Natural Law." Prod. Peter Joseph. Perf. Gabor Mate. Netflix. Gentle Machines Productions, 2011. Web.

[71] Alexander, Bruce. “The Rise and Fall of the Official View of Addiction." Bruce K. Alexander. Simon Fraser University, Burnbay, British Columbia. Bruce Alexander. July 2014. Web. 
[72] Alexander, Bruce. "The Rise and Fall of the Official View of Addiction." Bruce K. Alexander. Simon Fraser University, Burnbay, British Columbia. Bruce Alexander. July 2014. Web.

[73] Alexander, Bruce. “The Rise and Fall of the Official View of Addiction." Bruce K. Alexander. Simon Fraser University, Burnbay, British Columbia. Bruce Alexander. July 2014. Web.

[74] Alexander, Bruce. "The Rise and Fall of the Official View of Addiction." Bruce K. Alexander. Simon Fraser University, Burnbay, British Columbia. Bruce Alexander. July 2014. Web.

[75] Alexander, Bruce. "The Rise and Fall of the Official View of Addiction." Bruce K. Alexander. Simon Fraser University, Burnbay, British Columbia. Bruce Alexander. July 2014. Web.

[76] Alexander, Bruce. "The Rise and Fall of the Official View of Addiction." Bruce K. Alexander. Simon Fraser University, Burnbay, British Columbia. Bruce Alexander. July 2014. Web.

[77] "5 Most Common Disorders with Addictions." Dual Diagnosis. Foundation Recovery Network. Web.

$<$ http://www.dualdiagnosis.org/c0-occurring-disorders/5-common-c0-occurring-disorders-addictions/>.

[78] Alexander, Bruce K. The Globalisation of Addiction: A Study in Poverty of the Spirit. Oxford University Press, 2008, pp 153-27

[79] Mojtabai, Ramin. “Americans' Attitudes Toward Mental Health Treatment Seeking: 1990-2003." Psychiatric Services, vol. 58 no. 5, 2007, pp. 642-51. Web.

$<$ http://search.proquest.com.ezproxy.lib.ryerson.ca/docview/213083339?pq-origsite=summon>

[80] Chansonneuve, Deborah, and Aboriginal Healing Foundation (Canada). Addictive behaviors among aboriginal people in Canada, Aboriginal Healing Foundation, Ottawa, ON, 2007, pp.1.

[81] McMillan, Alan D., and Eldon Yellowhorn. First Peoples in Canada. Douglas \& McIntyre, Vancouver, BC, 2004, pp.3,41.

[82] McMillan, Alan D., and Eldon Yellowhorn. First Peoples in Canada. Douglas \& McIntyre,Vancouver, BC, 2004, pp.103-256

[83] McMillan, Alan D., and Eldon Yellowhorn. First Peoples in Canada. Douglas \& McIntyre,Vancouver, BC, 2004, pp.103-256.

[84] Manitowabi, Darrel and Marjory Shawande. "The Meaning of Anishinabe Healing and Wellbeing on Manitoulin Island."

Pimatisiwin: A Journal of Aboriginal and Indigenous Community Health, vol. 9.2, 2011. pp. 443. Web. <http://www.pimatisiwin. com/uploads/jan_20112/10Manitowabishawande.pdf>.

[85] Chansonneuve, Deborah, and Aboriginal Healing Foundation (Canada). Addictive behaviors among aboriginal people in Canada, Aboriginal Healing Foundation, 0ttawa, 0N, 2007, pp.5-7.

[86] McMillan, Alan D., and Eldon Yellowhorn. First Peoples in Canada. Douglas \& Mclntyre,Vancouver, BC, 2004, pp.20-280.

[87] Chansonneuve, Deborah, and Aboriginal Healing Foundation (Canada). Addictive behaviors among aboriginal people in Canada, Aboriginal Healing Foundation, Ottawa, 0N, 2007, pp.5-7.

[88] Chansonneuve, Deborah, and Aboriginal Healing Foundation (Canada). Addictive behaviors among aboriginal people in Canada, Aboriginal Healing Foundation, Ottawa, 0N, 2007, pp.5.

[89] Chansonneuve, Deborah, and Aboriginal Healing Foundation (Canada). Addictive behaviors among aboriginal people in

Canada, Aboriginal Healing Foundation, Ottawa, 0N, 2007, pp.5.

[90] Chansonneuve, Deborah, and Aboriginal Healing Foundation (Canada). Addictive behaviors among aboriginal people in Canada, Aboriginal Healing Foundation, Ottawa, 0N, 2007, pp.5-7.

[91] Chansonneuve, Deborah, and Aboriginal Healing Foundation (Canada). Addictive behaviors among aboriginal people in Canada, Aboriginal Healing Foundation, Ottawa, 0N, 2007, pp.5-7.

[91] Chansonneuve, Deborah, and Aboriginal Healing Foundation (Canada). Addictive behaviors among aboriginal people in Canada. Aboriginal Healing Foundation, 0ttawa, 0N, 2007, pp.10-15.

[93] Chansonneuve, Deborah, and Aboriginal Healing Foundation (Canada). Addictive behaviors among aboriginal people in Canada. Aboriginal Healing Foundation, 0ttawa, ON, 2007, pp.10-15.

[94] Chansonneuve, Deborah, and Aboriginal Healing Foundation (Canada). Addictive behaviors among aboriginal people in Cana-

da. Aboriginal Healing Foundation, Ottawa, 0 , 2007, pp.10-13.
[95] Chansonneuve, Deborah, and Aboriginal Healing Foundation (Canada). Addictive behaviors among aboriginal people in Canada. Aboriginal Healing Foundation, Ottawa, 0N, 2007, pp.10-13.

[96] Canada. The Truth and Reconciliation Commission of Canada. Honouring the Truth, Reconciling for the Future Summary of the Final Report of the Truth and Reconciliation Commission of Canada. The Truth and Reconciliation Commission of Canada, Ottawa, ON, 23 July 2015, pp. v. Web. <http://www.trc.ca/websites/trcinstitution/File/2015/Honouring_the_Truth_Reconciling_for_ the Future July 23_2015.pdf $>$.

[97] Canada. The Truth and Reconciliation Commission of Canada. Honouring the Truth, Reconciling for the Future Summary of the Final Report of the Truth and Reconciliation Commission of Canada. The Truth and Reconciliation Commission of Canada, Ottawa, ON, 23 July 2015, pp. vi. Web.

[98] Saul, John Ralston. The Comeback. Penguin Books, Toronto, 0N, 2014, pp. 166-178.

[99] "Intervention to Address Intergenerational Trauma: Overcoming, Resisting and Preventing Structural Violence." University of Calgary Medicine, Calory, AB, Winter 2012, pp. 3. W/eb. <https//www.ucalgary.ca/wethurston/files/wethurston/Report ventionToAddressIntergenerationalTrauma.pdf>.

[100] Chansonneuve, Deborah, and Aboriginal Healing Foundation (Canada). Addictive behaviors among aboriginal people in Canada. Aboriginal Healing Foundation, Ottawa, 0N, 2007, pp.19-22.

[101] Chansonneuve, Deborah, and Aboriginal Healing Foundation (Canada). Addictive behaviors among aboriginal people in Canada. Aboriginal Healing Foundation, Ottawa, 0N, 2007, pp.19-22.

[102] Chansonneuve, Deborah, and Aboriginal Healing Foundation (Canada). Addictive behaviors among aboriginal people in Canada. Aboriginal Healing Foundation, 0ttawa, 0N, 2007, pp. 28. 
ANISHINABEK HEALING BELIEFS 
Oh, Great Spirit Whose voice I hear in the winds,

And whose breath gives life to all the world,

hear me, I am small and weak,

Ineed your strength and wisdom.

Let me walk in beauty and make my eyes ever behold the red and purple sunset.

Make my hands respect the things you have made and my ears sharp to hear your voice.

Make me wise so that I may understand the things you have taught my people.

Let me learn the lessons you have hidden in every leaf and rock.

I seek strength, not to be greater than my brother,

but to fight my greatest enemy - myself.

Make me always ready to come to you with clean hands and straight eyes.

So when life fades, as the fading sunset,

my Spirit may come to you without shame. [1]

Anishinabek Prayer

\subsection{ANISHINABEK HEALING BELIEFS}

As we've explored in the previous chapters, Canada's indigenous culture have, and still are, suffering the repercussions of colonialism and how the assimilation disrupted and dislocated their society and ways of life. Today we can still see the consequences of the implementation of these western lifestyles and the eradication of their culture. It is also evident that the implications of our western society have had an impact on the wellbeing of non-indigenous people in Canada, particularly in the realms of mental health and addiction. The thesis proposes that we need to engage with the healing beliefs, practices, perspectives and mentalities of these indigenous populations in order to regain this aspect in our built environment and architecture, and, thus, begin to reintroduce into our society.

It is important to recognize the vast diversity among indigenous groups and tribes. Though there are some commonalities among indigenous populations, there is no monolithic set of beliefs that constitute Indigenous epistemology.[2] This thesis will focus on the traditional healing beliefs of Canada's Anishinabek people and will use these principles as informers for the creation of design strategies for healing spaces for people suffering with addiction. The following conclusions will represent the author's interpretation of healing principles which were validated and informed by members from an Anishinabek community. Once again, it is important to note that not all researched literature spoke specifically to Anishinabek healing and culture but also to Canadian and North American indigenous culture as a whole. However, the concepts and findings were authenticated and validated by Anishinabek community members to ensure they align with the beliefs and culture accurately.

The next section will explore traditional Anishinabek healing beliefs, rituals and cultural practices, as well as, examine five dominant principles that exhibit traditional Anishinabek ways of thinking, acquiring and sharing knowledge and world views. 


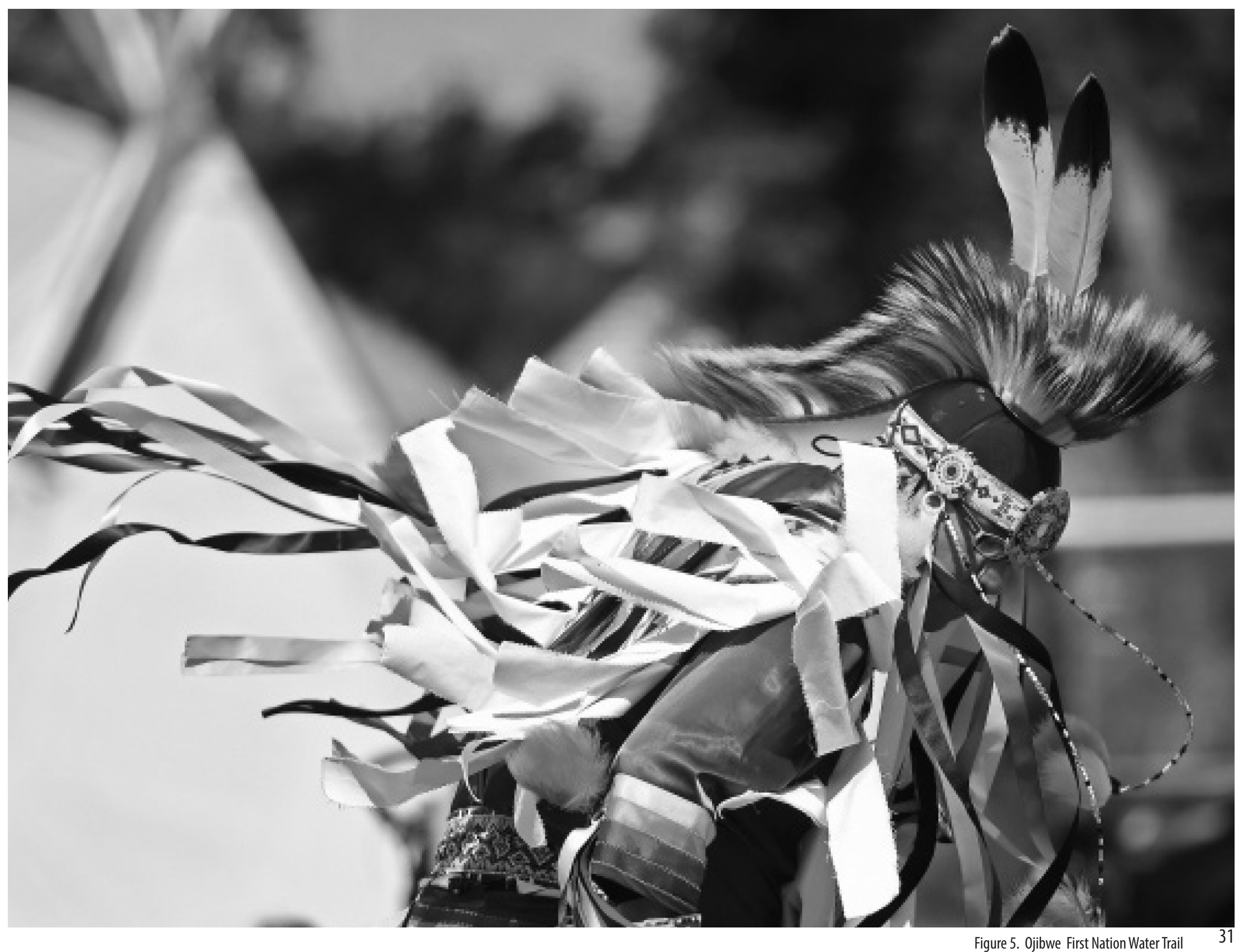


The importance of culture and societal structures is often overlooked in western societies when it comes to health and healing. The Anishinabek, along with many other indigenous groups, believes that their culture is a way of healing. As we've seen in previous chapters, it is evident that our environment, ie. our culture, society, relationships, etc, influence humans at a biological scale, as well as physically, emotionally, mentally and spiritually. Therefore, culture's role is a vital determinant our health.

The Anishinabek culture has strong healing and wellbeing beliefs, perspectives and world views. These views do not fully coincide with the perspectives and practices of our typical western society, in fact, more often than not, they contradict them. Healing is not a linear process; it is not clean or predictable and cannot be seen in isolation. It all starts with their perspective on their place and role in the world. In a western perspective, one sees themselves at the center and as a separate part of a finite universe and have trouble seeing beyond the realms of the physical and scientific. [3] From an Anishinabek perspective, one sees themselves as an equal part of the universe, which extends beyond the physical, into the spiritual and cosmological realms. They are equal partners and contributors. Trying to achieve a holistic, balanced life, walking a true and respectful journey is called seeking Mino-Pimatisiwin in the Anishinabek culture.[4] This next section will examine the cultural teachings and wellbeing beliefs and ways of seeking Mino-Pimatisiwin.

\subsection{THE STORY OF CREATION}

In the Anishinabek culture, spirituality is distinctly different from religion and it is deeply rooted in the spiritual world and spiritual relationships are a part of everyday life. [5] In Kathleen Wilson's dissertation on The Role of Mother Earth in Shaping the Health of Anishinabek: A geographical exploration of culture, health and place, she interviews an Elder from the Manitoulin area, asking if he has any difficulty practicing his spirituality. He goes on to correct her and answer, "Spirituality is not something you can practice like going to church. It cannot be turned on and off. It is something you live." [6] Spirituality is a way of life, embedded and ingrained in the culture and ways of living, providing a deeper connection with mother earth and the Creator. The Creation Story forms the basis for this spirituality and the spiritual connection that one has with all spirit beings created by the Creator, or also referred as the Great Spirit, Kitche Manitou. The following is one of the many different versions of the Creation Story, however all versions represent a symbolic narrative of how the world came into existence and all the creations came to be.[7] The following Creation Story is written by Basil Johnson, a Canadian Indigenous award winning, writer and storyteller.[8]

Kitche Manitou (The Great Spirit) beheld a vision. In this dream he saw a vast sky filled with stars, sun, moon, and earth. He saw an earth made of mountains and valleys, islands and lakes, plains and forests. He saw trees and flowers, grasses and vegetables. He saw walking, flying, swimming, and crawling beings. He witnessed the birth, growth, and the end of things. At the same time he saw other things live on. Amidst change there was constancy. Kitche Manitou heard songs, wailings, stories. He touched wind and rain. He felt love and hate, fear and courage, joy and sadness. Kitche Manitou meditated to understand his vision. In his wisdom Kitche Manitou understood that his vision had to be fulfilled. Kitche Manitou was to bring into being and existence what he had seen, heard, and felt. Out of nothing he made rock, water, fire, and wind. Into each one he breathed the breath of life. On each he bestowed with his breath a different essence and nature. Each substance had its own power which became its soul-spirit. From these four substances Kitche Manitou created the physical world of sun, stars, moon, and earth. To the sun Kitche Manitou gave the powers of light and heat. To the earth he gave growth and healing; to waters purity and renewal; to the wind music and the breath of life itself. On earth Kitche Manitou formed mountains, valleys, plains, islands, lakes, bays, and rivers. Everything was in its place; everything was beautiful. Then Kitche Manitou made the plant beings. These were four kinds: flowers, grasses, trees, and vegetables. To each he gave a spirit of life, growth, healing, and beauty. Each he placed where it would be the most beneficial, and lend to earth the greatest beauty and harmony and order. After plants, Kitche Manitou created animal beings conferring on each special powers and natures. There were two-leggeds, four-leggeds, wingeds, and swimmers. Last of all he made man. Though last in the order of creation, least in order of dependence, and weakest in bodily powers, man had the greatest gift - the power to dream. Kitche Manitou then made The Great Laws of Nature for the well being and harmony of all things and all creatures. The Great Laws governed the place and movement of sun, moon, earth and stars; governed the powers of wind, water, fire, and rock; governed the rhythm and continuity of life, birth, growth, and decay. All things lived and worked by these laws. Kitche Manitou had brought into existence his vision. [9] 
THE WESTERN PERSPECTIVE

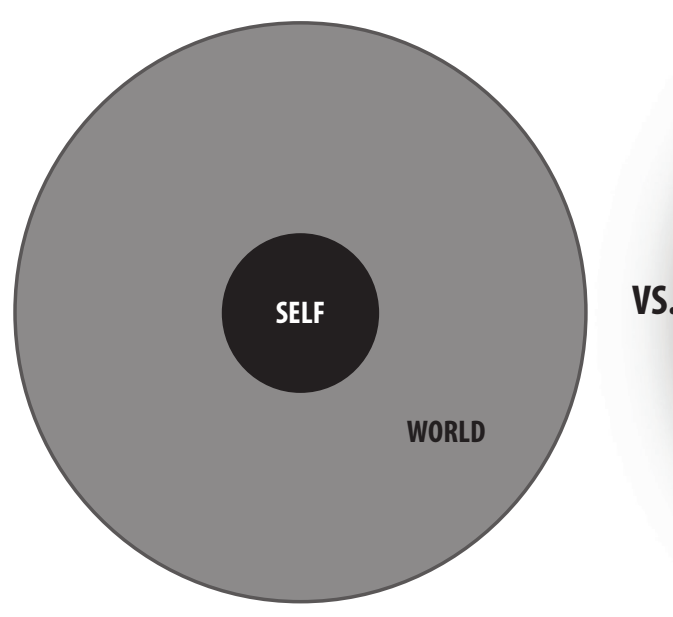

VS.
THE INDIGENOUS PERSPECTIVE

Figure 6. Western versus Canadian Aboriginal World View Adapted by Author

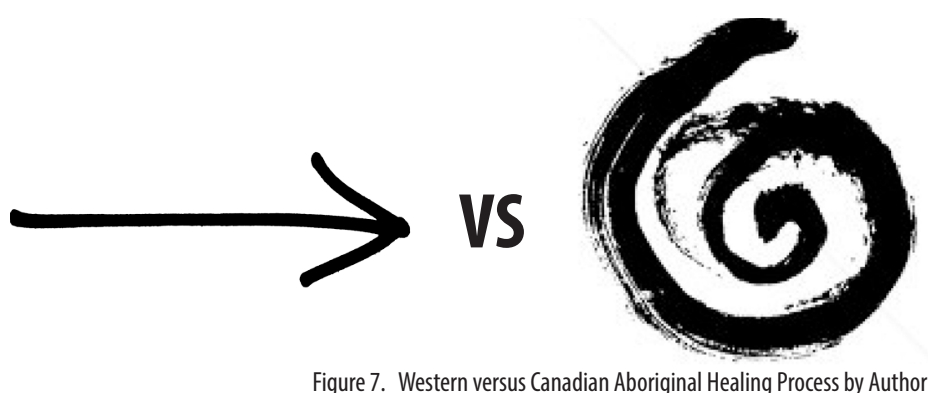


By understanding the Story of Creation, we can begin to understand the worldviews and perspectives of the culture. The equality and spirituality among all beings in the universe that Kitche Manitou gave life, growth, healing and beauty to and the reciprocal, equal relationship between all beings that are to live in harmony and balance with one another and with themselves.

As previously mentioned, this is one of the many versions of the Creation Story, as there are different versions for each geographic area and even within indigenous groups. This is partially due to the dominance of oral traditions and oral ways of sharing knowledge, forming relationships and connections.[10 ] Language and storytelling is an important tool that not only connects people to other beings, Mother Earth and the Creator, but also to their identity. Therefore, the loss of language due to European colonization was catastrophic to the Anishinabek and all Canadian Indigenous cultures. [11] The act of storytelling "is the opening, the breath, the connectedness of the soul, it's the link with others", "it is the method of learning and teaching principles." [12] Storytelling is not only conveyed through the spoken word, it is also done through song, dance and drumming. As anthropologist, Edith Turner points out, "Music and drumming and dance do this, as does the word itself, when expressed in a full state of experience - when being in the experience."[13] The power of the "story" and the storyteller have the ability to assist and facilitate the healing process and re-engage participants back with their spirituality.

As well, Indigenous storytelling takes on a different form than conventional storytelling, typical of most western culture. In North American Indigenous storytelling, stories are told as cyclical cycles of events, where typically, western tradition, organizes it through a linear approach. [14] This way of storytelling removes the focus and centrality from the author or narrator and stratifies it to the listeners, opening it up for collaboration between the listeners and the storytellers. [15]

Without delving too deep into the Creation Story, storytelling and spirituality, it is already evident that concepts of equality, balance, natural elements, mother earth and the notion of cyclical ordering is deeply rooted into the Anishinabek culture. Throughout the rest of the chapters, we will explore how these ideas manifest into the cultural practices, ways of life of the Anishinabek and how the culture becomes a dominant tool in the healing process.

\subsection{HERBAL HEALING PRACTICES}

Traditional Anishinabek herbal rituals contain strong healing benefits for all realms of one's life. Each treatment has cultural roots that reinforce the practices and ways of Anishinabek living. Though western medicine appears to be 'founded in "scientific discovery" we must acknowledge its validity and its lack of guarantee of success for all patients' [16] and, therefore, acknowledge that traditional indigenous medicines are just as valid. To further reinforce the power and validity of indigenous herbal practices, we must note that many of the western medicines we see today have roots in traditional medicines.[17] However, where western medicine's goal is to diagnose and conquer the disease, Anishinabek healing aims to provide a holistic response to the illness that includes social, cultural, familial and spiritual healing components. "Herbal medicines can't be arranged like Western medicine because there is a spiritual component which becomes weaker when it is analyzed. It is difficult for medical professions in the Western world to understand it. Western medicine is the physical, mental, emotional but not the spiritual. I find it's not there. In the Native world everything comes from the heart. That's where it is." [18]

As stated, many of the indigenous plant based healing remedies have formed the basis for pharmaceutical drugs that we currently see today in western medicine.[19] Yet, the application and use of the remedies approach the ailments from different perspectives. In traditional Anishinabek language, the term "medicine", in a western sense, has a distinctly different connection to health and healing due to its intrusion from colonial invasion and contemporary western medical practices.[20] The Anishinabek word for medicine is Mshki and means "strength from the earth". [21] Herbs are only picked on a needed basis, are not horded for future use and only mature plants are used. As we've been introduced by the Creation Story, we can begin to see the deep connections the indigenous culture has with the natural world and how it is believe that the path to wellbeing can be found in earth, its elements and creations. This led to the Four Sacred Medicines; sweet grass wiingash. (north), tobacco sema (east), cedar kiishig (south) and sage mshkwadewashk (west). [22] Each sacred herb corresponds with the four cardinal directions of the medicine wheel and represents certain principles and teaching of the culture.[23]

The importance and effectiveness of herbal healing practices goes beyond the conventional western medicinal approaches, which tend to treat and conquer specific physical manifestations of the ailment. Anishinabek herbal healing plays a multi-faceted role, which engages the ill physically, mentally, emotionally and spiritually. [24] The herbal practices are not delivered in isolation, they are often used in conjunction with a healing ceremony that engage and provide the individual with an experiential healing process, activating all four aspects of healing from the Medicine Wheel (See figure 11 on page 38 ), 
through a process or event that stimulates the whole body and all of its senses. [25] The next section will examine ceremonial practices, how they incorporate herbal medicines and how they facilitate healing.

\subsection{CEREMONIAL HEALING PRACTICES}

The Anishinabek culture, along with many other indigenous cultures, considers ceremonial practices as vital and instrumental to the healing process. These ceremonies often use herbs and incorporate, symbolically or literally, the four elements; fire, water, earth, air, accompanied with communal and spiritual gatherings to help facilitate healing.

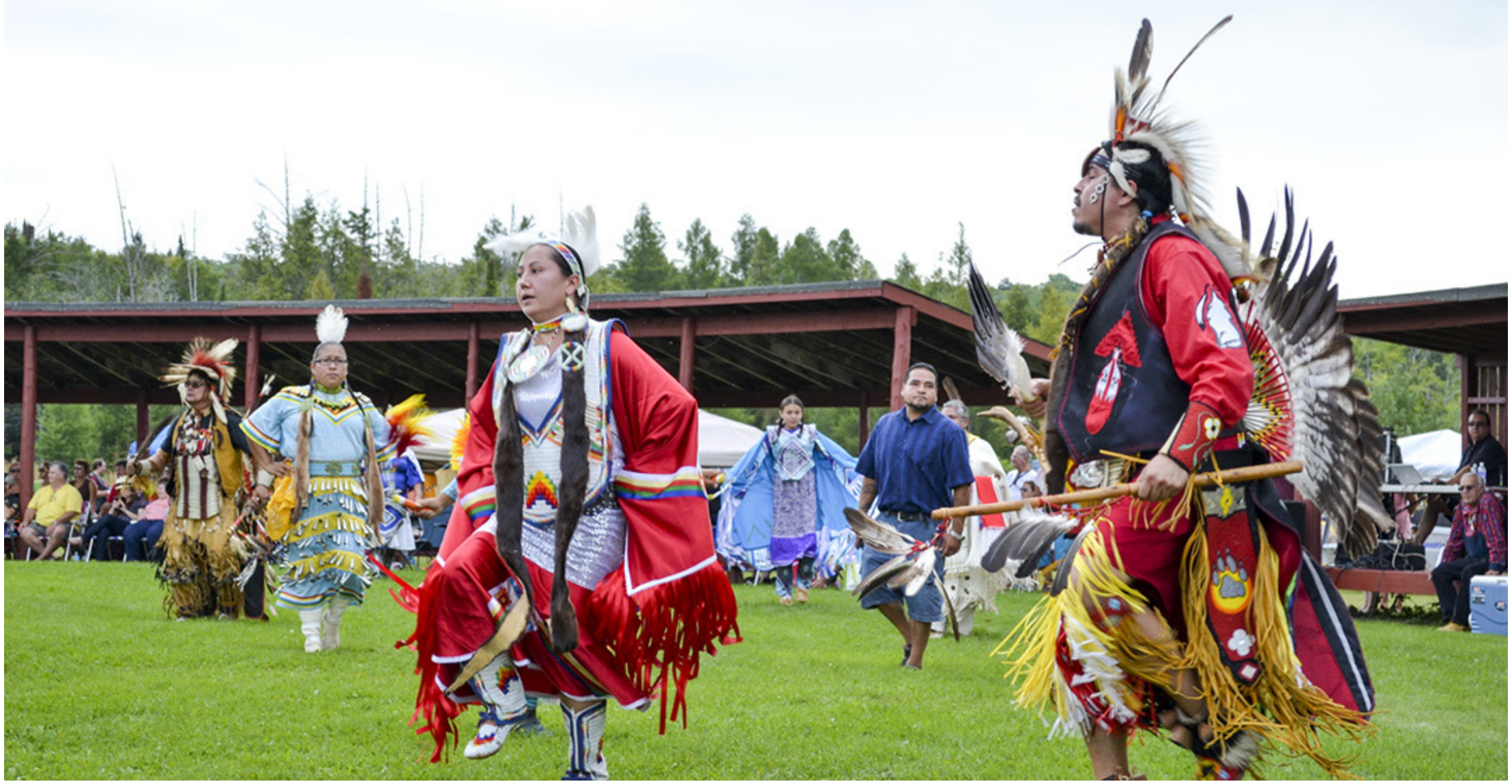

Figure 8. Pow Wow Ceremony 


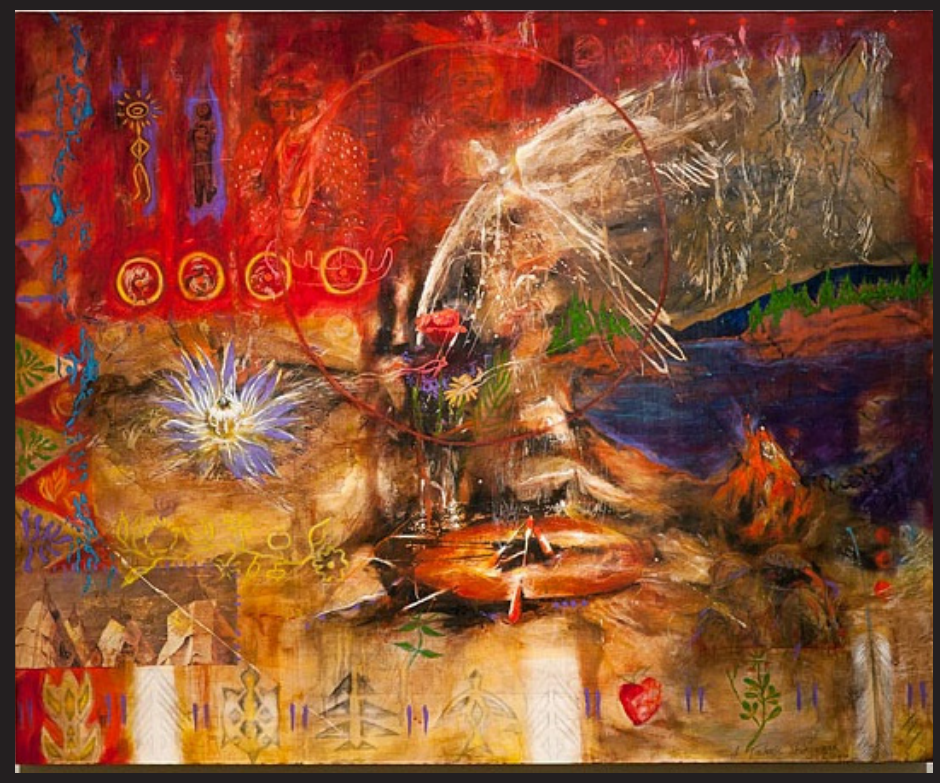

Figure 9. Anishinabek Art: Healing the Earth by Janice Toulouse

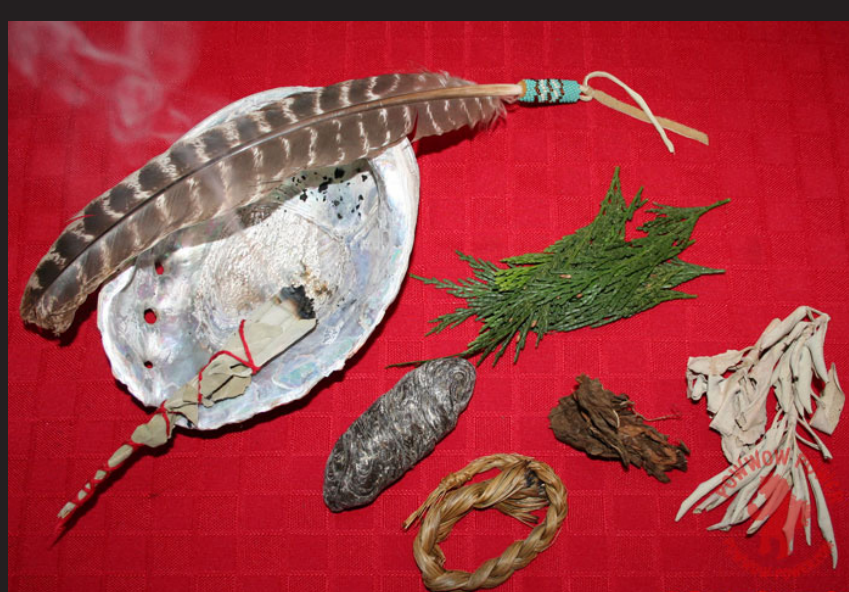

Figure 10. Smudging Ceremony
One of the most common types of healing ceremonies is the 'Healing Circle'. These consist of group gatherings, typically run by a shaman or elder, which aim to heal physical, mental, emotional and spiritual ailments through communal sharing, listening, acknowledging and respecting. Nothing said in the healing ceremony can be shared beyond its bounds, if this rule is not adhered to, then the individual is no longer able to participate in the circle.[26] Typically a symbolic feather, which represents duality, or another object, is used to pass around the circle for people who wish to share their experiences. Many contemporary alcohol treatment programs used today, such as AA (Alcoholics Anonymous), have their roots in this indigenous healing circle practice.[27]

Dances and songs are an integral part of the culture and healing and have evolved from observation of nature, animals or dreams.[28] They provide an outlet to express, release and connect the spiritual and physical worlds.[29] Originating from the Algonquin, which are part of the Ontario Anishinabek, the Pow Wow, which means "he who dreams,"[30] is a social gathering that involves, prayers, feasting, music, dancing and smudging. It is held to express indigenous identity and honor the earth and ancestors. Traditionally, it was held prior to a big expedition or a hunt.[31] A Pow Wow is a celebration of life, earth, all things in the universe and is a medium for spiritual and cultural expression.

Another commonly practiced ceremony is the 'Smudging Ceremony.' A Smudging Ceremony is a purification ritual that uses one of the four sacred medicines to cleanse the body, mind, heart and soul. The sacred herb is burned and the scented smoke gathered in the hands of the ill and washed over their body, particularly where the ailment is located.[32,33] As smoke rises to the sky, one's prayers are brought to the Creator, as well, negative energies and emotions are taken away. The act of burning the herbs also stimulates the brain, through smell, and produces bet-endorphins, a process that helps our bodies heal. [34] The ceremony can be held at any time, but usually before a meeting or gathering, however, it is also recommended to be done at home or work if any conflict or negative energies are present.[35] A shell (represents the water element) is often used as a container to hold the burning herb and the scent is fanned through space with an eagle feather.[36]

Though this thesis has briefly noted some of the common ceremonial healing practices in the Anishinabek culture, it will investigate the sweat lodge ceremony in with a more thorough and in-depth analysis, as it is one of the most influential healing ceremonies of the culture.[37] Though the sweat lodge is a widely common and popular North American indigenous healing ceremony, little quantitative studies have been done on it to analyze it effects.[38]

The Sweat Lodge ceremony is purification and cleansing ritual. It is often done when one is ill; mentally, physically, emotionally or spiritually to repair the damage done and reground the ill back to healthy holistic 
way of living, however, this ceremony specifically focuses on the spiritual aspect of healing and how it brings all other aspects together.[39] This is why, in particular, the sweat lodge ceremony provides a space where one who is struggling can connect with the Creator.

The structure of the sweat lodge is embedded with cultural symbolism, particularly through the physical structure of the lodge and the function of it. The overall structure represents the "womb of mother earth". [40] The sweat lodge is built with saplings and tree bark or animal skins, with four main structural saplings curved and tied together.[41] This creates four quadrants that represent the four directions of the Medicine wheel. The entrance faces the east, representing new beginnings and the rising of the sun.[42] The other three directions of the sweat lodge "are only to be used by spirits". [43] Furthermore, there are to be four rings that radiate outside of the sweat lodge, which are situated on the ground. These rings "represent the four levels of knowledge above the earth."[44] Upon entering the sweat lodge, one is to crawl through the east entrance, activating a sense of humility and "engag[ing] all realms of self." [45] A small hole in the center of the space is dug into the earth and filled with grandfather rocks. This is where the fire is lit, the herbs are sprinkled and water is poured to create steam and heat within the lodge. The space is enveloped in complete darkness. [46]

The ceremony starts by participants offering a gift of sacred tobacco before entering. [47] Once everyone has entered the lodge and the leader of the ceremony has carried in the grandfather rocks, four rounds of prayers are done, for each direction. During each round, participants and the leader will engage in song, drumming, and many physical and oral releases, including crying, laughing, screaming, and shaking (emotional aspect).[48] With each round of the ceremony the sweat lodge becomes extremely hot.'The physical aspect of self is pushed to its limits.'[49] Participants become very uncomfortable, yet are unable to leave. The anonymity of complete darkness, restriction and heightening of senses and the physical conditions of the space create an environment where mental aspect of self and ego is lost to the heat and emotions, allowing one's spiritual part of themselves to be ignited and ready to open up and connect with the Creator.[50]

These examples represent a few of the many ceremonies in the Anishinabek culture that connect all realms of human existence and create an experiential and communal environment for healing. There is a healing component in each of the ceremonies; they are the "medicine". The act of healing is an integral part of the culture and cultural practices, they are not separated, they are one.

\subsection{FOUR DIRECTIONS}

The symbol of the circle is extremely important to the culture, representing the interconnection of all life. It symbolizes an ongoing, balanced process that has no end and no beginning. It is the base for the Medicine Wheel, a native healing, teaching and meditative tool that represents harmony, balance, interconnectedness and the indigenous way of life. The Medicine Wheel is a circle equally split into four separate quadrants which represent the dimensions of health and cycles of life.[51] The wheel can also be used to represent many different meanings, such as the stages of life, season, aspects of life and wellbeing, elements in nature, sacred animals, ceremonial plants, times of day or trials of man.[52] Each of these are meticulously placed in certain quadrants of the wheel dependent on their meanings. East represents the spiritual wellbeing, north represents the head, the mind and mental wellbeing, south represents the heart, the emotional wellbeing and west represents the spirit, the energies of the world and body, the physical wellbeing, the life source.[53] One cannot be healthy or happy without all of these elements in balance and fulfilled in an individual, because they are all interrelated and one affects the other.[54] 


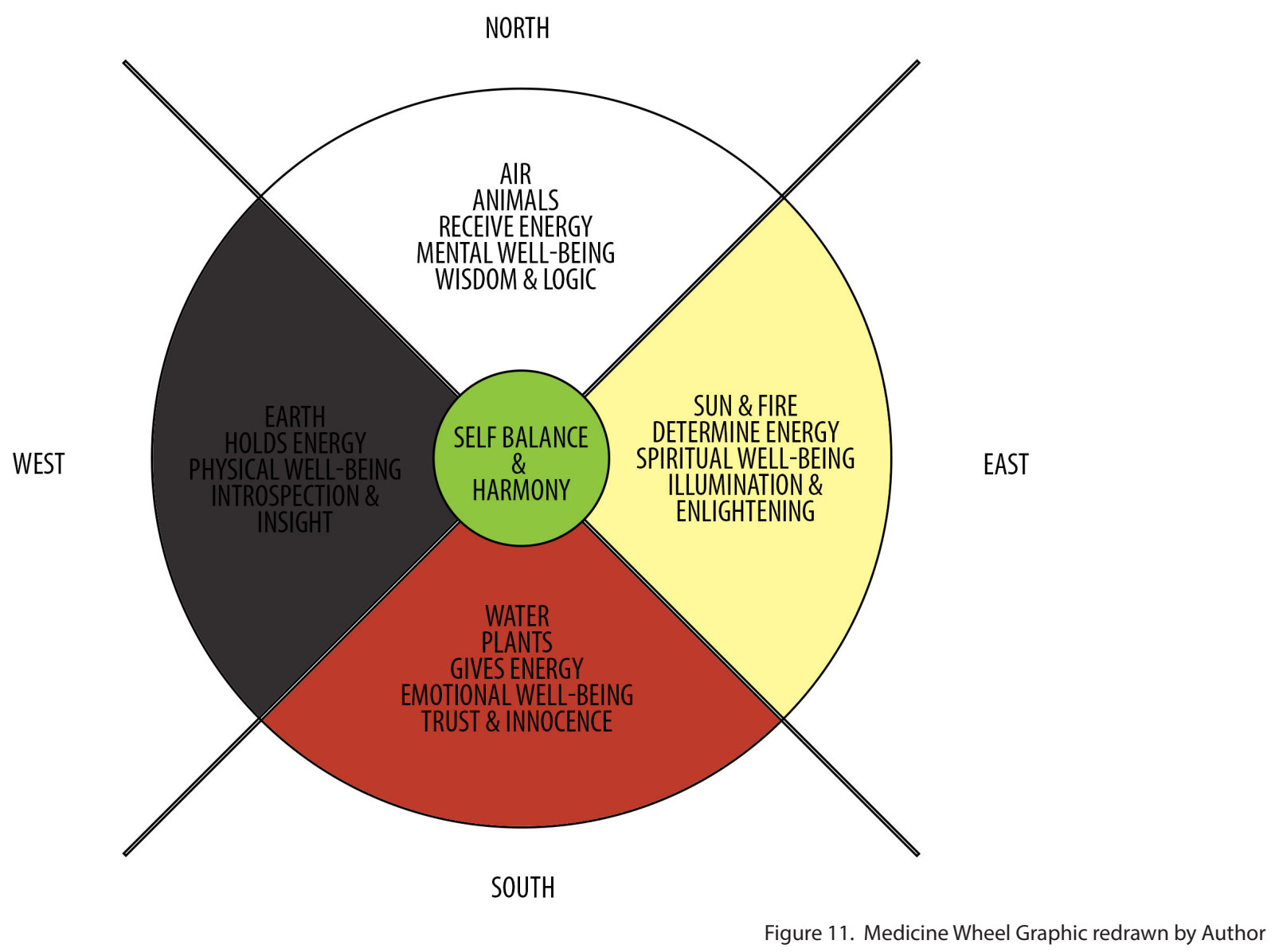


Along with the Medicine Wheel, the Anishinabek culture teaches the values of the Seven Grandfathers. These teaching traditions are orally passed down from generation to generation. They provide the moral and cultural foundation for a healthy society, a healthy individual and healthy world.[55] The Seven Grandfather teachings are just as valid to the healing process as the Medicine Wheel, sacred herds and ceremonial healing practices and it is believed that one cannot achieve wellbeing if they do not practice these traits and treat themselves and all other creations with these moral foundations. Each of these teachings cannot be achieved without the other. The Seven Grandfathers teachings include:

Humility: Realize that we are a sacred part of all creation. Live a self-less life and respect your place in the world

Courage: Find your inner strength and face your life with bravery. Defend what you believe and face your fears.

Honesty: Recognize and respect who you are. Be true to yourself and others. Do not deceive.

Wisdom: Observe life around you. Learn, live and cherish knowledge and allow it to guide you forward.

Truth: Be truthful and sincere. Have faith and trust in the truth.

Respect: Respect all creations and sharing equally. Do onto others as you would like you.

Love: Love carries all the teachings. Love is peace, inner acceptance and is the foundation for well-being. [56]

The combination of the Medicine Wheel, sacred herds, ceremonial healing practices and the Seven Grandfather teachings form the path towards healing and health of an individual, a community and a healthy world. These are very different approaches and values of healing that we do not actively seek to achieve in western health practices. It is a completely different view on what being healthy means. Each focuses on a holistic understanding of health that takes into account every aspect of the human, their interrelated qualities and relationships on earth. Looking at healing and health from this perspective, it begins to align with the Adaption-Dislocation theory of addiction, where the ailment is not solely stemming from biomedical, scientific problems, but from an imbalance in our current modern world and modern society, that deviates from the traditional values and ways of life. North America has begun to see introduction of the word "wellbriety" into the English language. This means achieving wellbeing and a sober life. [57] This is a treatment method for addiction that is based on the principles of Native American and most indigenous cultures. It is an international movement that seeks to break the cycle of damage and hurt that is caused by addiction. This is a step in the right direction, yet it has still not made it into the mainstream treatment in western society. $[58,59]$ 
Architecture is tied closely to culture as it represents humankind's ideologies, aspirations, values and perspectives of the world. It also has the ability to touch the soul, engage the body, stimulate the brain and activate the heart. One can find identity and belonging in architecture. Therefore, it is a key component to understanding cultures and how they functioned from all over the world. The following section will examine three traditional Anishinabek healing spaces in order to further extract and learn the cultural ideals and perspectives of the Anishinabek culture. Each of these healing spaces were present and practiced among the Anishinabek communities within Northern Ontario.

\subsubsection{THE SWEAT LODGE}

As we investigated in Section 4.4, the sweat lodge form was originally derived from wigwam and is a place of spiritual re-awakening and reconciliation.[60] It is a common space used for healing a multitude of illnesses in the Anishinabek tradition. The sweat lodge ceremony consists of the purification of the spirit, mind, and body. [61] The sweat lodge is a dome shaped structure made out of wood saplings bent and grounded into the earth. The interior of the lodge is slightly embedded into the ground and is centered around a central fire pit with an opening above to the stars and the sky. The exterior is covered in animal skins or bark from trees.[62,63] The sweat lodge represents a connection between the earth, the human and the cosmos, reconnecting all realms of life and re-grounding the user back to a spiritual balance.[64]

Place determined the materiality and structure of all dwellings. Availability of materials, ecological, weather systems and seasons are the primary determining factors about how the structure will be built. These experiences and interactions with building, materiality and the climate were informers that helped shaped how the Anishinabek perceive the world and live within it. It is through these experiences that meaning is embedded into these architectural spaces and the connections between other beings and the earth is reinforced. The act of embedding the sweat lodge into the ground symbolizes more than just the structural integrity of the sweat lodge. It represents a connection with mother earth. The idea of being part of it and intertwined with it. The structure of the saplings root into the earth and "grow out of it" to support the bark of tree or animal skins which enclose the structure.[65] The circularity and centralization of the structure also reflects the ideas of equality among space and its users.[66,67] Centered in the structure lies an opening to allow smoke to rise from the purification process. This opening also provides a connection to father sky, the stars and the cosmos, providing a beam of light when opened. The structure has a processional entrance from the east and the door facing the east direction. This symbolizes new beginning and rebirth and is connected to the cardinal directions and the medicine wheel. [68]

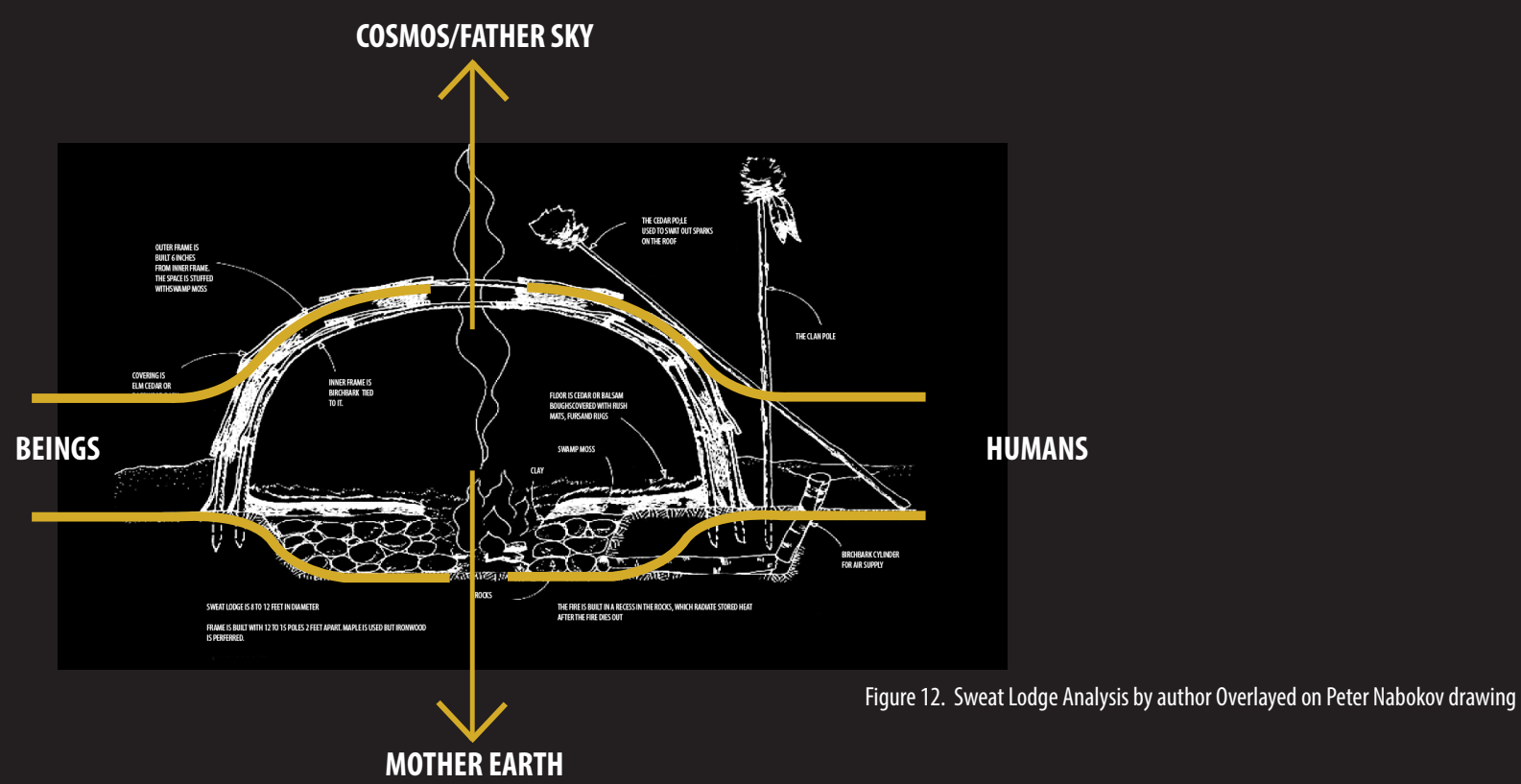




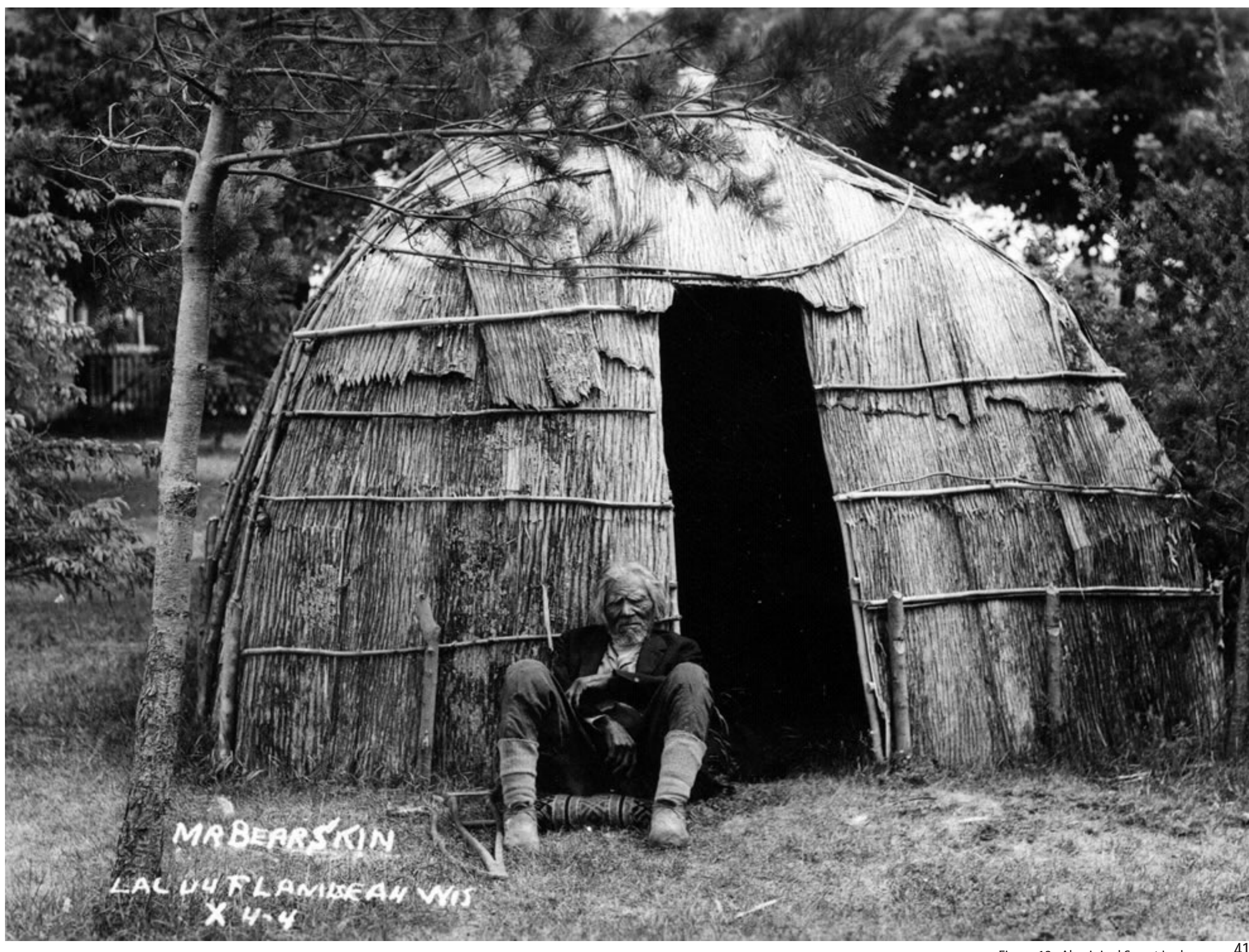


The longhouse may seem as though it is not a healing space, but rather a residential space. According to Peter Nabokov, author of the book Native American Architecture, "Residential structures serve a wide variety of utilitarian and symbolic functions, ranging from the fulfillment of basic needs for the physical shelter, to the practical and symbolic delineations of space, to the conveyance of a complex of signs designating ethnic identity and social status." [69] If we look at healing from an indigenous Anishinabek perspective, culture and ways of life are the vital determinants of health and healing. Nabokov further states that "architecture, then, was the principal tool for socialization - a means by which members of a tribe learned rules of behavior and a particular world view." [70] Particularly, residential spaces, architecture interact with the occupants, domestic behaviors and activities of the environments and begin to establish the rules and patterns of which the occupants live."[71]

The architecture of the longhouse and its interior spatial organization expressed the social hierarchy, boundaries between public and private and spaces that are multi-purpose, overlap and intertwine.[72] This emphasized the collective values of the Anishinabek culture and helped to inform how one understood oneself as an individual and as a collective. The dwelling could be as large as $40 \mathrm{~m} \times 6 \mathrm{~m} \times 6 \mathrm{~m}$, was a communal space that held multiple family units and the structure easily allowed for expansion to accommodate the growth within families or new members of the tribes.[73] The longhouse informed the kinship group, creating another layer to the relationship dynamics and another level of familial support. Within the longhouse a central corridor ran through the space where multiple hearths were dug in the ground each belonging to a family unit within the longhouse. The space held a variety of activities and domestic functions, such as sleeping, cooking, hanging clothes, playing games, storytelling and so on. [74] The overlapping of functions throughout this multipurpose environment brought vibrancy and life to it. It also brought the need to coordinate, help out and have patience for others and their activities. Though no other option was available, such as a private dwelling for each family, this social dynamic instilled ideas of communal support and teamwork. It extended support beyond the typical family unit and created a larger kinship group for individuals to rely on one another.

The density of the space and the distances between spatial activities speaks to the everyday life and the social organization.[75] The boundaries between public and private are transparent and open. Each "bedroom" or personal cubicle space is framed by the sapling structure of the longhouse. Though it may seem as if privacy is not an aspect of the culture, this is a fallacy. Private family and individual boundaries existed and were respected. [76] The architecture and these boundaries became a teaching tool that allowed people to acknowledge personal versus public space without physically separating them from one another, instilling the ability to respect one's personal space without the need for it to be closed off from all others, removing the complete isolation of an individual that much of our architecture today aims to achieve. [77]

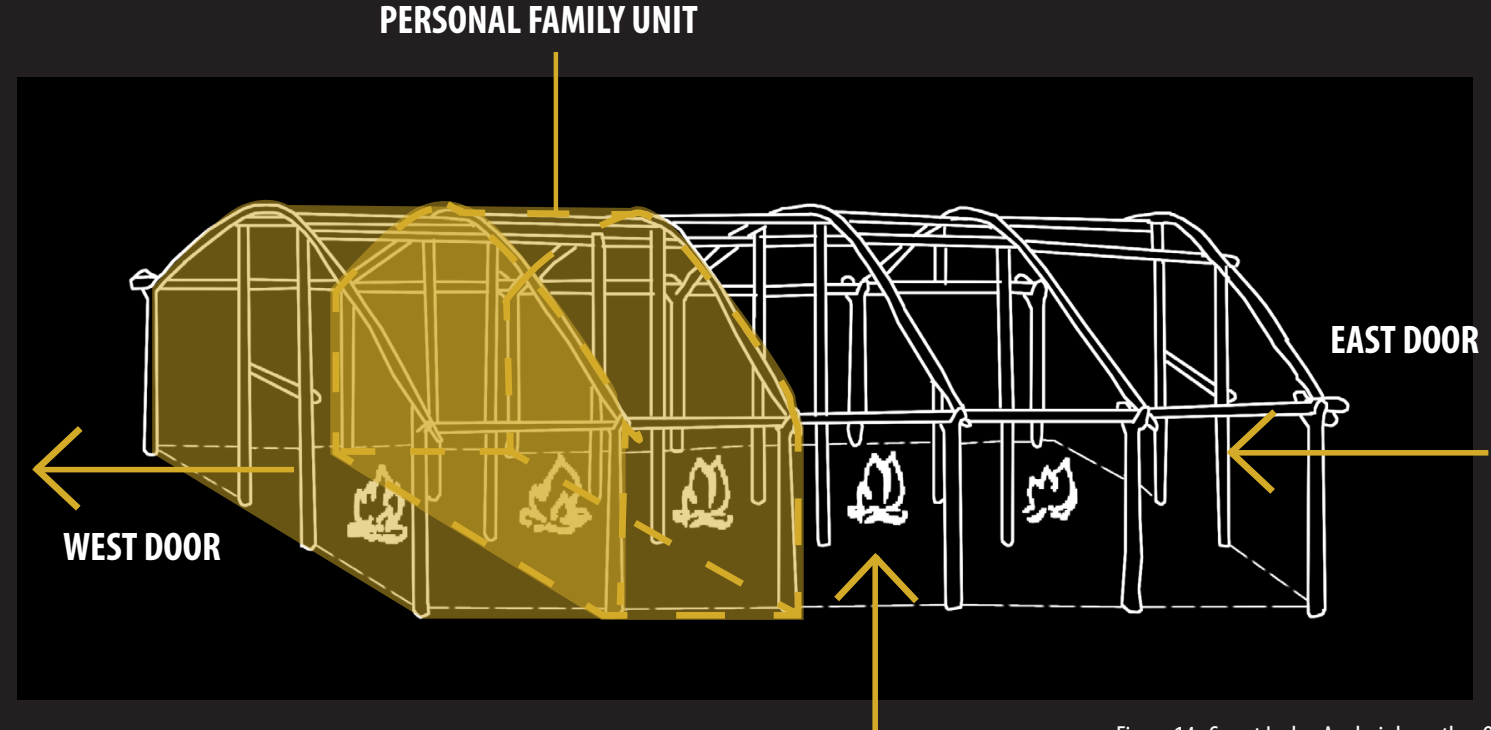




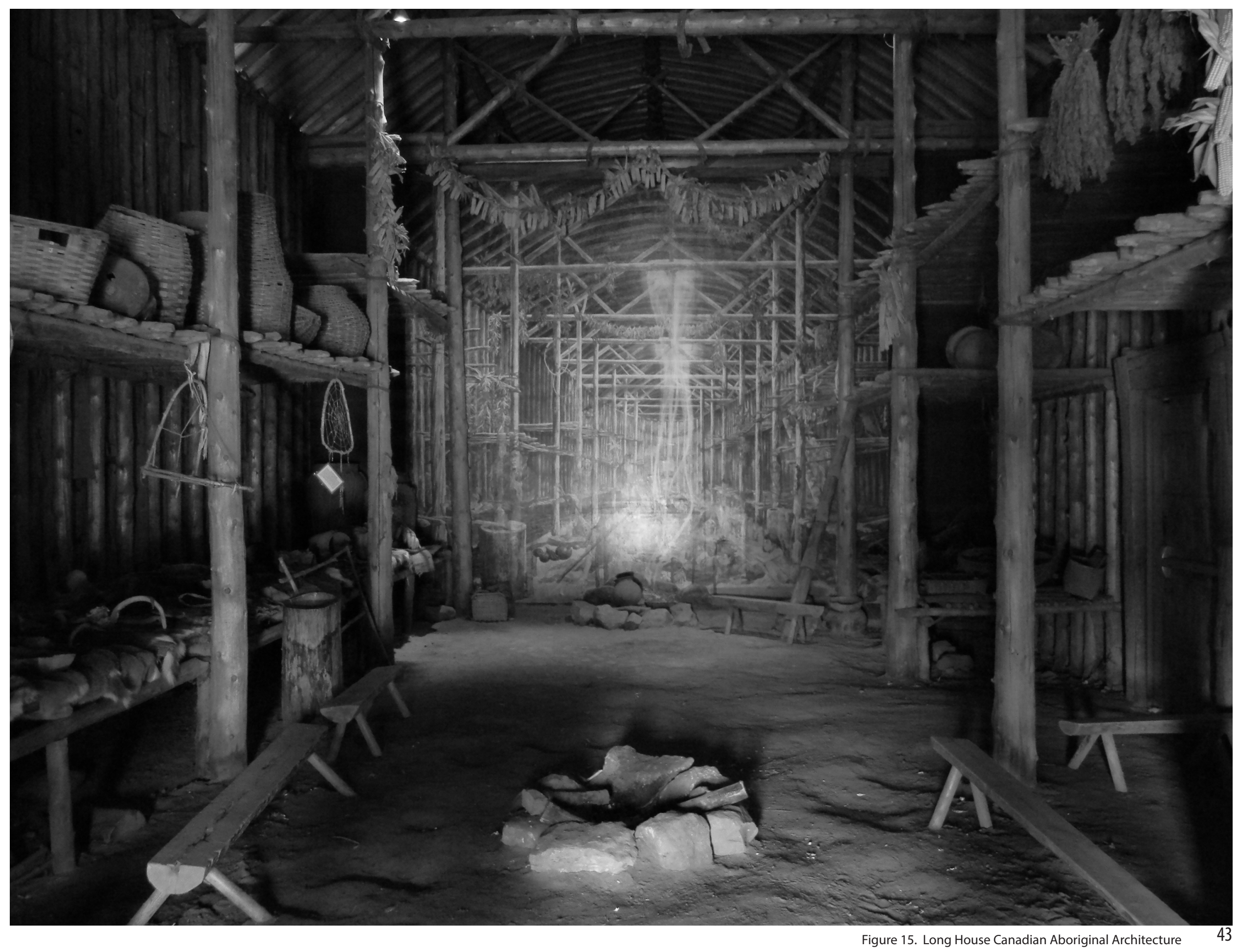


"The beauty of the trees,

the softness of the air,

the fragrance of the grass,

speaks to me.

The summit of the mountain,

the thunder of the sky,

the rhythm of the sea

speaks to me.

The strength of the fire,

the taste of the salmon,

the trail of the sun,

and the life that never goes away,

they speak to me.

And my heart soars." [78]

Chief Dan George

\subsubsection{NATURE}

Nature is the third healing space. It is all around us and it sustains our lives, yet, western society tends to take advantage of it or neglect its healing powers. Nature, also referred to as landscape in this thesis defined in the opening definitions, will include the earth and all of its products, features and forces; such as ecological forces, gravitational forces, all weather phenomenon, geology and geological forces, and will also include any cosmological products, features and forces. It is an essential component to Anishinabek healing. It is the connection with these spirits of the universe that is important in understanding and having an awareness of one's place, role and impact in the world. [79] The ever changing and dynamic processes that occur in nature put one's existence into a different perspective, one that acknowledges humans role as part of the earth and one that is equal and reciprocal to other beings, versus the hierarchical and superiority aspects western society tend to embody. We are equal to, not greater than, all spirits. This is not a perspective that can be reduced to science and quantifiable means. The divinity and spirituality of nature cannot be explained; it can only be felt and experienced. When one engages and acknowledges the processes of nature into their life, one can begin to feel that as humans, and as an individual, we are a small part of a bigger whole and the circle of life. 


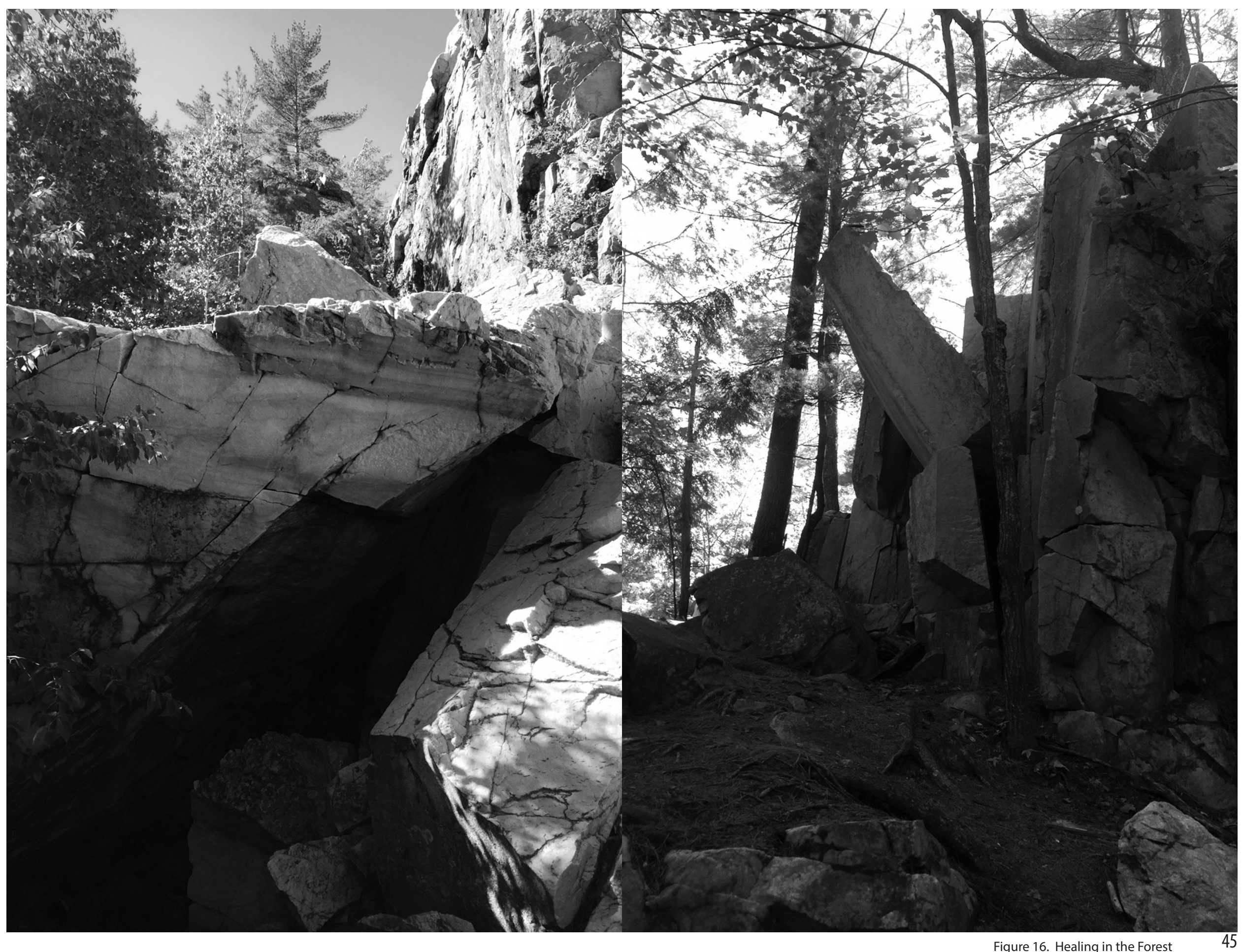




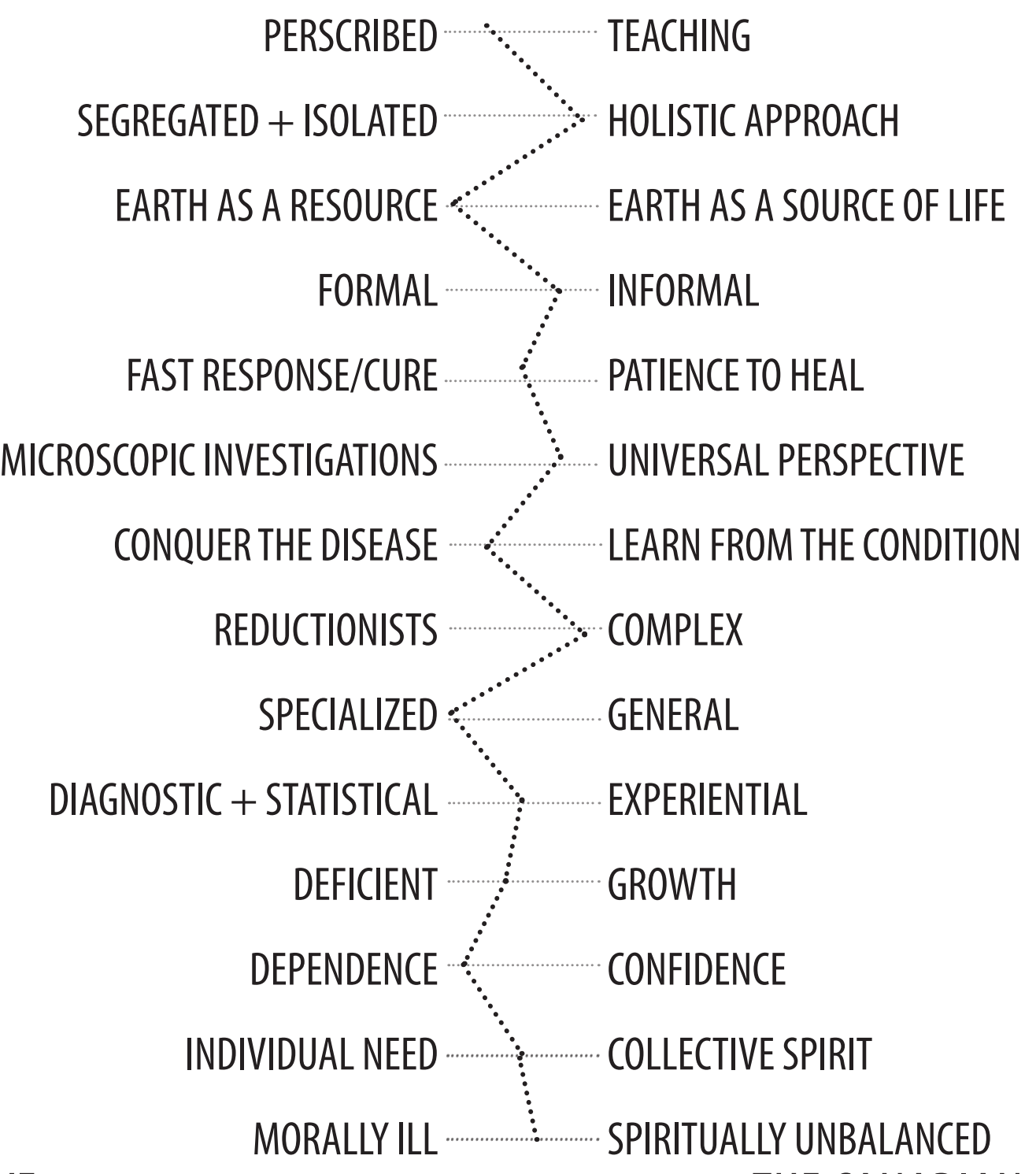

THE CANADIAN INDIGENOUS PERSPECTIVE

Figure 17. Comparison between Western Health + Canadian Indigenous Health with line showing where current addiction treatment lies drawn by Author 
The following section is a culmination of my research findings though literature reviews, key published documents, in particular Norton-Smith's book A Dance of Person and Place, which was a key literature in developing the basis for the research, community talking circles, interviews and consultations with the Anishinabek community. This thesis does not claim that these findings are universal or are the only ones of the culture, however, it represents five elements of the culture that this thesis believes can contribute to healing and is currently missing in contemporary architectural practices.

4.8.1 PLACE

When one refers to place in Western society, one is often referring to a point of origin or a destination, but place embodies a more complex and dynamic relationship that is tied to meaning, which is often overlooked in western society. This is not say that western perspectives do not find value or meaning in place, this would be ignorant to claim. However, the Anishinabek culture is inherently tied to landscapes, where western societies typically do not make this strong connection. The history of people and the history of land are intertwined together in the culture.[80] Landscapes determine how the culture lives, eats, builds, socializes and forms spiritual practices and values. It is not a commodity or a means of profit, as it is viewed in western societal structures. The Anishinabek do not "own" lands, they are part of them, living with and not off of them.[81] This provides a clear distinction between western ideologies and Anishinabek, where western societies see the earth as a resource, and Anishinabek see it as a life source. People are even given names to reflect how they interact with the lands, ie. plants, animals, landforms, ecological systems.[82] Therefore, place becomes a vital referent for people and how they exist in the universe and their spirit.[83]

As mentioned, Anishinabek knowledge, like in many indigenous cultures in Canada, is inherently tied to the land, particularly landscapes, landforms, biomes and the seasonal and ecological experiences.[84] Due to this, land becomes a way of organizing the world and the human role within it. "Place is a spiritual relationship with the tangible world that connects aspects of life... Place is multidimensional. It entails both the physical and emotional characteristics and refers to more than just a geographic space... in other words, place is the interaction between location and resident." [85] It is where time and space meet. This is drastically different than how western, North American societies perceive of the world. The western perspective is ordered in a chronological sequence of time, [86] placing importance on a linear perspective versus one of circularity and cyclical ways of viewing, as the Anishinabek culture does. This values place over chronology, as it centralizes it in framing perspectives of the world. A chronological and linear view places importance on progression and time which moves away from place and the past. [87] Place holds knowledge, wisdom and life, it is not merely a point in space or a destination.

The linearity of western thought processes and systems disconnects us from the places that we live. Time and efficiency of time become more important than where we are and who we are with ("who" in the expansive sense of the Anishinabek, beyond the "human being"). This is particularly reinforced by our increasing use of the digital world and our globalized economy, which, subconsciously, reinforces the idea that place is now of little value to society.

\subsubsection{PERSPECTIVES ON “BEING"}

In the Anishinabek culture, there is no word for natural and, therefore, no distinction between natural and supernatural.[88] This is due to their expansive view of "being", a concept deeply explored by Norton-Smith.[89] The dichotomies between human, nature and the supernatural have strong delineations in western ideologies, even our semantics pose these strict separations between these realms. In the Anishinabek culture, the conception of person and human is not inherently connected. [90] A person is a being that has a spirit (manitou), [91] therefore, the conception of person expands. The Anishinabek believe that, not only, animals and plants have spirits, but physical forces, such as wind, weather, ecological systems, landforms and the cardinal directions all have a spirit.[92] For example, in a "Western sense, the sun is a natural object, but in an Anishinabek sense, it is a non-human person with a spirit."[93] "[Indigenous] paradigms include ideas of constant flux, all existence consisting of energy waves/ spirits, all things being animate, all existence being interrelated, creation/existence having to be renewed, space/place as an important referent and languages, songs stories and ceremonies as repositories for the knowledge that arise out of these paradigms."[94] This ideology equates to human beings, essentially, being spirit beings, that are equal to all other "persons" or "beings" on earth. This redefinition of the "person" and of human being equaling a "spirit being", stratifies the perspective of the humans role in the world and eliminates any hierarchical relationships. Therefore, the distinction that we are conscious beings therefore we are superior is eliminated. 
With this world perspective, the familial relationships become quite dynamic, as compared to traditional western familial structures. Intimate family relationships extend beyond human persons to non-human ones, [95] while in western society familial structures are quantified by being a human being and having blood-relations. "All persons in the nexus of relationships have equal value and are due respect by virtue of playing creative roles in the same dynamic processes."[96] This recognizes that humans are part of the creation of our earth and universe and gives responsibility to the human to be part of the stewardship of the earth. These concepts also connect back to the Seven Grandfather teachings which provide the moral groundwork on how to treat all "persons" or "beings" on earth. It acknowledges that human existence and wellbeing, is dependent on the existence and health of other beings, therefore, treat all with the Seven Grandfather teachings.

\subsubsection{INTERRELATED WORLD}

Just as western society uses time as an ordering system for the world's processes and maintains a linear thought; it also uses a rigid system of dividing knowledge that keeps them distinct and separate from each other, leading to little or no opportunity for comparison and contemplation in western thought and philosophy. We see this clear delineation in the organization of universities, corporations, offices and government bodies, which are separated into different departments and sectors. [97] These hard distinctions are not drawn, in fact they do not exist. The Anishinabek culture and way of thought uses the concept of connectivity as a means of organizing the world and understanding how the past, present and future unfolds.[98] Just as value is embedded in the cyclical cycles of the land, knowledge, growth and all world systems are viewed in a circular, intertwined, connected, growing and re-iterating web of experiences. Knowledge seems to be "carried with us.....which seems to be designed to outlast us, to take on a life of its own, to be something eternal" [99] When experiencing the world, Anishinabek are constantly looking for emerging patterns and ways experiences can be connected, from the past, present and future. The concept of reciprocity again becomes extremely important between all persons (ie. human persons and non-human persons). Therefore, the actions of one individual have a ripple effect that impacts the individual, the family, the community, the nation, the earth and the universe. [100]

This interconnectedness extends beyond the physical realm. "Because the true reality of [Indigenous] people is a tandem of physical and metaphysical realities, native thinkers have encountered visions and spirits on a regular basis as a part of life. This aspect of the metaphysical is similar to the dreams of individuals in a western society, who sometimes find answers to questions that could not be answered by their conscious minds."[101] These experiences are just as valid in the universe as waking experiences are. The skeptical attitude that western culture has of dream and other worldly experiences does not exist, as the Anishinabek see these experiences as truthful and real. Knowing, being and existing in the Anishinabek culture involves 'seeing' the world from these perspectives and 'seeing' is the most powerful tool that the human possesses. "Seeing involves mentally experiencing the relationships between tangible and non-tangible things in the world and in the universe, it is acceptance of fact that the relationship exists between a tangible item like a mountain and a dream." [102]

This notion of interconnectivity and relatedness is not unique to the Anishinabek and other indigenous cultures. This concept has been discussed in many other religions, disciplines, science and society. What is unique is how it frames and forms knowledge systems and ways of seeing the world which extend beyond the human and physical realms of life.

\subsubsection{EXPERIENTIAL KNOWLEDGE}

The word experience has been re-iterated throughout the past chapters when describing the cultural principles. This is due to the fact that the Anishinabek view the acquiring and value of knowledge as the performance of life or embodied experience that rises from human action.[103] Experiences are knowledge, knowledge is 'seeing', and seeing is finding connections between experiences, a process that also works in a cyclical cycle. Unlike Western societies, putting its highest value on propositional knowledge, which is declarative, descriptive and factual, the Anishinabek culture puts its highest value on procedural knowledge, which is performed, exercised, shaped or guided by human experience.[104] This is not to say that the Anishinabek knowledge system and views do not have propositional knowledge, or vice versa, however the ways of knowing, or'seeing' weigh heaviest on procedural knowledge, shaped by humans experiences and goals. The western knowledge acquiring system is scientific, goal oriented, chronological and rationalized. Unlike most western societies, there is a distinction between truth and fact in the Anishinabek culture. [105] This is because of the experiential foundation of knowledge building. "The pure content of our sense experiences alone underdetermines how the world really is, and any one of a number of radically different actual worlds is consistent with experience." [106] It could be said that the Anishinabek knowledge system is based on "perceptual phenomenology," $[107,108,109]$ creating a strong experiential foundation for knowledge systems and ways of living. This creates practical applications for knowledge versus propositional facts; which are collected and goal oriented. 
The act of performance, engagement and participation is, therefore, an essential facet of the culture. If we return back to the practiced ceremonies and rituals, it becomes evident that the physical, spiritual, emotional and mental engagement in the ceremonies is an experiential process that is vital to healing. These engagements of the human senses that extend beyond touch, taste, sight, smell, and hearing, brings meaning and healing to the action, to the individual, the family, the community, the nation and the earth. Many portions of these ceremonies and rituals are symbolic in nature, yet what gives meaning and facilitates healing is the engagement of act of performing the ceremony. Therefore, "performance of or with all sorts of unwritten symbols becomes the principal vehicle of meaning and world creation and recreation...."[110] Though the function of the symbol is the same in both Western and Anishinabek cultures, the difference lies in the meaning of the symbol gaining significance through performance. Once again, this is not to say the concept of symbolic meaning reinforced by performance does not exist in Western society, the difference lies in the fact that it is performed and experienced as a common daily occurrence and meaning is found through theses occurrences, therefore, knowledge is derived through everyday life.[111] This also ties back to the value of place in the culture. Place gains meaning through the experience and interaction with it. To become a place, humans must interact with the environment and landscape. As mentioned, the western conception of the history relies on time, which finds it meaning through the progression of events and is temporal. The Anishinabek conception of the history relies in place, where meaning is created spatially over time through experience. [112] However, it is impossible to distinguish the two, temporal and spatial. Because we experience time in space and space in time, each becomes equally significant. [113] This is why the performative action and the experiential qualities of life are the basis for the Anishinabek knowledge system, which is organized the world in a circular order.

\subsubsection{CIRCULAR WORLDVIEW}

Placing value on time over space or vice versa equates to a disembodied world and society. Linear ordering systems, as in western ideologies, place value on time and chronology. Anishinabek world ordering systems use a circular and cyclical process for ordering the world. "Circularity orders both temporal and spatial sense experience."[114] Norton-Smith goes on to explain that the "temporal comings and goings, begins with the cardinal direction a spatial ordering."[115] For example, seasons, the lunar cycle or hunting and gathering cycles imbue both temporal qualities and spatial qualities.

Circularity then extends to all realms of existence as the cycles of time and space determine place and experience from a cyclical ordering. It brings equality and balance to all life forms, practices and organizations of social life. The concept of the circle then becomes fundamental to understanding knowledge and living an Anishinabek way of life. Indigenous scholar, James Dumont, writes "The circle, being primary, influences how we as Aboriginal [indigenous] peoples view the world. In the process of how life evolves, how the natural world grows and works together, how all things are connected, and how all things move toward their destiny. Aboriginal [indigenous] peoples see and respond to the world in a circular fashion and are influenced by the examples of the circles of creation in our environment".[116] A circular worldview encompasses the equality of the expansive view of the world and beings, the value and reoccurring importance of place, the interrelatedness of the universe and the performative experiential foundations of knowledge. "A circular worldview, rather than a linear way of thinking, puts the focus of the worldviews on relationships and balance. From this perspective, mental health can be understood as achieving a balance between the emotional, mental, physical and spiritual, components of oneself finding a balance and relationship with other beings."[117]

[1] Native Women's Centre. "Traditional Teachings Handbook." Aboriginal Healing Outreach Program. Native Women's Centre, Aboriginal Healing \& Outreach Program, 2008. Web.

$<$ http://www.nativewomenscentre.com/files/Traditional_Teachings_Bookletpdf>.

[2] McMillan, Alan D., and Eldon Yellowhorn. First Peoples in Canada. Douglas \& McIntyre, Vancouver, BC, 2004, pp.3,41.

[3] Norton-Smith, Thomas M. Dance of Person and Place, The: One Interpretation of American Indian Philosophy. State U of New York, Albany, New York, 2010, pp. 1-74.

[4] Hart, Michael. Seeking Mino-pimatisiwin: An Aboriginal Approach to Helping. Fernwood, Halifax, NS,2002, pp. 44.

[5] Wilson, Kathleen J. The role of mother Earth in shaping the health of Anishinabek: A geographical exploration of culture, health and place. Queen's University, Ann Arbor, Ml, 2001, pp. 133,147,163.

[6] Wilson, Kathleen J. The role of mother Earth in shaping the health of Anishinabek: A geographical exploration of culture, healt and place. Queen's University, Ann Arbor, Ml, 2001, pp. 133
[7] Interview Participant. Personal Interview, 26 April 2016.

[8] Johnston, Basil. Ojibway Heritage. University of Nebraska Press, New York, NY, 1976, pp.176.

[9] Johnston, Basil. Ojibway Heritage. University of Nebraska Press, New York, NY, 1976. 12-13.

[10] Wilson, Kathleen J. The role of mother Earth in shaping the health of Anishinabek: A geographical exploration of culture, health and place. Queen's University (Canada), Ann Arbor, 2001, pp. 133,147,136.

[11] Wilson, Kathleen J. The role of mother Earth in shaping the health of Anishinabek: A geographical exploration of culture, health and place. Queen's University (Canada), Ann Arbor, 2001, pp. 135-38.

[12] Turner, Edith. "Life, Death, and Humor: Approaches to Storytelling in Native America." Arctic Anthropology, vol. 40, no. 2, Charlesloettesville, Vl, 2000, pp. 23. Web. <http://www.jstor.org.ezproxy.lib.ryerson.ca/stable/40316586?pq-origsite=summon\&seq=1\#page_scan_tab_contents $>$.

[13] Turner, Edith. "Life, Death, and Humor: Approaches to Storytelling in Native America." Arctic Anthropology, vol. 40, no. 2 Charlesloettesville, VI, 2000, pp. 23. Web. <http://www.jstor.org.ezproxy.lib.ryerson.ca/stable/40316586?pq-origsite=sum 


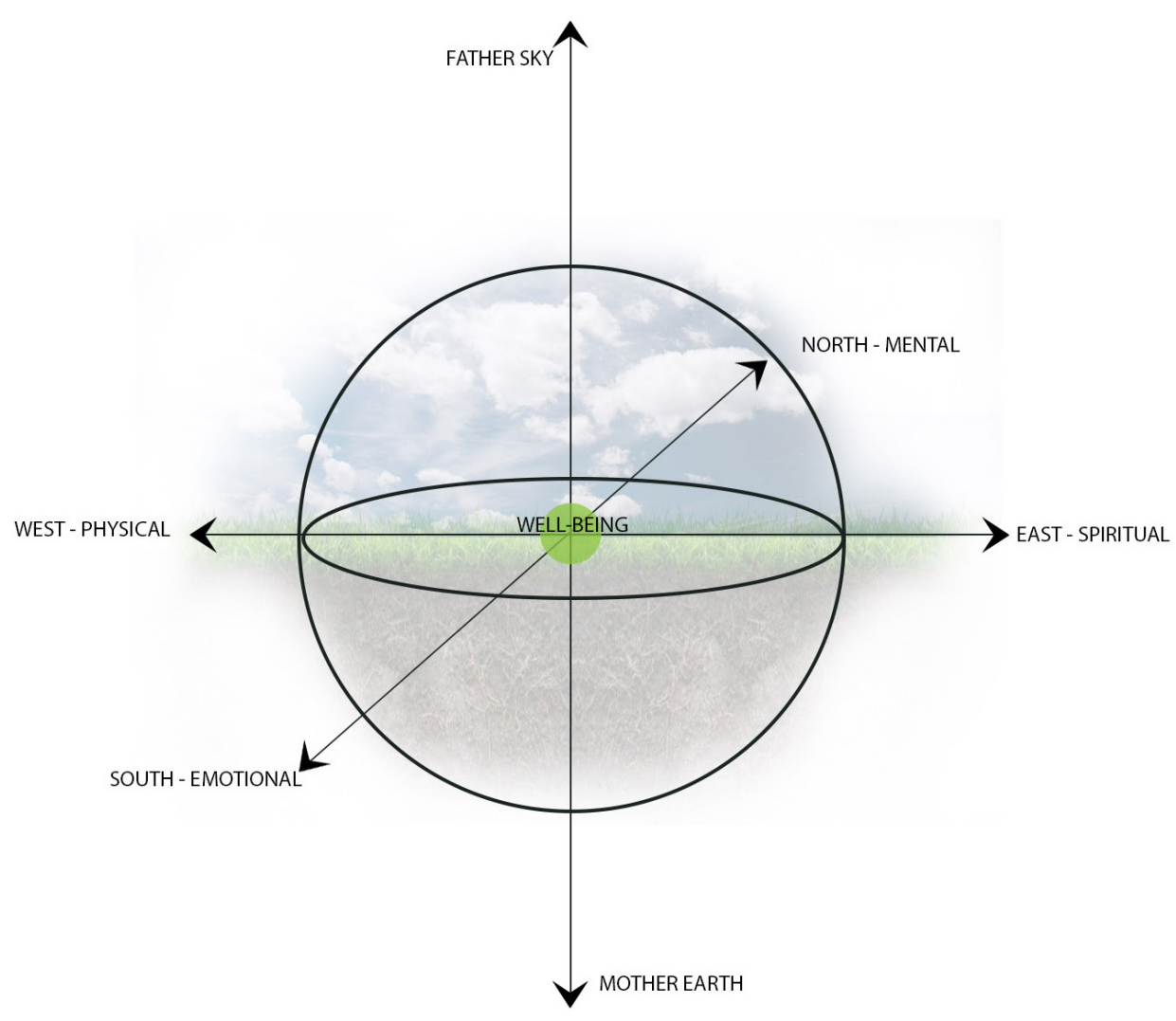

Figure 18. The Seventh Direction - Well Being + Balance drawn by Author 
mon\&seq=1\#page scan tab contents>.

[14] Bruce, Heather E. "Hoop Dancing: Literature Circles and Native American Storytelling." The English Journal, vol. 93, no. 1 2003, pp. 55. Web.

$<$ http://www.jstor.org.ezproxy.lib.ryerson.ca/stable/3650571?pq-origsite=summon\&seq=2\#page_scan_tab_contents $>$. [15] Bruce, Heather E." Hoop Dancing: Literature Circles and Native American Storytelling."The English Journal, vol. 93, no. 1, 2003, pp. 55. Web.

[16] "Aboriginal Medicine." Aboriginal Medicine. University of Ottawa, 8 July 2009. Web. <http://www.med.uottawa.ca/sim/ data/Aboriginal_Medicine_e.htm>

[17] "Aboriginal Medicine." Aboriginal Medicine. University of Ottawa, 8 July 2009. Web.

18] Wilson, Kathleen. "Therapeutic Landscapes and First Nations Peoples: An Exploration of Culture, Health and Place." Health and Place, vol. 9, no.2, Hamilton, 0N, 2003, pp. 89. Web. <http://home.cc.umanitoba.ca/ hallmanb/files/GE0G4290-readings$\mathrm{pdf} /$ wilson-2003.pdf>.

[19] Pheasant, Kenny. “Ceremonies - Manidokewinan." Anishinaabemdaa. Little River Band of Ottawa Indians. Web. <http:// www.anishinaabemdaa.com/\#/about/ceremonies/Ceremonies>.

[20] Manitowabi, Darrel and Marjory Shawande. "The Meaning of Anishinabe Healing and Wellbeing on Manitoulin Island." Pimatisiwin: A Journal of Aboriginal and Indigenous Community Health, vol. 9.2, 2011. pp. 442. Web. <http://www.pimatisiwin com/uploads/jan_20112/10ManitowabiShawande.pdf $>$.

[21] Pheasant, Kenny. "Ceremonies - Manidokewinan." Anishinaabemdaa. Little River Band of Ottawa Indians. Web. <http:// www.anishinaabemdaa.com/\#/about/ceremonies/Ceremonies>.

[22] Pheasant, Kenny. "Ceremonies - Manidokewinan." Anishinaabemdaa. Little River Band of Ottawa Indians. Web.

[23] Pheasant, Kenny. "Ceremonies - Manidokewinan." Anishinaabemdaa. Little River Band of Ottawa Indians. Web.

[24] Hill, (Gus) L. P. Understanding Indigenous Canadian traditional health and healing. Wilfrid Laurier University, Waterloo, ON, 2008, pp. 8-9. Web. <http://search.proquest.com.ezproxy.lib.ryerson.ca/docview/304805019?pq-origsite=summon>

[25] Wilson, Kathleen. "Therapeutic Landscapes and First Nations Peoples: An Exploration of Culture, Health and Place." Health and Place, vol. 9, no.2, Hamilton, 0N, 2003, pp. 89. Web.

[26] Pheasant, Kenny. "Ceremonies - Manidokewinan." Anishinaabemdaa. Little River Band of Ottawa Indians. Web.

27] Pheasant Kenny. "Ceremonies - Manidokewinan" Anishinaabemdaa. Little River Band of Ottawa Indians. Web.

[28] ]Government of Canada. "The First Nations: The Powwow." Library and Archives Canada. Collections Canada, Ottawa, 0N,08 Aug. 2012. Web.

$<$ https://www.collectionscanada.gc.ca/aboriginal-music-song/028012-2200-e.html>.

[29] Hill, (Gus) L. P. Understanding Indigenous Canadian traditional health and healing. Wilfrid Laurier University, Waterloo, ON,

2008, pp. 48-50. Web.

[30] Government of Canada. "The First Nations: The Powwow." Library and Archives Canada. Collections Canada, Ottawa, ON, 08 Aug. 2012. Web.

[31] Government of Canada. "The First Nations: The Powwow." Library and Archives Canada. Collections Canada, Ottawa, 0N, 08 Aug. 2012. Web.

[32] Pheasant, Kenny. "Ceremonies - Manidokewinan." Anishinaabemdaa. Little River Band of Ottawa Indians. Web.

[33] Hill, (Gus) L. P. Understanding Indigenous Canadian traditional health and healing. Wilfrid Laurier University, Waterloo, $0 \mathrm{~N}$, 2008, pp. 33-35. Web.

[34] KiiskeeNtum. "Gifts from the Creator for Man's Use... The Smudging Ceremony." Aboriginal Multi-Media Society (AMMSA) vol. 16, no. 2, 1998, pp. 21. Web.

<http://go.galegroup.com.ezproxy.lib.ryerson.ca/ps/i.do?p=AONE\&u=rpu_main\&id=GALE|A30214013\&v=2.1\&it=r\&sid= summon\&userGroup=rpu main\&authCount $=1>$.

[35] Pheasant, Kenny. "Ceremonies - Manidokewinan." Anishinaabemdaa. Little River Band of Ottawa Indians. Web.

[36] Pheasant, Kenny. “Ceremonies - Manidokewinan." Anishinaabemdaa. Little River Band of Ottawa Indians. Web.
[37] Schiff, Jeannette W, and William Pelech. "The Sweat Lodge Ceremony for Spiritual Healing." Journal of Religion \& Spirituality in Social Work: Social Thought, vol. 26, no. 4, 2007., pp. 71. Web. <http://journals1.scholarsportal.info.ezproxy.lib.ryerson.ca/ pdf/15426432/v26i0004/71_tslcfsh.xml>.

[38] Schiff, Jeannette W., and William Pelech. "The Sweat Lodge Ceremony for Spiritual Healing." Journal of Religion \& Spirituality in Social Work: Social Thought, vol. 26, no. 4, 2007., pp. 71-93. Web.

[39] Hill, (Gus) L. P. Understanding Indigenous Canadian traditional health and healing. Wilfrid Laurier University, Waterloo, ON, 2008, pp. 31. Web.

[40] Hill, (Gus) L. P. Understanding Indigenous Canadian traditional health and healing. Wilfrid Laurier University, Waterloo, ON 2008, pp. 31. Web.

[41] Hill, (Gus) L. P. Understanding Indigenous Canadian traditional health and healing. Wilfrid Laurier University, Waterloo, $0 \mathrm{~N}$

2008, pp. 31. Web.

[42] Hill, (Gus) L. P. Understanding Indigenous Canadian traditional health and healing. Wilfrid Laurier University, Waterloo, ON 2008, pp. 31. Web.

[43] Hill, (Gus) L. P. Understanding Indigenous Canadian traditional health and healing. Wilfrid Laurier University, Waterloo, $0 \mathrm{~N}$, 2008, pp. 31. Web.

[44] Hill, (Gus) L. P. Understanding Indigenous Canadian traditional health and healing. Wilfrid Laurier University, Waterloo, ON 2008, pp. 31. Web.

45] Hill, (Gus) L. P. Understanding Indigenous Canadian traditional health and healing. Wilfrid Laurier University, Waterloo, 0N, 2008, pp. 31. Web.

[46] Hill, (Gus) L. P. Understanding Indigenous Canadian traditional health and healing. Wilfrid Laurier University, Waterloo, 0N, 2008, pp. 31. Web.

[47] Hill, (Gus) L. P. Understanding Indigenous Canadian traditional health and healing. Wilfrid Laurier University, Waterloo, ON 2008, pp. 31. Web.

[48] Hill, (Gus) L. P. Understanding Indigenous Canadian traditional health and healing. Wilfrid Laurier University, Waterloo, ON 2008, pp. 32. Web.

49] Hill, (Gus) L. P. Understanding Indigenous Canadian traditional health and healing. Wilfrid Laurier University, Waterloo, 0N, 2008, pp. 31-33. Web.

[50] Hill, (Gus) L. P. Understanding Indigenous Canadian traditional health and healing. Wilfrid Laurier University, Waterloo, ON, 2008, pp. 33. Web.

[51] Dapice, Ann N. .The Medicine Wheel." Journal of Transcultural Nusring. University of Ottawa Faculty of Medicine. SAGE Publications, vol. 17, no. 3, july 2006, pp. 251. Web.

$<$ http://www.med.uottawa.ca/sim/data/assets/documents/Aboriginal_medicine wheel.pdf>.

[52] Hill, (Gus) L. P. Understanding Indigenous Canadian traditional health and healing. Wilfrid Laurier University, Waterloo, ON, 2008, pp. 40-51. Web.

[53] Hill, (Gus) L. P. Understanding Indigenous Canadian traditional health and healing. Wilfrid Laurier University, Waterloo, ON 2008, pp. 40-51. Web.

[54] Dapice, Ann N. “The Medicine Wheel."Journal of Transcultural Nusring. University of Ottawa Faculty of Medicine. SAGE Publications, vol. 17, no. 3, july 2006, pp. 251. Web.

[55] Native Women's Centre." Traditional Teachings Handbook." Aboriginal Healing Outreach Program. Native Women's Centre, Aboriginal Healing \& Outreach Program, 2008. Web.

[56] Native Women's Centre." Traditional Teachings Handbook." Aboriginal Healing Outreach Program. Native Women's Centre, Aboriginal Healing \& Outreach Program, 2008. Web.

[57] Coyhis, Don, and Richard Simonelli. "The Native American Healing Experience." Substance Use \& Misuse, vol. 43, no. 12-13, 2008. pp. 1927.

[58] Coyhis, Don, and Richard Simonelli. "The Native American Healing Experience." Substance Use \& Misuse, vol. 43, no. 12-13, 
2008., pp. 1927-49.

[59] Owen, S. (2014). "Walking in Balance: Native American Recovery Programmes". Religions, vol. 5, no. 4, Basel, Switzerland, 2014, pp. 1042-43.

[60] Nabokov, Peter, and Robert Easton. Native American Architecture. Oxford University Press, New York, NY, 1989, pp. 72. [61] Schiff, Jeannette W., and William Pelech. "The Sweat Lodge Ceremony for Spiritual Healing." Journal of Religion \& Spirituality in Social Work: Social Thought, vol. 26, no. 4, 2007., pp. 71-72. Web. <http://journals1.scholarsportal.info.ezproxy.lib.ryerson. ca/pdf/15426432/v26i0004/71 tslcfsh.xml>.

[62] Hill, (Gus) L. P. Understanding Indigenous Canadian traditional health and healing. Wilfrid Laurier University, Waterloo, $0 \mathrm{~N}$ 2008, pp. 31. Web.

[63] Nabokov, Peter, and Robert Easton. Native American Architecture. Oxford University Press, New York, NY, 1989, pp. 73. 64] Hill, (Gus) L. P. Understanding Indigenous Canadian traditional health and healing. Wilfrid Laurier University, Waterloo, $0 \mathrm{~N}$, 2008, pp. 31-33. Web.

[65] Nabokov, Peter, and Robert Easton. Native American Architecture. Oxford University Press, New York, NY, 1989, pp. 73.

[66] Hill, (Gus) L. P. Understanding Indigenous Canadian traditional health and healing. Wilfrid Laurier University, Waterloo, ON, 2008, pp. 31-33. Web.

[67] Nabokov, Peter, and Robert Easton. Native American Architecture. Oxford University Press, New York, NY, 1989, pp. 70. [68] Hill, (Gus) L. P. Understanding Indigenous Canadian traditional health and healing. Wilfrid Laurier University, Waterloo, $0 \mathrm{~N}$, 2008, pp. 31-33. Web.

[69] Williams-Shuker, Kimberly “An Analysis of Intravillage Longhouse Variability at the Draper Site."Paper presented at 1997 the Longhouse Conference: Inquiries into the Architecture, History and Symbolism of the Longhouse, Rochester Museum and Science Center, Rochester, NY, 1997. Web. <http://www.pitt.edu/ klwst25/draper.html>.

[70] Nabokov, Peter, and Robert Easton. Native American Architecture. Oxford University Press, New York, NY, 1989, pp. 70.

[71] Nabokov, Peter, and Robert Easton. Native American Architecture. Oxford University Press, New York, NY, 1989, pp. 70.

[72] Williams-Shuker, Kimberly “An Analysis of Intravillage Longhouse Variability at the Draper Site." Paper presented at 1997

the Longhouse Conference: Inquiries into the Architecture, History and Symbolism of the Longhouse, Rochester Museum and Science Center, Rochester, NY, 1997. Web.

[73] Williams-Shuker, Kimberly "An Analysis of Intravillage Longhouse Variability at the Draper Site." Paper presented at 1997 the Longhouse Conference: Inquiries into the Architecture, History and Symbolism of the Longhouse, Rochester Museum and Science Center, Rochester, NY, 1997. Web.

[74] Williams-Shuker, Kimberly “An Analysis of Intravillage Longhouse Variability at the Draper Site." Paper presented at 1997 the Longhouse Conference: Inquiries into the Architecture, History and Symbolism of the Longhouse, Rochester Museum and Science Center, Rochester, NY, 1997. Web.

75] Williams-Shuker, Kimberly "An Analysis of Intravillage Longhouse Variability at the Draper Site." Paper presented at 1997 the Longhouse Conference: Inquiries into the Architecture, History and Symbolism of the Longhouse, Rochester Museum and Science Center, Rochester, NY, 1997. Web.

[76] Williams-Shuker, Kimberly “An Analysis of Intravillage Longhouse Variability at the Draper Site." Paper presented at 1997 the Longhouse Conference: Inquiries into the Architecture, History and Symbolism of the Longhouse, Rochester Museum and Science Center, Rochester, NY, 1997. Web.

[77] Williams-Shuker, Kimberly "An Analysis of Intravillage Longhouse Variability at the Draper Site" Paper presented at 1997 the Longhouse Conference: Inquiries into the Architecture, History and Symbolism of the Longhouse, Rochester Museum and Science Center, Rochester, NY, 1997. Web.

78] George, Dan, and Helmut Hirnschall. My Heart Soars. Hancock House, Saanichton, B.C., 1974

[79] Norton-Smith, Thomas M. The Dance of Person and Place: One Interpretation of American Indian Philosophy. Albany, New York: State U of New York, 2010, pp. 92

[80] Buggey, Susan. "An Approach to Aboriginal Cultural Landscapes." Historic Sites and Monuments Board of Canada (n.d.): n. pag. Parks Canada. Government of Canada, Mar. 1999, pp. 1-4. Web. < http://www.pc.gc.ca/docs/r/pca-acl/images/Aboriginal_Cultural_Landscapes e.pdf $>$.

[81] Ross, Rupert. Indigenous Healing: Exploring Traditional Paths. Google Play Ebook, Penguin Canada, 2014

[82] Ross, Rupert. Indigenous Healing: Exploring Traditional Paths. Google Play Ebook, Penguin Canada, 2014.

[83] Ross, Rupert. Indigenous Healing: Exploring Traditional Paths. Google Play Ebook, Penguin Canada, 2014.

[84] Ross, Rupert. Indigenous Healing: Exploring Traditional Paths. Google Play Ebook, Penguin Canada, 2014.

[85] Ross, Rupert. Indigenous Healing: Exploring Traditional Paths. Google Play Ebook, Penguin Canada, 2014.

[86] Burkhart Yazzie, Brian. "What Coyote and Thales can teach us: An outline of American Indian." An outline of American Indian Epistemology in American Indian Thought: Philosophical Essays, vol. 29. Ed. Archuleta, Elizabeth. The University of Nebraska Press, Lincoln, NB, 2005, pp. 17-19.

[87] Burkhart Yazzie, Brian. "What Coyote and Thales can teach us: An outline of American Indian." An outline of American Indian Epistemology in American Indian Thought: Philosophical Essays, vol. 29. Ed. Archuleta, Elizabeth. The University of Nebraska Press, Lincoln, NB, 2005, pp. 17-19.

[88] Norton-Smith, Thomas M. Dance of Person and Place, The: One Interpretation of American Indian Philosophy. State U of New York, Albany, New York, 2010, pp. 83.

[89] Norton-Smith, Thomas M. Dance of Person and Place, The: One Interpretation of American Indian Philosophy. State U of New York, Albany, New York, 2010, pp. 77-93.

90] Norton-Smith, Thomas M. Dance of Person and Place, The: One Interpretation of American Indian Philosophy. State U of New York, Albany, New York, 2010, pp. 85

[91] Ross, Rupert. Indigenous Healing: Exploring Traditional Paths. Google Play Ebook, Penguin Canada, 2014.

[92] Norton-Smith, Thomas M. Dance of Person and Place, The: One Interpretation of American Indian Philosophy. State U of New York, Albany, New York, 2010, pp. 137.

93] Norton-Smith, Thomas M. Dance of Person and Place, The: One Interpretation of American Indian Philosophy. State U of New York, Albany, New York, 2010, pp. 84.

94] Ross, Rupert. Indigenous Healing: Exploring Traditional Paths. Google Play Ebook, Penguin Canada, 2014.

[95] Norton-Smith, Thomas M. Dance of Person and Place, The: One Interpretation of American Indian Philosophy. State U of New York, Albany, New York, 2010, pp.91-93

[96] Norton-Smith, Thomas M. Dance of Person and Place, The: One Interpretation of American Indian Philosophy. State U of New York, Albany, New York, 2010, pp.92

[97] Norton-Smith, Thomas M. Dance of Person and Place, The: One Interpretation of American Indian Philosophy. State U of New York, Albany, New York, 2010, pp. 4

[98] Dumont, J. "Culture, behaviour, \& identity of the Native person". NATT-2105: Culture, behaviour, \& identity of the Native person Laurentian University Press, Sudbury ON, 1989, pp. 48.

[99] Burkhart Yazzie, Brian. "What Coyote and Thales can teach us: An outline of American Indian." An outline of American Indian Epistemology in American Indian Thought: Philosophical Essays, vol. 29. Ed. Archuleta, Elizabeth. The University of Nebraska Press, Lincoln, NB, 2005, pp. 20

[100] Hill, (Gus) L. P. Understanding Indigenous Canadian traditional health and healing. Wilfrid Laurier University, Waterlo0, ON, 2008, pp. 53. Web.

[101] Fixico, Donald L. The American Indian Mind in a Linear World: American Indian Studies and Traditional Knowledge. Routledge, New York, NY, 1999, pp. 70.

[102] Fixico, Donald L. The American Indian Mind in a Linear World: American Indian Studies and Traditional Knowledge. Routledge, New York, NY, 1999, pp. 3.

[103] Burkhart Yazzie, Brian. "What Coyote and Thales can teach us: An outline of American Indian." An outline of American Indian Epistemology in American Indian Thought: Philosophical Essays, vol. 29. Ed. Archuleta, Elizabeth. The University of Nebraska Press, Lincoln, NB, 2005, pp.20. 
[104] Norton-Smith, Thomas M. Dance of Person and Place, The: One Interpretation of American Indian Philosophy. State U of New York, Albany, New York, 2010, pp. 57-58.

[105] Burkhart Yazzie, Brian. "What Coyote and Thales can teach us: An outline of American Indian." An outline of American Indian Epistemology in American Indian Thought: Philosophical Essays, vol. 29. Ed. Archuleta, Elizabeth. The University of Nebraska Press, Lincoln, NB, 2005, pp. 24.

[106] Norton-Smith, Thomas M. Dance of Person and Place, The: One Interpretation of American Indian Philosophy. State U of New York, Albany, New York, 2010, pp. 57-58.

[107] Norton-Smith, Thomas M. Dance of Person and Place, The: One Interpretation of American Indian Philosophy. State U of New York, Albany, New York, 2010, pp. 62.

[108] Burkhart Yazzie, Brian. "What Coyote and Thales can teach us: An outline of American Indian." An outline of American Indian Epistemology in American Indian Thought: Philosophical Essays, vol. 29. Ed. Archuleta, Elizabeth. The University of Nebraska Press, Lincoln, NB, 2005, pp.23-26.

[109] Cajete, Gregory and Leroy Little Bear. Native Science: Natural Laws of Interdependence. Clear Light Books, Santa Fe, NM 2000, pp. 2.

[110] Norton-Smith, Thomas M. Dance of Person and Place, The: One Interpretation of American Indian Philosophy. State U of New York, Albany, New York, 2010, pp. 57,78.

[111] Norton-Smith, Thomas M. Dance of Person and Place, The: One Interpretation of American Indian Philosophy. State U of New York, Albany, New York, 2010, pp. 87,98.

[112] Norton-Smith, Thomas M. Dance of Person and Place, The: One Interpretation of American Indian Philosophy. State U of New York, Albany, New York, 2010, pp. 120-122

[113] Norton-Smith, Thomas M. Dance of Person and Place, The: One Interpretation of American Indian Philosophy. State U of New York, Albany, New York, 2010, pp. 120-128.

[114] Norton-Smith, Thomas M. Dance of Person and Place, The: One Interpretation of American Indian Philosophy. State U of New York, Albany, New York, 2010, pp. 125.

[115] Norton-Smith, Thomas M. Dance of Person and Place, The: One Interpretation of American Indian Philosophy. State U of New York, Albany, New York, 2010, pp. 125.

[116] Dumont, J. "Culture, behaviour, \& identity of the Native person". NATT-2105: Culture, behaviour, \& identity of the Native person Laurentian University Press, Sudbury 0N, 1989, pp9. 48.

[117] Chansonneuve, Deborah (2007) in Lee, Deborah. "Indigenous Knowledge Organization: A Study of Concepts, Terminology, Structure and (Mostly) Indigenous Voices." Partnership : the Canadian Journal of Library and Information Practice and Research, vol. 6, no. 1, 2011., pp. 11 
ADDICTED ARCHITECTURE 


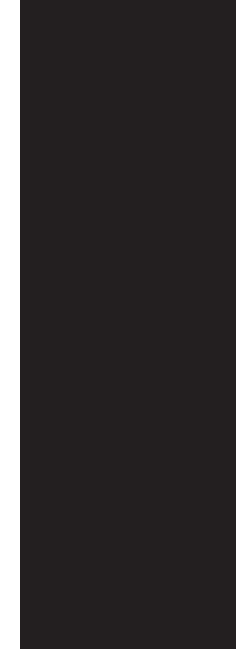

"... society needed more and more addictions to feed our cravings. If we try to stop, we go into withdrawal, unable to find any way to distract ourselves from responsibility, unable to avoid the consequences of our choices."

\subsection{ADDICTED ARCHITECTURE}

Healthcare architecture has come a long way in western society, in terms of the creation of health and healing spaces. As recent as the 1950's, healthcare architecture provided many spaces that contradicted today's aspects and perspectives on healing. [1] This was also reflective of the related healing practices and treatment methods of western societies of the time. We have progressed and have begun to recognize the value in thought provoking, meditation spaces, spaces that encourage communal and social interactions and spaces that enhance connections to the natural environment. Many rehabilitation facilities are now designed to promote and amplify these qualities. Yet, there is more that we, as architects and members of society, can do. Architects have still not been able to remove the sense of "institutionalization" from these atmospheres and create successful healing environments. We still seem to fail in terms of creating healing spaces particularly for people who suffer from the complications of addiction. Architecture for addiction treatment seems to be trapped in a paradigm of straight hallways, privatized bedrooms, delineations between interior and exterior and so on. The next chapter examines the evolution of addiction rehabilitation spaces in North America and the current treatment facilities that exist for people suffering with addiction.

\subsection{THE EVOLUTION OF ADDICTION TREATMENT FACILITIES IN NORTH AMERICA}

The evolution of healthcare facilities in North America, particularly, in the field of addiction, has come a long way over the past hundred years.[2, 3, 4] Healthcare used to be rooted back to a spiritual and homeopathic approach to healing, where one would be treated in the home, with natural herbs and spiritual purification. [5] Overtime it evolved into a system of institutionalization where healing took place in an ordered and quarantined box that consisted of repetitive spaces for people to "heal", closed off from the rest of the world. This idea then evolved into the mega-institution, the mega hospital. These megahospitals took up entire blocks and enormous chucks of land in cities, putting the ill into a confined and segregated space. [6] In recent history, it has started to become evident that community, nature, and meditation is vital to the healing process and it has been incorporated in the design for these spaces. [7] The introduction of smaller scaled projects for specialized or specific illness that take into perspective these ideals when designing have begun to emerge. However, in the design of spaces for addiction treatment, architects have failed to adequately grasp the nature of healing and wellbeing. Architecture still tends to lie in the realm of homogenized and capitalized space production. This is because western society does not fully grasp the determinants and individual and societal consequences of addiction. [8] It is clouded by the scientific official view of addiction and has not been able to design spaces that fully grasp and address addiction and create healing environments for treatment facilities. 
The evolution of addiction treatment architecture in North America dates back to the early 18th century. Its evolution followed closely with the development of the official view of addiction and mental health. Upon the introduction of alcohol to indigenous cultures, it became rapidly evident that there was a growing problem concerning its consumption and it was further disrupting the lives of the indigenous people. [9] From the 1750's to the early 1800's, the use of "sobriety circles" grew amongst indigenous and non-indigenous groups. [10] At this time, addiction was seen as a problem of poor morals or lack thereof. [11] Starting in the late 1700's, the notion of alcoholism as a medical disease began to emerge. In 1784, Dr. Benjamin Rush wrote his seminal work entitled Inquiry into the Effects of Ardent Spirits on the Human Mind and Body, where he argues that drunkenness is a chronic condition and needs to be classified as a medical disease. [12] His work, along with the growing problem of alcohol abuse, spurred the beginning of the temperance movement and religious confrontations, such as Reverend Lyman's Six Sermons on Interdependence where he attempts to rebut the medical classification of addiction and reclaim it as a fault of poor moral character, stating that an inebriate is "addicted to sin".[13] At this time people who displayed drunkenness of signs or alcohol abuse were housed in prisons, mental asylums or treated through religious interventions, and, in turn, many temperance societies began to grow in numbers over the coming century.[14] In 1850, in Ontario, the first hospital to house the mentally ill was built on Queen street west called the Provincial Lunatic Asylum, known today as the Center for Addiction and Mental Health (CAMH). [15]

The recognition of alcoholism as a disease began to grow and so did different forms of treatments. In 1879, Dr. Leslie Keeley claimed to be able to cure the disease of alcohol abuse, which included a 31 -day stay at a treatment center that provided healthy foods, exercise, fresh air and nature, along with many other experimental injection and lobotomy techniques. [16,17] Though the latter half of the treatment plan was ineffective and inhumane, the former provided the framework for many rehabilitation facilities and programs today. Spreading throughout North America, the Keeley Institutes gained popularity and typically consisted of homes, located in the countryside, secluded from others, providing ample outdoor spaces.

Prior to the First World War, and as the temperance movement began gaining strong momentum, many homes and asylums were closing down around the turn of the century, bringing the "drunks" back to the streets, prisons and insane asylums.[18] By 1907, and well into the 1920's, waves of laws across North America were demanding for the sterilization of "defective" people, i.e. the mentally ill, developmentally challenged, alcoholics, addicts and indigenous peoples. [19] By the 1920's, it was illegal to consume, make or sell alcohol in the majority of North America (Prohibition for Canada: 1918-1920; United States: 1920-1933). [20, 21]

By the 1930-40's, the body of knowledge regarding addiction began to grow as many academic and government institutions began to conduct research on alcoholism and addiction, leading the way to the beginning of Alcoholics Anonymous in 1935 and the incorporation of the "Minnesota model", which set the groundwork for the 12-step program teachings.[22] In the 1950's, western society in North America began to see even more medicalization of alcoholism and addiction from pharmaceutical companies. In 1952, the U.S. FDA approved the use of the prescription drug, Disulfiram, to treat alcohol addictions. [23] This was part of the rise of the pharmaceutical industry and prescription drugs to treat illnesses. It wasn't until 1956 when the American Medical Association officially declared that alcoholism was an illness. [24]

The 1950's also brought about the halfway house movement. Its purpose was to provide a space for people who were, essentially, outcasts of society, a transition home to help ease their way back into the community. [25] These typically resembled the residential dwellings of the area; however, many were in poor condition and suffered from overcrowding. It wasn't until the late 1980's and into the early 90 's that North America began to see the creation of addiction treatment facilities for specialized addictions.[26] At this time, and still today, there exists a range of types of treatment facilities, each stemming from the predecessors, including secluded home-like settings, institutionalized facilities or temporary clinics and counseling, or elements of all these combined and at different scales.

The proliferation of the computer in the 1990's brought a new type of treatment space, the internet. During the 90's and up to today, an explosion of online support groups and treatment services have become available. [27] This completely eradicates and changes the communal aspects and the physical engagement in the recovery process. By blurring the geographical boundaries and disengaging the patient from the physical and real realms of the world and their recovery. 


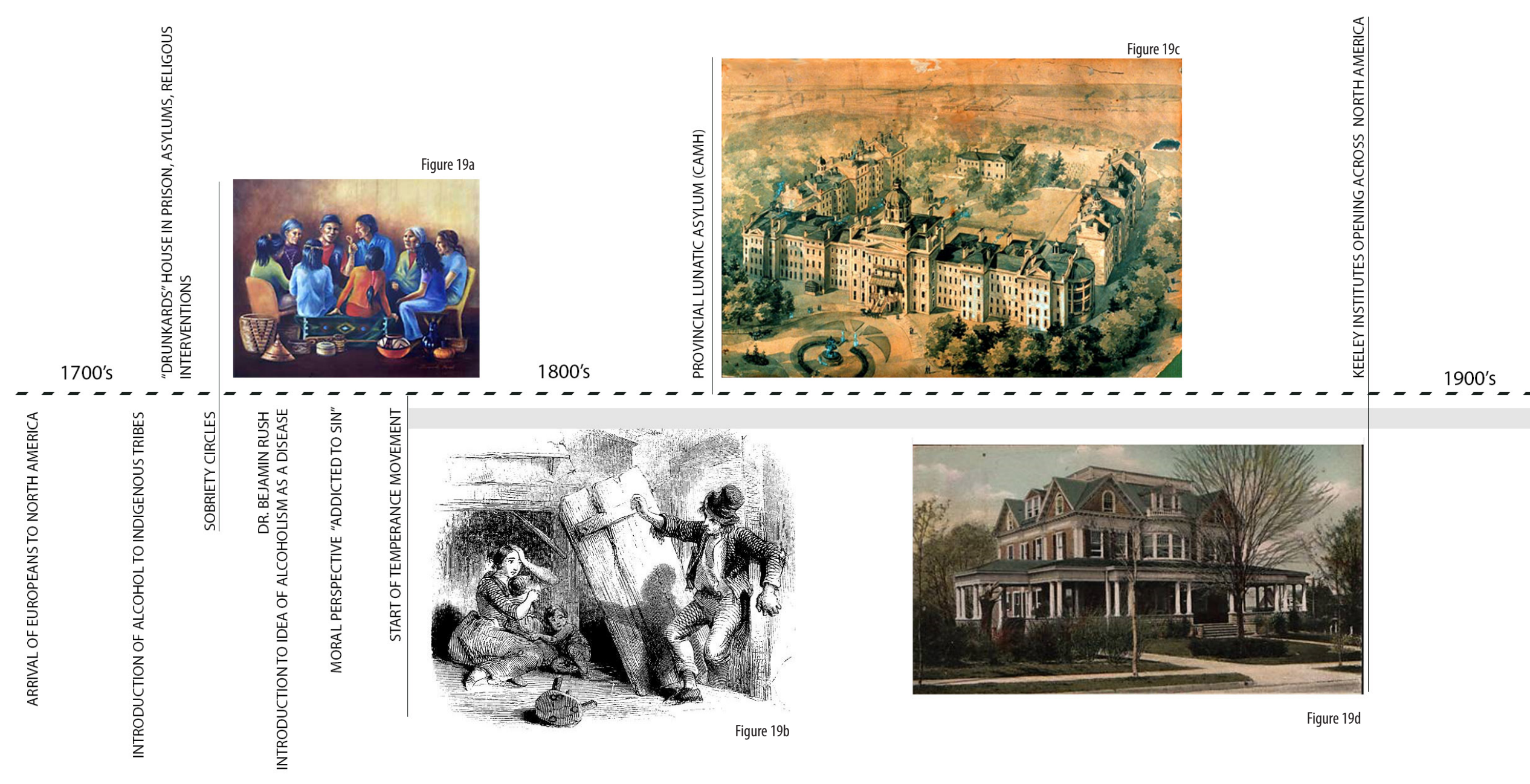


When we examine the evolution of architectural spaces for addiction treatment along with the evolution of theory and methods of addiction treatment in the North America we can begin to see a correlation between the ideas and how they are formally and spatially organized in architectural design. If we examine our current facilities for addiction treatment, we can see an amalgamation of the concepts and ideas that have circulated through the North American, Western perspective of addiction over the past few centuries. The fact that society struggles to truly understand addiction and is bombarded with this official view in the media, which carries a heavily medicalized version, has made it difficult to implement an appropriate treatment plan, let alone find an appropriate architectural model. This is why we see such a variety of "addiction treatment spaces" throughout the country and throughout the western world. Though the diversity of treatment types is not necessarily a negative thing, when it still conforms to the societal practices that have led to the proliferation of the ailment, it is detrimental. Architects, who design these types of healing spaces, must begin to work with the professionals from the field of addiction and work with the community and groups who are struggling with addiction to delve deep into the roots of the issues. We can no longer just graze the surface of these conditions when we are producing these spaces and favor profits and efficiency of the design over the quality of healing of the space, when in reality, in the long run, it could save money. We must understand the issues beyond the scientific realm of discovery. This is the architects' moral and professional responsibility if we value our roles in society.

[1] Burpee, Heather. History of Healthcare Architecture. Integrated Design Lab Puget Sound, 2008, pp. 1. Web. $<$ http://www.mahlum.com/pdf/historyofhealthcarearchburpee.pdf $>$.

[2] White, William L. Slaying the Dragon: The History of Addiction Treatment and Recovery in America. The Lighthouse Institute, Bloomington, IL, 1999 .

[3] Schrank, Sarah and Didem Ekici. Healing Spaces, Modern Architecture, and the Body. Routledge, 2016, Ebook

[4] Boekel, Andrea. Architecture for Healthcare. Images Publishing Group, Victoria, AU, 2008

[5] Ackerknecht, Erwin H. A Short History of Medicine. Johns Hopkins University Press, Baltimore, ML, 1982, pp. 30-35.

[6] Helminski, Laura. "[Hospital]ity Hospitable Hospitals: The Place of Healing." Electronic Thesis or Dissertation. University

of Cincinnati, 2014, pp. 13-14, 21-22. OhioLINKElectronic Theses and Dissertations Center. Web. < https://etd. ohiolink.edu/ pg_10?0::N0:10:P10_ETD_SUBID:93531>.

[7] Sternberg, Esther M. Healing Spaces: The Science of Place and Well-Being. Belknap Press of Harvard University Press, Cambridge, MA, 2009, pp. 108-114, 183-189.

[8] Alexander, Bruce. "The Rise and Fall of the Official View of Addiction." Bruce K. Alexander. Simon Fraser University, Burnbay, British Columbia. Bruce Alexander. July 2014. Web.

[9] Beauvais Fred, Ph.D. “American Indians and Alcohol." Alcohol Health \& Research World, vol. 22, no. 4, 1998, pp. 253. Web. $<$ http://pubs.niaaa.nih.gov/publications/arh22-4/253.pdf>.

[10] White, William L. "Significant Events in the History of Addiction Treatment and Recovery in America." Slaying the Dragon: The History of Addiction Treatment and Recovery in America. William White Papers, 2001, pp. 1. Web.

$<$ http://www.williamwhitepapers.com/pr/AddictionTreatment\&RecoverylnAmerica.pdf >

[11] Foundations Recovery Network. "History of Rehab Facilities." Dual Diagnosis. Foundations Recovery Network. Web.

$<$ http://www.dualdiagnosis.org/drug-addiction/history-rehab-facilities/>.

[12] White, William. L. "A lost world of addiction treatment." Counselor, vol. 17, no. 2, 1991, pp. 2. Web.

$<$ http://www.williamwhitepapers.com/papers/>

[13] White, William L. "Significant Events in the History of Addiction Treatment and Recovery in America." Slaying the Dragon: The History of Addiction Treatment and Recovery in America. William White Papers, 2001, pp. 1. Web.

[14] White, William L. "Significant Events in the History of Addiction Treatment and Recovery in America." Slaying the Dragon: The History of Addiction Treatment and Recovery in America. William White Papers, 2001, pp. 1-2. Web.

[15] Centre for Addiction and Mental Health. "Historical Chronology of CAMH's Queen Street Site." CAMH: Centre for Addiction and Mental Health. CAMH. Web.

$<$ http://www.camh.ca/en/hospital/about_camh/CAMH_redevelopment/history_of_queen_street_site/Pages/history_of_ queen_street_site.aspx>.
[16] Havens, F. M., Henry Coleman, and Leslie E. Keeley Co. An Open Letter : Descriptive of Dr. Keeley's method of Treatment and Cure of Drunkenness, 1891. Web. <https://babel.hathitrust.org/cgi/pt?id=dul1.ark:/13960/t57d6cr81;view=1up;seq=3>.

[17] White, William L. "Significant Events in the History of Addiction Treatment and Recovery in America." Slaying the Dragon: The History of Addiction Treatment and Recovery in America. William White Papers, 2001, pp. 3. Web.

[18] White, William L. "Significant Events in the History of Addiction Treatment and Recovery in America." Slaying the Dragon: The History of Addiction Treatment and Recovery in America. William White Papers, 2001, pp. 4-5. Web.

[19] Foundations Recovery Network. "History of Rehab Facilities." Dual Diagnosis. Foundations Recovery Network. Web. $<$ http://www.dualdiagnosis.org/drug-addiction/history-rehab-facilities/>.

[20] Webb, Holland. "Temperance Movements and Prohibition." International Social Science Review, vol. 74, no. 1, 1999., pp. $61-70$.

[21] White, William L. "Significant Events in the History of Addiction Treatment and Recovery in America." Slaying the Dragon The History of Addiction Treatment and Recovery in America. William White Papers, 2001, pp. 2. Web.

[22] Foundations Recovery Network. "History of Rehab Facilities." Dual Diagnosis. Foundations Recovery Network. Web. $<$ http://www.dualdiagnosis.org/drug-addiction/history-rehab-facilities/>.

[23] White, William L. "Significant Events in the History of Addiction Treatment and Recovery in America." Slaying the Dragon: The History of Addiction Treatment and Recovery in America. William White Papers, 2001, pp. 7. Web. [24] White, William L. "Significant Events in the History of Addiction Treatment and Recovery in America." Slaying the Dragon The History of Addiction Treatment and Recovery in America. William White Papers, 2001, pp. 7. Web.

[25] White, William L. "Significant Events in the History of Addiction Treatment and Recovery in America." Slaying the Dragon: The History of Addiction Treatment and Recovery in America. William White Papers, 2001, pp. 18. Web.

[26] White, William L. "Significant Events in the History of Addiction Treatment and Recovery in America." Slaying the Dragon The History of Addiction Treatment and Recovery in America. William White Papers, 2001, pp. 14-16. Web. [27] White, William L. "Significant Events in the History of Addiction Treatment and Recovery in America." Slaying the Dragon: The History of Addiction Ireatment and Recovery in America. William White Papers, 2001, pp. 16. Web. 
CRITIQUING CONTEMPORARY PRACTICE 


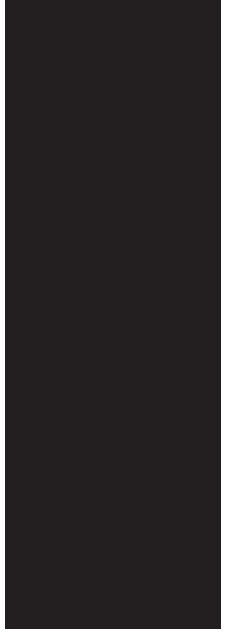

\subsection{CRITIQUING CONTEMPORARY PRACTICE}

Though there seems to be no consensus of what treatment is appropriate or what type of facilities are appropriate, there are many architects and institutions who have excelled in the creation health and healing spaces. It is important to acknowledge the advancements in contemporary architecture today, in order to build off the ideas and grow the profession. The following portion of the thesis examines six different precedents that fall under two categories; three different precedents which have exceeded in the design of addiction rehabilitation spaces in Ontario and three theoretical precedents that examine how architects have interpreted the indigenous culture and translated it into architecture within Canada. All projects, with the exception of one, are situated within the Ontario context. It examines how these spaces have begun to challenge normative design practices and also how they have failed to escape and break the barrier of our western healing spaces through architecture. 

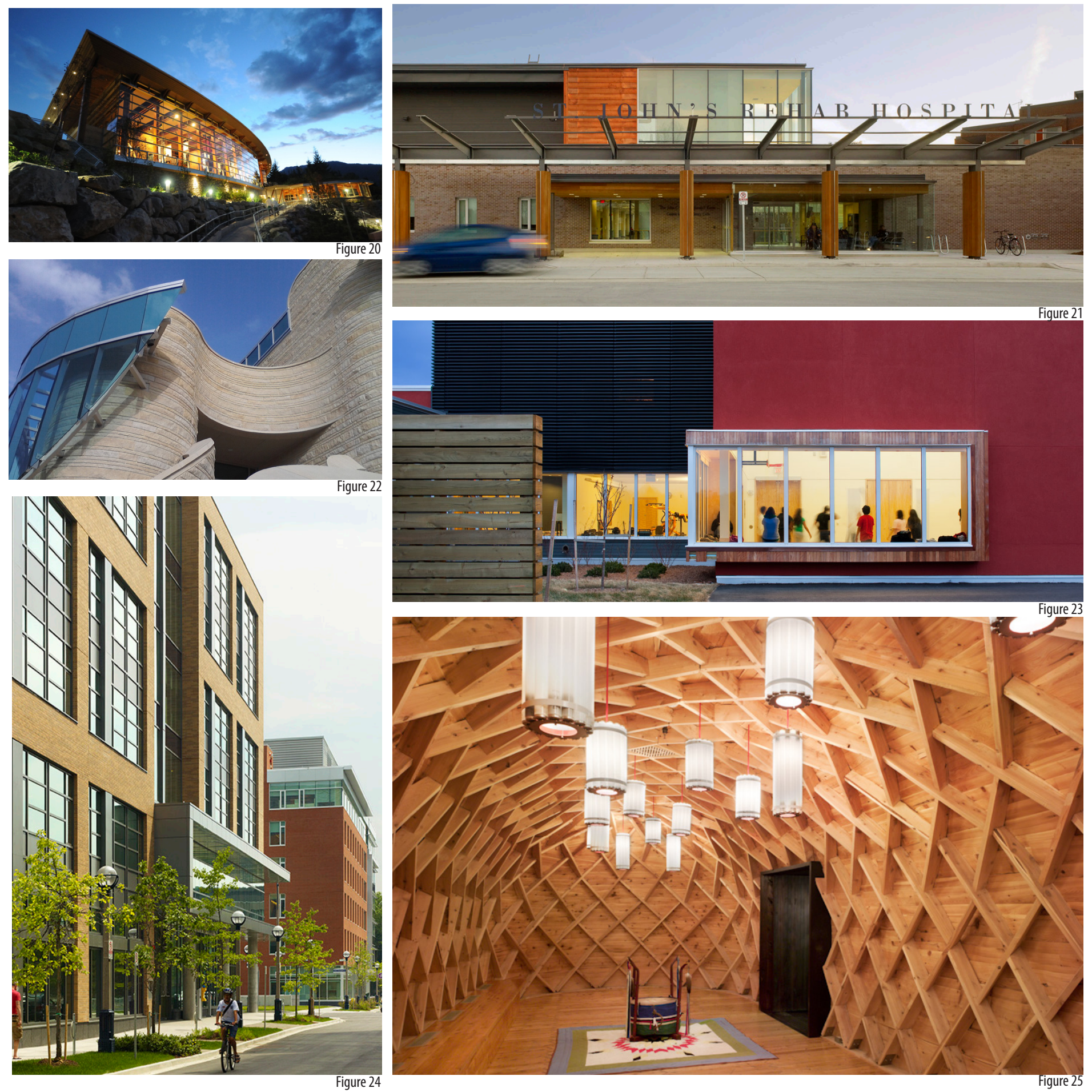


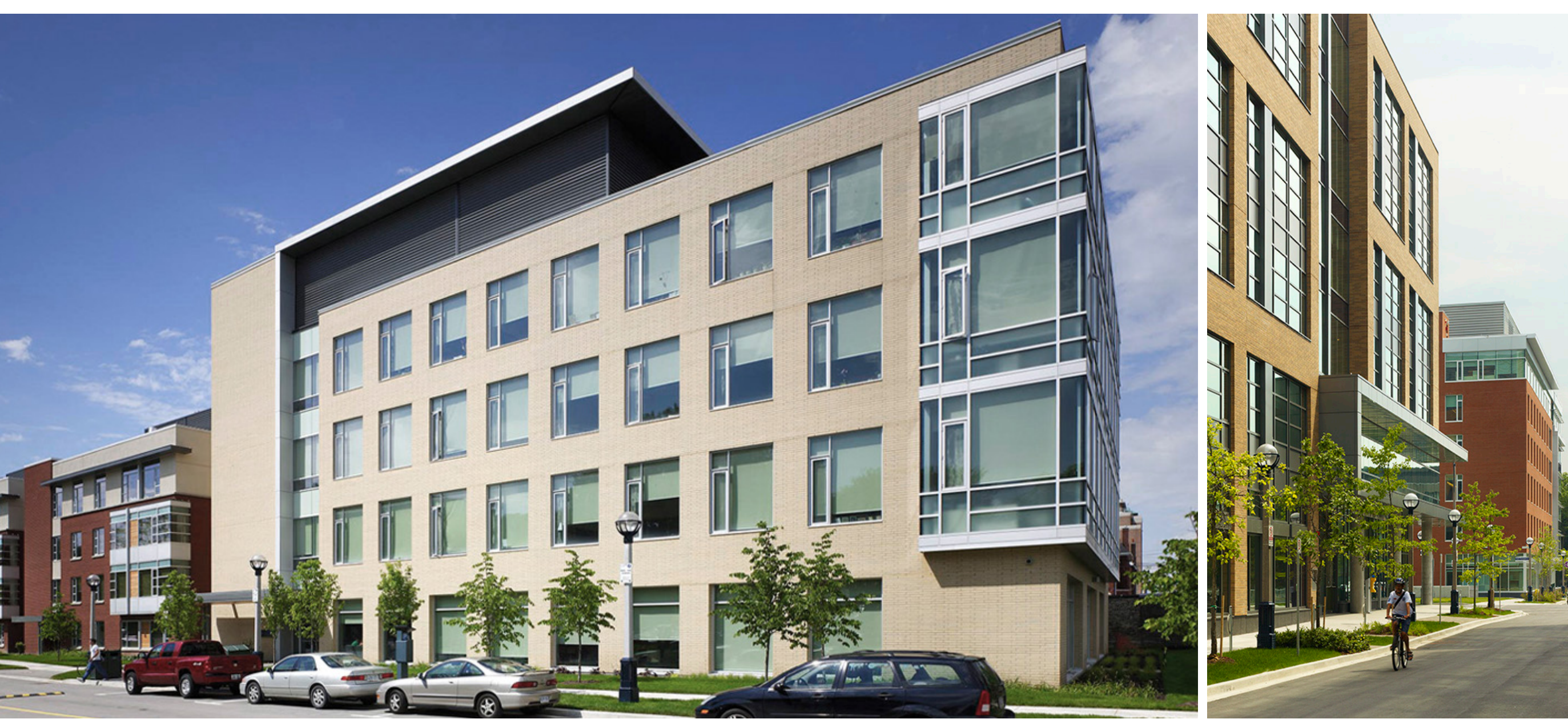


The Centre for Addiction and Mental Health facility, located in Toronto, Ontario, is the first phase of a multi-phased project, completed in 2009. The project was designed in partnership with Kearns Mancini Architects, Montgomery and Sisam Architects and KPMB Architects, all firms located within Toronto. The facility is an over 100,000 square feet and located on the existing site of the CAMH program. The program is one of the largest centres for addiction and mental health recovery in the province. The project is located on the heart of the Queen Street west corridor and is part of a new, mixed use campus. [1]

The project intention is to create a new"integrated urban village,"breaking the boundaries that typically exist between the urban landscape, community, addiction and mental health facilities. The project deeply focuses on integrating the facility into the surrounding community and consists of a mixed use residential, institutional and commercial facilities. Blurring the boundaries without segregating programs and people are at the forefront of the design proposal and returning to community is a large part of the treatment program and the architecture. Creating a home-like environment and visual connections to the outdoors were key objectives in the design of the facility, along with creating a safe and secure environment. [2]

The project decentralizes and integrates the facility into the existing surrounding community and incorporate spaces and programs that draw people into the facility. This removes the isolation and separation that most mental health facilities possess. This move removes the stigma, sense of neglect and distinction between community members and people who are attending the facility. This is important because the sense of difference, neglect or lack of belonging are detrimental factors to the condition of one's mental health, whether they are members of the facility or of the community. By blurring the boundaries between these two groups, a sense of approval and respect is created.

When we begin to further engage with the building, it still maintains a strong distinction between spaces, particularly by function and by interior and exteriors relationships. The building meets the ground with abrupt force and shoots out of it. An artificial landscape of mowed and manicured lawns, sprinkled with trees and paths fill in the in between spaces from each building. The interior space is drastically distinguished from the exterior space. There is no mutual relationship of interaction created between the two environments, between the users of the spaces and they are restricted to either pavement, lawn space or an air-conditioned box.

Spaces are separated by functions. Though in some cases, due to privacy and confidentiality, such as the offices, functional separation is required, and, in turn, so is privacy, however, bedroom and communal spaces are defined and rigid solid walls or panes of glass. The circulation space, however, begins to blend with lounge space and potential spaces for gathering, individual contemplation or moments of chance encounter.
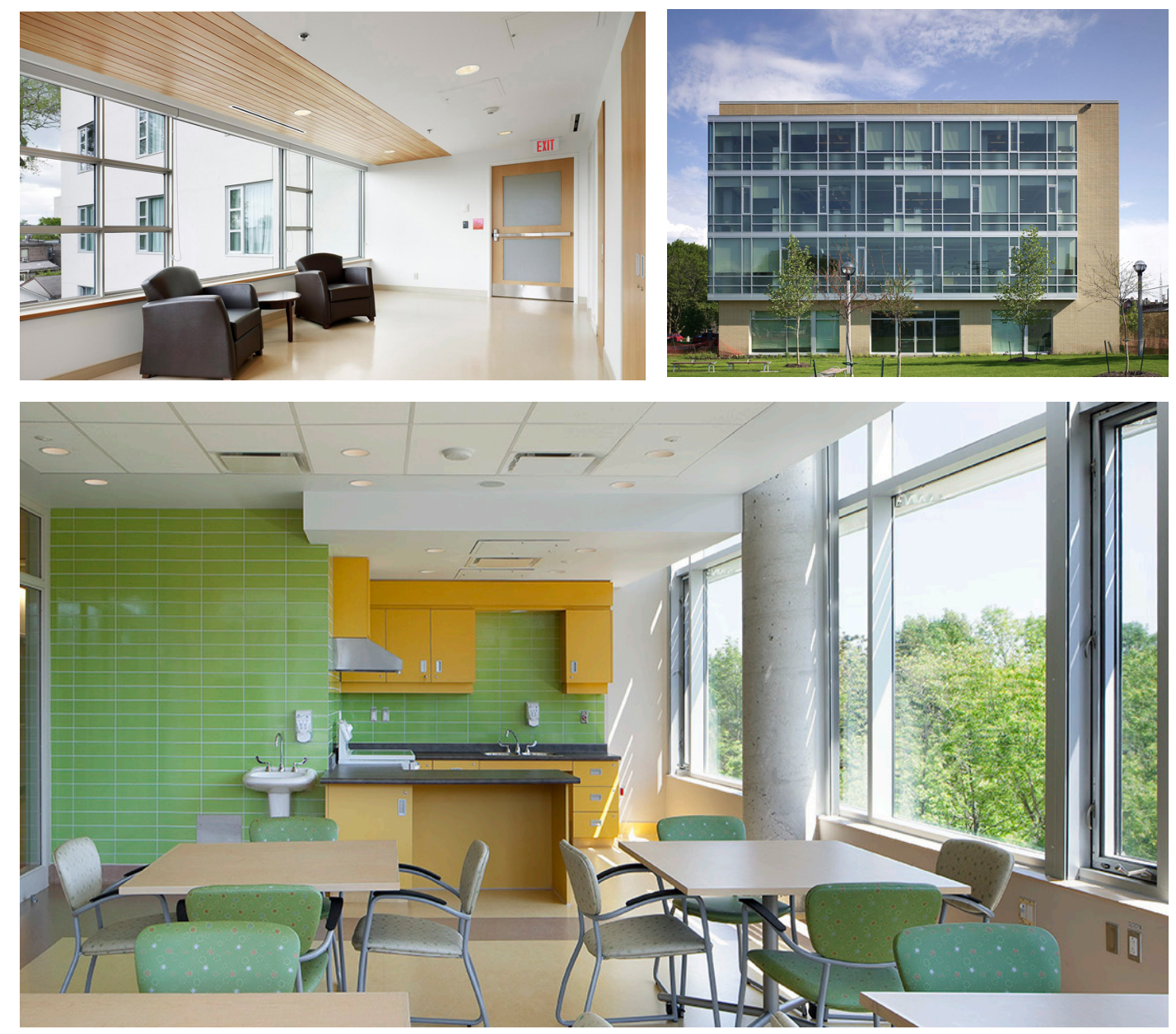

The materiality of the building, on both the interior and exterior, is flat and monotonous. Sealed and shiny surfaces of the floors and counters compliment the continuous brick facades that are met with steel frames and glass panes. Though every element does not need to be a natural, organic and dynamic material, a balance and contrast between the two is not present in the design. 
Designed by Montgomery Sisam Architects, located in of Toronto, Ontario, St. John's Rehabilitation Centre, the project is a 48,300 square foot addition and renovation project to an already existing health facility. Located on a 23 acre lot, the facility was first built in the 1930's and caters to people recovering from illnesses and injuries. Though this facility does not specifically cater to people suffering from addiction, it still begins to excel in the production of healing and well-being environments.[3]

The approach to the building is lined with a colonnade of trees, giving the facility the feel of a resort. Upon entering the facility, you are directly connected to the outdoors, with clear and unobstructed views through the building to the ravine in which the project is situated. The facility consists of an open concept design. There are two large rehabilitation gyms that are visually open and accessible to the users of the building, blurring the lines between programs and privacy. The material pallet consists of wood, concrete and steel and starts to bring human and natural dimensions to the design. Throughout the facility there are multiple multi-disciplinary and flexible treatment spaces. [4]

Yet, the design of St. John's Rehabilitation Facility stays within the bounds of contemporary practice. Like the previous project, it creates a hard boundary between interior and exterior spaces. There is an abrupt transition between the two that does not allow for them to blend and engage with each other beyond the breeze blowing through an open door or the sun rays penetrating through the glass panes and overheating the interior space.

This facility, unlike the previous project, is isolated and segregated onto its own large piece of land, tucked away in the bush, beside a ravine, with minimal engagement with other facilities, functions and the community. This disengages the facility from the surrounding community and restricts access and circulation of people to patients or visitors. Though the scale of the building begins to address the human, it is still confined into one centralized facility.

The design envelopes its users, functions and activities into a rigid stacking of boxes and rectangular spaces. It provides long, single corridor halls, with little vertical movement and kinesthetic engagement with the space and the building. However, this may be due to ease of accommodating barrier accessibility requirements. The way of designing is Cartesian in nature and has no regard for its connect to the surrounding environment, particularly the landscape. It appears as if the site has been flattened and clear cut, a consequence of its history, as it is situated within the Greater Toronto Area. However, the design still does not provide opportunities to engage with the landscape or the natural world. One is either inside or out. This is due to safety concerns, building systems concerns (ie. Heating and cooling), and maintenance concerns, which all boil done to a worry about financial feasibility and profits.
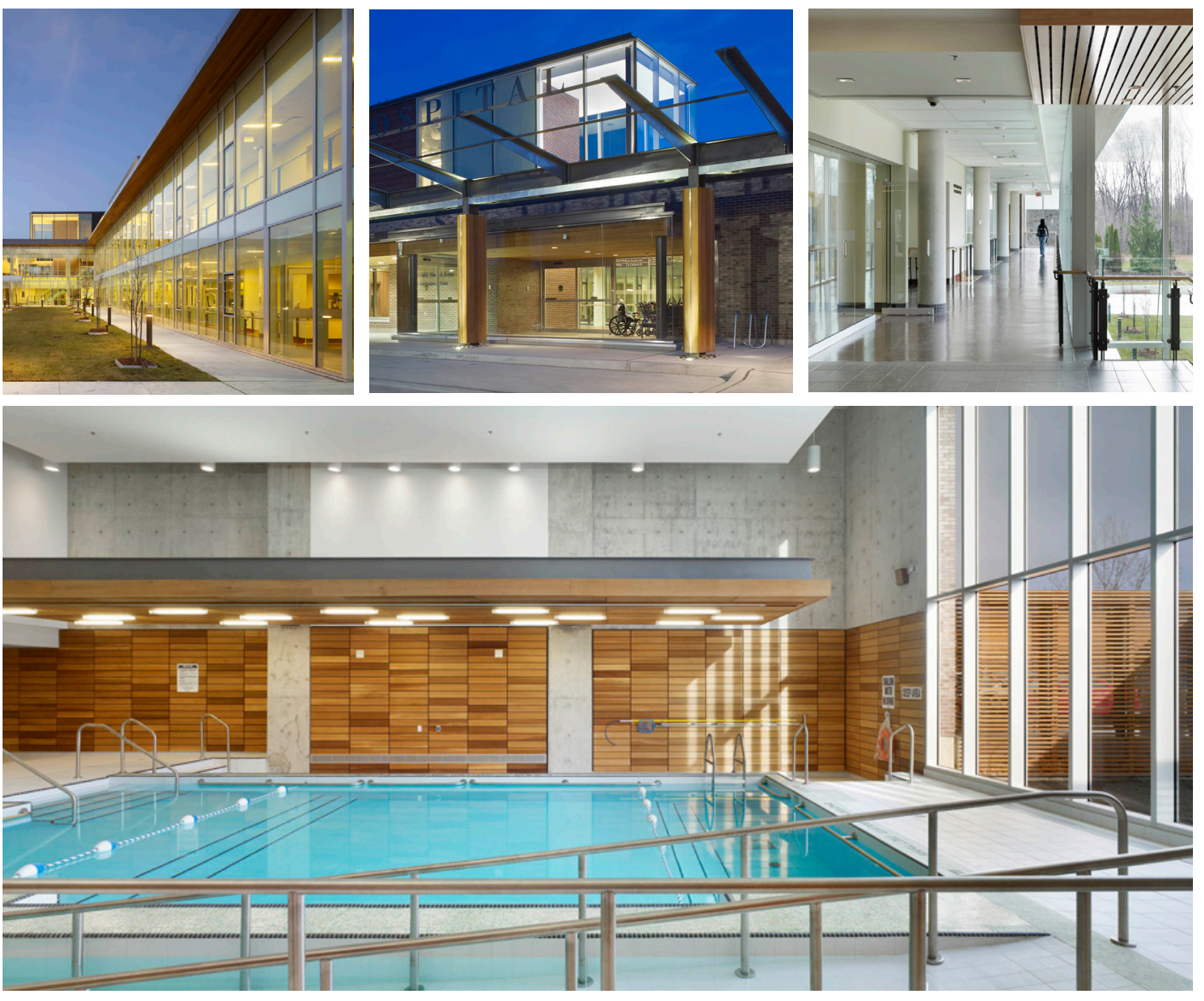

Figure 31-35 St. John's Rehab

The design also provides consistent and repetitive spatial and atmospheric conditions, particularly is terms of materiality and access to light, which is amplified through the single loaded corridors and clerestory windows. Though the amplification of natural light promotes healing and is beneficial to the interior spaces, by providing a monotonous environment for users, it promotes a sense of disengagement and container like spaces. 


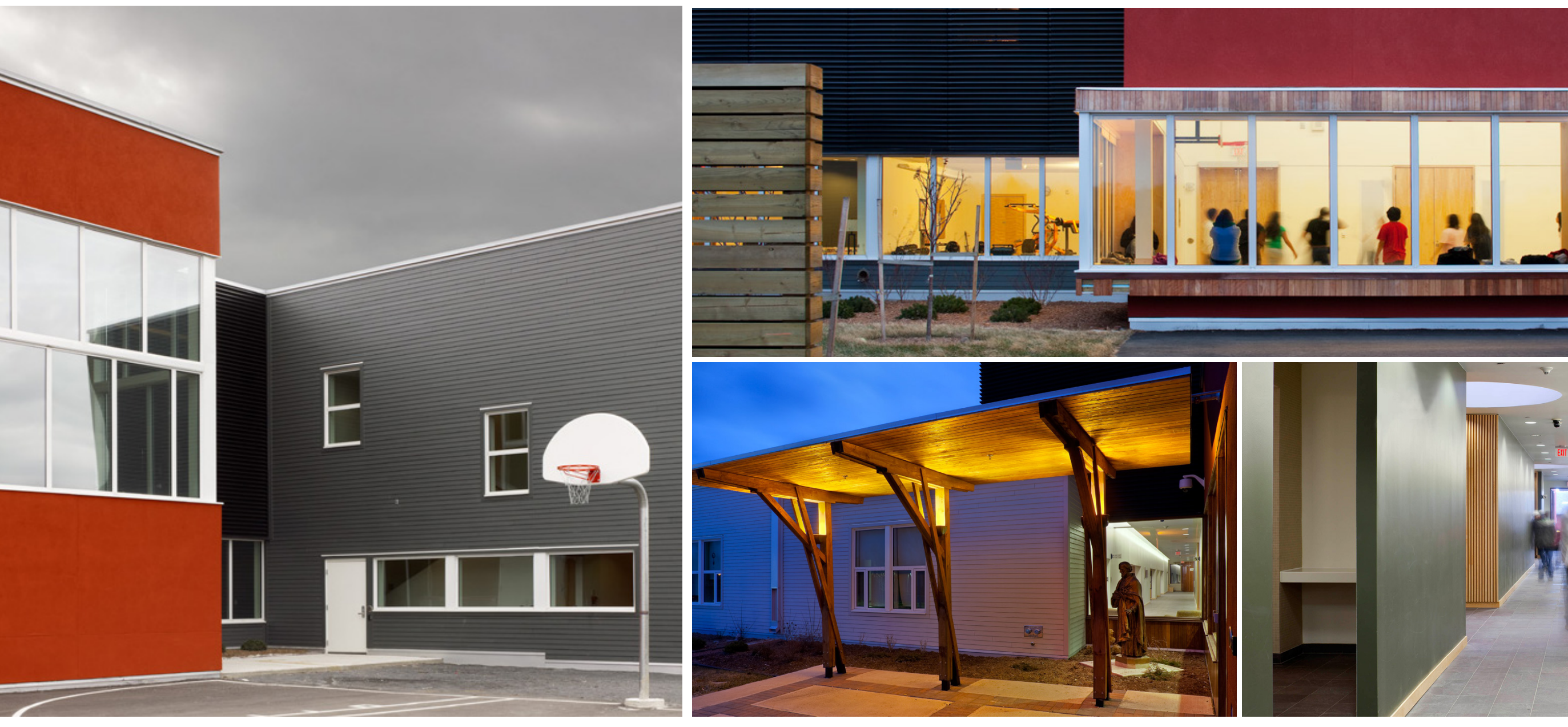


The following section of the thesis analyzes the projects through a collective critique. This method is implemented because each project is challenge with the same struggles put forth by our current society and profession. The critiques given to each project as an individual and as a whole are not meant to portray them as failures, but are formed by the thesis statement and research conducted.

\section{Visual Dominance}

The human body experiences space through all senses. Smell, touch, hearing, taste, sight and heart. Each project that has had exemplary mention in the field of healthcare architecture in Ontario, yet, it has only focused on one main sense in the design; sight. This is a short coming in our field and our culture. We tend to only recognize the visual manifestations of life and devalue all of our other senses. We do not consciously recognize all of our other senses. These projects reinforce this idea. Tactility, olfactory, auditory, and gustatory and spirituality do not seem to be part of these design intentions. This reduces the experience of the users, reducing it to an experience that privileges the visual sense, and, therefore, not fully engaging one in a encompassing experience of space or place.

\section{The Horizontal Plane and the Box}

Each project encapsulates its programs and its users in a space that is horizontal and Cartesian in nature. It creates these box-like environments for its users throughout each space that provide predictable and rudimentary conditions. These spaces do not engage the users in a kinesthetic experience and create a simple and easy circulation throughout the building. Users can walk aimlessly through space the building and the design does not cause one to acknowledgment changes or the diversity of their surroundings. Everything is uniformed and squared off. This further helps to disengage one from their environments, contributing to the idea of placelessness and one's unawareness of space.

The "Well Tempered Environment"

You can blame it on our climate in Canada, but that is taking the easy way out. We live in a world that separates the interior from the exterior. We create spaces that put natural elements and process at more than an arm's length away and we strive to create space that is contained, controlled and comfortable. This further separates us from our world, the processes of life and change in which we are a part of. This act of separation allows us to disengage ourselves from the natural world, which is detrimental, as it further enforces the conception that humans being separate from the natural world, which we are not. We are an active and vital part of it. This is why we see such degradation to our earth and societies across the globe. This is harmful to the healing process and is one of the reasons why we live such segregated and individualist lifestyles. Technologies and building systems allow us to separate ourselves. The invention of HVAC systems and lighting systems have allowed us to remove ourselves from the environment and place ourselves in sealed boxes that artificially simulates the ideal environment in which a human would like to live, work and play. This issue here lies in the fact that we are secluding ourselves from the rest of the world. As mentioned from a participant at the community meeting, 'the elements are not necessarily a bad thing', 'however, our need or desire to shut ourselves off from them further numbs users and allows them to neglect the conditions of their surroundings that are not part of the man-made world.

\section{A Communal Connection}

Communal and social interactions seem to be a dominant design principle in each of the case studies and, I agree, this is a vital role to the creation of sustainable and affective healing spaces, however, each project views community connections at a distance. Once again, visual connections between individuals are valued more than others. The spaces begin to create a dynamic of multi-purpose and multi-use activities yet they are still extremely segregated by functions. Other than visual connections, the spaces that are specifically programmed to be multi-use, where, typical individualists western lifestyles are still promoted throughout the designs. Rooms are segregated from each other in the name of privacy. Community mentalities are then restricted to specific programs and we then drastically segregated our lives between personal and public activities, where the users have no option to begin to bend these boundaries if they wish to.

\section{Sterile, Clean and Controlled}

Efficiency and maintenance appears to be a main objective of the design of health spaces. I am not claiming that this is wrong or a negative attribute to these designs, but when it stands in the way of creating meaningful and experiential spaces that connects users to the world, the community and themselves, it then becomes a problem. As previously mentioned, our society values ease, speed, comfort and efficiency 
above all else...well except profit, yet these attributes help to create more profit. The quest for a sterile, clean and controlled environment takes away the true aspects of life. Real life is not clean, it is not sterile and it cannot be controlled. When we create spaces that proliferates these ideas to the patients we are further removing them from reality in the name of functional and monetary efficiency. It removes the joys, the challenges, and the haptic, sensorial nature of life, which makes our existence beautiful. Nothing is perfect and nothing should be perfect, otherwise we are living an illusion. These environments we create as a result consist of these clean, sleek, flat and monotonous surfaces. This is not just applicable to healthcare architecture but architecture throughout the western world.

Each of the projects explored provide a solid point of departure for the creation of healing spaces and have exceeded excellence in the field however, standard practices still shackle the architect from exploring this idea of healing further. We can begin to see, through these analyses, how modern society and culture influence the design of spaces. This allows us to move forward and to begin to add-on and expand on these already successful projects. We need to take into consideration their downfalls and limitations in order to improve upon the architecture that is being created in the field of health care. We need a new way of looking at healing that challenges the status quo of typical western health practices, particularly in regards to spaces concerned with addiction and mental health. We need a new perspective in which to view healing that aligns with the spiritual and wellbeing issues facing these specific users and our society as a whole. It is then, as architects, that we can begin to create successful healing spaces for society. 
The Wabano Aboriginal Health Centre is a 45,000 square foot expansion and renovation project located in Ottawa, Ontario, completed in 2013. Designed by the Aboriginal architect, Douglas Cardinal, the project was a response to the growing demand for aboriginal services in the city. The project was designed with the themes of earth, water, fire and sky in mind. The facade consists of an undulating and curving vertical surface that wraps the building. This is meant to represent flowing water, a symbol of life.[7]

The main ceremonial and community gathering space is located just off the entrance of the facility. It is a double height, mezzanine space with a dome shaped roof supported by 13 columns, representing the lunar cycles. The roof is divided into four quadrants and painted the symbolic colors of the Medicine Wheel. At the center of the space a small circular skylight is located in the dome and on the floor tiles are colored in a pattern to represent the 8 star blanket. The mezzanine space allows users to look down onto the activities in the main gathering space. [8]

The Wabano Health Centre is elaborate and expressive. It's curves are designed to speak to the fluidity of water and circularity of the Canadian Indigenous culture, acting sculpture. If one stands close to the building and gazes up, it appears as if is a cloud diminishing into the sky, curving and hugging it, bringing a feeling of spirituality to the form. The building begins to represent the culture architecturally, without being literally symbolic of traditional indigenous vernacular forms. However, there is a sense that the building is trying too hard and imposing itself onto the site and its users.

The materials present themselves in contrast with one another. The modern curved glass folds over the tiered and stack stone walls, stopping at a small point with an abrupt finish. This is showcasing the duality of each material, a concept that is embedded into the indigenous culture, where good cannot exist without bad, light cannot exist without dark and so on. However, though the building appears to be dynamic and complex, in terms of materiality, its palette is monotonous and lacks tactility. Particularly the interior of the building, takes on a sterile and monotonous environment, where the material palette is smooth and consists of gypsum and tile.

The interior of the large domed shaped gathering space is painted with the colours of the medicine wheel and each colour faces the appropriate, corresponding direction, with the center providing a view

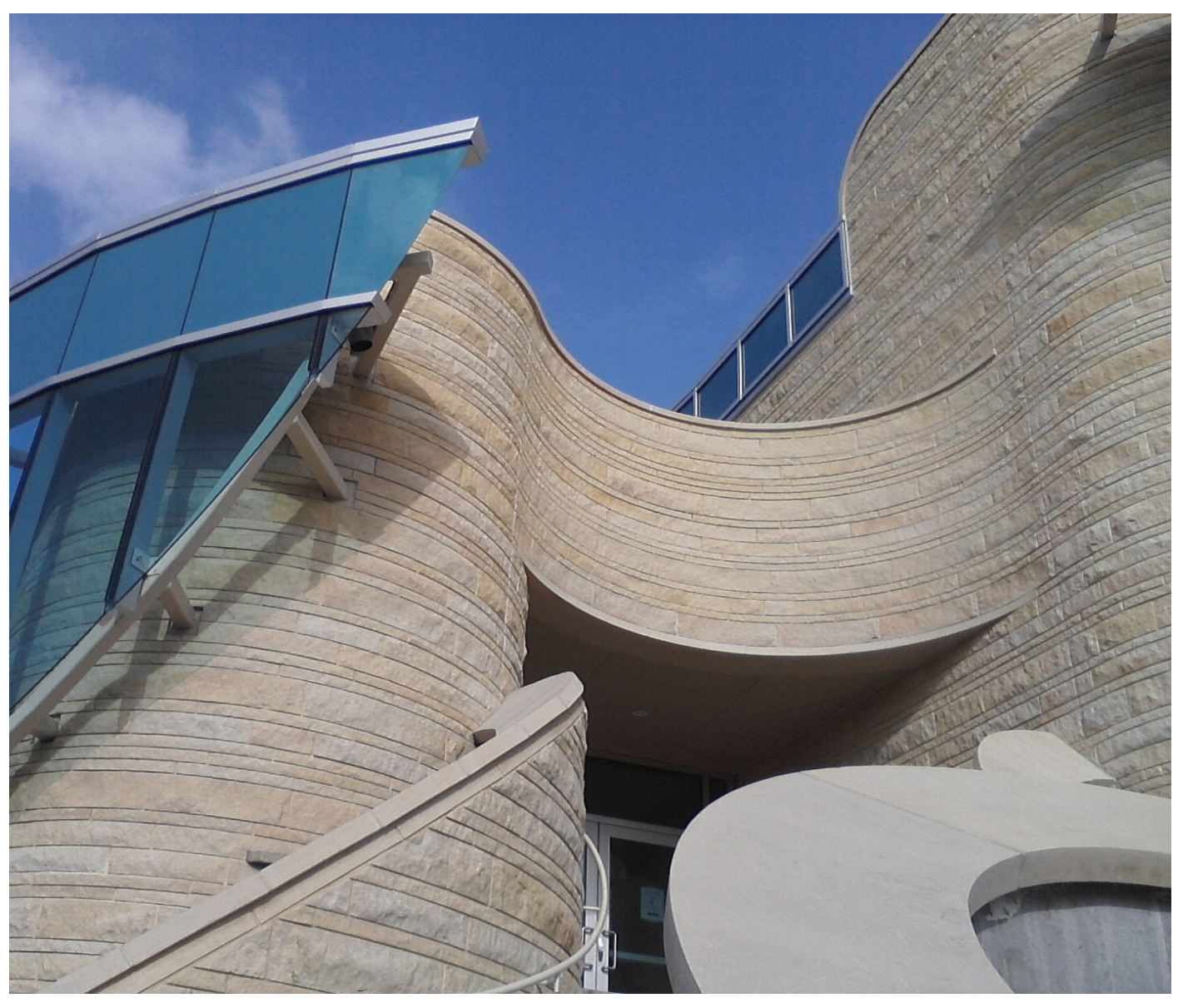
to the sky. Below it, on the floor, a coloured wood radiating form sits in the centre of the room. These gestures, in my opinion, are not considered architectural. They are interior applications that reference the culture literally through colour and shape, applied to the building instead of being integrated with it and forming the design strategies. 

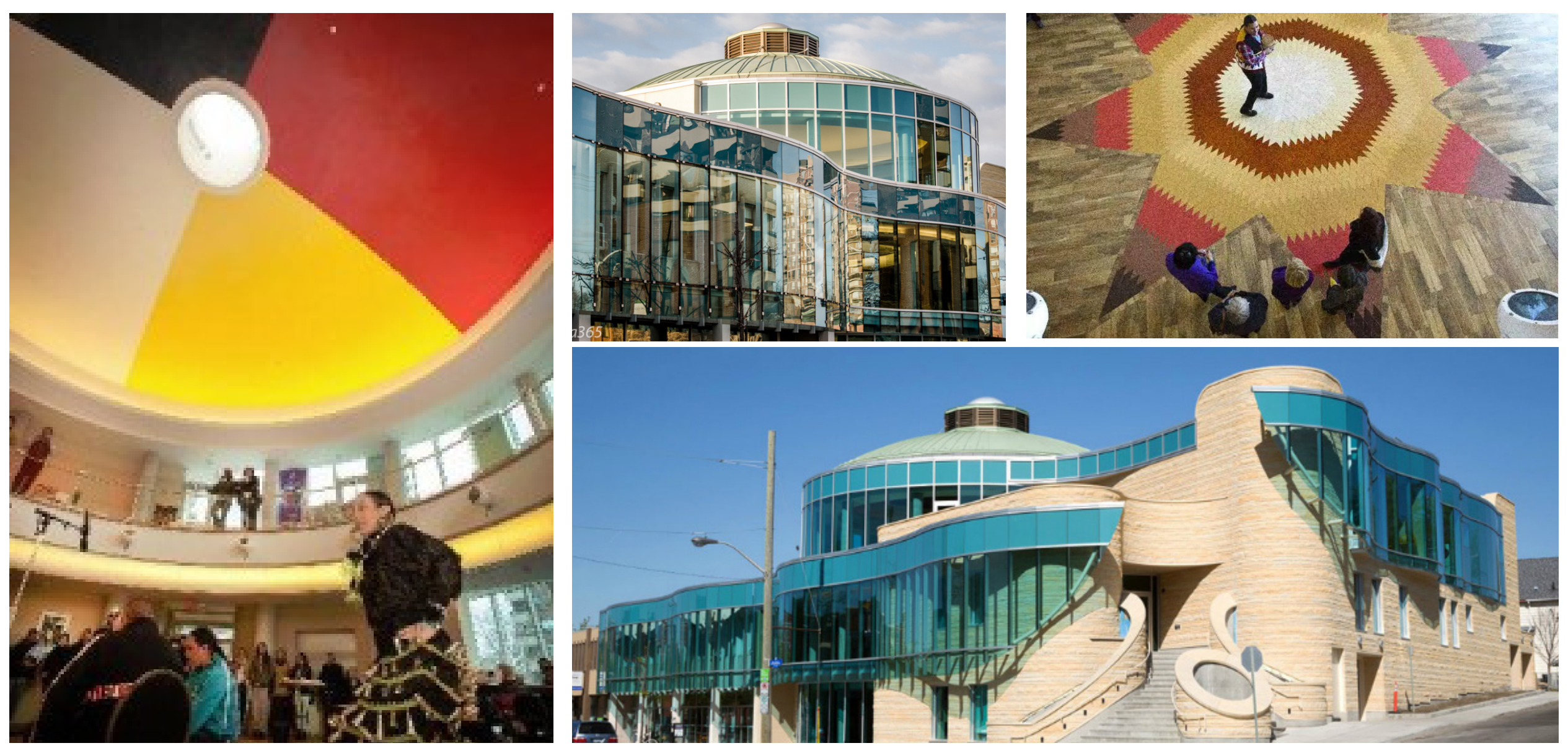

Figure 41-45. Wabano Health Centre 


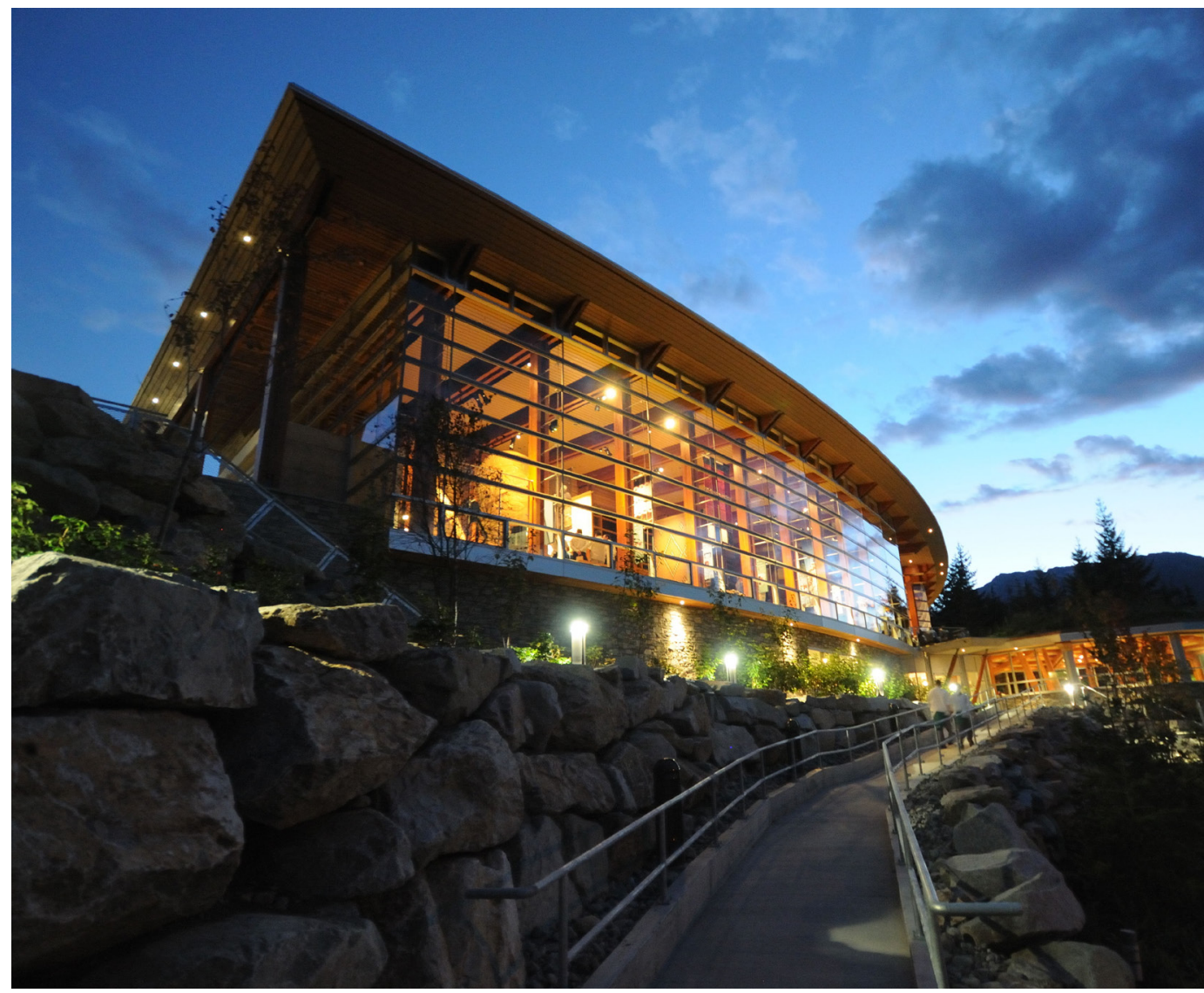

Designed by architect Alfred Waugh and Formline Architects, the Squamish Lil'Wat Cultural Centre is design for the Squamish and Lil'Wat tribes. The 31,000 square foot facility celebrates these two tribes and brings them together. Located in Whistler, British Columbia, at the foot of the mountains the project is embedded into the edge of the landscape, acting as a "doorway to forest." [9]

The design of the centre takes a contemporary approach to the traditional longhouse of the Squamish tribe and the traditional underground Itsken dwelling of the Lil'Wat tribe. The facility primarily consists of wood timber post beams, cedar doors and carvings, wood wall panels and bent "sapling-like" members on the interior of the façade. This creates a warm and soft material pallet of the facility. The main hall is a double height mezzanine space for the display of art and artifacts and has double height glazing with views to the outdoors.[10]

The concept behind the development of the form of the Squamish Lil'Wat Cultural Centre was to take inspiration from the traditional vernacular forms of the longhouse, representing the Squamish tribe, and the istken, which is a circular structure, embedded into the ground, which representing the Lil'Wat tribe. These forms are literally symbolic of their vernacular predecessors. This application of culture, in my opinion, appears superficial. This is not to say that these symbolic forms are not valid in the design, however, in terms of healing and representing the culture, they do not go beyond visually impacting the users.

Though the building sits at the bottom of a mountain landscape, rich with ancestral history, cultural meaning and indigenous knowledge, the building keeps the exterior environment at a distance. The long processional ramp that leads to the main entrance and the use of rough, natural finished stone retaining wall begins to speak to a connection with landscape and with the natural elements of the site by creating a sense that the building is a emerging from the landscape. However, like typical North American architecture, a distinct barrier between inside and out is still drawn. This creates a literal and psychological separation between humans and other beings in the landscape. It only provides a visual engagement with the exterior, restricting the interaction and the relationship between beings. I am not claiming that the interior should be open and fluid into the exterior, however, the progression from one environment to the next is too abrupt, causing this disconnection. 

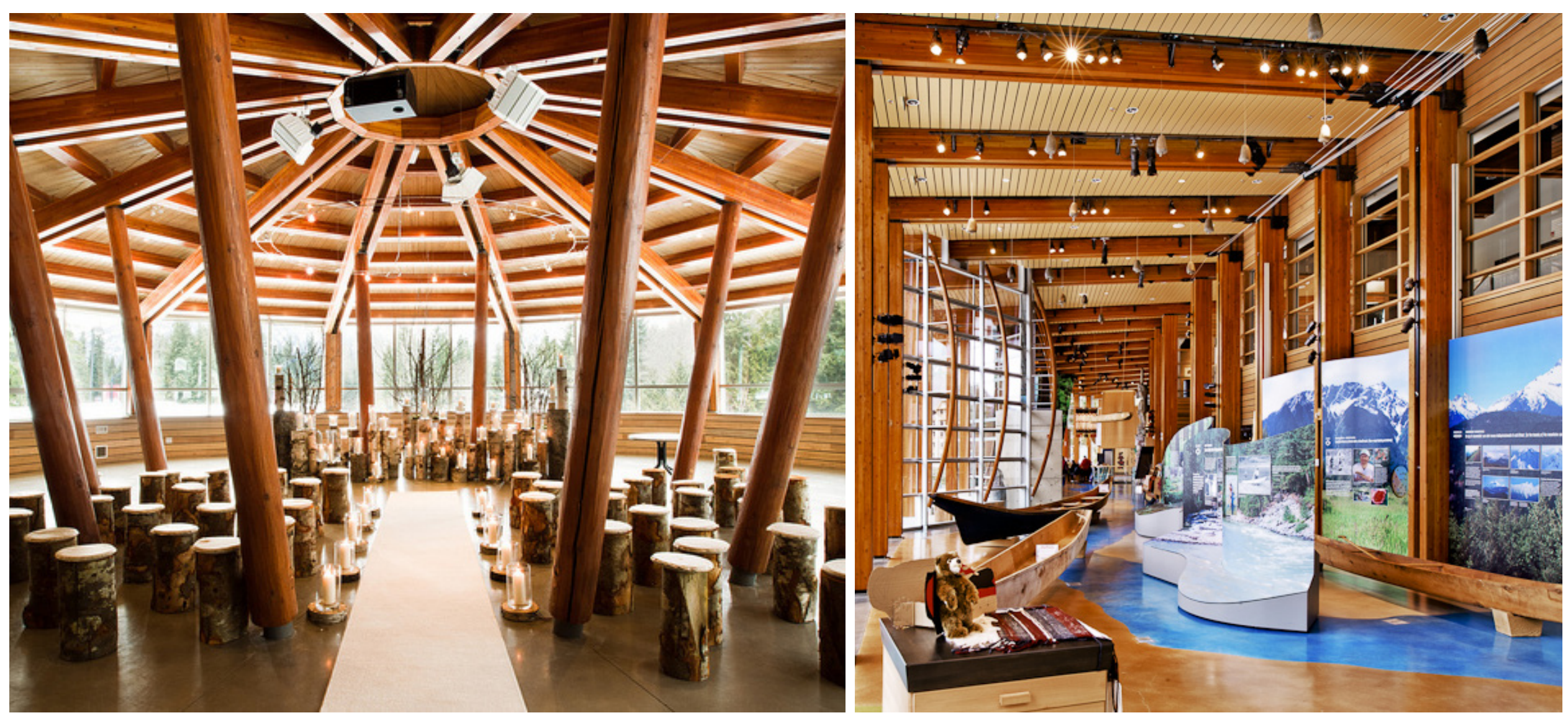

Figure 42-44. Squamish Li'Wat Cultural Centre 

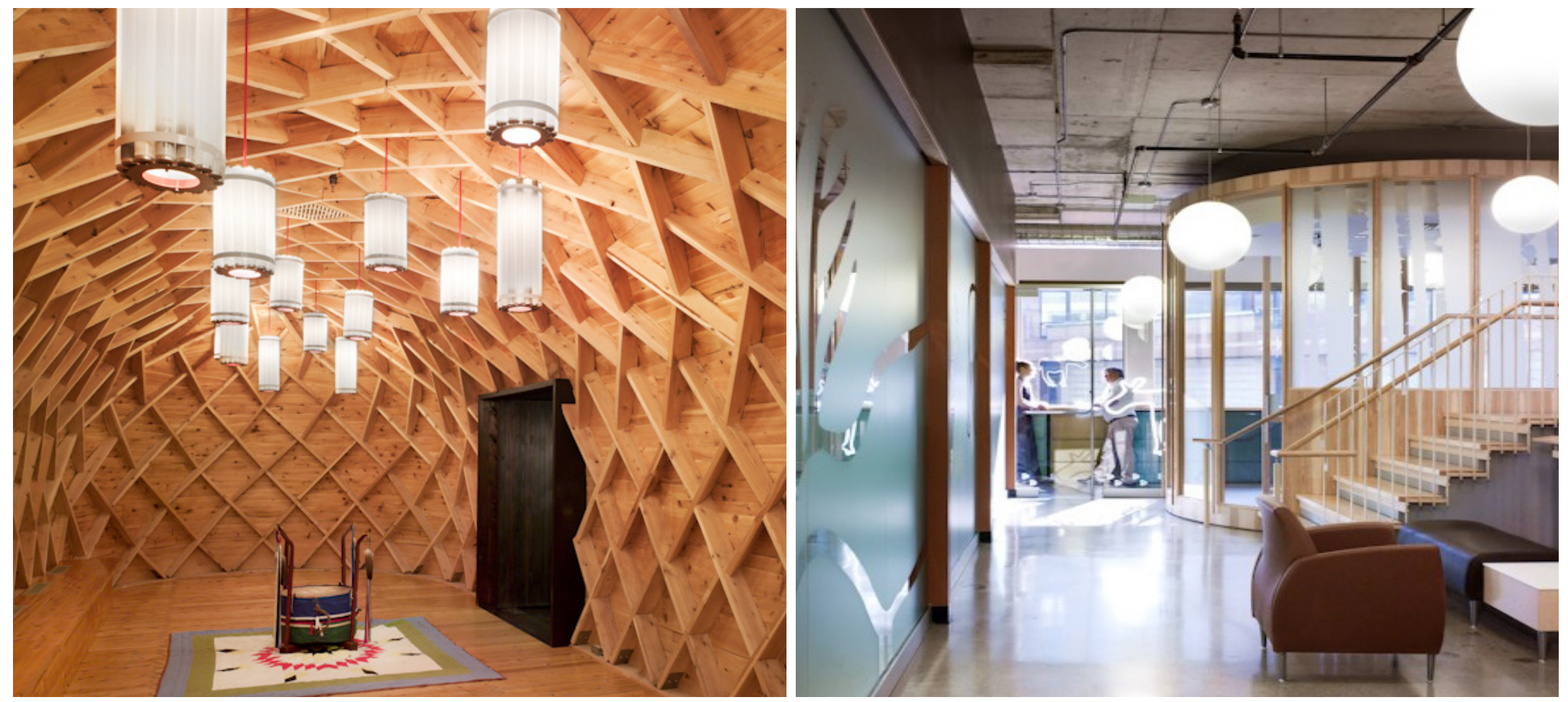
THE CENTRE FOR NATIVE CHILD AND FAMILY WELLBEING

Located in the heart of downtown Toronto, The Centre for Native Child and Family Well-Being is designed to reconnect the diverse population of urban Aboriginal people in the city and provide a haven where they can return back to nature and back to their culture. Designed by Levitt Goodman Architects, the project is a renovation of an existing 1980's office building. The office was stripped to the structure and transformed. The main space is a double story, open concept, mezzanine space. The tiling on the floor is colored and pattern to represent a "giant welcoming blanket." [11]

Just off of this space a contemporary interpretation of the longhouse is located. The design is a free standing meeting room that was computationally modelled and prefabricated. The interior of the structure consists of a lattice like system and covered by cedar paneling. On the roof of the facility, a small healing lodge and native plant garden blankets the roof. The interior of the space is very light, bright and airy with skylights and frosted glass walls as office partitions. This allows for a level of transparency between spaces and a visual connection to other activities. The architects collaborated with local aboriginal artists and created multiple different graphics to be applied throughout the project. [12]

The form of the meeting room takes the traditional vernacular form and interpret it into a contemporary context. It begins to find success in this regard, particularly on the interior of the form, where the lattice structure is display. However, it acts as an artifact that is injection into the design, disjointed and separate from the rest of the space. It acts as a small building within a building.

The material palette is balanced. There is an intersection of "modern" manufactured materials, such as the concrete blocks and columns, and "traditional" materials, such as the wood elements. This balance begins to bridge the traditional with the contemporary. The concrete block wall is left in its natural state and the concrete columns are unfinished, showing the markings of the formwork. The ceiling and piping is left exposed as well. This brings a sense of material honesty, tacitly and life to these elements and materials. Function and structure is exposed, wear and tear and celebrate and, even though these are perceived as highly manufactured materials, their natural tactility and character is expressed.

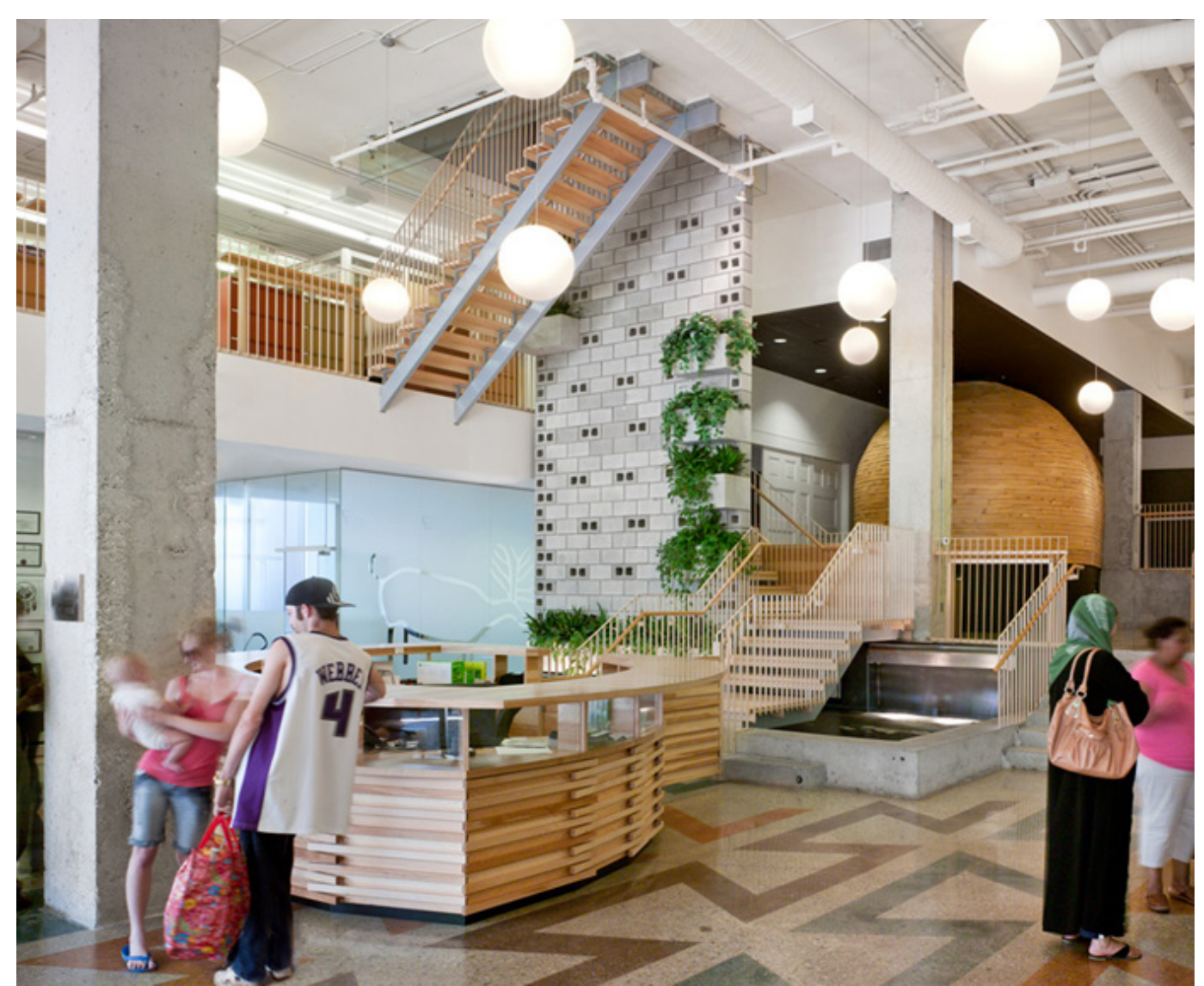

Figure 45-47. Centre for Native Child and Family Well-Being 
The following section of the thesis analyzes the projects through a collective critique. This method is implemented because each project is challenge with the same struggles put forth by our current society and profession. The critiques given to each project as an individual and as a whole are not meant to portray them as failures, but are formed by the thesis statement and research conducted and are particularly examining how architects have interpreted indigenous cultures from architecture.

\section{Dominance on Visual Connections}

Once again, there seems to be dominance on the visual aspects of the design. Cultural interpretations are manifested solely though visual solutions. This does not reflect the experiential and social qualities of the culture. These ideas are not ingrained into the design. It becomes a modern western 21st century project, with cultural symbols and materials inserted into the building. The culture needs to guide every aspect of the architecture and guide the users to utilize and experience space by incorporating indigenous principles.

Literally Symbolic

The concept of symbolic representation through form has been a tool that architects have used since the beginning of time. It provides a nostalgic connection and meaning to spaces and forms. There are two main strategies in which symbolism can be implemented into space; abstract symbolism and concrete symbolism. These projects tend to represent the latter. The contemporary interpretation of vernacular aboriginal architectural forms is a common design move that is used in all three of the case study projects. This literal symbolism draws on the memory and historical connections that indigenous people have to these forms. This is not necessarily a bad approach; however, this reinterpretation can be seen as an inauthentic and an inserted application of culture. It does not fully understand the principles, culture and beliefs and ingrain it to the architecture beyond forms. It is a surface level attempt and application of integrating culture into the design, reverting back to the past and not progressing forward.

\section{Material Driven}

Due to the indigenous culture's close connection to the natural world, there is a predominant use of wood as a natural building material. Though I do not believe that its use and application are incorrect or inappropriate, my criticism is that materiality as a tool for cultural translation into architecture is overdone and does not dig deep into its cultural relevance and connections. Wood does provide a tactility, smell and atmosphere that is a valuable too in interpreting culture but perhaps a deeper look at materiality and vernacular aboriginal architecture is needed. One that examines the meaning and value of locally sourced materials has on spatial productions and where material honesty is explored.

\section{Interior Applications}

Each project takes an approach of interior applications of graphics and colors to connect to culture, through tiles, paint colors, art pieces and carvings. These tools make it instantly recognizable what culture is being represented in the space. These types of design decisions, in my opinion, begin to fall off the spectrum of what is considered architecture and overlap with the field of interior design/decorating. They begin to become applied cultural interpretations, not interpretations engraved into the formal configuration of space. They are stylistic and decorative elements that are added to the design.

\section{SUMMARY}

Each of the projects explored were designed to represent the Indigenous users and culture. This is why we see such obvious attempts to translate the culture into the building. However, the cultural principles and beliefs are extremely valuable to more than just the indigenous culture and were superficial applications. Architects must learn from them and their history and practices. In particular in the creation of healing architecture, architects must explore the tools we have to engage in this dialogue and engrain these principles into every aspect of the architecture to create appropriate and affective healing environments. 
[1] Montgomery Sisam Architects. "Centre for Addiction and Mental Health Phase 1B." Montgomery Sisam Architects Inc. Web. $<$ http://www.montgomerysisam.com/projects/centre-addiction-and-mental-health-phase-1b >

[2] Montgomery Sisam Architects. "Centre for Addiction and Mental Health Phase 1B." Montgomery Sisam Architects Inc. Web. $<$ http://www.montgomerysisam.com/projects/centre-addiction-and-mental-health-phase-1b>.

[3] Montgomery Sisam Architects. "Sister of St. Margaret Smith Addiction Treatment Facility." Montgomery Sisam Architects Inc.,

n.d. Web. <http://www.montgomerysisam.com/projects/sister-margaret-smith-addictions-treatment-centre>.

[4] Montgomery Sisam Architects. "Sister of St. Margaret Smith Addiction Treatment Facility." Montgomery Sisam Architects Inc.

n.d. Web. <http://www.montgomerysisam.com/projects/sister-margaret-smith-addictions-treatment-centre>.

[5] Montgomery Sisam Architects. "Sister of St. Margaret Smith Addiction Treatment Facility." Montgomery Sisam Architects Inc. n.d. Web. <http://www.montgomerysisam.com/projects/sister-margaret-smith-addictions-treatment-centre>.

[6] Montgomery Sisam Architects. "Sister of St. Margaret Smith Addiction Treatment Facility." Montgomery Sisam Architects Inc. n.d. Web. <http://www.montgomerysisam.com/projects/sister-margaret-smith-addictions-treatment-centre>.

[7] Wabano Centre for Aboriginal Health. "Our Building - Wabano." Wabano: Our Building Comments. Web. <http://www.wabano. com/about/our-building/>

[8] Altass, Angela. "Wabano Health Centre." Wabano Centre for Aboriginal Health. Award Magazine, Canada Wide Media Ltd., June

2013. Web. <http://www.wabano.com/wp-content/uploads/2012/08/Wabano-AWARD-Magazine-June-2013.pdf>.

[9] Formline Architecture + Urbanism "Squamish Lil'Wat Cultural Centre." Formline Architecture + Urbanism. 2008. Web. <http://www.formline.ca/SQUAMISH-LIL-WAT-CULTURAL-CENTRE>

[10] Forestry Innovation Investment "Squamish Lil'Wat Cultural Centre Case Study." Naturally Wood. Forestry Innovation

Investment. Web. <http://www.naturallywood.com/sites/default/files/Squamish-LilWat-Cultural-Centre-Case-Study.pdf>.

[11] Bozikivic, Alex. "Native Child and Family Services, by Levitt Goodman - Nomeancity." The World of Architecture, No Mean City, As Seen From Toronto. 21 Mar. 2011. Web.

<http://www.nomeancity.net/tour-native-child-and-family-services-by-levitt-goodman/>

[12] "Native Child and Family Services of Toronto / Levitt Goodman Architects." ArchDaily. 16 Mar. 2011. Web.

<http://www.archdaily.com/120391/native-child-and-family-services-of-toronto-levitt-goodman-architects> 
ARCHITECTURAL HEALING 


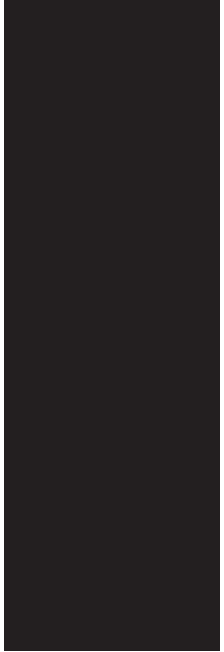

"Man takes a positive hand in creation whenever he puts a building upon the earth beneath the sun. If he has birthright at all, it must consist in this: that he, too, is no less a feature in the landscape than the rocks, trees, bears or bees of all that nature to which he owes his being."

-Frank Lloyd Wright

\subsection{ARCHITECTURAL HEALING}

It is evident that disconnection, unawareness and placelessness are common themes and conditions experienced in western societies. The current western modern world has continued to reinforce and homogenize our world. However, the lack of place, meaning and engagement in our current environments has been recognized as a serious problem over the past century, particularly in architecture. This desire to regain spirit back to spaces and locations in order to create places of meaningful connection for human engagement and experience is mainly focused in the philosophy of phenomenology and is recognized by many architects, urban planners and theorists who have been activists for implementing these ideas into the production of our spaces. Many of these ideas and concepts of space draw parallels between many of the principles in the Anishinabek culture. The following chapter will briefly touch on these concepts and ideologies that have penetrated the profession and reflect some of the qualities of the Anishinabek culture. Its purpose is to briefly explore how these ideas have influenced certain architects and architecture in order to learn how we can begin to combine these ideologies for architectural healing spaces, to exhibit the role that architecture can play in the creation of these spaces and to exhibit architectures ability and influence in incorporating the Anishinabek principles into design.

Phenomenology is "the science of phenomena as distinct from that of the nature of being; An approach that concentrates on the study of consciousness and the objects of direct experience."[1] It studies how one experiences and perceives space. In this context, spatial experience is not restricted to solely the physical aspects, but also the abstract non-physical qualities and happenings of space. As stated by philosopher Edmund Husserl, "pure phenomenology is the science of pure consciousness."[2] It encompasses experience beyond the five main human senses. Therefore, our experience of space goes beyond the physical, beyond our bodies and into the realms of consciousness and spirit. It includes the social activities, language, memory, imagination, anger, desires, thought and so on. This kind of personal experiential awareness is an important aspect in understanding how meaning is embedded in spaces through experience and how connections to place are made. This concept aligns with the how Anishinabek culture experiences the world and its procedural epistemic views. It provides substance and dynamism to space and experience and acknowledges that space and time are experienced together. In a current architectural culture that puts all its value in the visual experience of space, this becomes a unique challenge for the architect. 
The term "genius loci" refers back to ancient Roman times. It was a word that represented the belief in the Spirit of Place. Ancient Romans believed that "every being has its'genius', its guardian spirit. This spirit gives life to people and places, accompanies them from birth to death and determines their character" and that "man experienced his environment as a revelation of definite "genii"'[3] This was an essential part of understanding yourself, your relationship to the world and others in ancient times. "[Man] understood that it is an existential necessity to come to terms with the genius of the locality where his life takes place."[4] In ancient times, man did not challenge the "spirit of place" but embraced it into their lives and made it part of their spirit. "To identify with a place primarily means to be open to its character or'genius loci' and to have a place in common means to share the experience of the local character." [5] It was about a respect for place that was formed by the natural, cosmological and cultural landscapes in their entirety and interrelation. Architecture was a big part of embracing and contributing to the spirit of place, to its atmospheres and characters. Defining space today seems to be a challenge for us. This is because we live and work with such scientific means of measurements, placing the most value on monetary gains and place is not something that can be scientifically analyzed or quantified.

"Architecture's understanding between built form and meaning has been too static and is hindering a more powerful understanding of place."[6] This has been restricted by our inability to understand place and quantify it. We are challenged by its abstract, emotional and experiential qualities. Yet, even though the architect's role is to 'concretize the abstract qualities of life', [7] we are struggling to determine what place is in our current contemporary age. Perhaps it refers back to Henri Lefebvre's production of space and conceptual triad. There is a missing link or a misplaced intention. How can we understand the abstract qualities of life when we are not engaging in the life and the people who are creating place. We've seen attempts in the previous case studies to revive and respect the spirit of place in the cultural interpretations into architecture. However, "To respect the 'genius loci' does not mean to copy old models. It means to determine the identity of the place and to interpret it in ever new ways." [8] This is the architects challenge. It is not about mimicking or reinventing, but it's about how architecture can continue the 'essence' of place through building.

This disconnection to place and spirit of place in western society has led to the separation of humans from their environments, from their cities, communities and inner selves. The concepts of phenomenology, genius loci, spirit of place and connection to nature and community begin to fall in line with the Traditional Anishinabek views and connections to the world, where the spirits of the world were embraced and incorporated into their ways of life and views of the world. The spirit of place was a part of them and they were a part of the spirit of place. This relationship was vital to a healthy community, healthy individual and a healthy world. These are concepts that have been incorporated into many architectural projects, however, often; they are lacking certain elements and are completely confining themselves to the normative practice of our contemporary western society.

Through this research, it becomes evident that architects and architecture can play a vital and beneficial role in the healing process for people struggling with addiction and wellbeing issues. We now know that addiction cannot be reduced to scientific measurements and solutions, as is practiced in western societies. It is a spiritual impoverishment, predicated by our divorce from traditional values and practices that connected us to the earth, to other beings and to the universe. The dissatisfaction, disconnection and dislocation within the western world is manifested through addiction and it is an adaptation, a survival tactic, to escape one's sorrows and struggles with our current realities which our societal values and beliefs have instilled upon us. When we examine the Anishinabek culture and history, we are provided with a polar perspective that experiences and lives in a world that is drastically different than the western framework of life and begins to address the cause and challenges outlined in the adaptation-dislocation theory of addiction that people suffering from addiction face.

This thesis will explore how architecture can create authentic healing spaces that break away from the economic and capitalist confines of our North American western society that shape our current architectura practices. The thesis will explore how the traditional Canadian Indigenous Anishinabek culture and healing beliefs can be incorporated architecturally through the design of a Community and Residential Welbeing Addiction Facility. The facility will be both a community center for the greater community and a residential treatment facility that provides a transition place for people who have undergone detoxification programs, yet, are not ready to re-enter the community without support. This thesis does not posit to revert to the past ways of living of the Anishinabek. It proposes an intersection between indigenous Anishinabek healing beliefs and principles and contemporary western treatment programs and facilities and explores how it is manifested through architecture. Through a phenomenological approach, architecture can begin to re-engage the mind, the body, the heart and the soul of people suffering from mental wellbeing issues and address the cause and ease the challenges of an addict. 
It is important to define this new healing process and understand the essence of traditional Anishinabek healing beliefs and, then, how it can be manifested though architectural strategies and tactics. The research has led to the distillation of five main principles from the Anishinabek culture that are currently lacking in western architectural healing spaces and how, through these traditional Anishinabek healing perspective, these five principles will be the foundations for creating healing spaces for people suffering from addiction wellbeing issues.

It is hard to reduce and delineate the Anishinabek culture into a few defining principles or strategies. This is due to the interwoven aspects of the culture, all of these principles overlap and cannot work without the other. The holistic, relatedness, intertwined and overlapping aspects of the culture pose a challenge when trying to complete this task. However, in order to provide direction, a guide and ease of translation directly into architecture, they were defined, along with three strategies and numerous tactics to further implement these principles. Therefore, in order to help define these strategies, we must take into consideration the dynamism of the culture. As previously examined, the main architectural goals and how they are executed and embedded into the design are derived from the main principles extracted from Chapter 4.0. These principles govern the strategies, process, execution and connectivity of the design. The concept of a circular worldview drives the iterative and cyclical process of the actual design process and the experience of the design. It is what holds the design together and underlies all the principles within the process. The overlapping lines of the diagram represent the relatedness of each architectural strategy, signifying how one action effect all the strategies involved and the overall experience of the space, playing part of an integral whole, while the radiating rings represent the ripple effect from the individual to the community to nature. The following are three main strategies that will facilitate the engagement of the five principles into the design.

1) Create environments that encourage performative action and experiential engagement that engage the body, heart, mind and spirit within space by heightening sense and self-awareness in spaces and during everyday life activities.

2) Design spaces that amplify aspects and the locality of place through natural elements and process in order to enlighten the users of the physical setting, the dynamic processes of their lives and give specify in our globalized and homogenized society.

3) Create opportunities in spaces that engage and promote social interaction and relationship building and foster the expansion of the "kinship" group.

[1] "Definition of Phenomenology in English." Oxford Dictionaries. Oxford University Press. Web.

$<$ http://www.oxforddictionaries.com/definition/english/phenomenology>

[2] Norberg-Schulz, Christian. Genius Loci: Towards a Phenomenology of Architecture. Rizzoli, New York, NY, 1980, pp. 5.

[3] Norberg-Schulz, Christian. Genius Loci: Towards a Phenomenology of Architecture. Rizzoli, New York, NY, 1980, pp. 45.

[4] Norberg-Schulz, Christian. Genius Loci: Towards a Phenomenology of Architecture. Rizzoli, New York, NY, 1980, pp. 45.

[5] Norberg-Schulz, Christian. Genius Loci: Towards a Phenomenology of Architecture. Rizzoli, New York, NY, 1980, pp. 63.

[6] Rodman, Margret in Milgrom, Richard. "Sustaining Diversity: Participatory Design and the Production of Urban Space."

ProQuest Dissertations Publishing, York University, Toronto ON, 2003, pp. 122. Web.

$<$ http://search.proquest.com.ezproxy.lib.ryerson.ca/docview/305290411?pq-origsite=summon>.

[7] Norberg-Schulz, Christian. Genius Loci: Towards a Phenomenology of Architecture. Rizzoli, New York, NY, 1980, pp. 182. 
NORTH

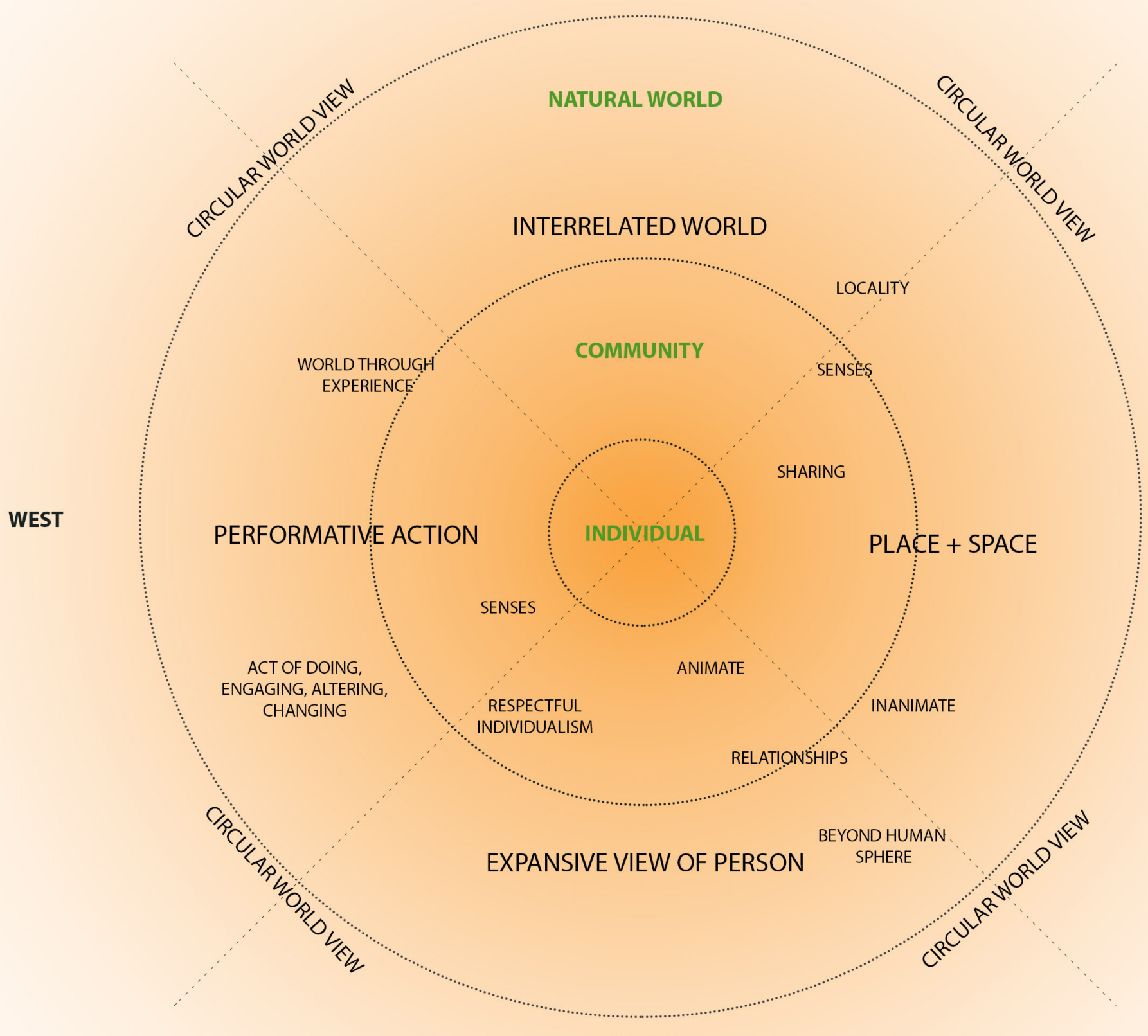

\section{EXPLORATION OF TACTICS}

BLUR BOUNDARIES CREATE POLYVALENT SPACES OVERLAP FUNCTIONS THROUGH SCALE, MATERIALITY,

CIRCULATION, THRESHOLDS SPACE FOR INDIVIDUAL EXPRESSION ENHANCE OPPORTUNITIES FOR SHARING

AMPLIFY ELEMENTS OF WEATHER AND ECOLOGY

ENHANCE ASPECTS OF PLACE

USE OF LOCAL MATERIALITY USE OF VERNACULAR BUILDING TECHNIQUES

REFLECT, BLEND AND CONNECT TO LANDSCAPES

MATERIAL TACTILITY + HONESTY LIGHT + SHADOW

RHYTHM AND SEQUENCE KINESTHETIC, PHYSICALLY ENGAGING THRESHOLDS

INTERACTIVE ELEMENTS

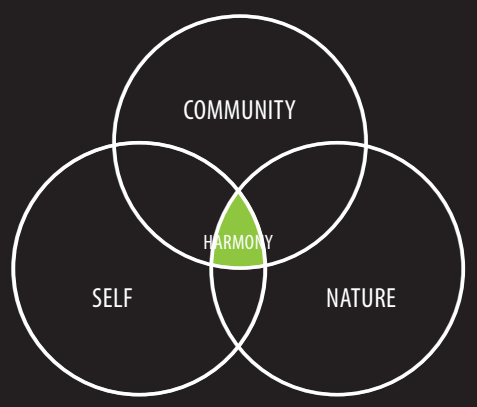

Figure 49. The Harmony of Healing by Author

SOUTH

Figure 48. Architectural Design Strategies Through an Anishinabek Perspective 
RE-ENGAGING THE SPIRIT

Madison Dozzi-Perry 


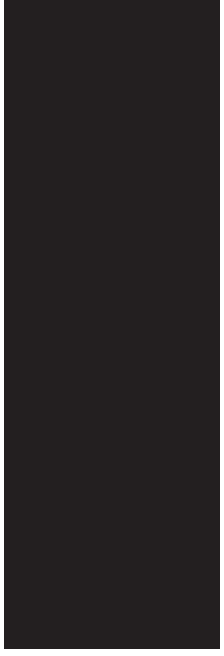

\subsection{DESIGN PROPOSAL}

The following section culminates my research and explorations in the design of a Community + Residential Wellbeing Addiction Facility. The project is presented through a series of perspectives, sections and plans which showcase the building as a series of different moments as one travels through the site along with explanations of how I have transferred Anishinabek concepts of wellbeing into architecture.

Throughout the next section I will describe the experience of a patient's first journey through the building. This will be from the perspective of someone who is arriving to the facility for the first time and moving in for treatment. I will also explain the architectural tactics used throughout the project and how they are manifested architecturally.

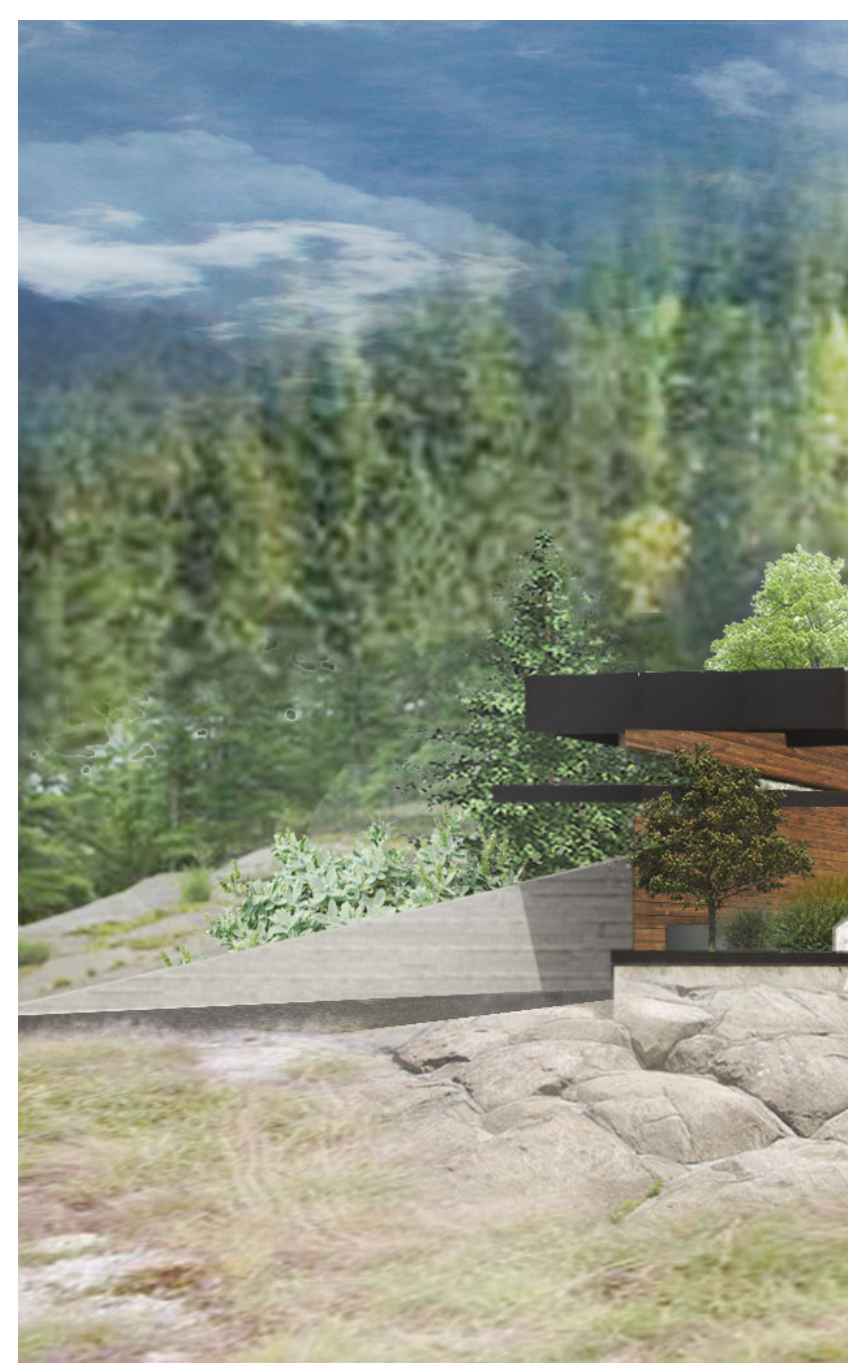


You have made it into the car and are pulling into the site. You're halfway there and your

family is sitting in the front seat, trying to convince you of how great this new experience will be, but you're not listening, you're stuck in your own mind, unaware of your surroundings. As you pull into the site, you expect to be confronted with an overpowering box sitting on the earth. Instead you see a building...or buildings...that are emerging from the landscape. Your heart calms, just a little bit, and your curiosity spikes.

\section{SITE PLAN}

The site is located on existing ceremonial Pow Wow grounds. These grounds include a circular Pow Wow facility, a Teepee structure, a gazebo, recreational spaces for outdoor hockey and baseball and storage facilities. The site also contains hiking trails that connect to the trail systems throughout Manitoulin Island. An existing dirt road exists on the site that connects a residential community to the north and the highway to the west. To the south of the site exists a Canadian indigenous owned post-secondary educational institute. The inventory of spaces and adjacent facilities provide an optimal site for this program. It creates a hub on the site for community activity and draws people into the facility. 


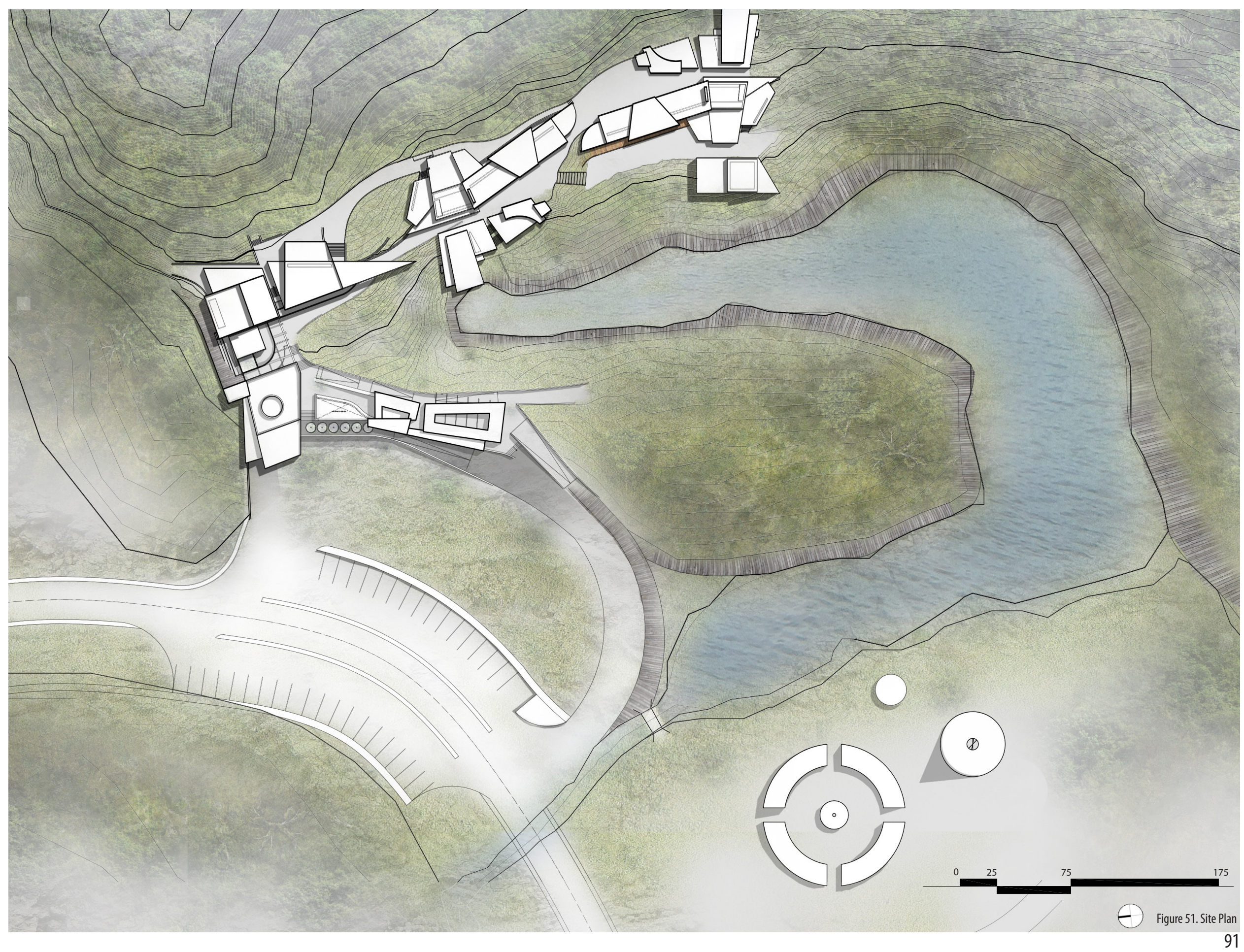


The building's location on the site is at the bottom of a gradually steep hill, embedded in the forest that becomes part of the Manitoulin cliffs and hiking trails. At the bottom of this hill sits a marsh-like pond that collects water from the site and surrounding area. This pond of water changes depending on the season and wraps around a small peninsula that is planted with trees and low brush. The trees on site consist of a mixture of deciduous and coniferous trees, such as hawthorn, birch, pine, maple, elm, oak and ash. The hill is predominantly Precambrian rock.

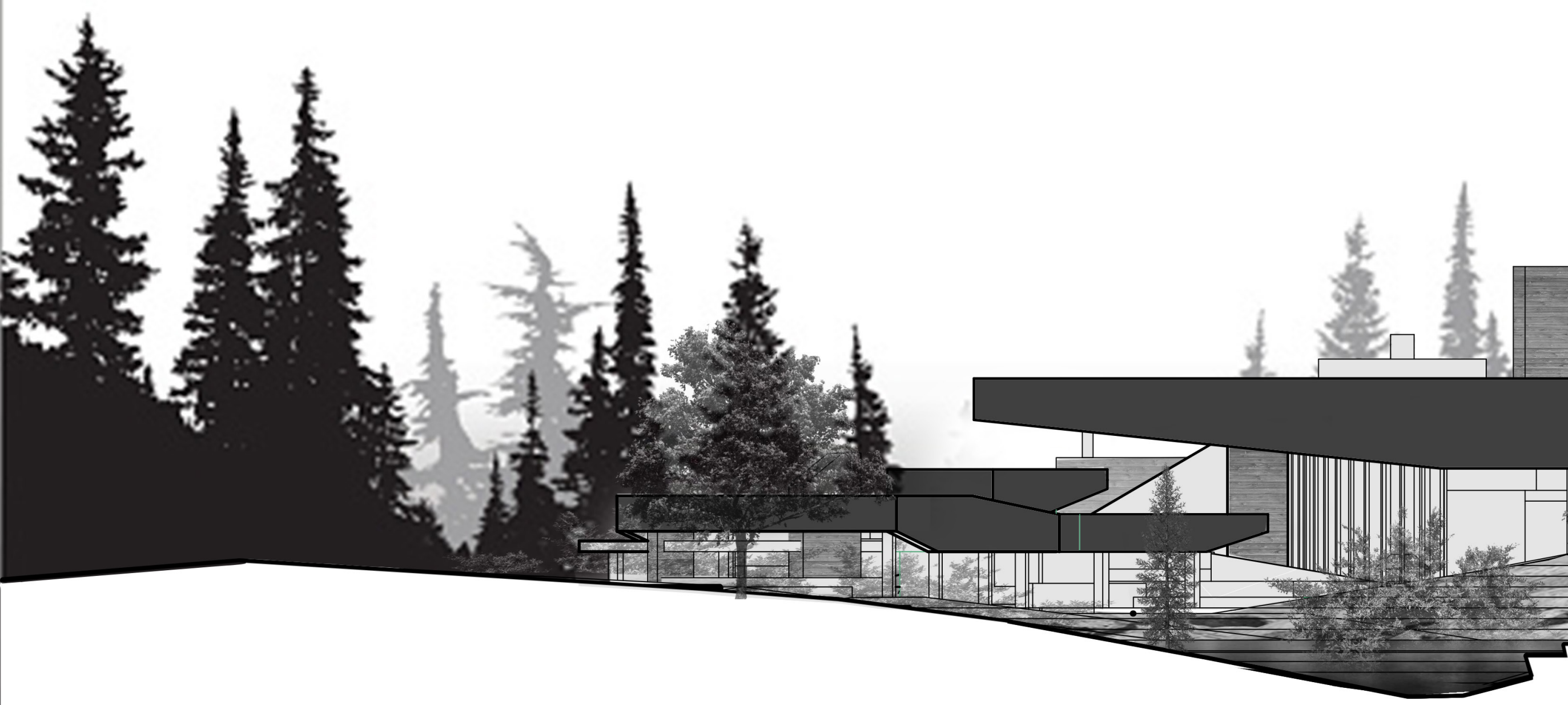




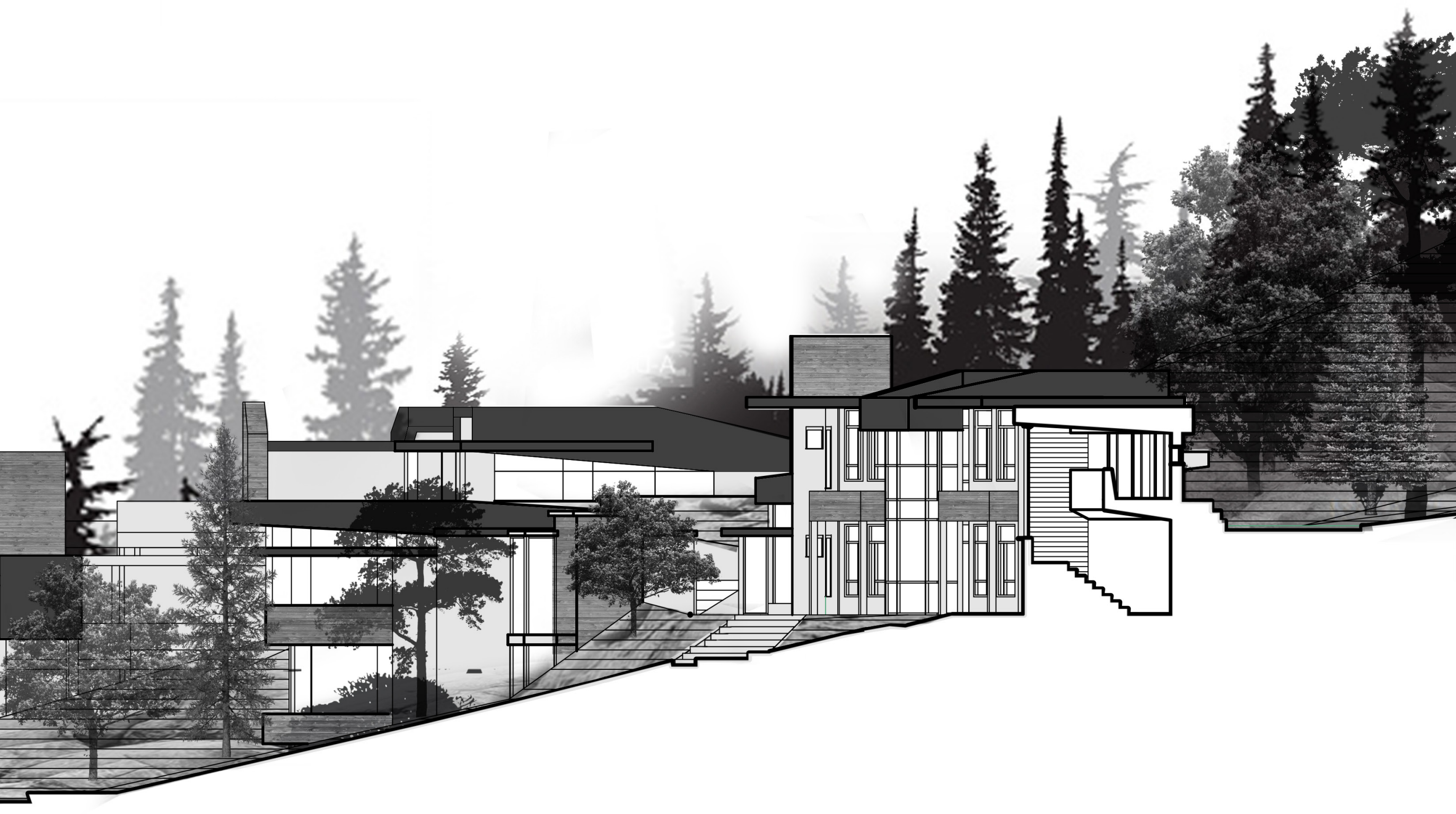




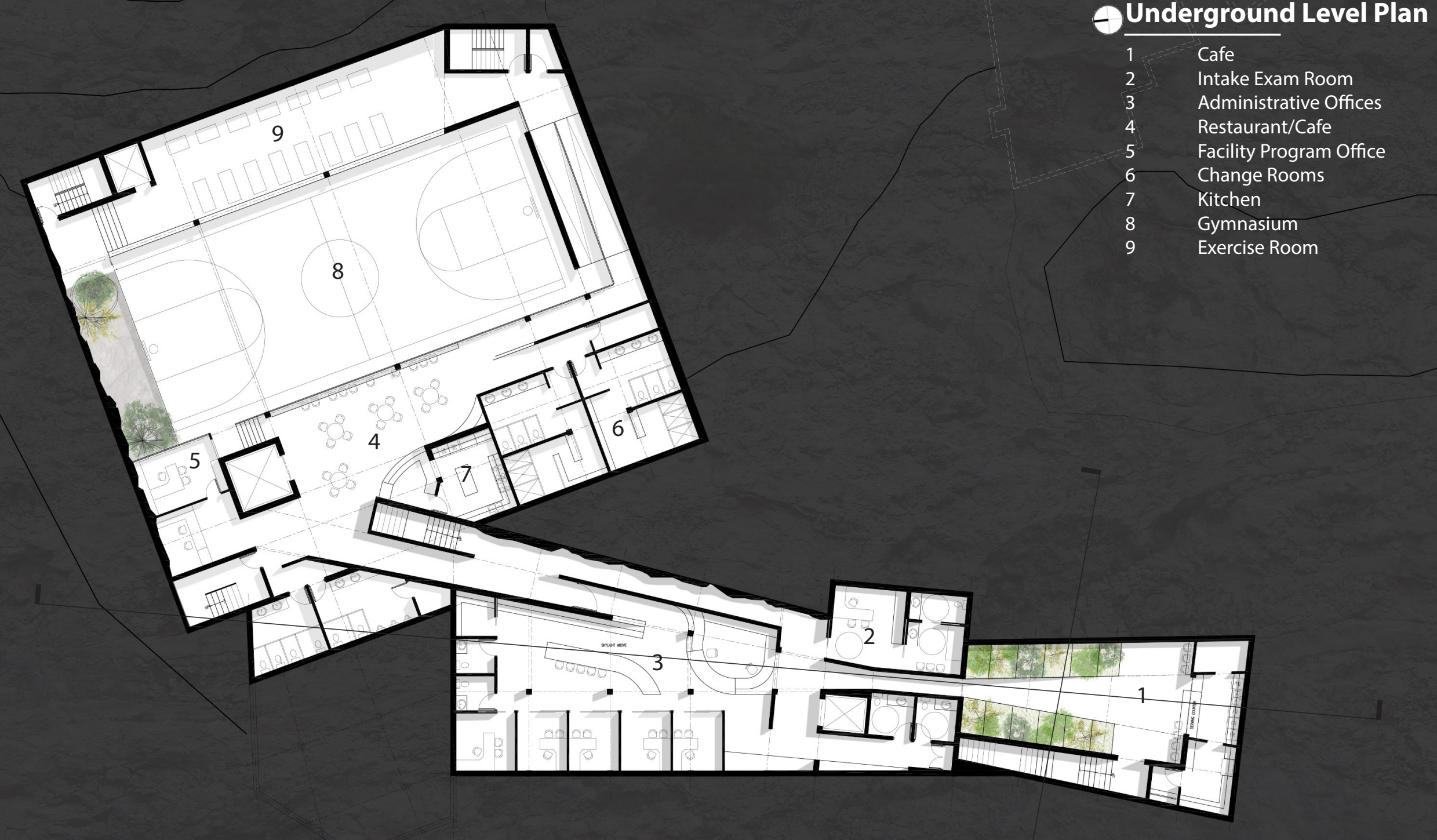









\section{Permeability}

The permeability of the building, physically, visually, acoustically and spatially, begins to drop the barriers between spaces and people. It creates an environment that allows for connectivity and direct links through the use of multiple paths for individuals to engage with the site based on their purpose while creating a vibrant social space that encourages movement through the site. It also allows for a sense of transparency between space and function, removing the intimidation of entering the facility. A large portion driving the design was to create permeability of the natural environment into the building.

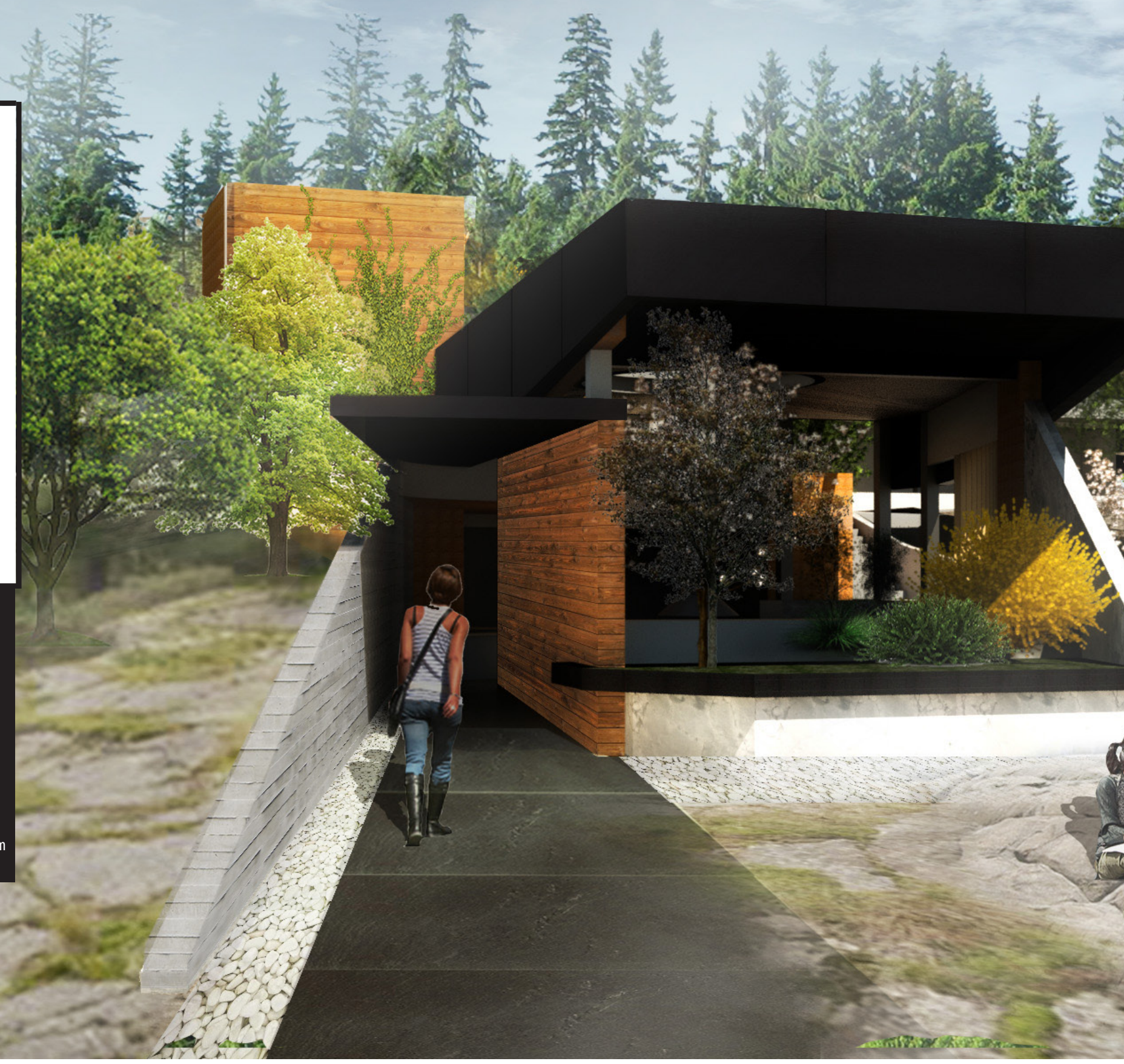




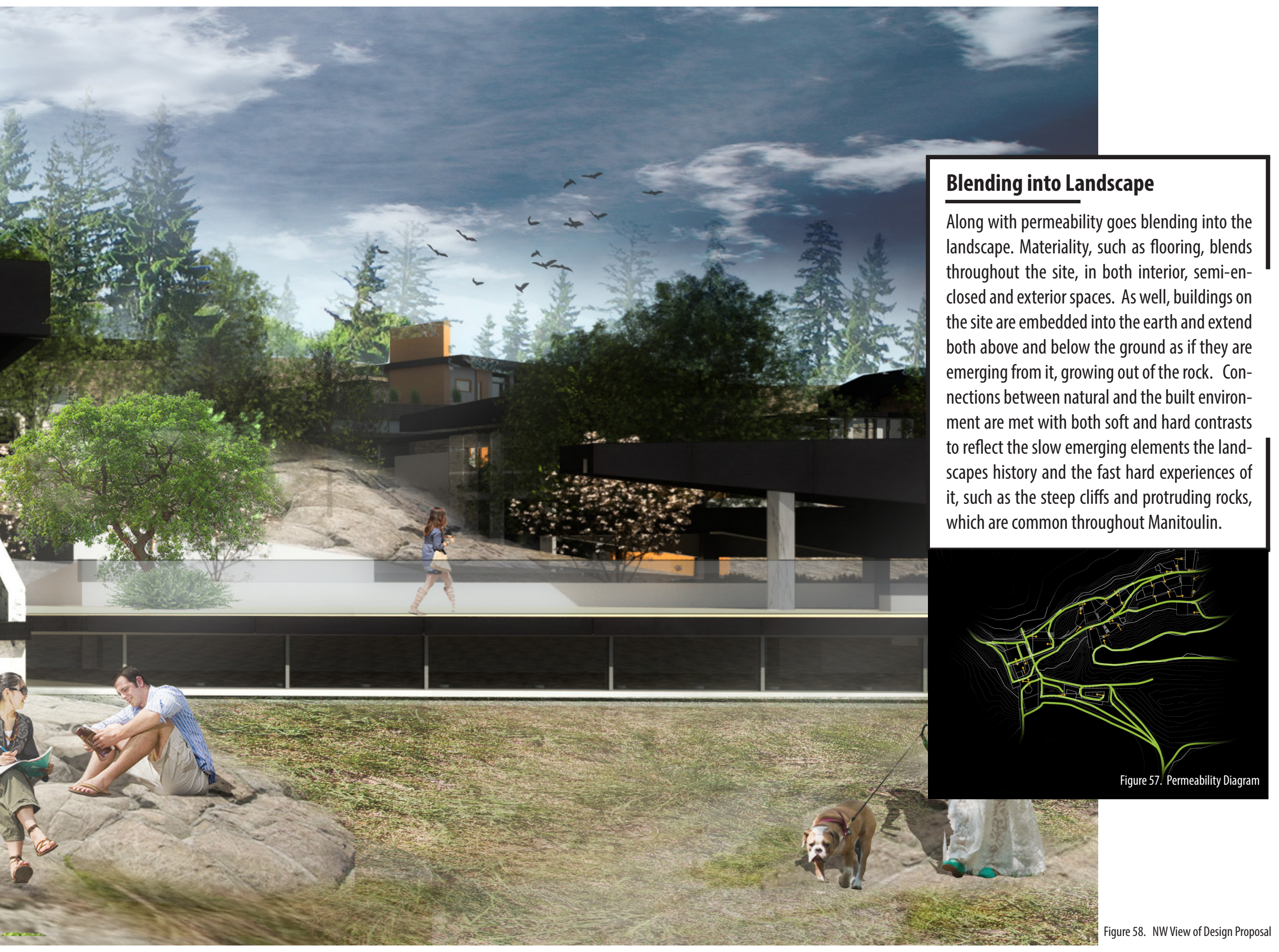


You notice that on the edges of the pathway water is lapping over the stones, toward the direction you are intended to go. This water is a result of the rainfall from the morning, slowly flowing through the site, accumulating in these troughs, directing you into the facility. You lift your head and feel a little more comfortable. To your left you see the activity in the below ground space. To your right you see the power of the rock and forest, abruptly meeting the sloped retaining wall, which follows the topographic of the site as it lifts and falls. Above you the bright blue sky is interrupted by the wood beams from the building which slowly protrude, more and more from the roof plane, directing you forward onto your journey.

\section{Reflecting Place}

Part of blending into landscape is reflecting place. This concept is very important to the Anishinabek culture. Place is a knowledge holder, it is an experiential and vital part of the culture. Therefore, the building attempts to reflect it. Roof planes, walls and floors are designed to rise, fall and protrude from the landscape and other building elements. This is achieved by creating strong angular planes that appear to be floating and emerging from the land. This speaks to the "place" [Manitoulin Island and the Canadian Shield] at a larger scale. The angularity and complexity of the building speaks to place at a more local scale, deriving its form, elevations and angles from the specific landscape and contours of the site. The materials used throughout the building also further reflect elements of place as many are locally sourced and available. These materials include the natural vegetation, white quartzite, wood from the trees removed on site, concrete and armor stone.

Left: Figure 59. View from Ramp to Enter Site/Building Right: Figure 60 . Progression into the Building

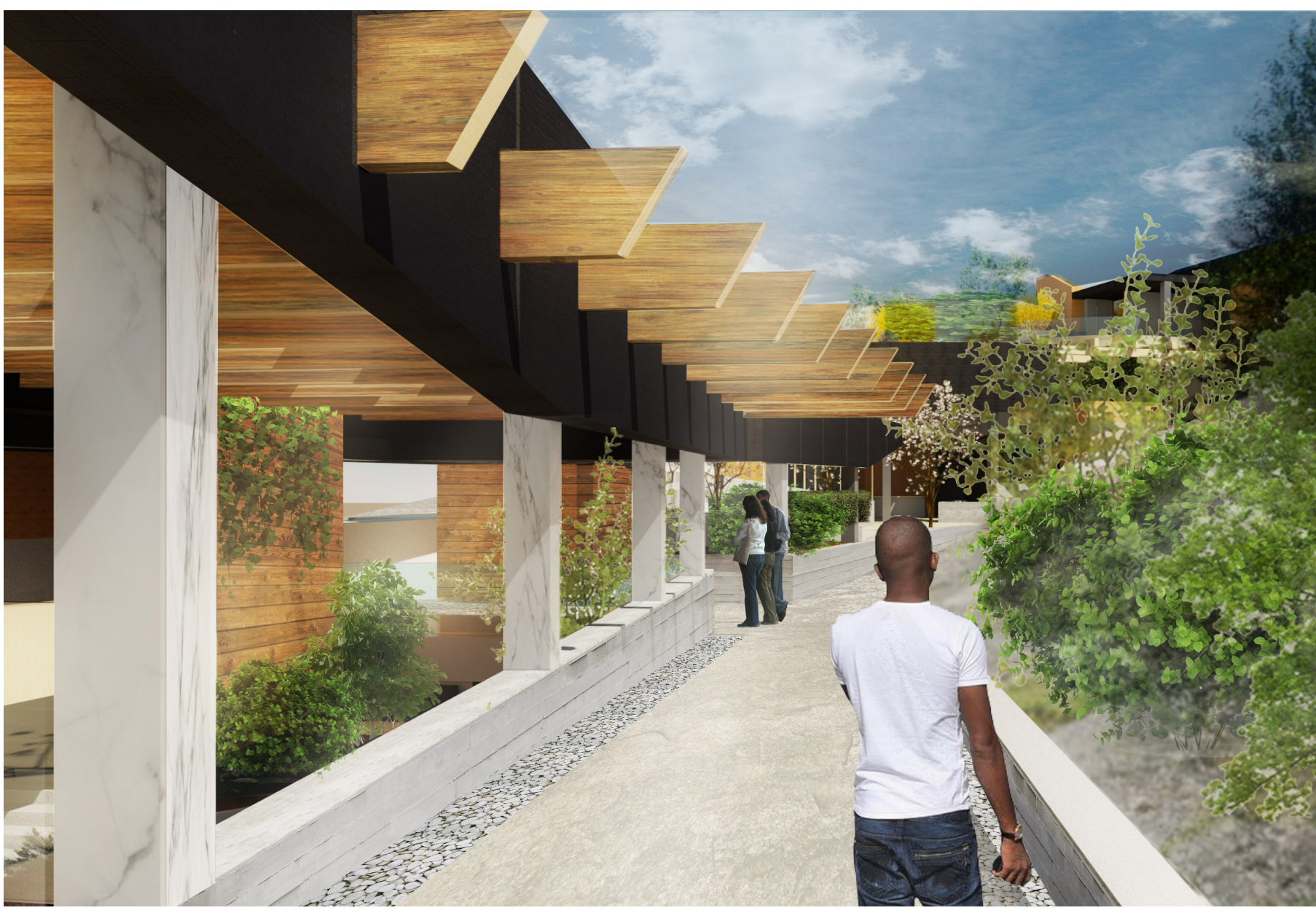



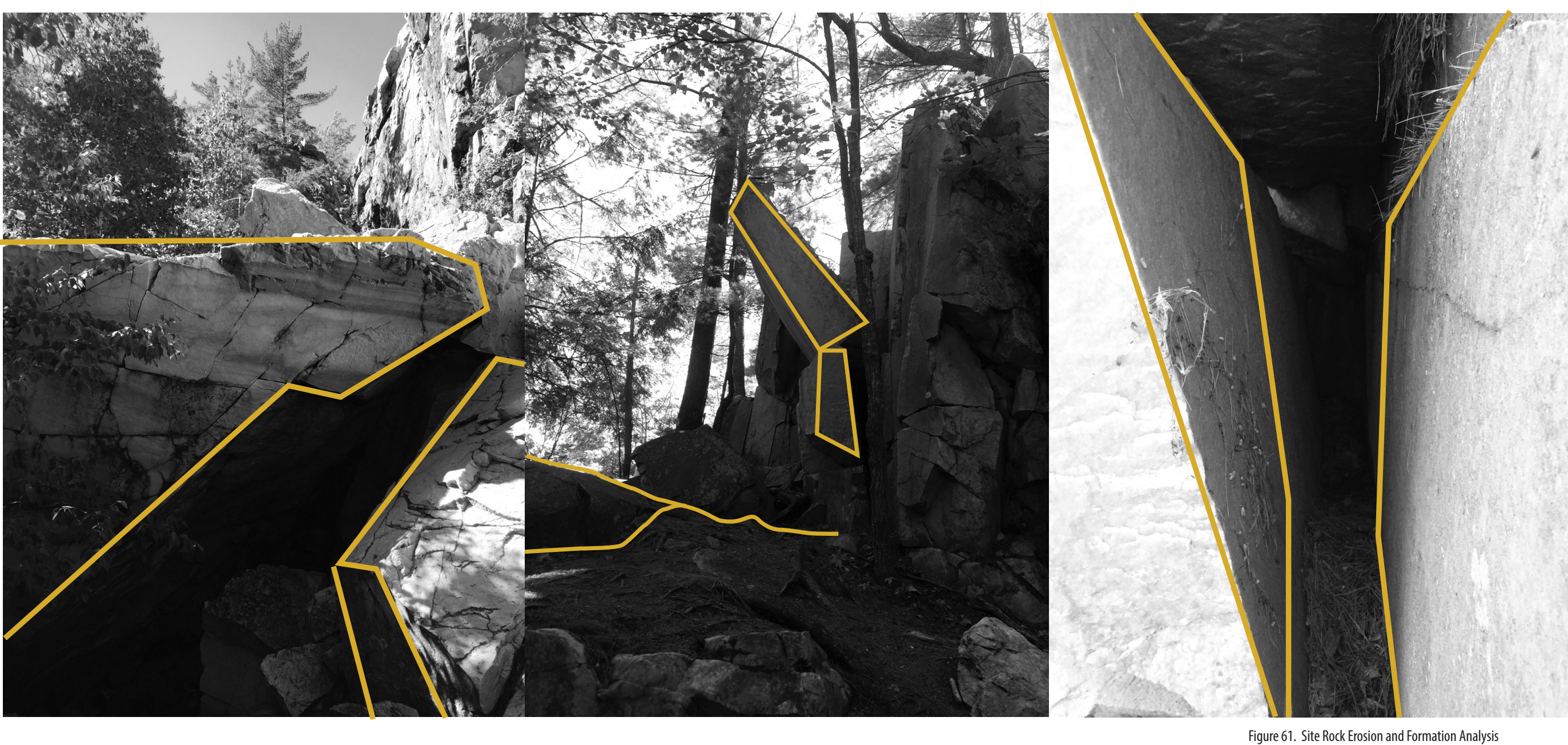


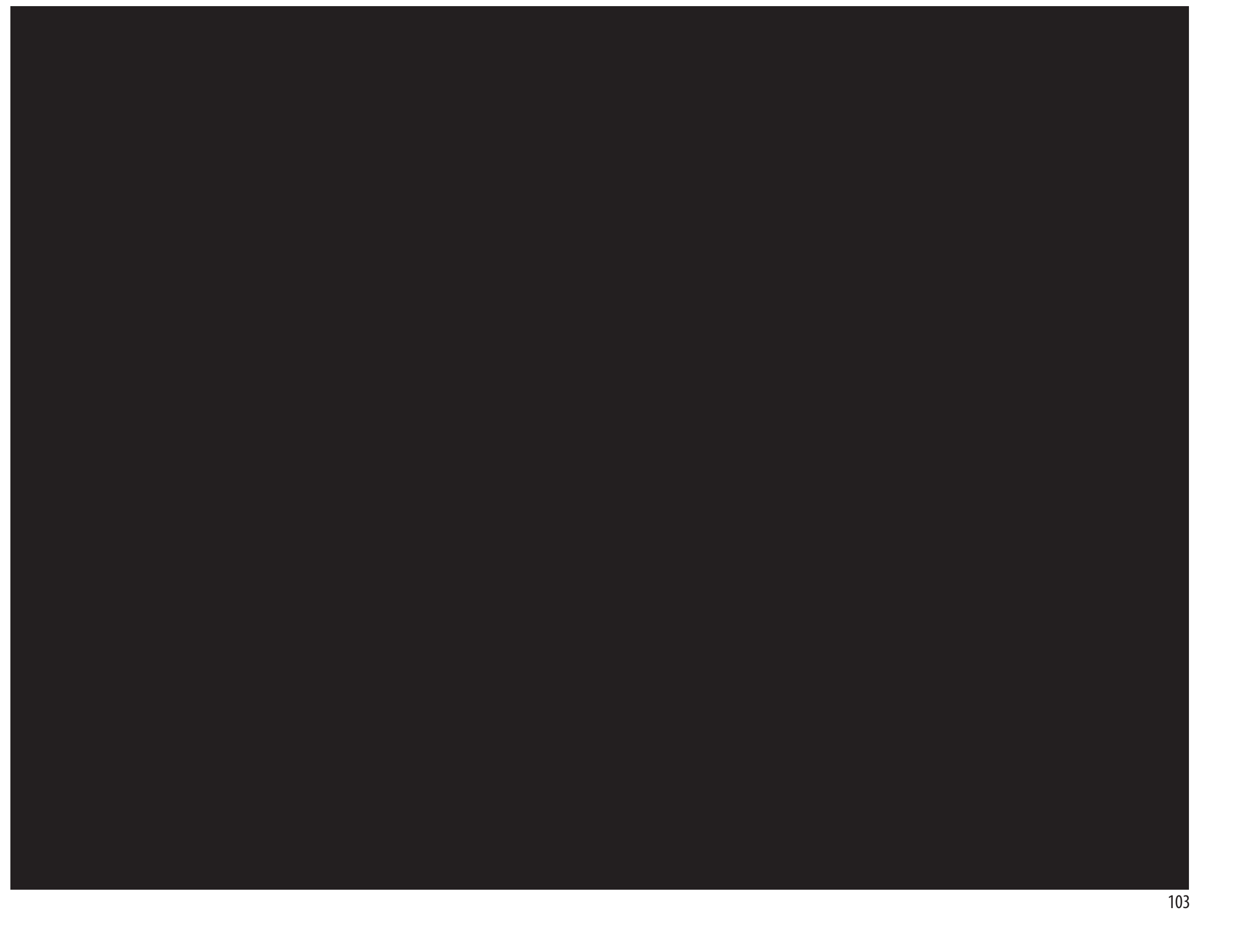


You come to a pause in your journey, where the roof planes of two buildings stop just before touching each other. You look a little further. You notice the water from the morning rainfall is slowly dripping from the roof plane, showing the remnants of the waterfall that was there in the morning. You continue forwards, towards it. You think to yourself, 'Am I inside yet? Have I entered the facility?'

\section{Thresholds}

Thresholds play a multi-faceted role in this thesis. Not only does it contribute to permeability and the concept of blending into the landscape, it also holds a strong component in blurring boundaries between spaces, both interior and exterior and public and private. The intent is to create a gradual transition between interior and exterior which removes these boundaries. By creating a slow progression into the building while still maintaining connections to the weather, the sky, the sun and the rest of the landscape, this transition is soft and slow, versus abrupt and hard. The threshold also represents an in between space. This is drawn from the idea of contrast and dichotomies expressed in the community interviews and meetings. It becomes a prolonged in between space, the "dawn" time of the dav in architectural form is the threshold.

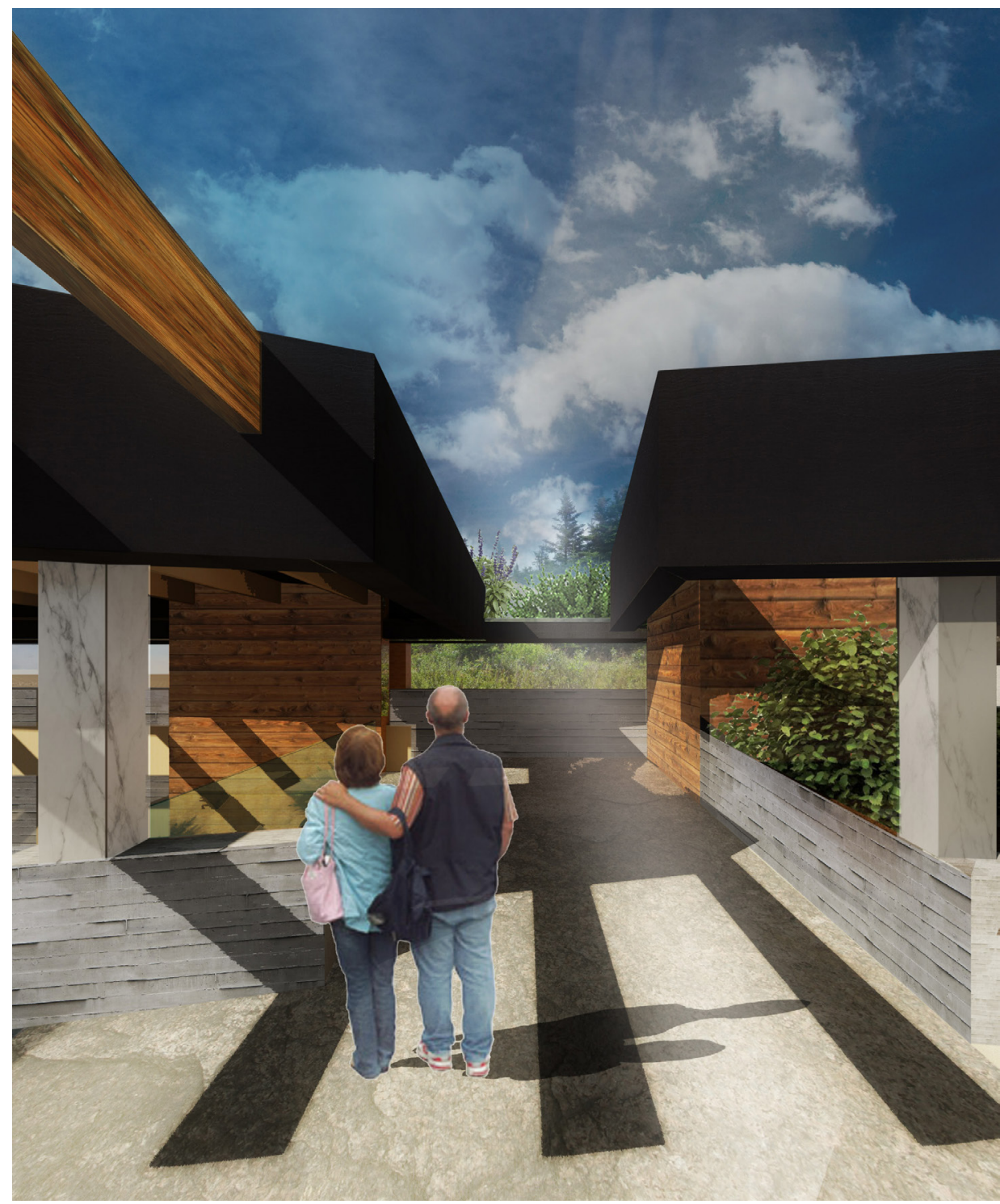

Figure 62. Entering the Building - "In between" 


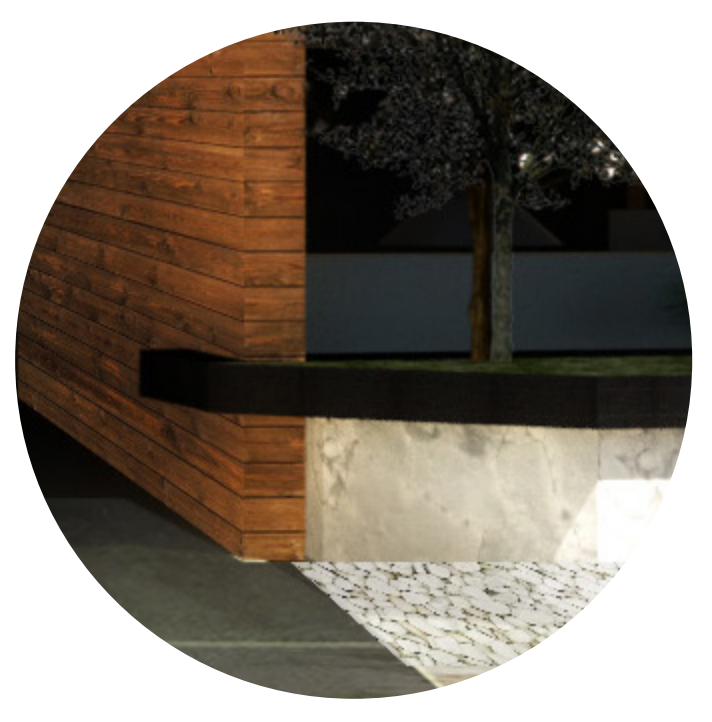

\section{Overlapping Planes + Spaces}

The use of overlapping and emerging planes is to represent the landscape and place and as well as the interwoven aspects of life, healing and relationships. The overlapping and layering of elements in the design also begins to blur the boundaries of interior, exterior, public and private, community space versus residential space. It creates an intermediate space, a third space that is not one or the other but a combination of both.

Figure 63. Overlapping Planes + Spaces

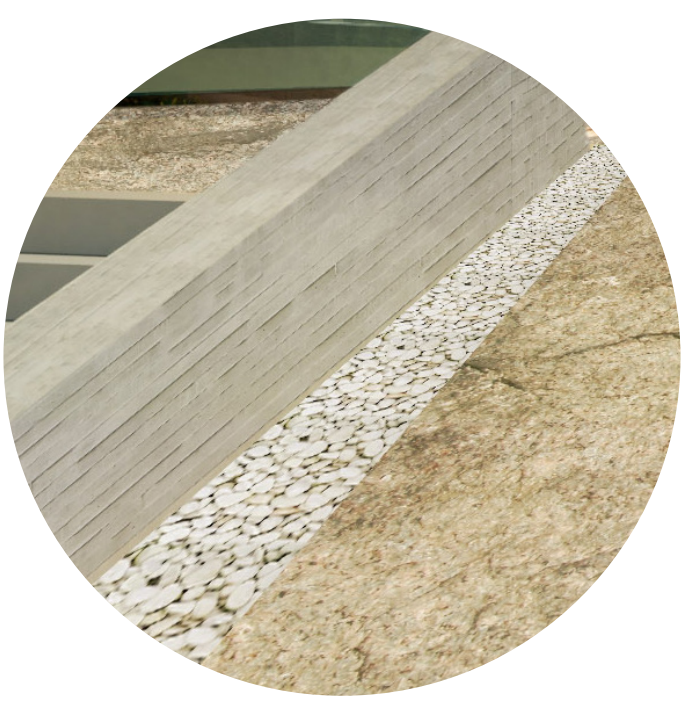

\section{Layers of Time}

Materiality in the project is also meant to represent time and erosion. As weather and activities take place and materials erode they express life and experience, like wrinkles on one's face. The materials chosen, particularly the stone and wood, literally show time and life in the tactility and visual appearance. All natural materials used will be in their natural form, with no polished finishes, in order to show the life and erosion and maintain its tactility.

Figure 64. Layers of Time

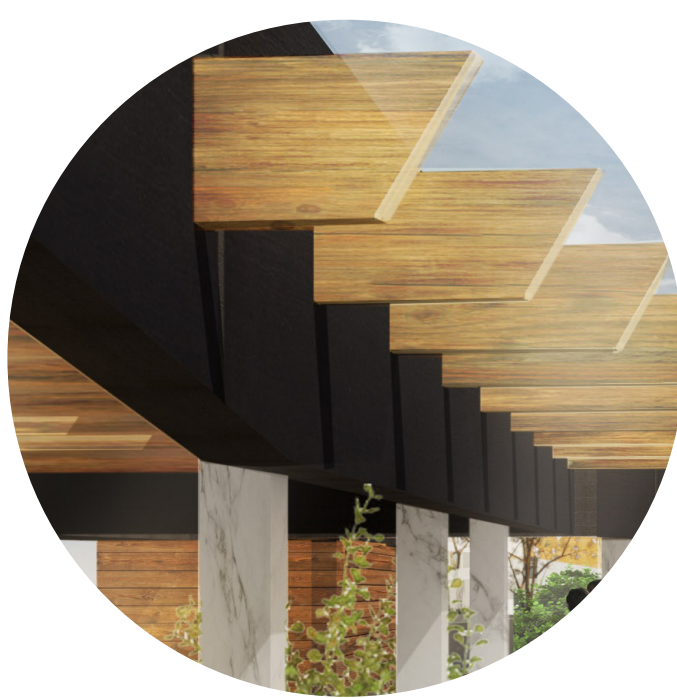

\section{Emerging Elements}

The emerging and protruding elements are used to represent the site, place and to blend different programs and spatial functions, such as interior, exterior, private and public. These elements are detailed to show a smooth but abrupt protrusion through an element, such as the roof joists and the wall, as seen above. The details show a small reveal, a gap, between the roof joist and the wall to give the impression that the joist is protruding out. 


\section{Kinesthetic Engagement}

Currently, in most contemporary architecture, particularly in addiction treatment facilities, movement through space is kept to horizontal and linear experiences. The movement of a body through space is kept static and the opportunity to engage the users in a kinesthetic experience is neglected. This is a tool that not only engages space but also time. The choreography of spaces in relation to the human body can, and should, extend beyond the visual. It must become sensorial and escape the sterile and uniform character of typical contemporary architecture for addiction treatment facilities. Through material tactility, spatial scale, connections to exterior spaces, exposure to elements of weather and the engagement of the body in a dynamic and by engaging the user in multi-leveled spaces this is achieved. However, there is a challenge of maintaining barrier free accessibility in terms of multi-leveled, physically engaging spaces. This was a challenge in the design but was very important to accommodate.

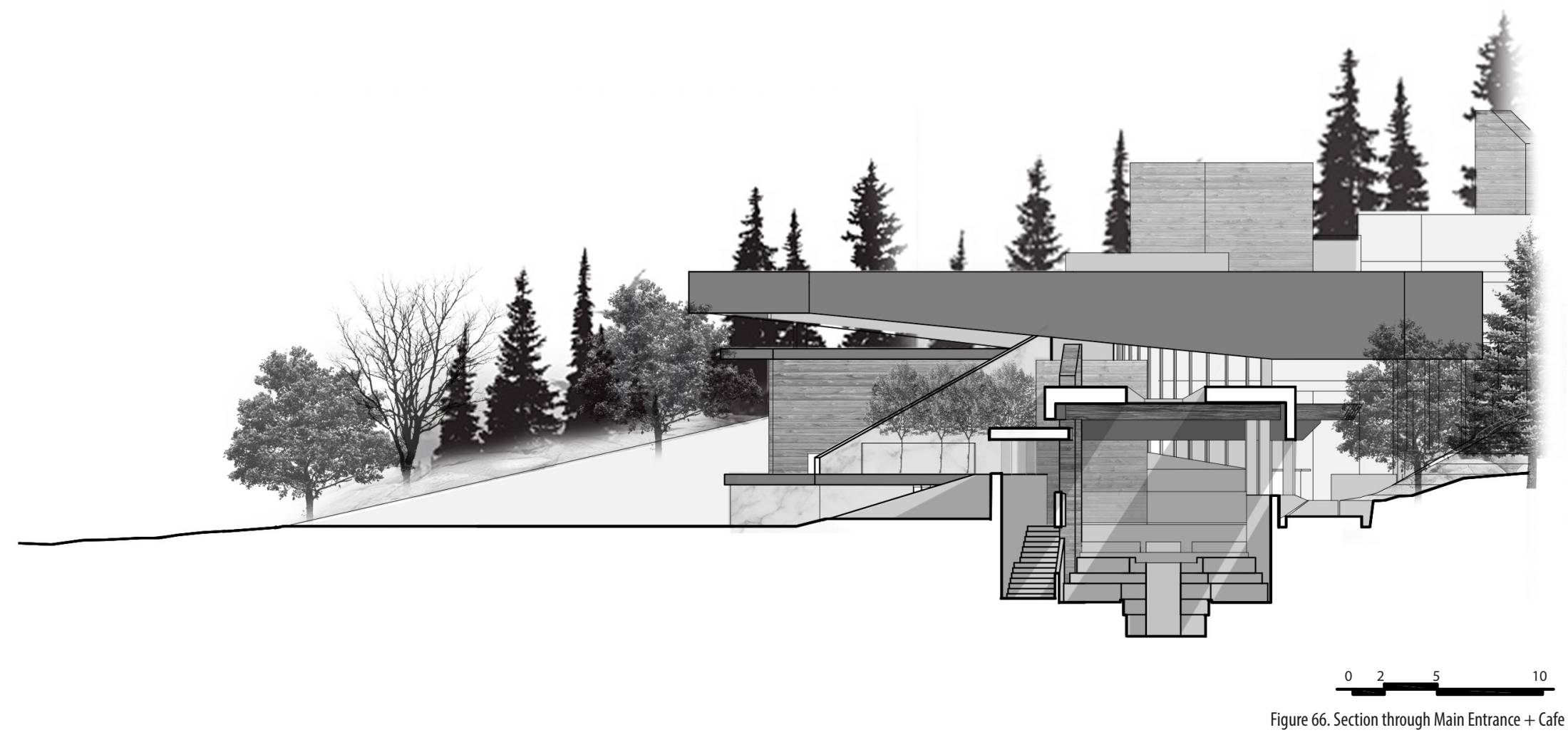




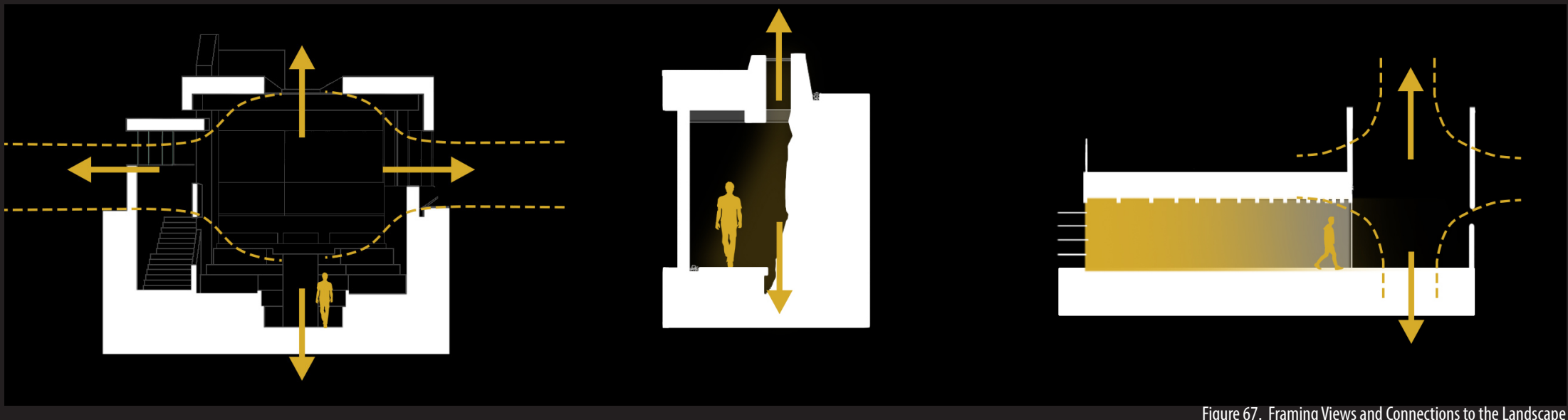

\section{Framing Views}

The tactic of framing views in the design is to amplify certain spaces, provide direction and guidance for the user and to maintain visual, physical and auditory connections to exterior spaces. The placement of openings on solid walls versus floor to ceiling glass walls/no wall was decided based on these design intentions. They were also used to promote movement through space or promote sedentary spaces, creating pauses in one's journey. Smaller punched windows were used as a guiding element to move people through space. Though this may cause a pause in one's progression through the design, it encourages moments of contemplation and quick reflection on one's journey. Framed views with large and expansive openings, liberates the space from the definition of solid walls and are meant to be point in the experience for a longer pause and relaxation. 


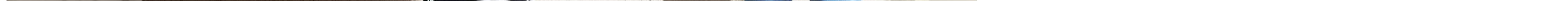


You're down, embedded in the earth. Your anxiety peaks for a second but then subsides as you look up to the sky, the light, the sun, acting as your guide through the building. You follow its direction, which leads your eyes to a small, tight corridor, illuminated with soft light at the end of it. As you approach it, you run your hands along the wall, the bumps, the ridges and

all of the energy of the tiered planter walls, pulsing through your fingertips. Your family is behind you, as you are unable to walk side by side down the corridor. You are getting closer and tighter. You are more aware of your space, the rhythm of the light and shadow in your journey. You are alone with yourself, your body, only for a moment, looking forward to the light of

your recovery, of your future.

\section{Light + Shadow +Rhythm}

The sun, and one's connection to it, plays and important role in the design. It gives direction, references location and time of day. Through light and shadow, rhythm is used to create different speeds of movement through space. Hard shadows are used to promote a faster movement and softer shadows used to promote pause, thought and reflection. It also allows for the lowering of demand on artificial lighting, therefore, the natural cycles of the earth determine the qualities and activities of space.

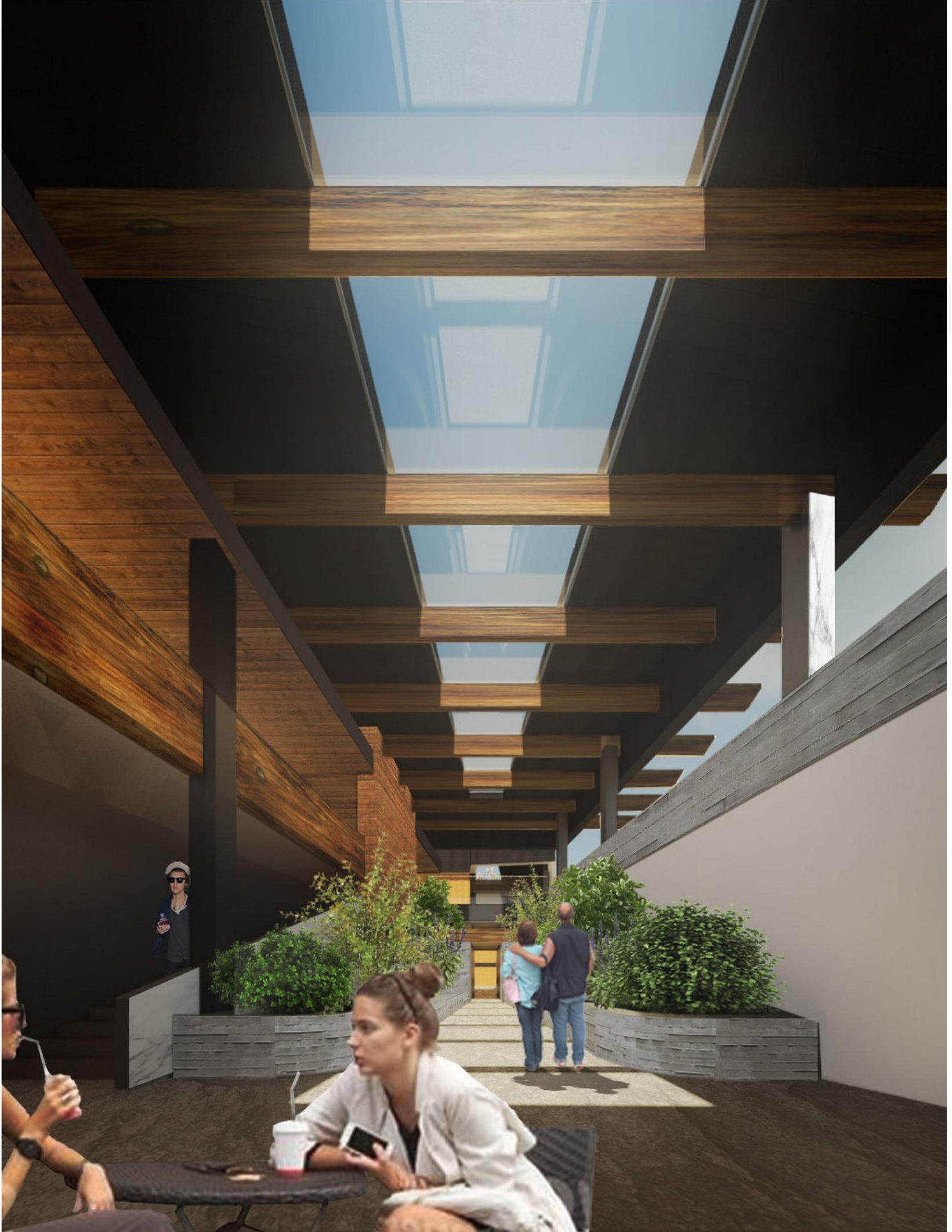


You arrive at the end of the corridor and the ceiling opens up to the sky; you are liberated by the blue sky above you, sound of the birds, drips of water and the soft breeze grazing your skin. You look forward and see a slice of human activity. As you peer into the next space, a soft spoken receptionist ushers you in to administrative space where you meet your counsellor, fill out forms and go through the intake process. Once this process is complete, you are brought by your counsellor to your new "home." You smirk at yourself..." this will not by my home."

\section{Embedding into the Earth}

Embedding the building into the ground is done to connect with the earth. This is why the building is one level partially below grade, creating a solid surrounding and a new horizon for the users. The sky, sun and the light become very important referencing elements, connecting the user with the ground plane and the sky. The stimulation of being below ground in an enclosed and more confined space, as one's depth and perception of space is restricted, heightens one's senses and awareness of their surroundings. This amplifies the users connection between earth and sky and reground them with the 5th and 6 th dimensions of the medicine wheel.

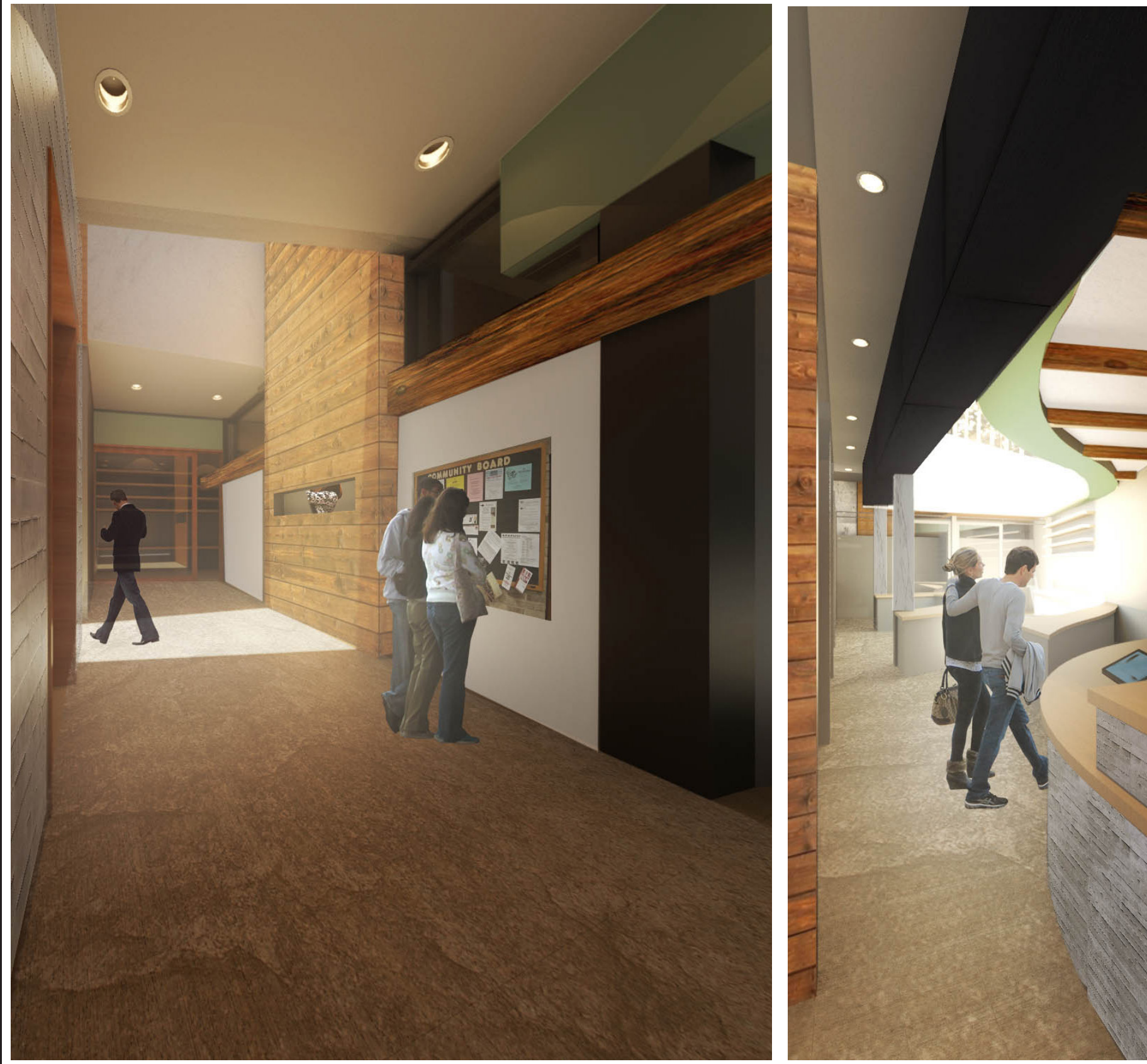



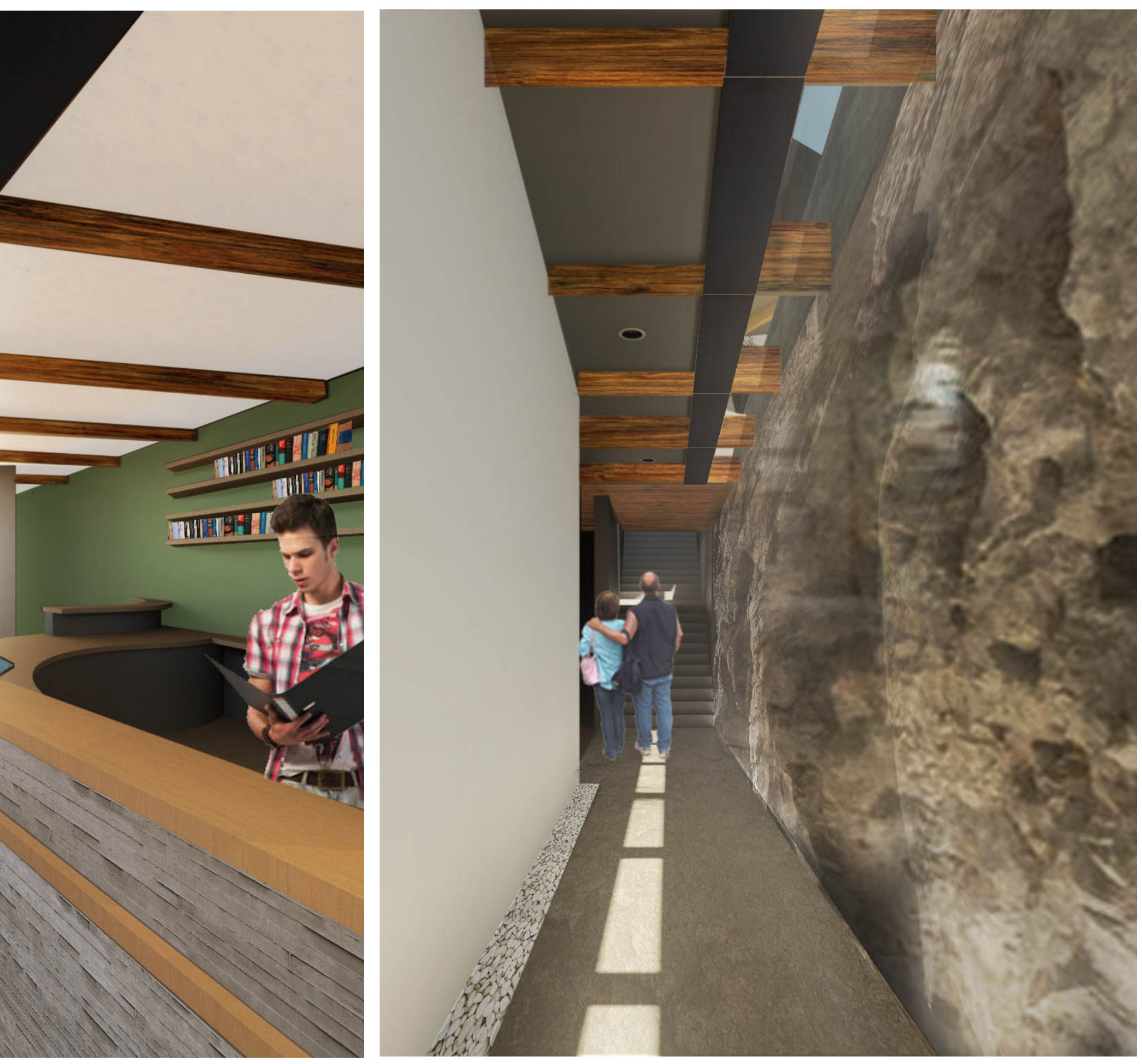

You are brought into another tight corridor... you really are doing this. Once again, you are forced to walk in single file, one after the other. This gives you a moment to focus, with little distractions. Your vision is restricted, but your hand is drawn to the exposed bedrock, you feel the coolness of the air crisp against your skin and hear the sound of the trees swaying in the wind. You build a sense of awareness of yourself and your environment

\section{Scales of Space}

Scale of space is used to restrict the users horizontal visibility and heighten other senses in particular spaces, such as the transition between the café to the administration reception and offices or from the administration offices to the semi enclosed atrium space. The scale is small, tight and visually restricted. This is to control the users experience and emotions and reduce stimuli during the most anxious transition through these spaces. In these spaces tactility is increase split connections to the sky and nature are amplified and rhythm and movement are encouraged. The designs goal is to ease the user from one stage to the next and contribute to the overall process of their healing and transition back into the community.

\section{Figure 70. Intake + Administration Reception}

Figure 71. Administrative Office

Figure 72. Transition to Atrium/Gymnasium 


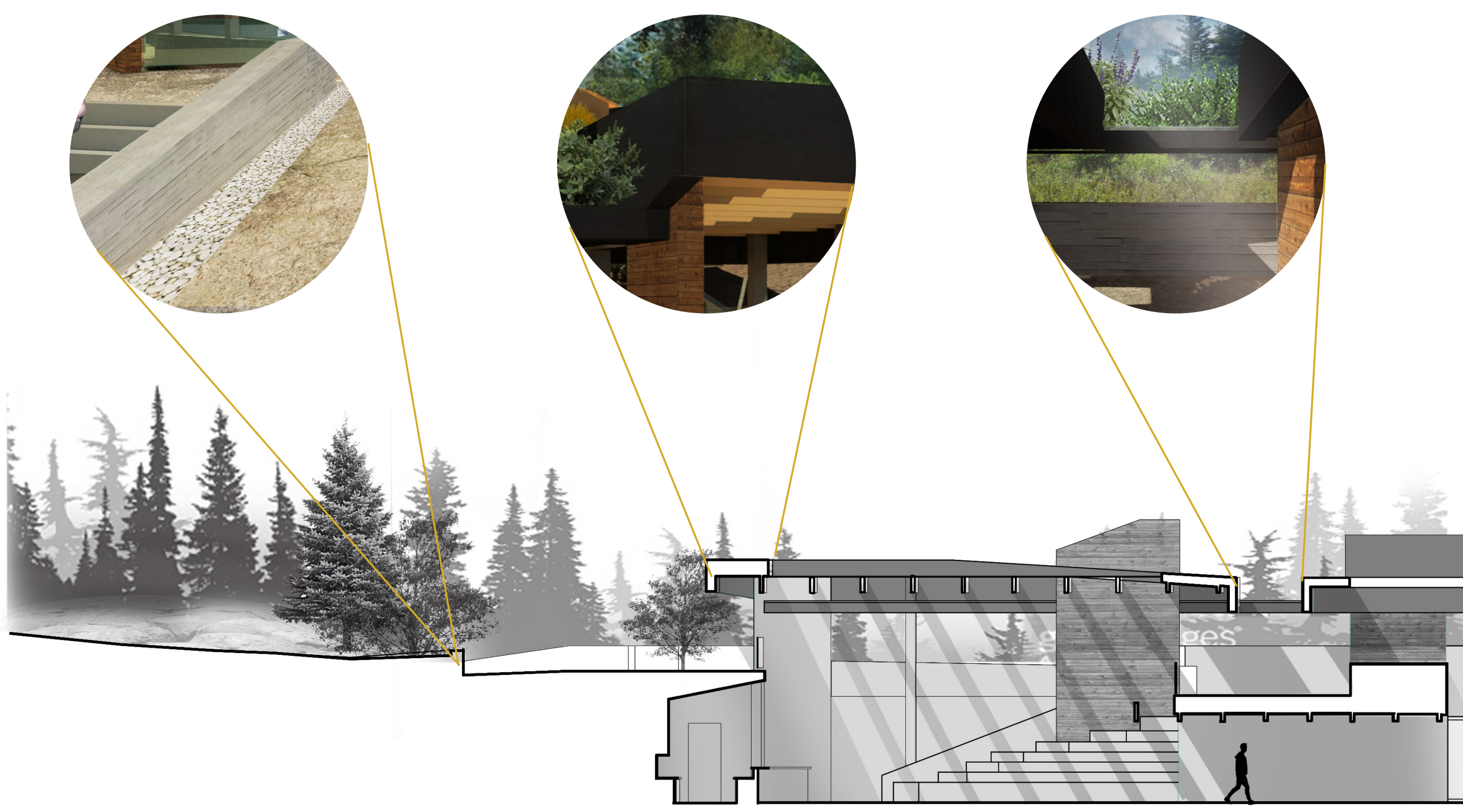




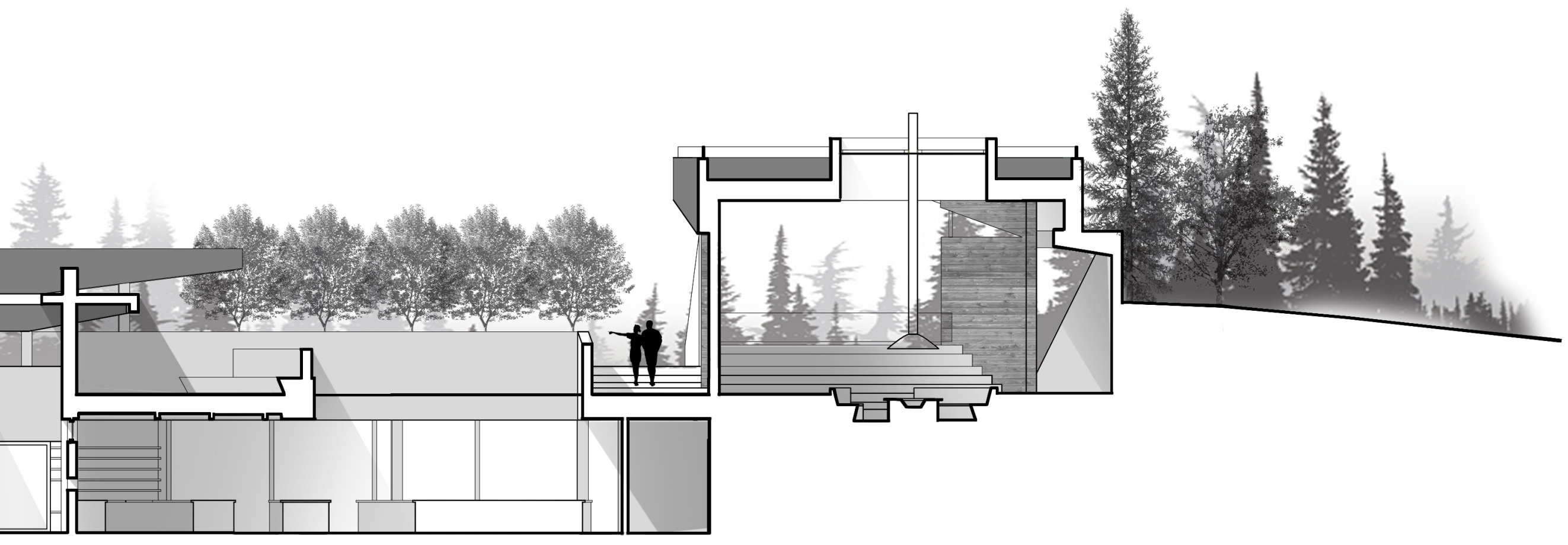

Figure 73. Longitudinal Section of Administrative Space + Atrium - Summer 

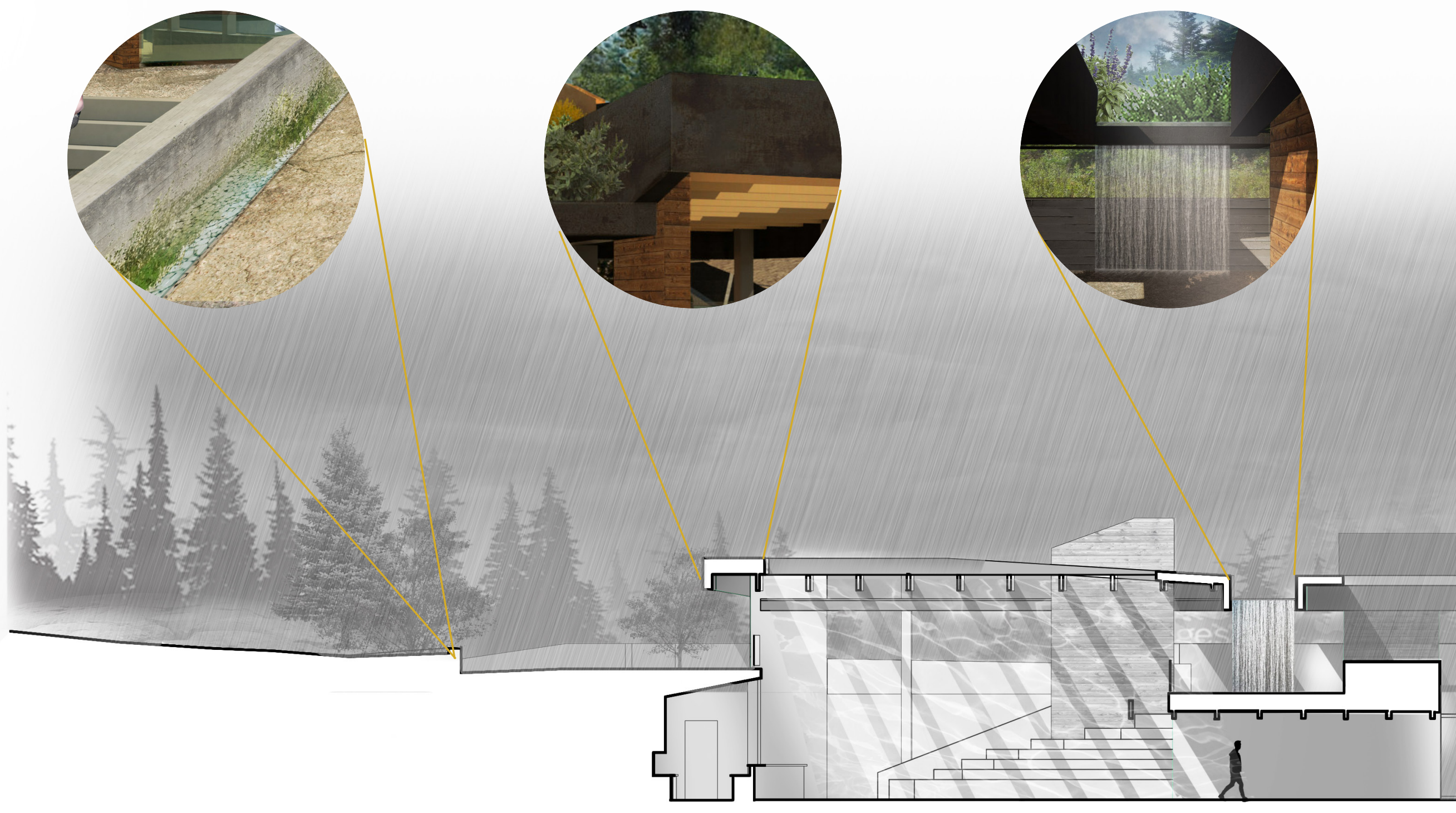


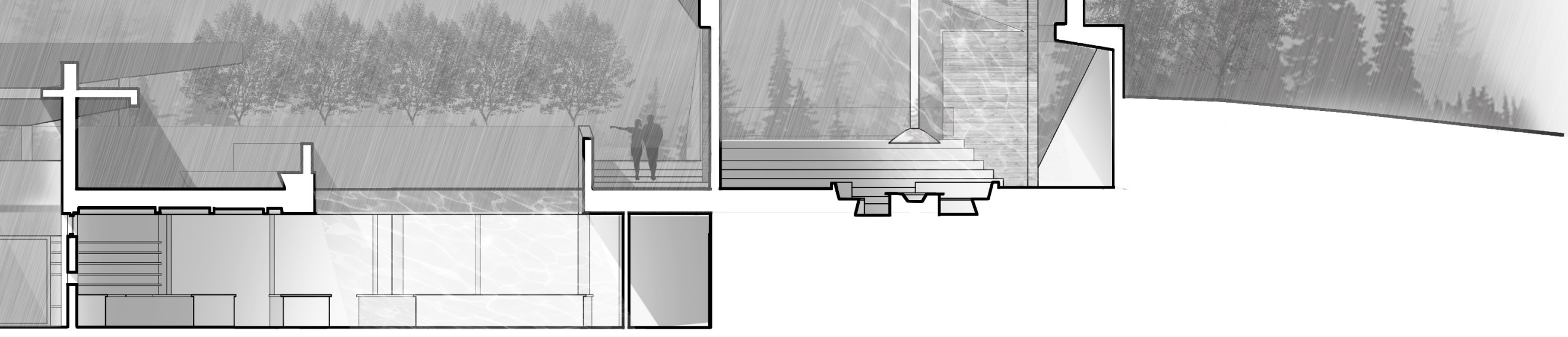

igure 74. Longitudinal Section of Administrative Space + Atrium - Rainfall 


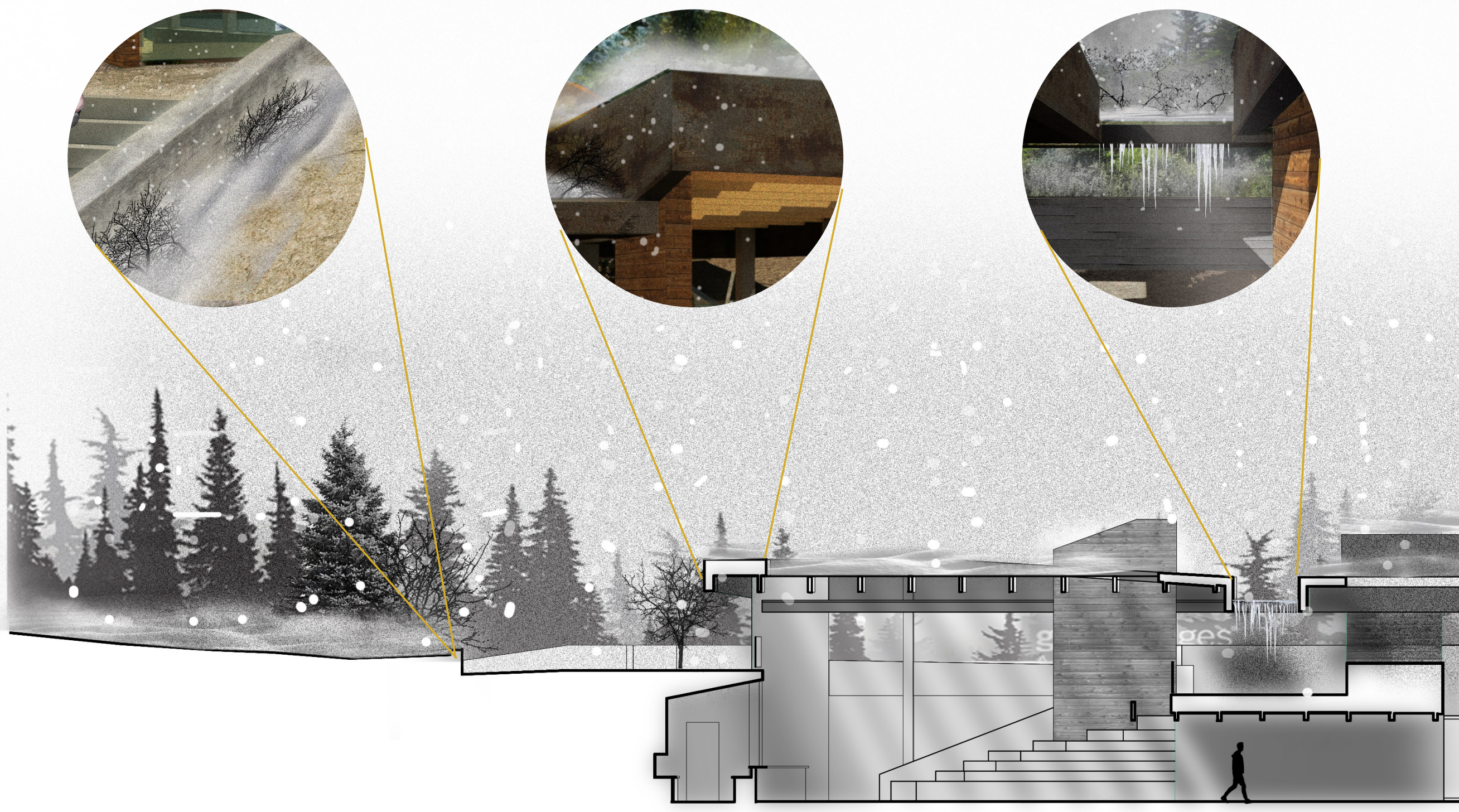




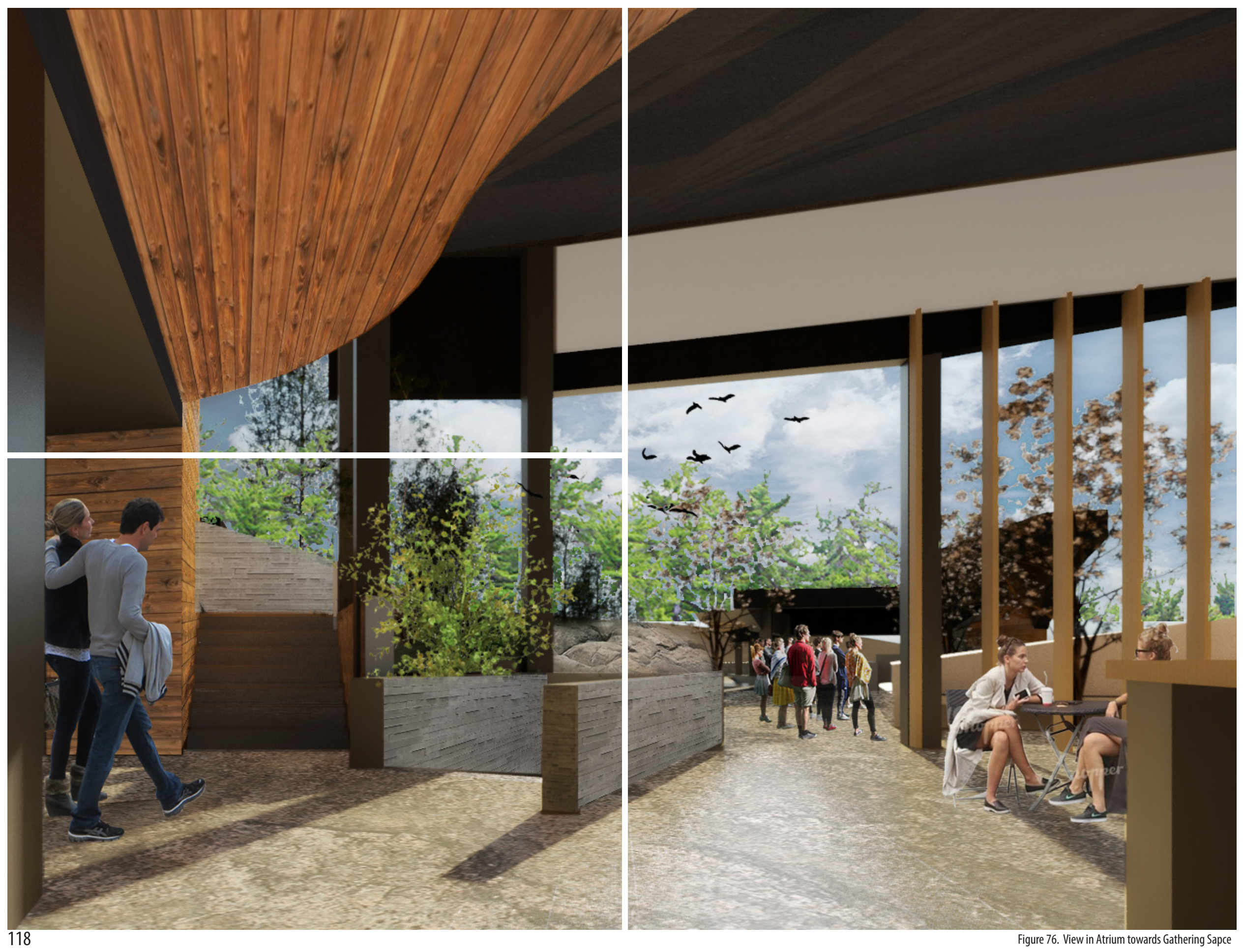


As your journey continues down the corridor, you ascend upstairs and pop up above the ground. But you still don't know... are you outside? Or are you inside? At first, you are not sure where you are. Yet, the space is flourishing with life. People are circulating through, in and out of the spaces. Once again, you feel the strong breeze cooling your skin but now you also feel the rays of sun heating it. The ground seems slightly wet. 'Was it from the rainfall this morning?" You see a group gathering by a large fire pit that protrudes and extends to the sky. You then are distracted from that, as you hear the sounds of cheering and the squeaking of running shoes. A intramural community basketball game is in process in the gymnasium. You are then distracted again by the beauty of the indigenous art exhibit that fluidly spreads throughout the spaces, intertwining with different activities and climbing up the tiered steps towards the forest. Your counsellor tells you that you must to continue with your journey to your room, but in the back of your mind you are excited to return and explore. 


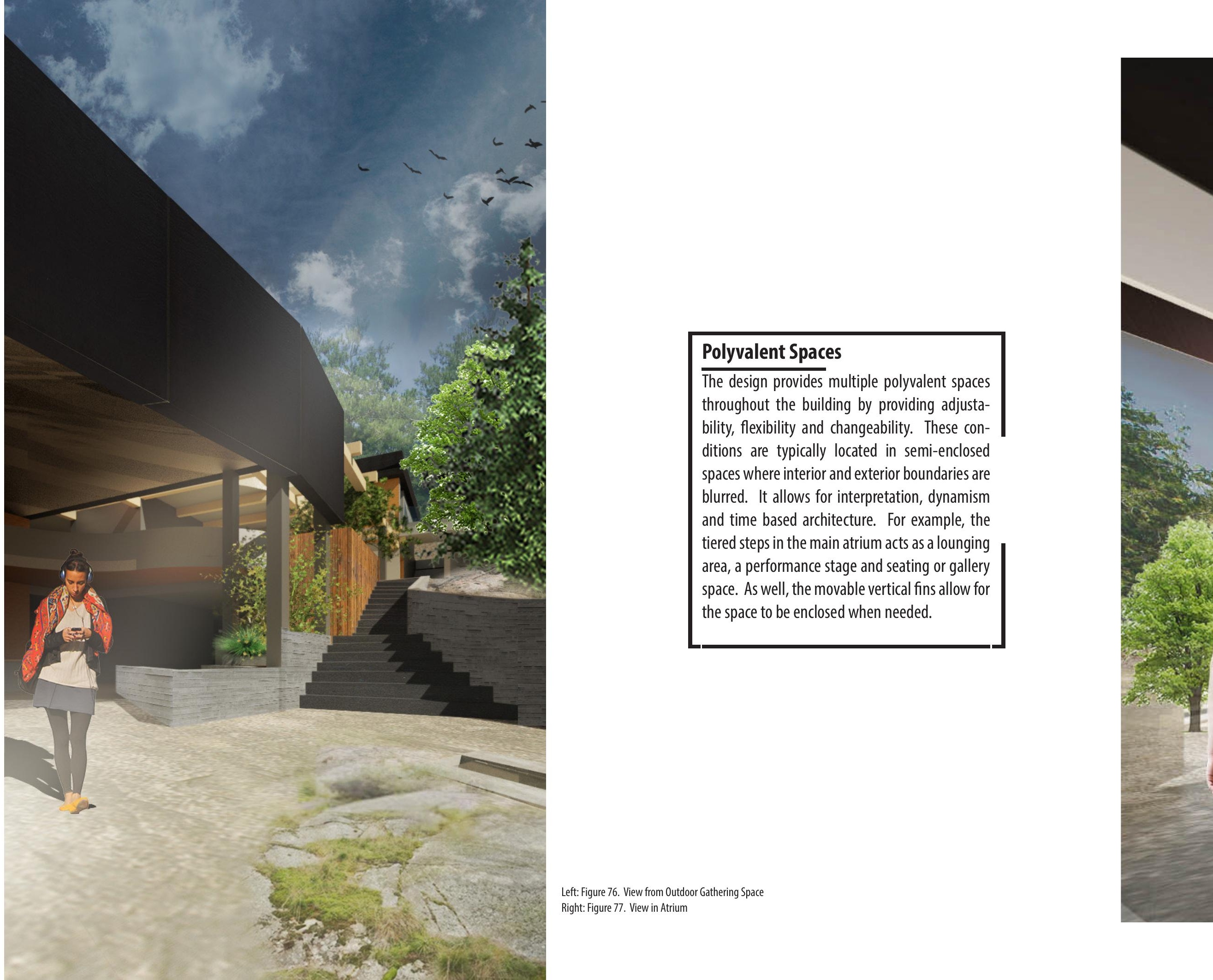




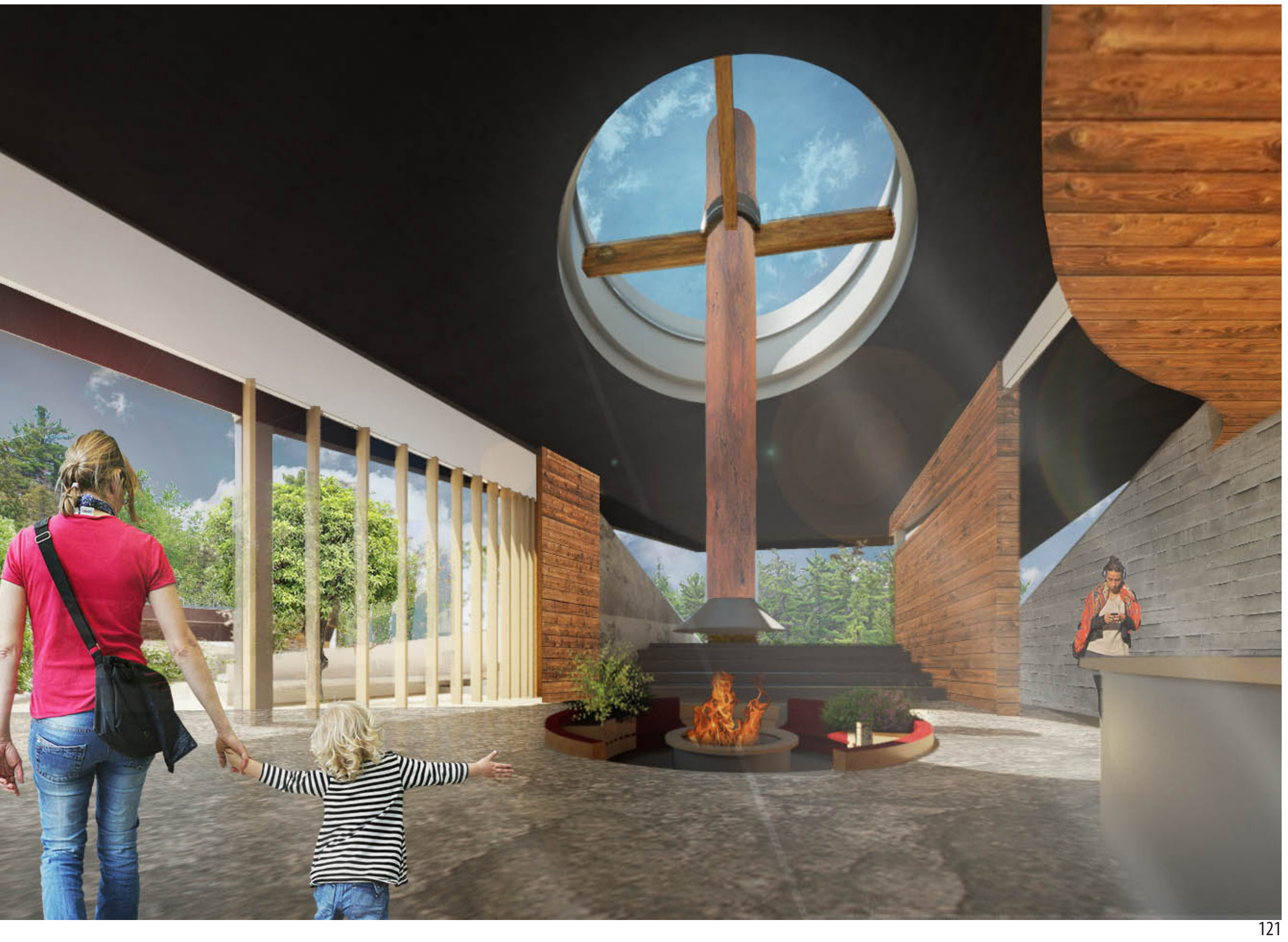




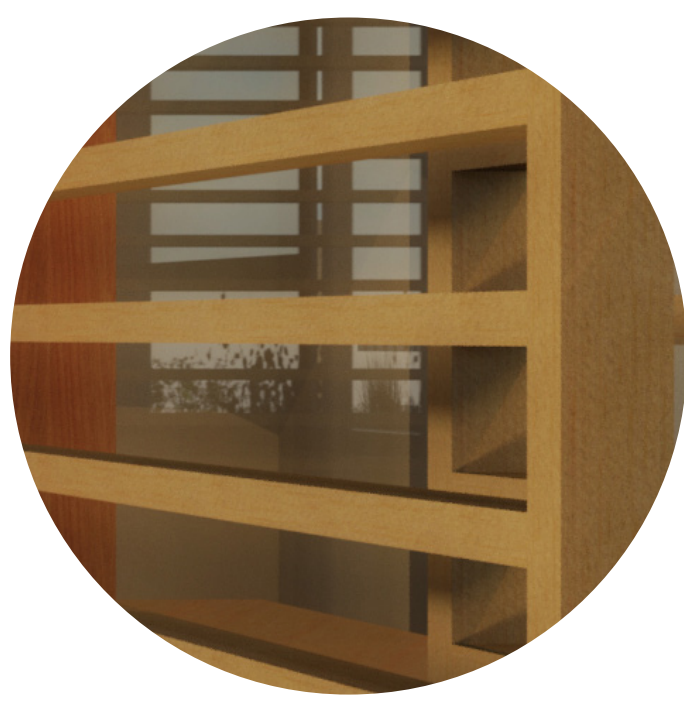

\section{Interactive Elements}

The incorporation of interactive elements into the design, gives the user agency. They are able to alter and manipulate their space based on their own needs and desires. One of these elements includes the interactive screens in the bedroom spaces. These are typically the spaces where hard divisions between public and private functions are drawn. By incorporating adjustable wood screen sliding doors with louvres that can control the transparency of the space, this allows for individuals to determine their own personal space while providing the opportunity to have different degrees of separation. Complete physical transparency between spaces would restrict one's ability to have personal time and to conduct private activities, such as changing clothes. The screens also provide a sense of control and ownership to individuals who, typically would be in an environment that restricts their freedoms.

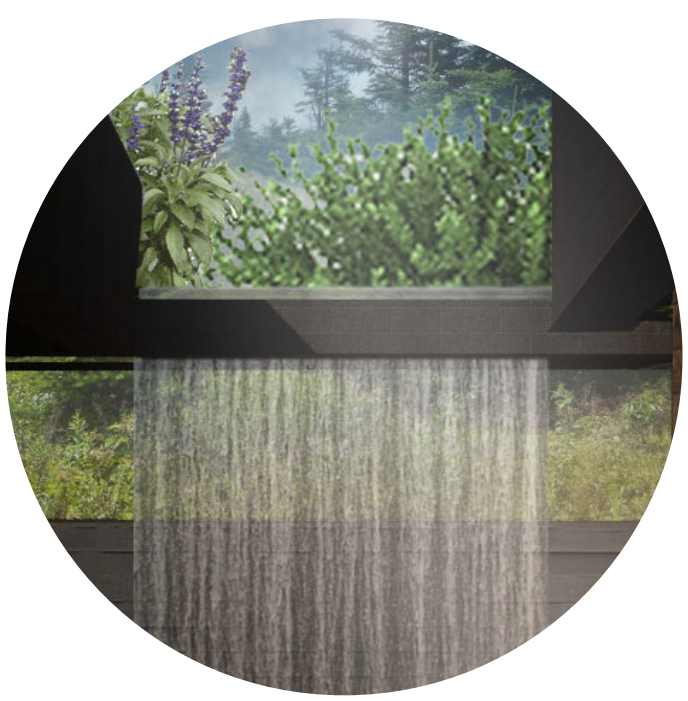

\section{Ecological Features}

Amplifying elements of ecology and weather is a tactic used to display the climatic and ecological systems through the building. The building then becomes part of these processes. There are two kinds of engagement with this concept. This first is the active engagement with features, where weather, particularly, rain, is collected on the site and funneled to create rain gardens and pools on the edges of the walkway, water fall or pool features, which gather from the roofs to create water features that pour from the building. The second is a more passive engagement, one that amplifies the natural fall, gravity and flow of the ecological processes. This includes the collection of rain, snow or sun on skylight planes, where the conditions of the exterior are directly reflected onto interior spaces through light, shadow and movement of the weather conditions. Another tactic considered was how water, snow or a sun ray cascades and falls on different materials, where certain materials create depth, shadow and rugged interactions and some create smooth, reflectivity and soft interactions with these elements.

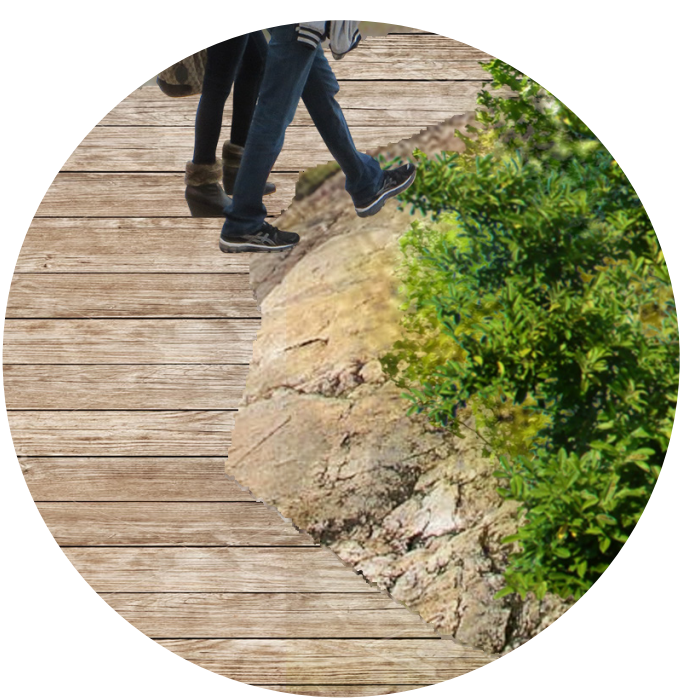

Extending the Landscape

The extension of the landscape is used to blur boundaries between interior and exterior and to bond both the landscape with the building. This is done through elements such as the boardwalk. The stone that emerges from the earth on the site sets the boundary for how the boardwalk curves and meets it. The wood planks are kept at one consistent level and would seep away into the stone, meeting it and ending at its presence. The stone on the boardwalk would consist, overtime, of weathered grey-beige wood finish that compliments the natural stone. This tactic is also done when ramps slowly emerge from the earth. The boundaries between each element are smooth, soft and the transition is slow. This is done to juxtapose the moments in the design where elements abruptly emerge and protrude from the earth. The dichotomy between these two strategies speaks to the natural landscape and erosion process, where rock emerge slowly and gradually overtime and where the abrupt collision of the earth plates create sharp protrusion from the landscape. 


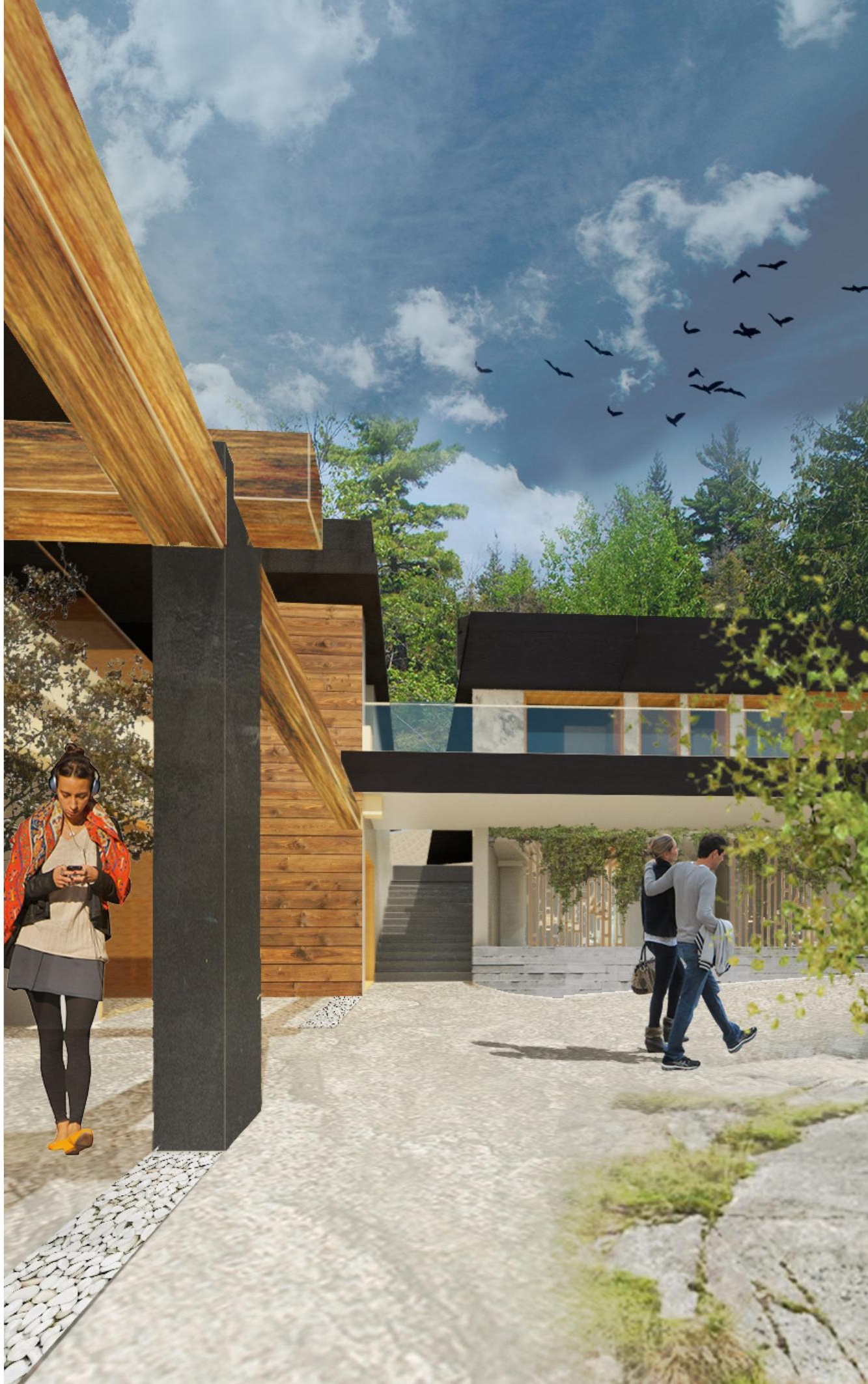

\section{Amplify Elements + Weather}

Operable windows and non-confined, semi-enclosed spaces allow for wind and air to flow through the building. The element of fire is incorporated into gathering spaces and water elements from rain water run-off systems that collect water into pebble troughs and direct the water features throughout the site and towards the pond. Skylights collect water to create water features and allow the light to penetrate below and create the shadow of dancing water onto interior spaces.

Left: Figure 79-81. Zoomed in Details by Author Right: Figure 82. Level Two Management Office Leve 


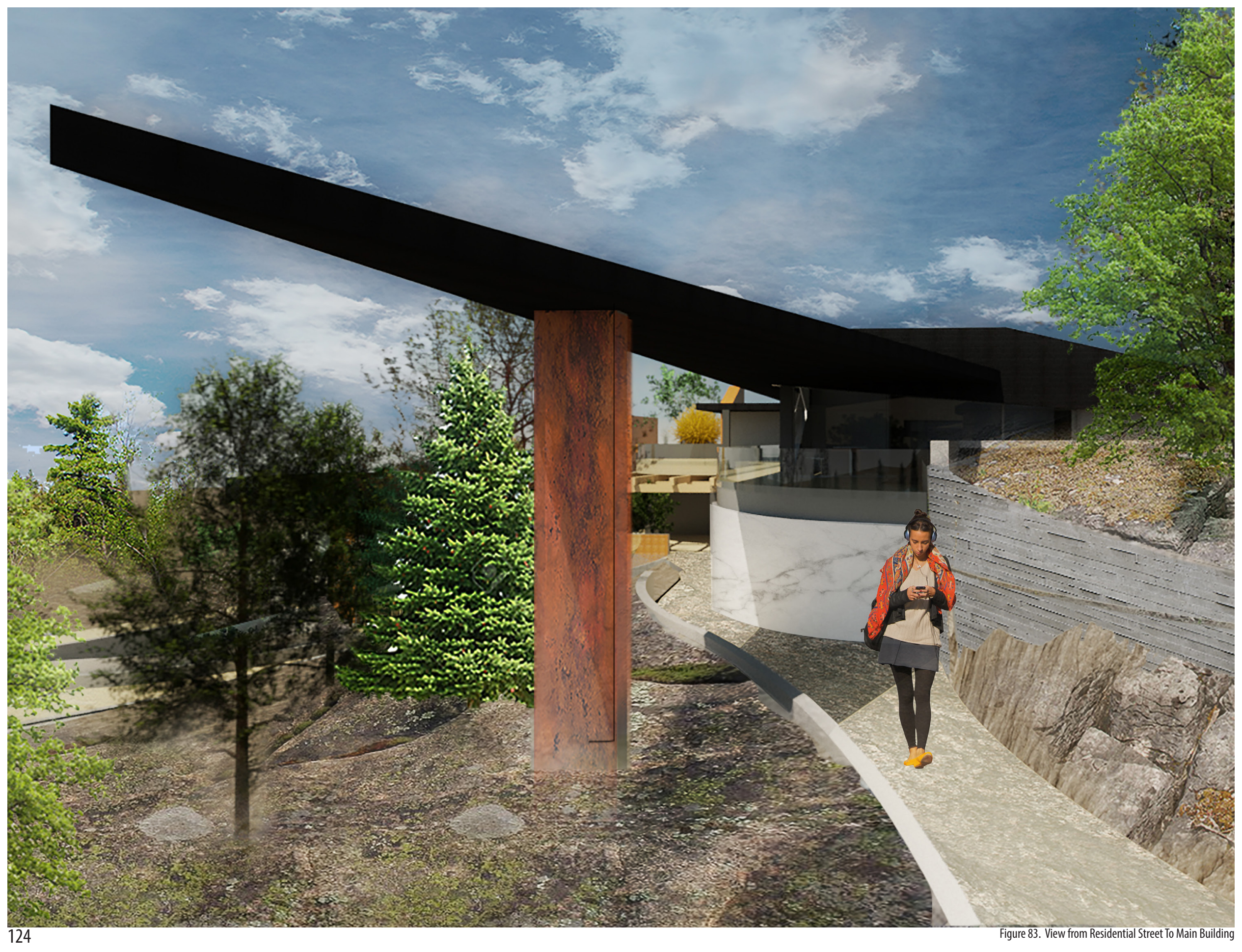



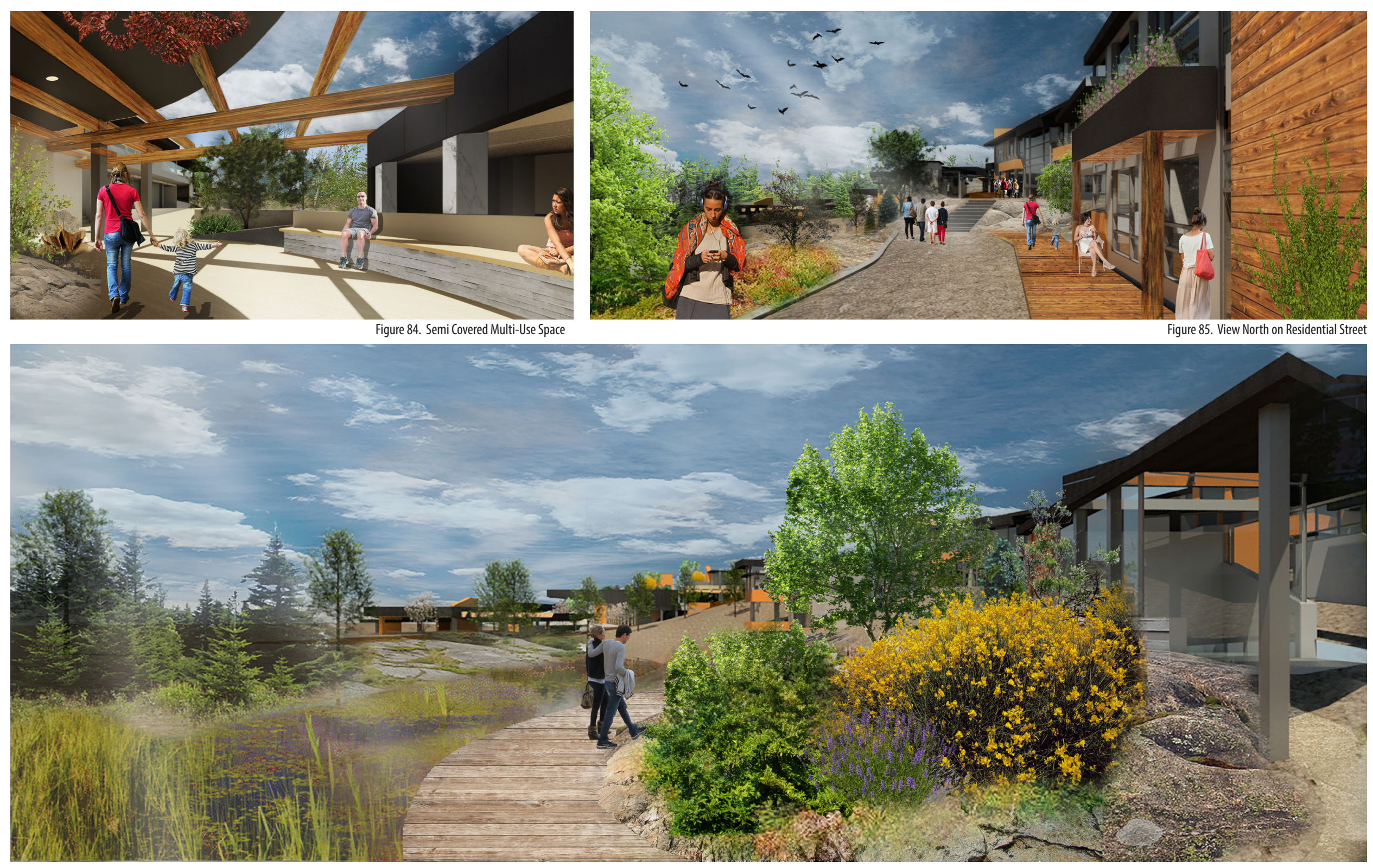


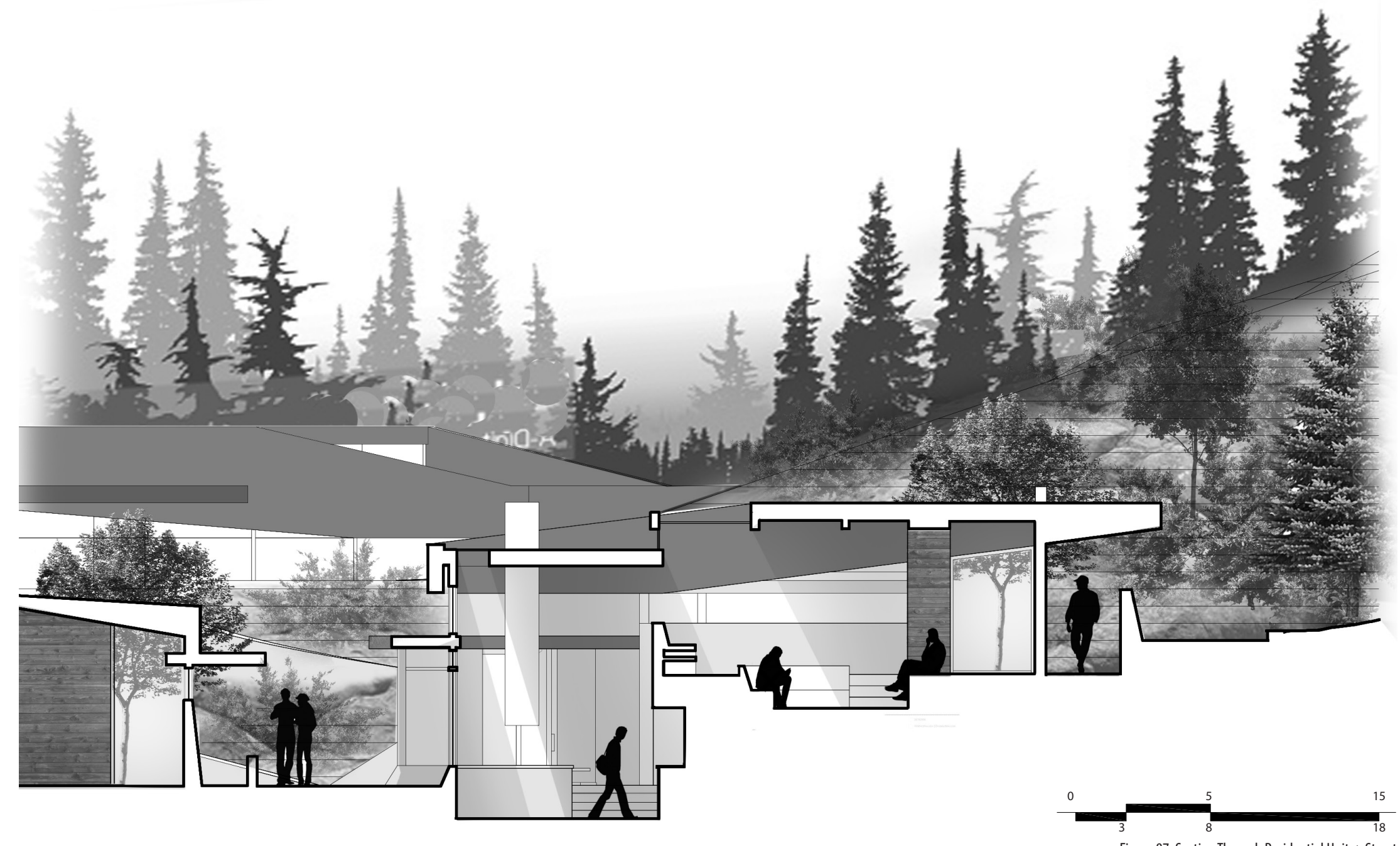

Figure 87. Section Through Residential Unit + Street

\section{Decentralization}

The facility is designed to decentralize the program. Programs and spaces are separated into multiple buildings which spread throughout the site. This tactic causes users to travel between both interior and exterior spaces, making the site and building pedestrian friendly as it designed at a human scale. It creates a new dimension to health and community centres that engage users in a more social and interactive dynamic, rejuvenating the public realm. It also creates a network of streets and permeable buildings that connect to the existing facilities on the site, surrounding neighborhoods and buildings and to the existing hiking path network throughout Manitoulin Island. 
$\Theta$ Residential Street Plan

Main Residential Entrance

Residential Common Space

Street

Aftercare Offices

Community Space (ie. Art)

Aftercare Porch

Boardwalk

Marsh-Pond

Gathering Space

Green House/Gardening Shed

Residentiał Wing , s.t.

Staff Office + Room

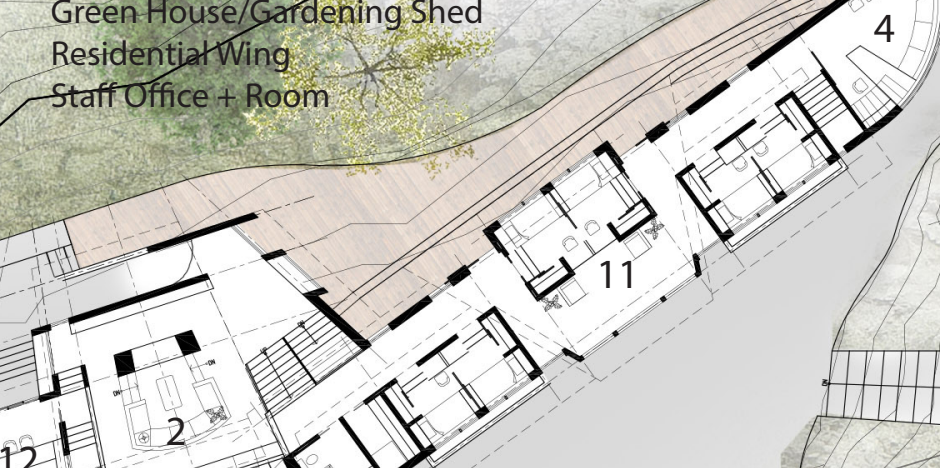

드래

(3)

101 


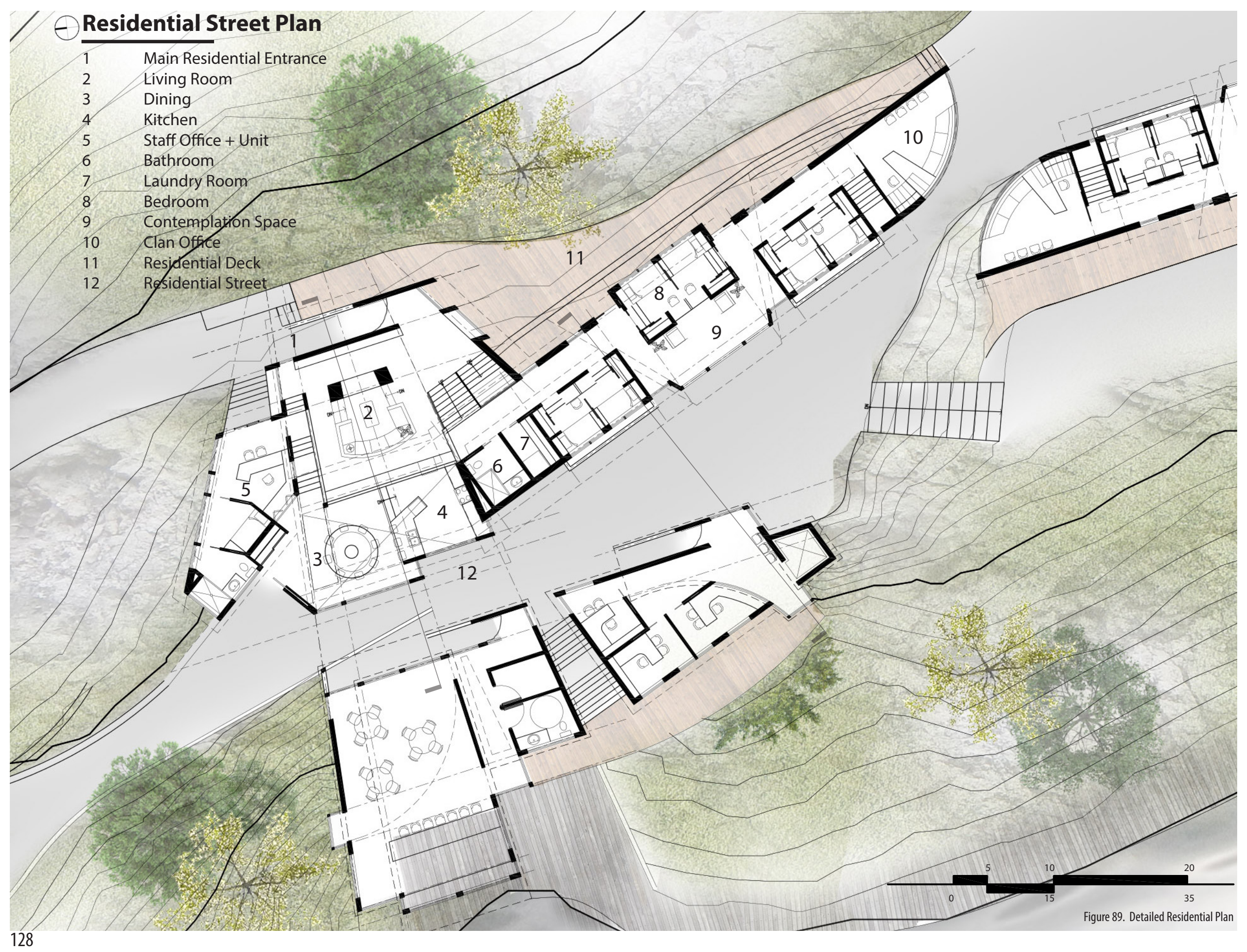




\section{Residential Street}

The following section focuses on the clan homes. The main goal that drove the design of the homes was to provide a sense of ownership and responsibility among patients for their clans' home. The bedroom units and living spaces were designed to appear as they are part of a larger street network that blends private and public functions through the use of overlapping materials and planes, extended walls and roofs and combining residential and community spaces with the "street". The dynamic of the street and the community programs spread throughout the site draws in community members, providing greater opportunities for interaction, reducing the stigma and segregation, which is typical of addiction treatment and mental health facilities.

\section{Overlapping Spaces}

The overlapping of spaces, both spatially and figuratively provide a conscious and subconscious sense of connection to other people, other spaces and other environments. It allows for users to decide on their degree of interaction with certain activities and people, allowing the choice of subtle engagement while still respecting personal space, boundaries and emotions. It also provides greater opportunity for social interactions and sharing of space with members of the facility and members of the community.

\section{- Aftercare Unit Plans}

1 Living Room

2 Kitchen

Dining

Bathroom

Bedrooms [4]

Bathroom

Group Room
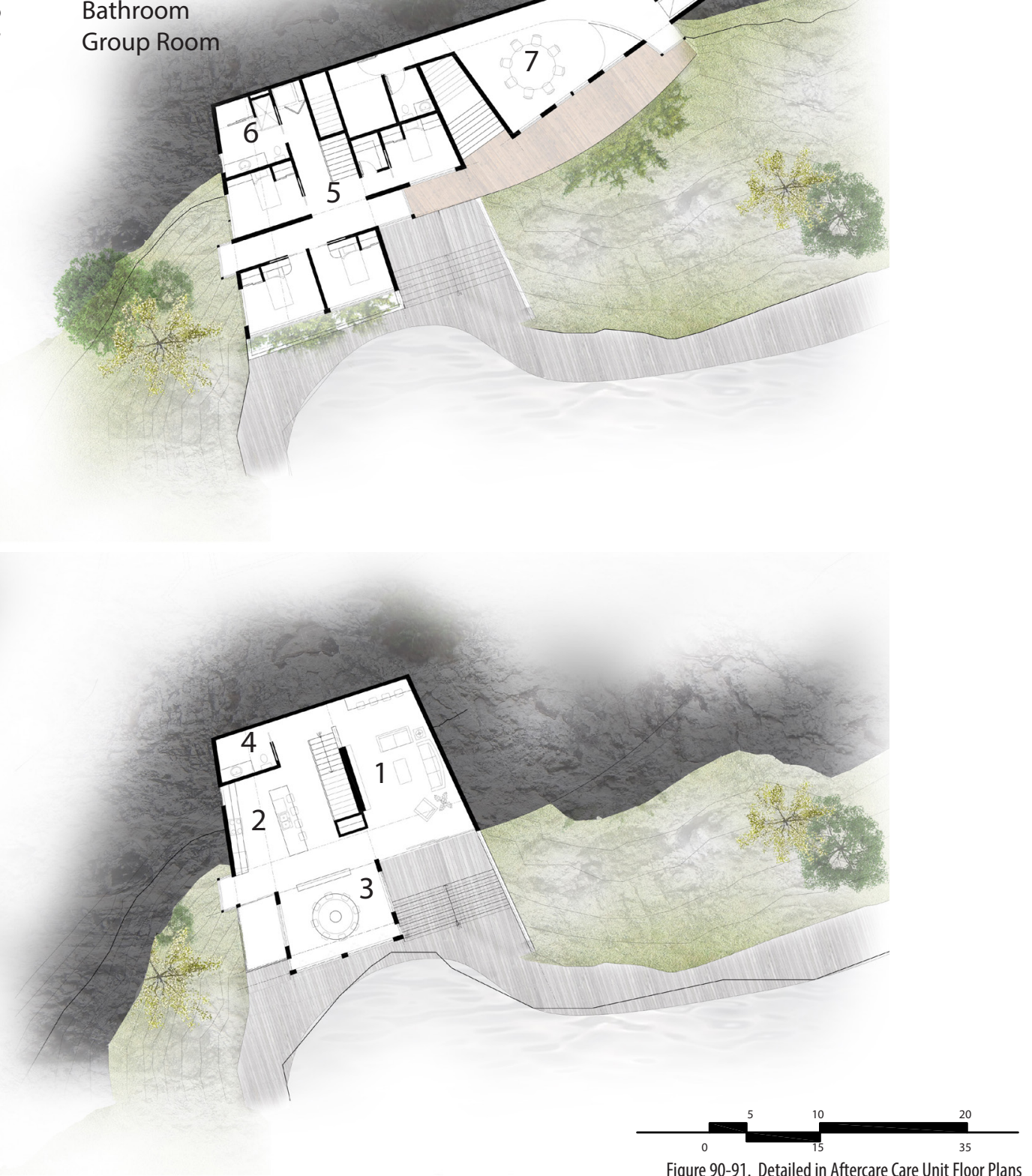

Figure 90-91. Detailed in Aftercare Care Unit Floor Plans 


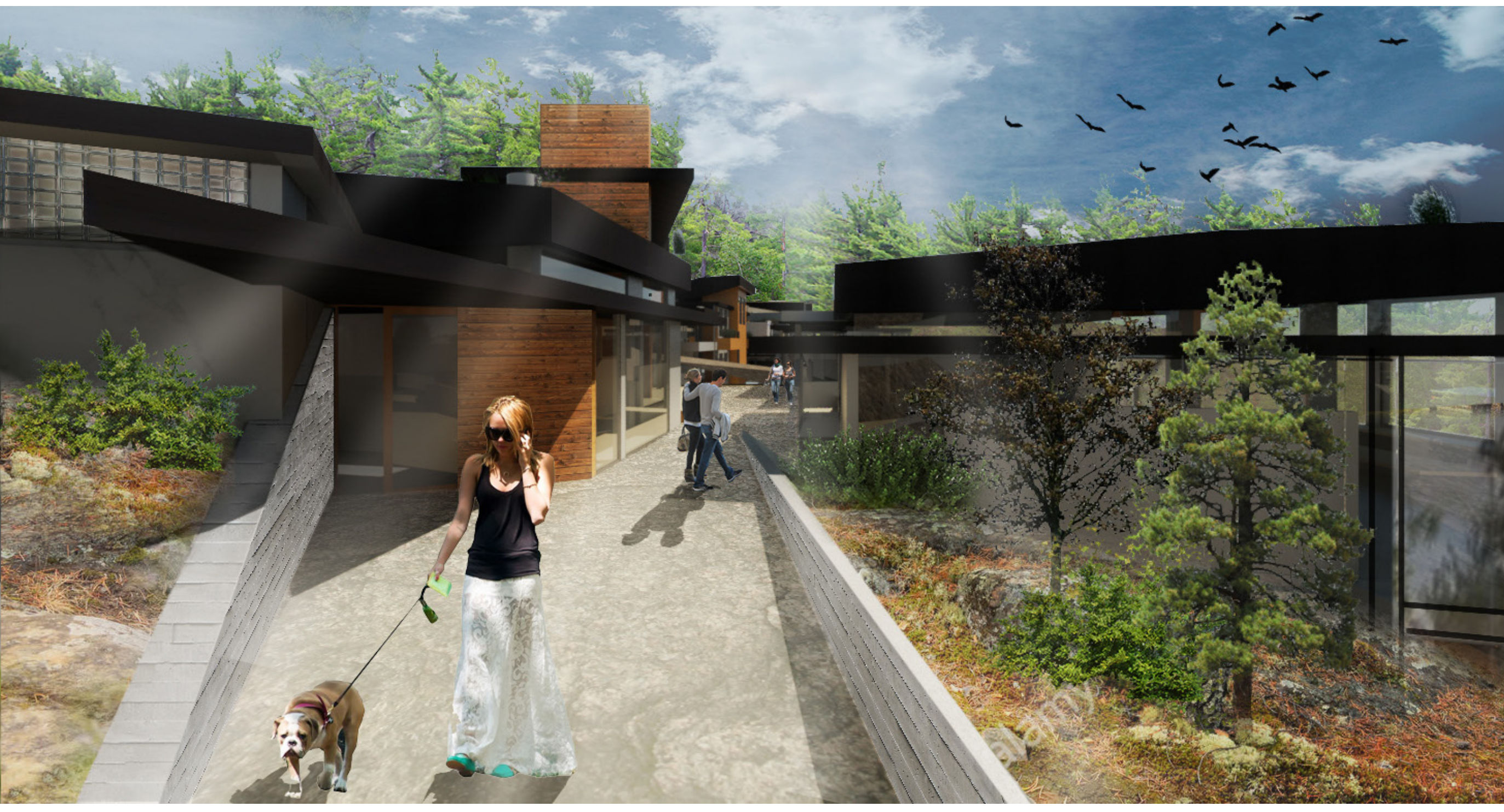


You climb another series of stairs and continue your journey up the landscape, towards your new room flowing, ascending and descending with it. You travel over and through the site, until you are directed to the street where your new house is located. The street is filled with people spilling in and out of the buildings, stopping to talk to friends they met on their own journeys or they are simply sitting and relaxing, enjoying the moment. You are pulled into your new house by the overextended roof planes and the walls that slowly emerge from the earth.

Left: Figure 92. View Approah Residential Street Right: Figure 93. Main Entrance to Residential Unit

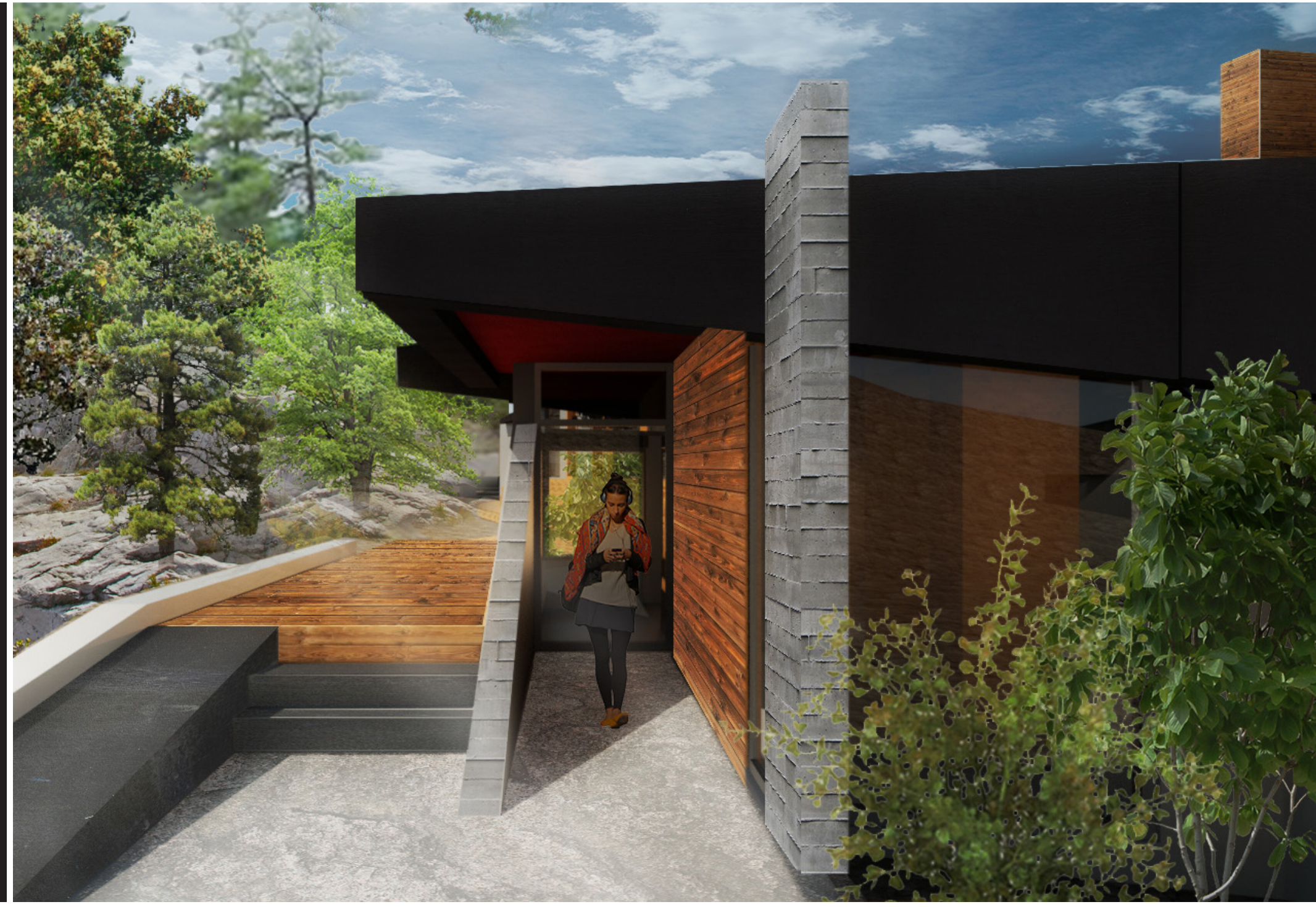




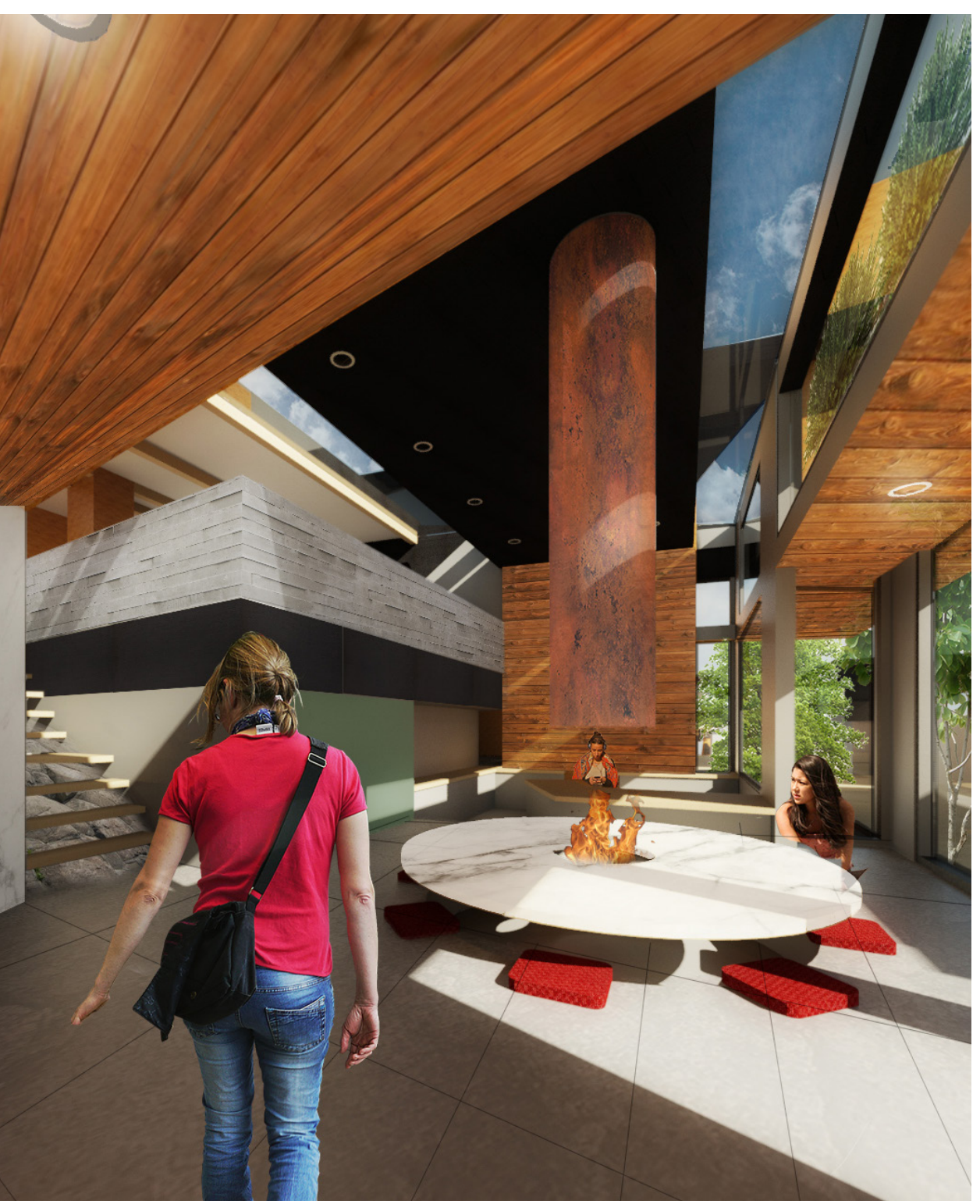

Figure 94. View of Residential Dining + Kitchen

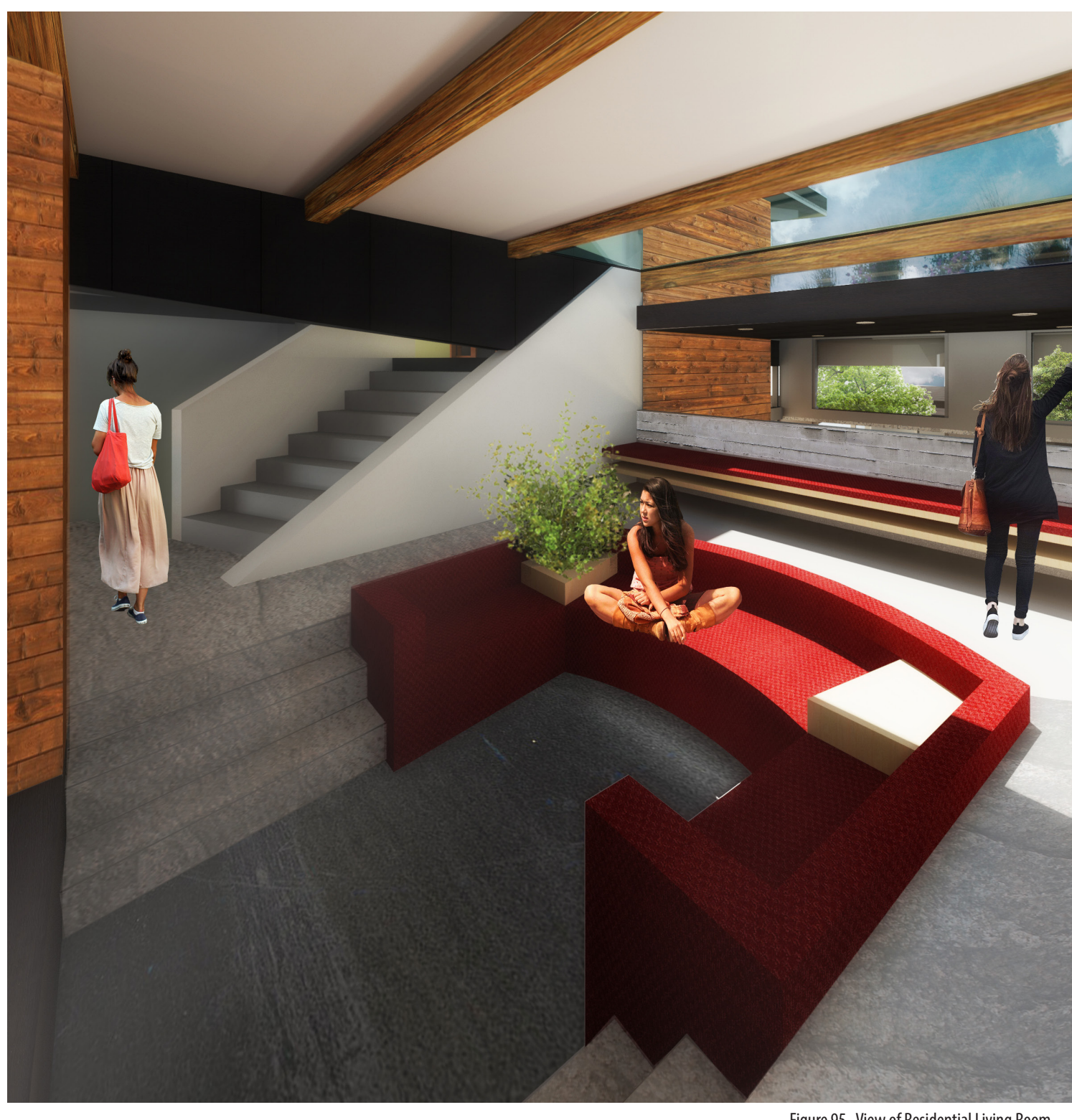

Figure 95. View of Residential Living Room 


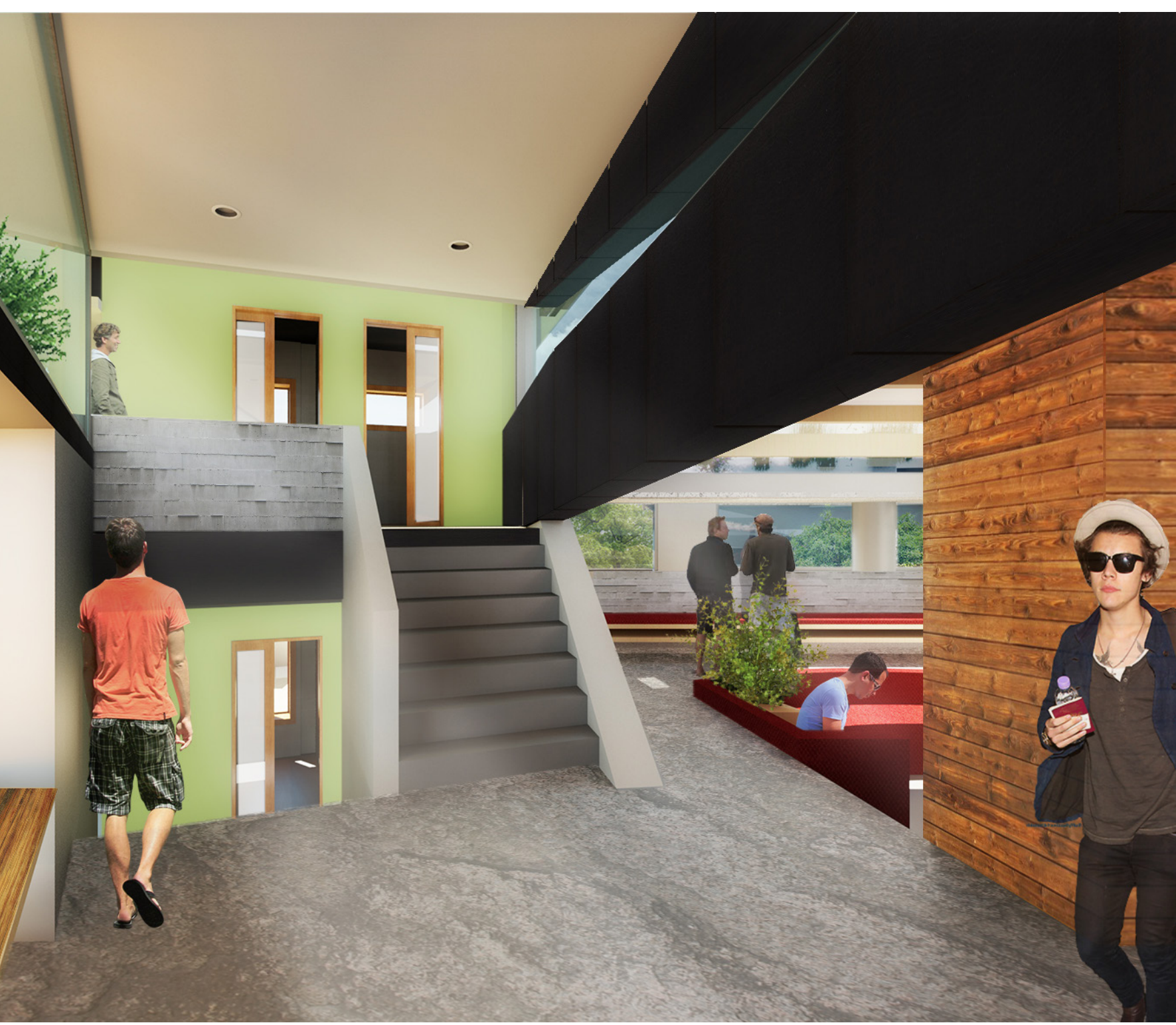

Figure 96. View of Entering the Residential Unit
You enter your new house and you realize it is your new home. As you pass through the dining room, kitchen and living room, you encounter your new family. They are getting home from work or volunteering in the community centre facilities on site, they are reading a book on the couch, talking to a counsellor and waving to you as you pass by. 'This is not so bad,' you think to yourself. You are shown around and then brought to your room. It's completely open, exposed. You panic for a second. Your family settles you in, unpacking and organizing your belongings. The counsellor asks you to relax for the next hour and then you are to meet for a group talking circle. You say your goodbyes to your family and your stress is at an all-time high. You need your own privacy and time to think. 'Can I do this?' you think to yourself. 'I'm not ready yet. What if I fail?' You slide your door closed, shut the louvres. You now have total privacy to sit with your thoughts. Moments pass, then you hear slight noise and laughter coming from your new home and street. The joys of the atmosphere begin to calm you down. You then hear a knock at your door, it's your bedroom neighbour, inviting you to talk. You slightly open your door and flip the louvres. This is the first step, and, before you know it, your door will not only be open, but you mind, heart, body and soul will too be open again to your future. 

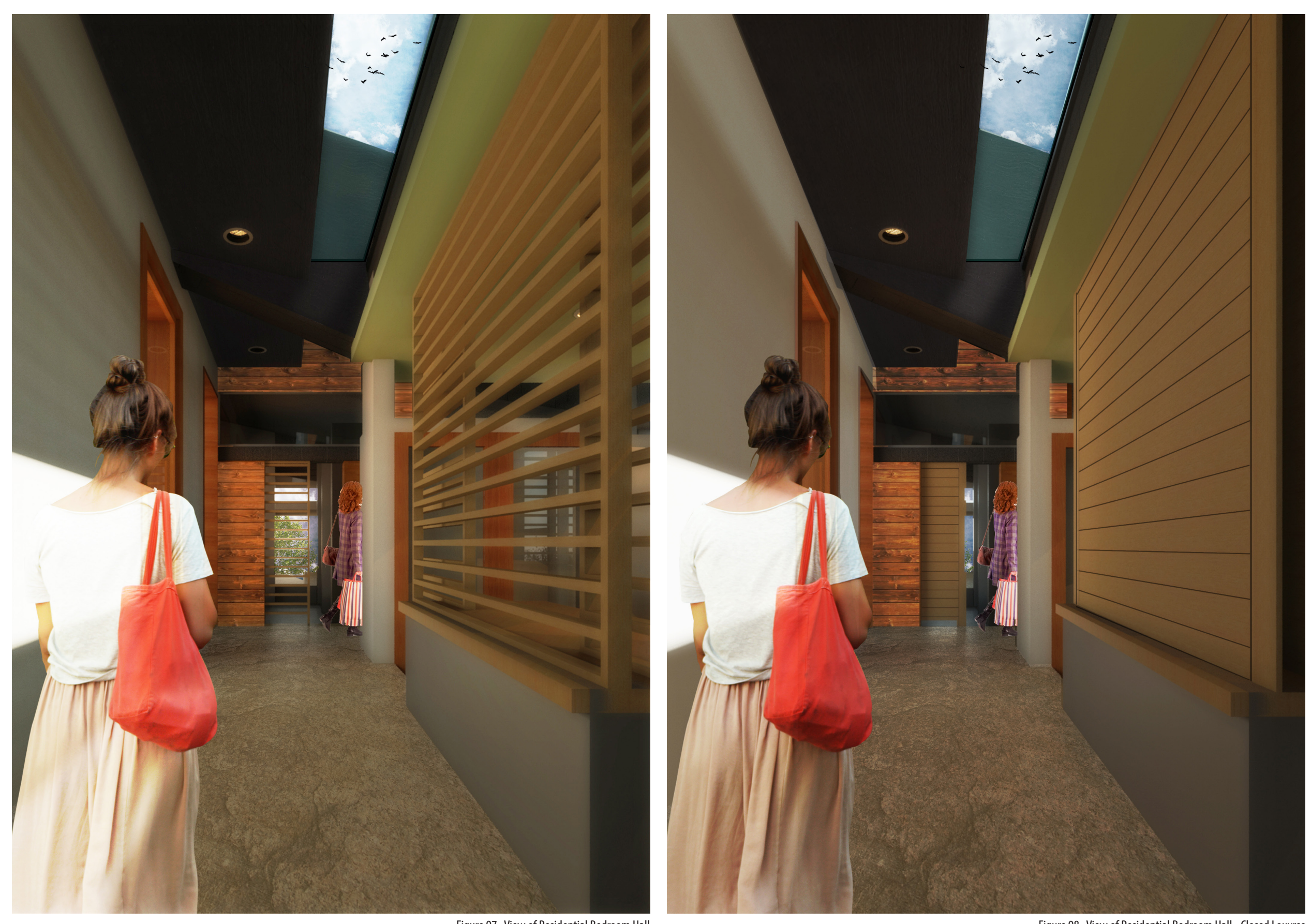


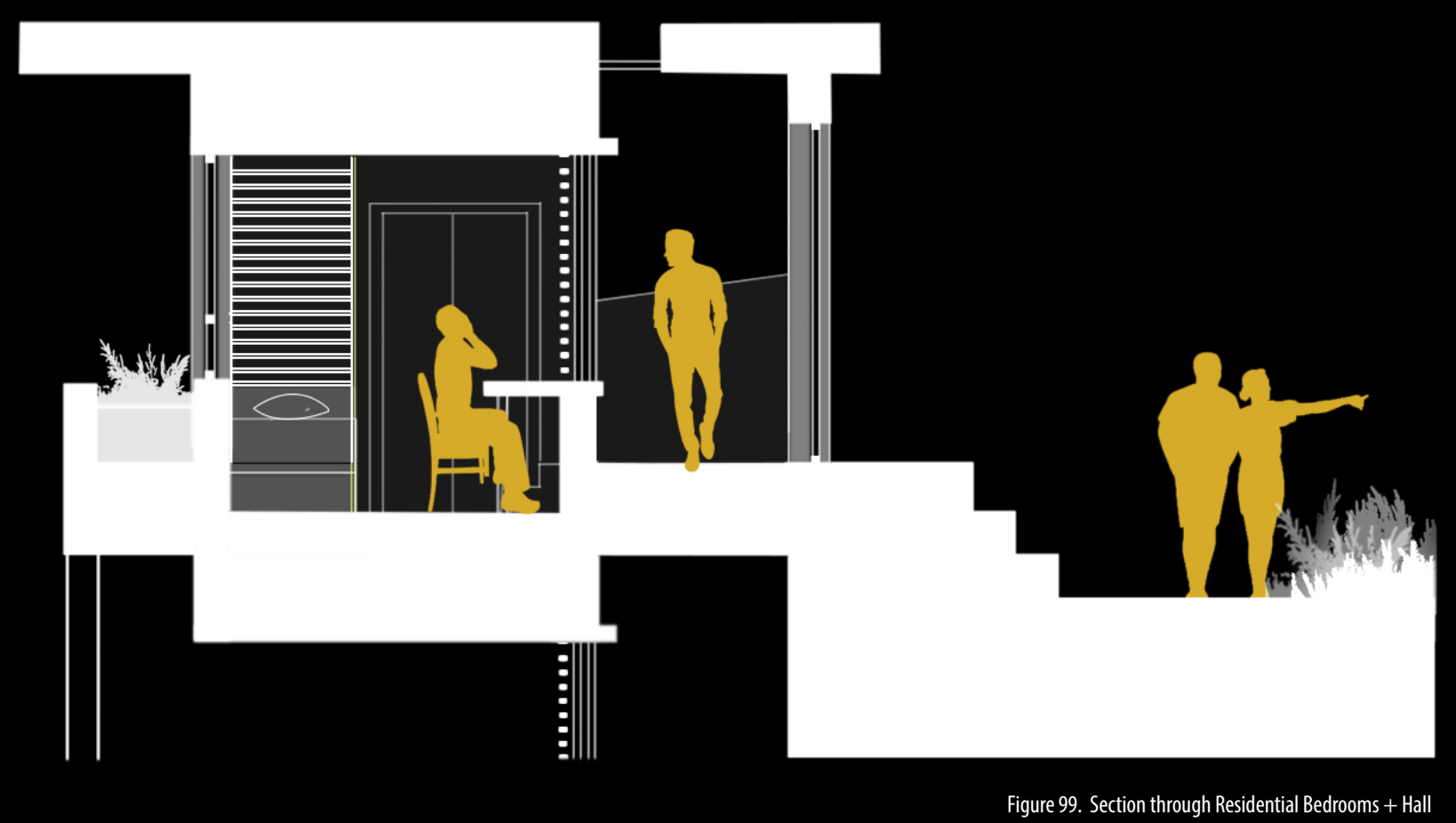




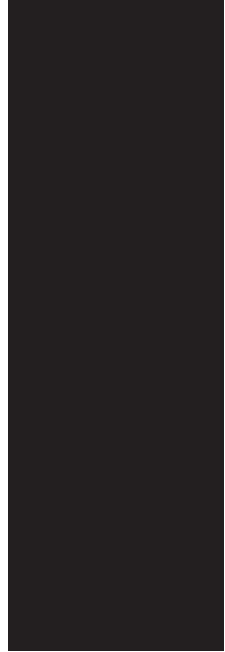

\subsection{CONCLUSION}

Architecture has the capacity to begin to either further propagate and perpetuate these problems or implement change by re-engaging the spirit through learning, incorporating and respecting the Anishinabek culture and people. However, this thesis is merely an exploration into how to incorporate the Anishinabek culture into an architectural model for Addiction Wellbeing centres.

Though many Canadian indigenous communities are suffering from the repercussions of the past, these consequences are very much in the present today as communities are plagued with more mental health problems, in particular, addiction, the culture is one of the riches in healing and wellbeing beliefs, which are embedded deep into the foundations of it, guiding almost all aspects of life and Anishinabek culture. Appropriation of the culture is not the intention of this thesis, it is about a chance to come together to learn and grow and to acknowledge our faults as a western society and build a mutual respect. It's about creating space and places that better our nation as a whole. This is a theme that has been reiterated through the thesis, separation versus integration and connectivity.

The complexity of the Anishinabek culture could take years to fully grasp and understand. It is a culture rich in healing beliefs and wellbeing. However, this thesis does not posit to revert to the past. It is a call for an intersection of contemporary western architectural practices and addiction treatment with the Anishinabek values and perspectives. The project that manifested from the research and design iterations is a point of departure in the investigations into the idea of integrating principles of the culture into the design of addiction wellbeing facilities. However, I believe these principles must extend beyond addiction facilities and into everyday architecture. As my research has displayed, culture is a tool for healing, and society as a whole must be re-investigated in order to extend healing into everyday architecture and peoples everyday lives. Our current spaces neglect to provide us healing environments; however has the ability to achieve much more. The examination and exploration of the Creation Story, Medicine Wheel, Seven Grandfather teachings, herbal healing, ceremonial practices and vernacular architecture has reinforced and validated the five principles distilled from the research.

The significance of places is to connect all aspects of life; past, present and future. It represents the knowledge of all that was and all that will be, centralizing and framing the Anishinabek perspective through cyclical, non-linear ways of ordering, building a relationship of respect and spirituality. Place is considered a "being" that has a spirit. This extension of "being" beyond the human allows for the stratification of all elements, energies and forces on earth, eliminating hierarchical relationships and creating reciprocity among all beings. Therefore, all creation should be treated with the Seven Grandfather teachings. The interrelation of beings, activities, events and experiences then become more significant as they effect all creation, which in turn, affects oneself. The experiential foundations of the culture relates to each of these principles. Knowledge, meaning and connections all are part of a performative and procedural foundation of knowing and seeing. All these knowledge systems work in cyclical and circular cycles. This is why the final principle, a circular worldview, encompasses all the four principles. A circular world view orders both time and space, brings equality, harmony, balance and a reiterative perspective on the world. Defining these principles is a hard task architecturally, as each intertwine and overlap with one another. Therefore, translating these ideas into architecture was difficult. Not only due to their interwoven aspects, but also due to their intangibility. There is no way to determine if the proposal created is a success without having experienced it in real time and space. Additionally, as the literature from the research states, each individual perceives their surrounding differently than others, and each of these perceptions are equally valid and true. However, the strategies and tactics this thesis implemented to apply these principles are points of departure in the investigation between addiction, the Anishinabek culture and architecture. 
Moving forward I hope to be given the opportunity to further investigate the interrelation between these three subjects and work with the community to further develop them though the design of an addiction treatment facility. This will allow for the opportunity to take this research a step further and investigate how these principles can be incorporated into architecture in an environment with strict economic restrictions and the constraints of conventional North American architectural practice. Though some of the architectural tactics explored may appear extreme or unrealistic, this thesis posits that in order to achieve healing spaces and environments that address addiction, their needs to be a shift in society as a whole. Architecture can only act as a catalyst to propagate these principles and ideas and inform society of a new way of thinking. 
APPENDIX + BIBLIOGRAPHY 


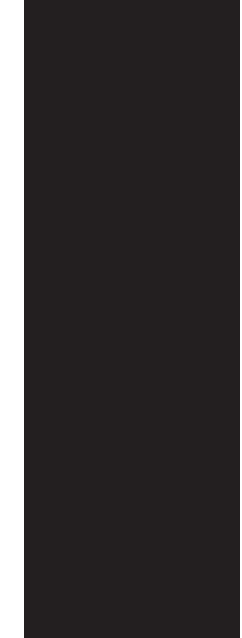

\section{SITE ANALYSIS}

Located in an Anishinabek community in Northern Ontario, on Manitoulin Island, the community is surrounded by the North Channel of Lake Huron and is the second largest Anishinabek community on Manitoulin Island. Settled in the middle of the 19th century when many Anishinabek, located on the north shore, came and relocated and is the home of the Anishinabek of the Three Fires; Odawa, 0jibway and the Pottawattomi Nations, it has a population of a total of 2,543 residents. The area is surrounded by step cliffs and bluffs. Though a thriving community, it still suffers from many of the problems that plague indigenous communities across Canada; higher suicide rates, problems with alcohol and drug use, unemployment, mental health problems and poor infrastructural support and housing.

The site was chosen in collaboration with a member Chiefs Council of the community. Located off of a main vehicular artery, the site sits amongst a barren landscape, in terms of the built environment, and a fruitful landscape, in terms of the natural environment. The expansive and open site sits at the edge of a tree covered hill with an existing traditional pow wow site and open field recreational space on the grounds. 

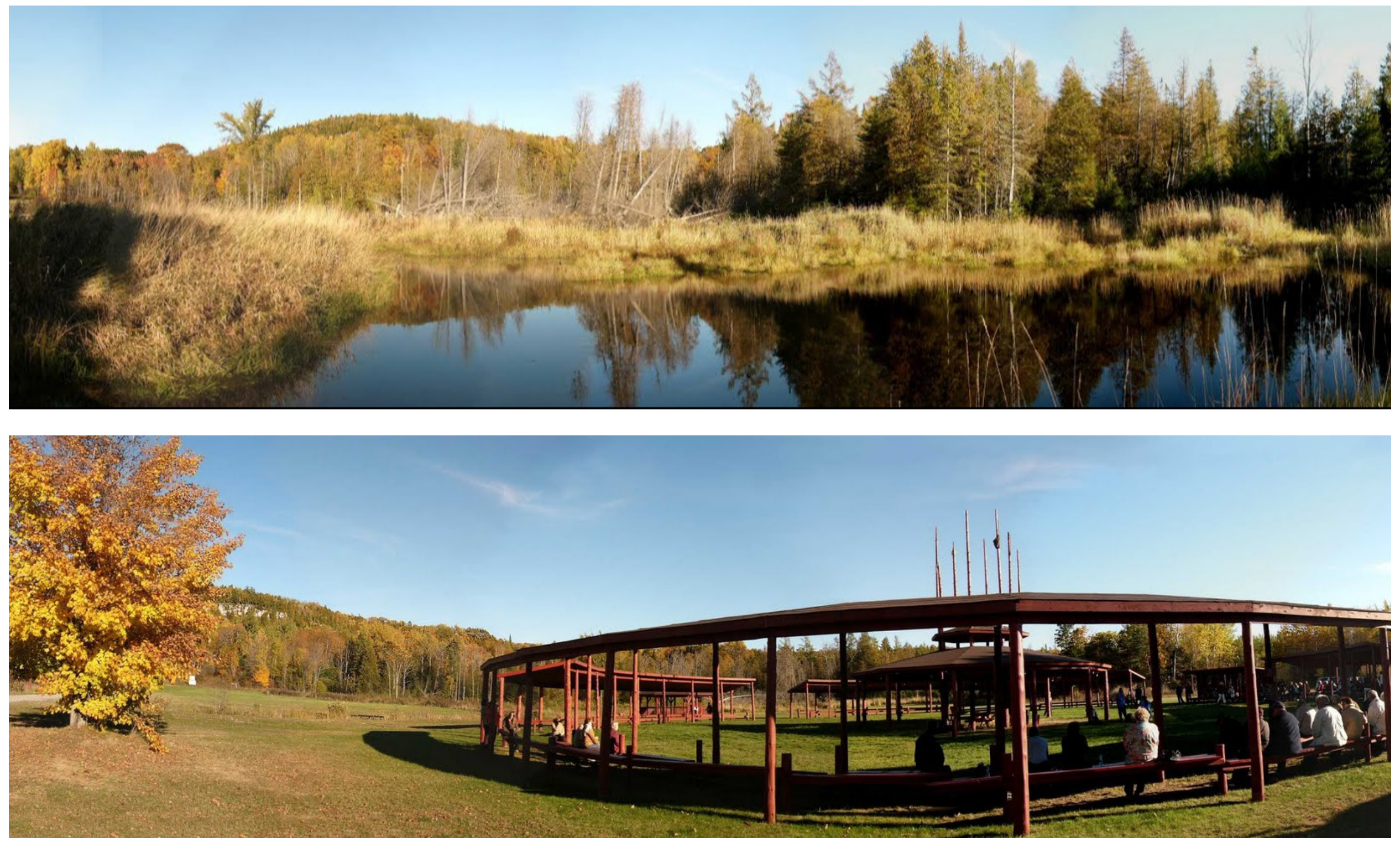

Figure 100-101. Photographs of Site 

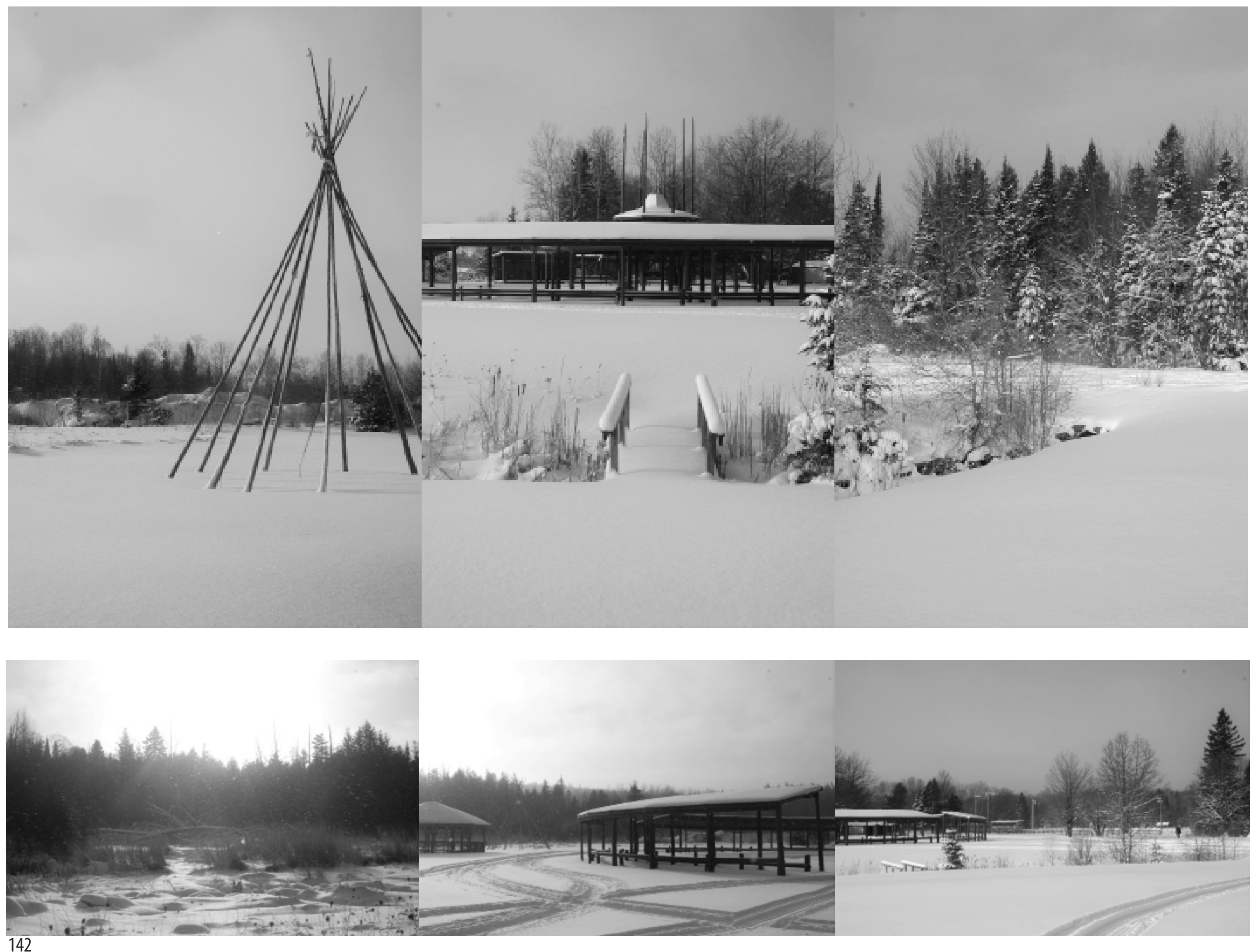

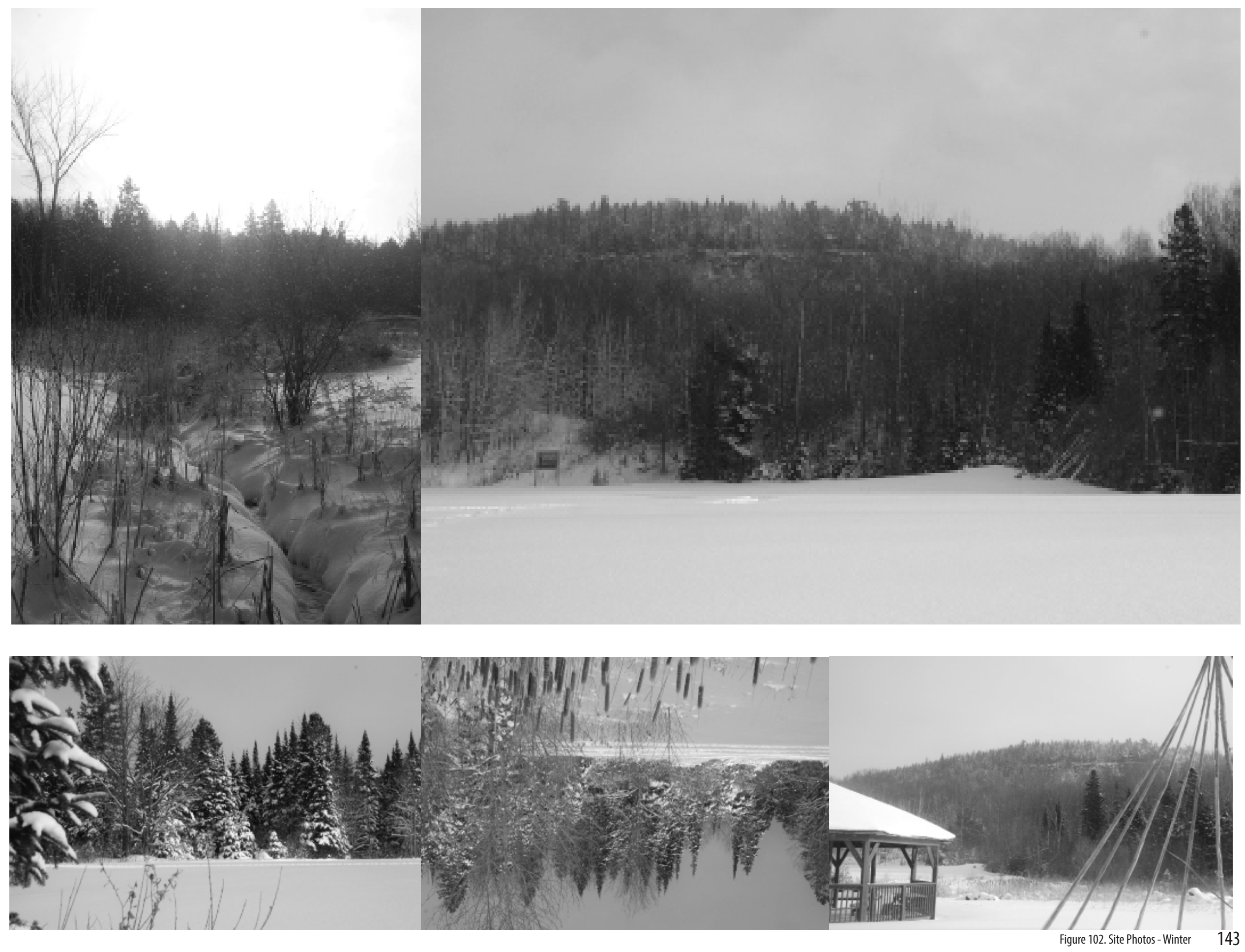

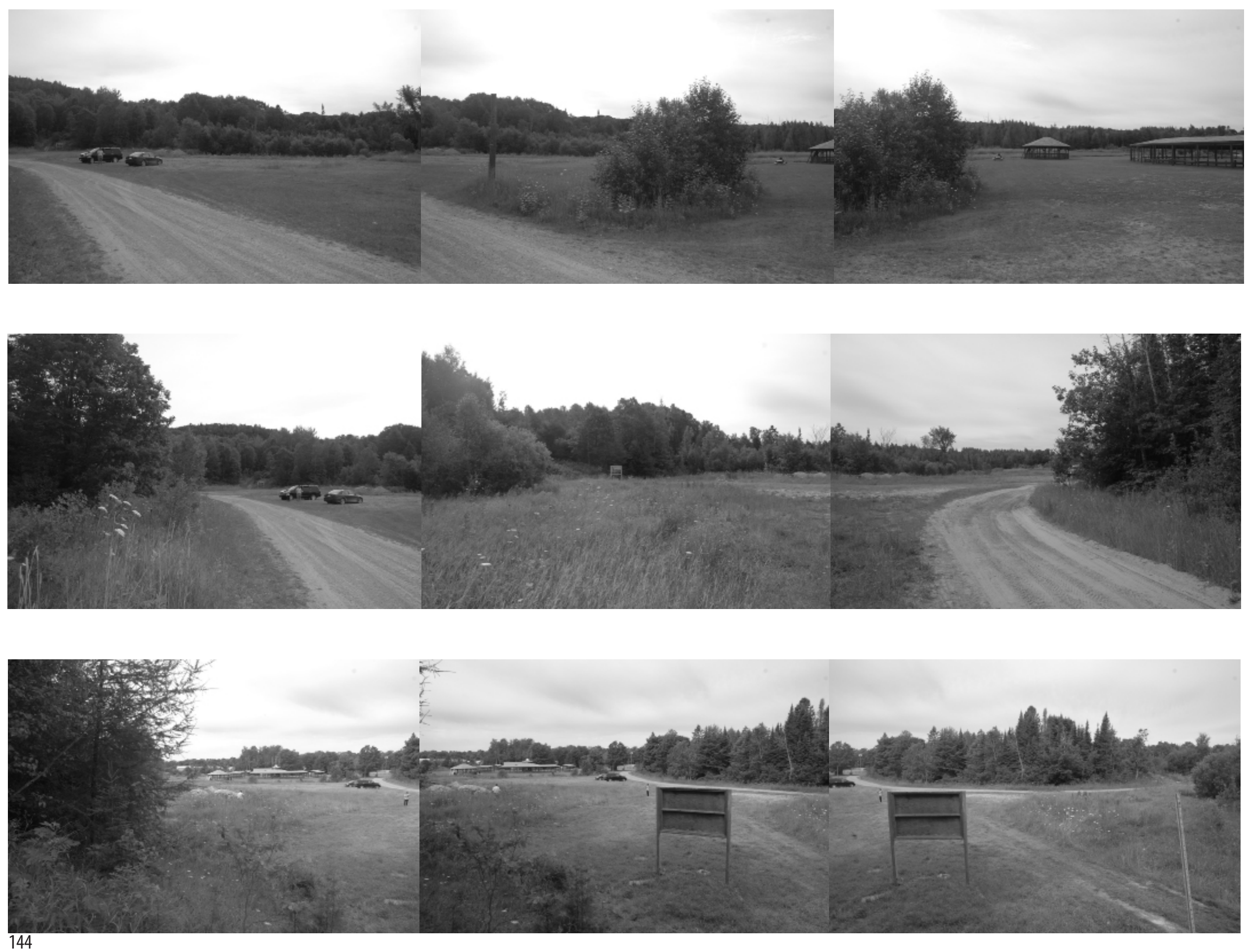

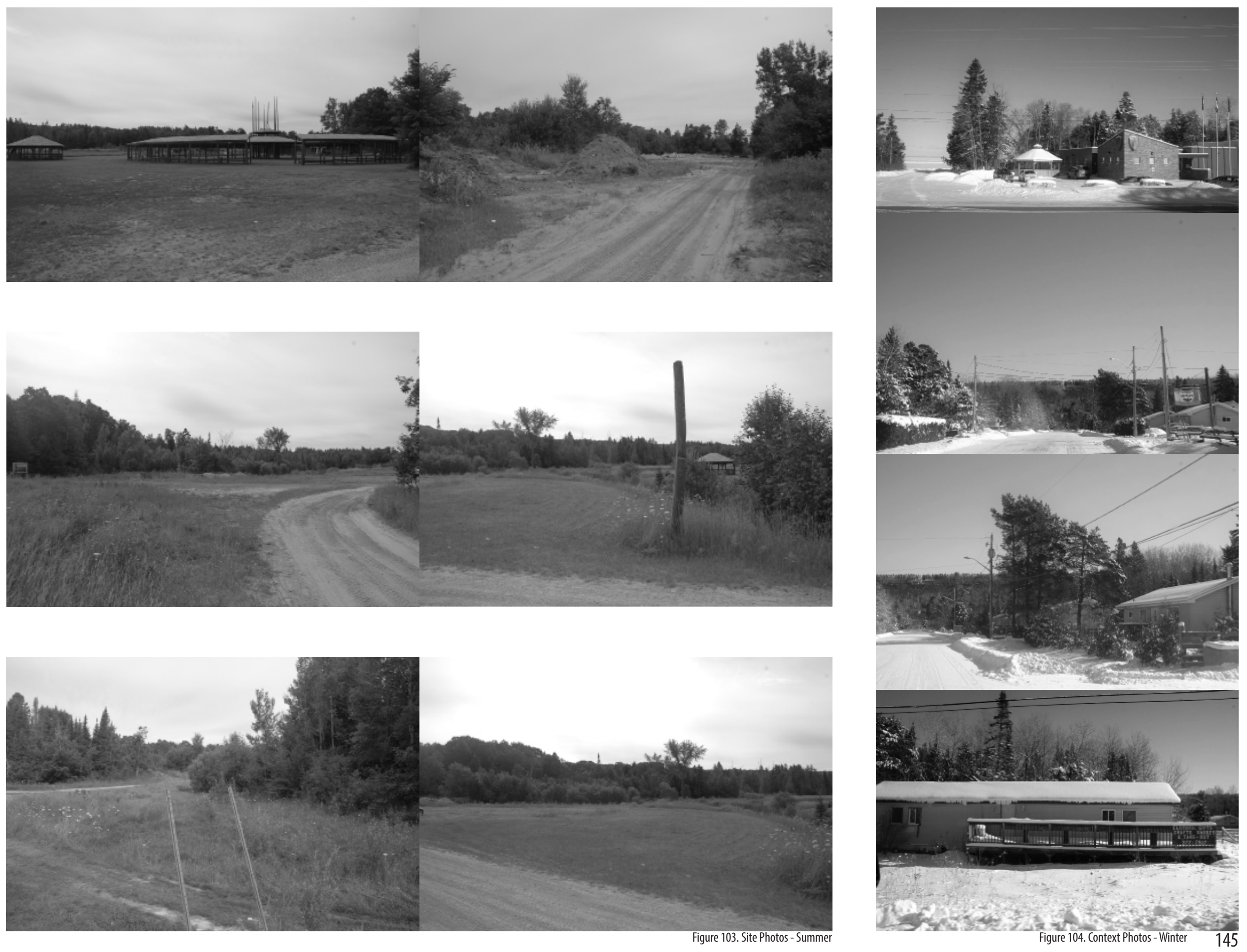


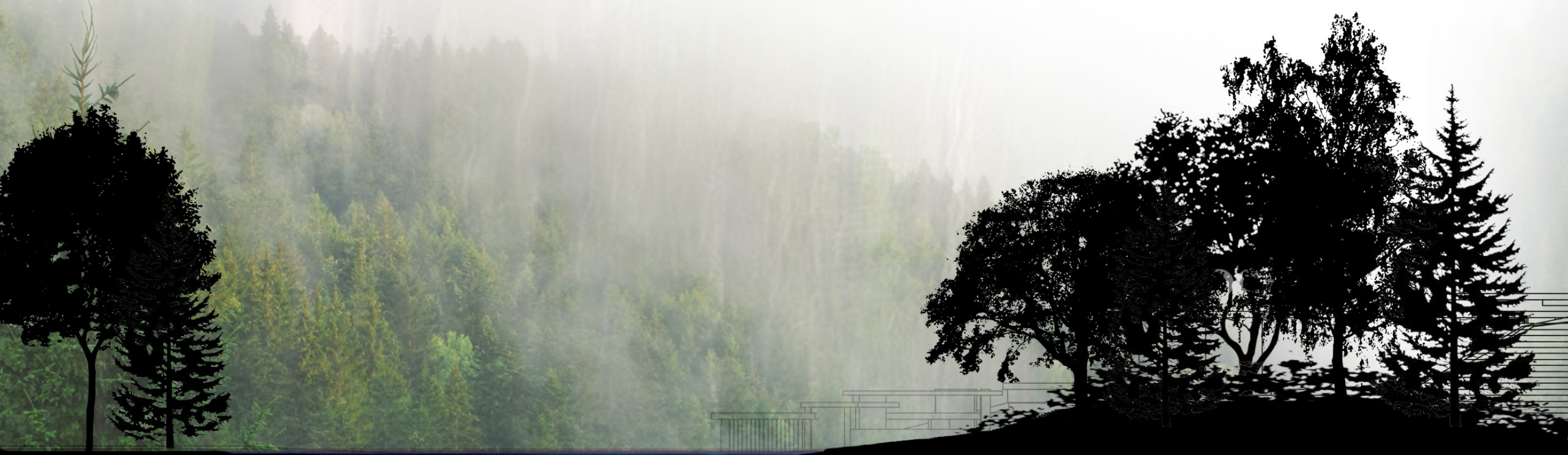




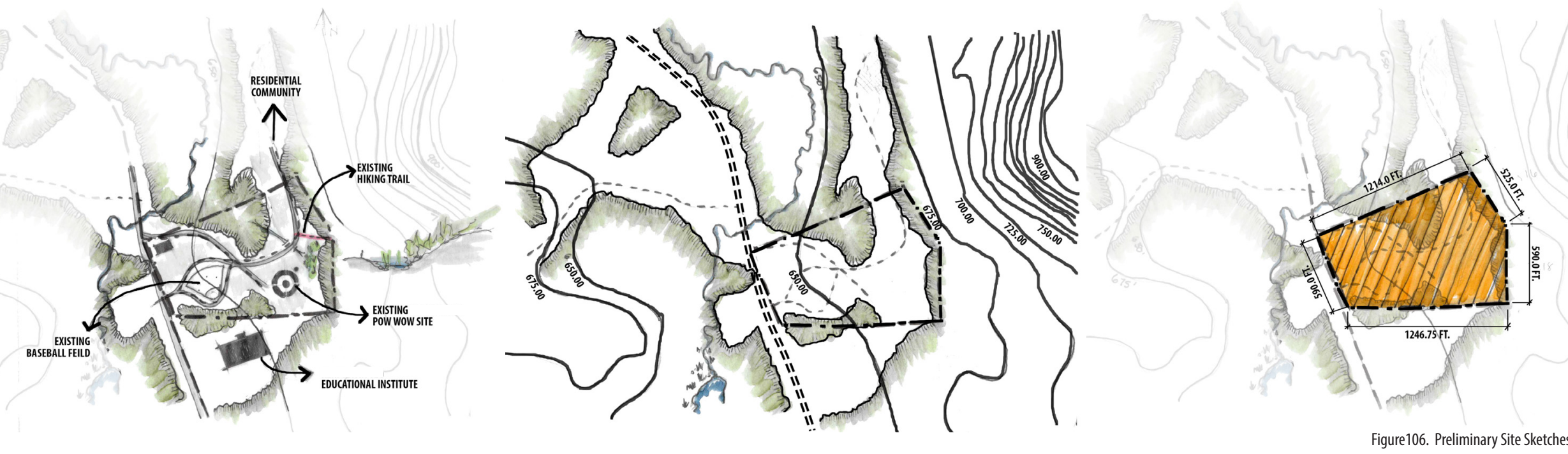


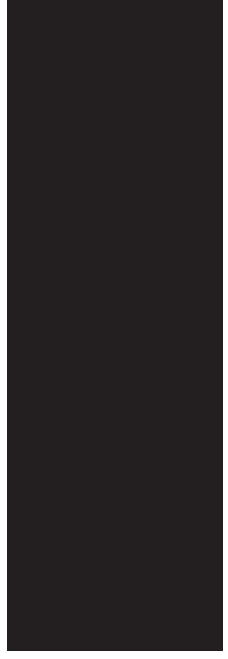

\section{PROGRAMMATIC + SPATIAL ANALYSIS}

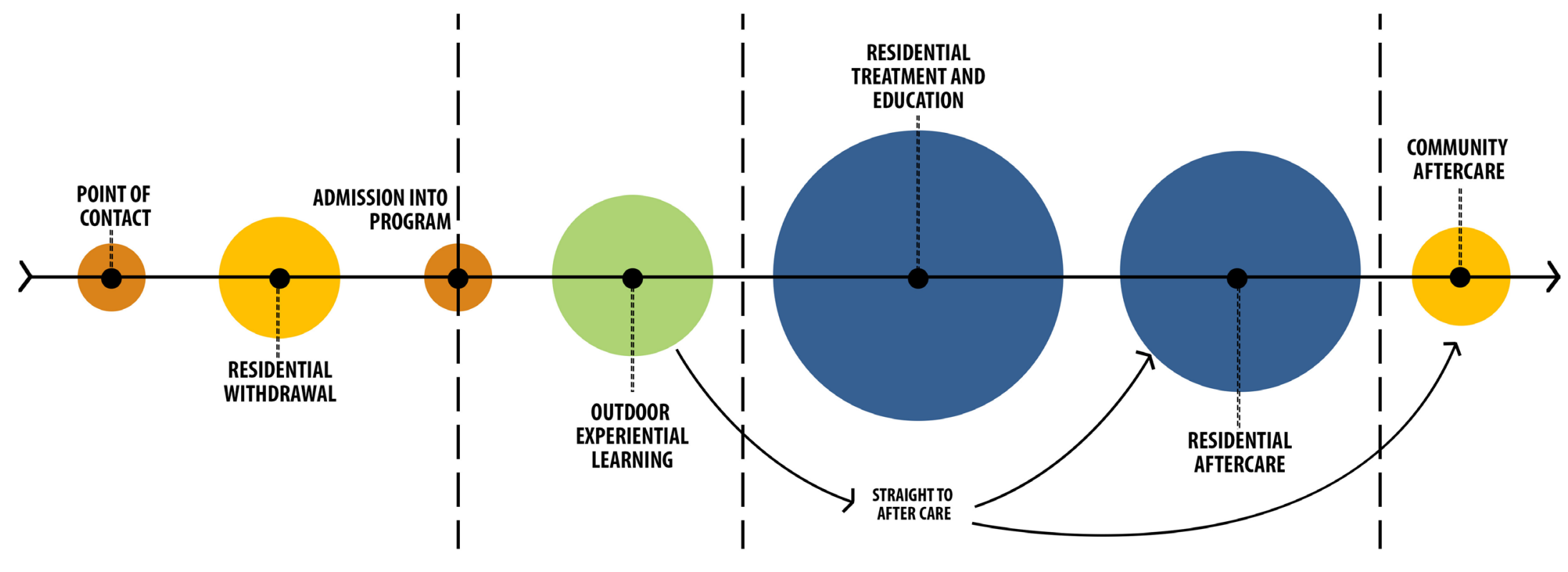

Figure 107. Healing Treatment Program developed by Collaborator and Community Council drawn by Author 

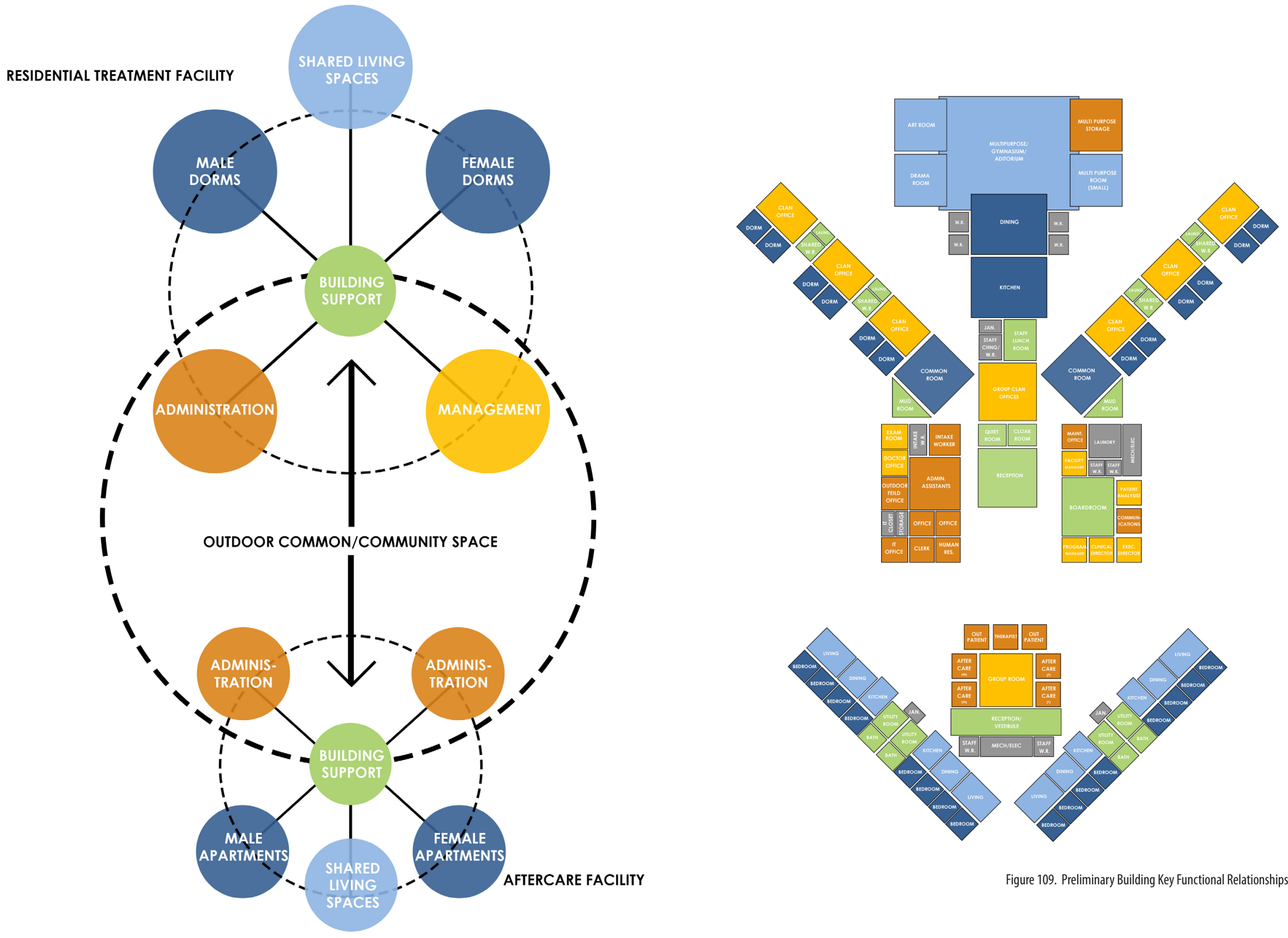

Figure 108. Site Key Functional Relationships 
RESIDENTIAL TREATMENT FACILITY

\section{ADMIIISTRATION + MANAGEMEIT}

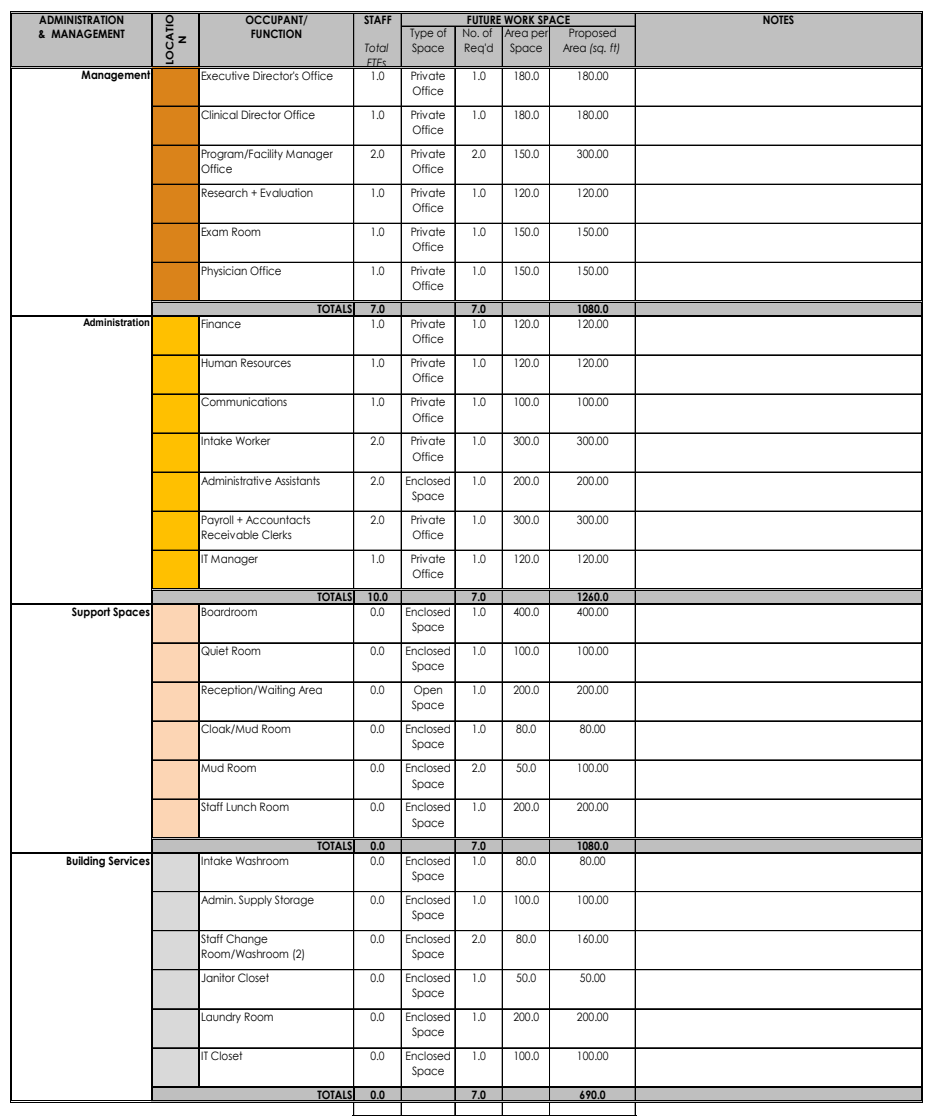

SHARED LVING SPACES

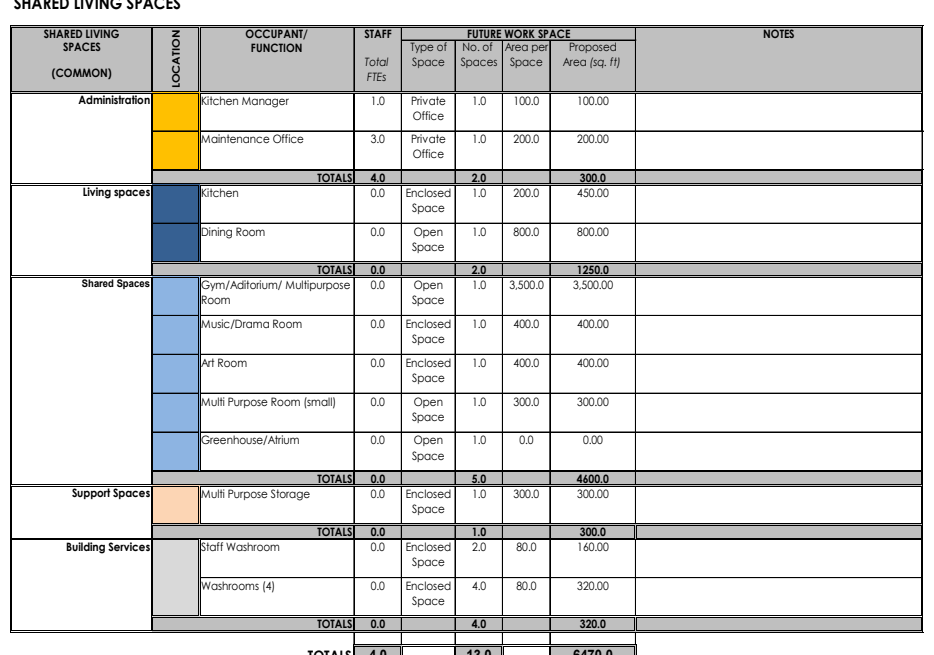

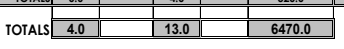

\section{AFTER CARE FACILITY}

MALE + FEMALE FACLITY

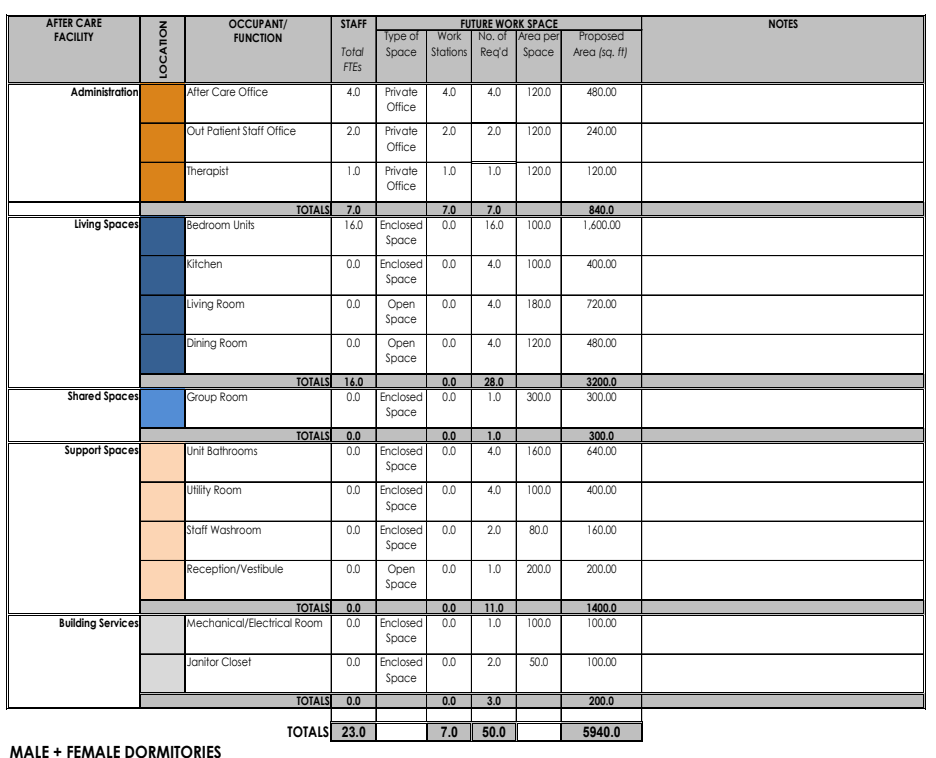

MALE + FEMALE DORMITORIES

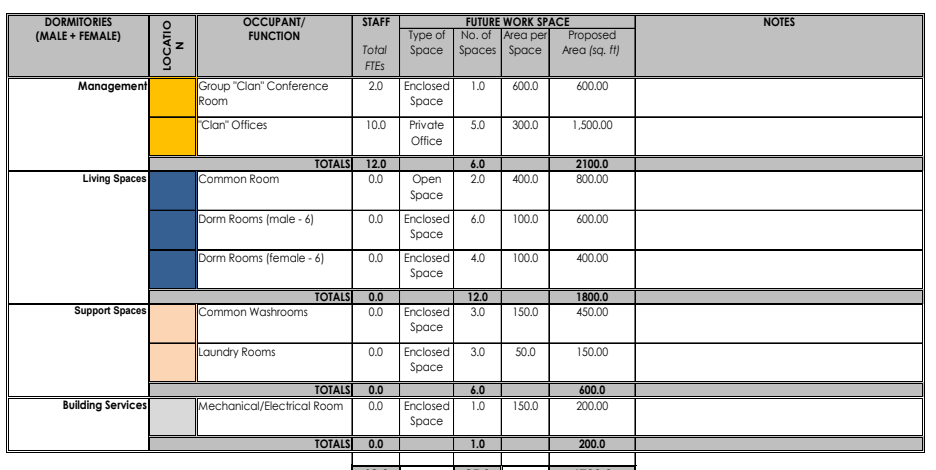

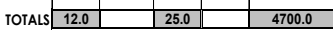

\section{OUTDOORS SPACES}

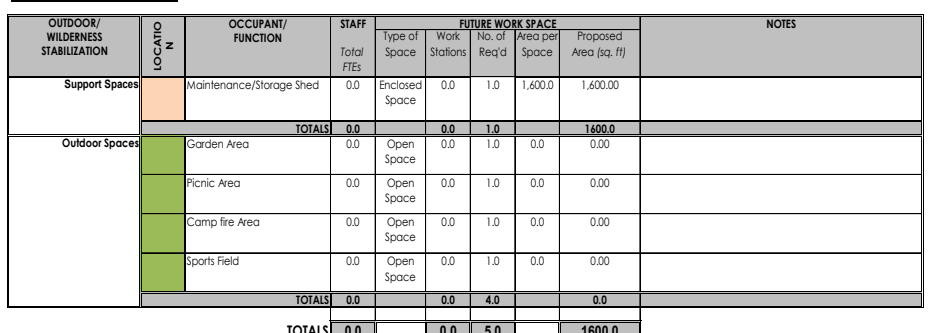

Figure 110. Preliminary Building Spatial Requirements 

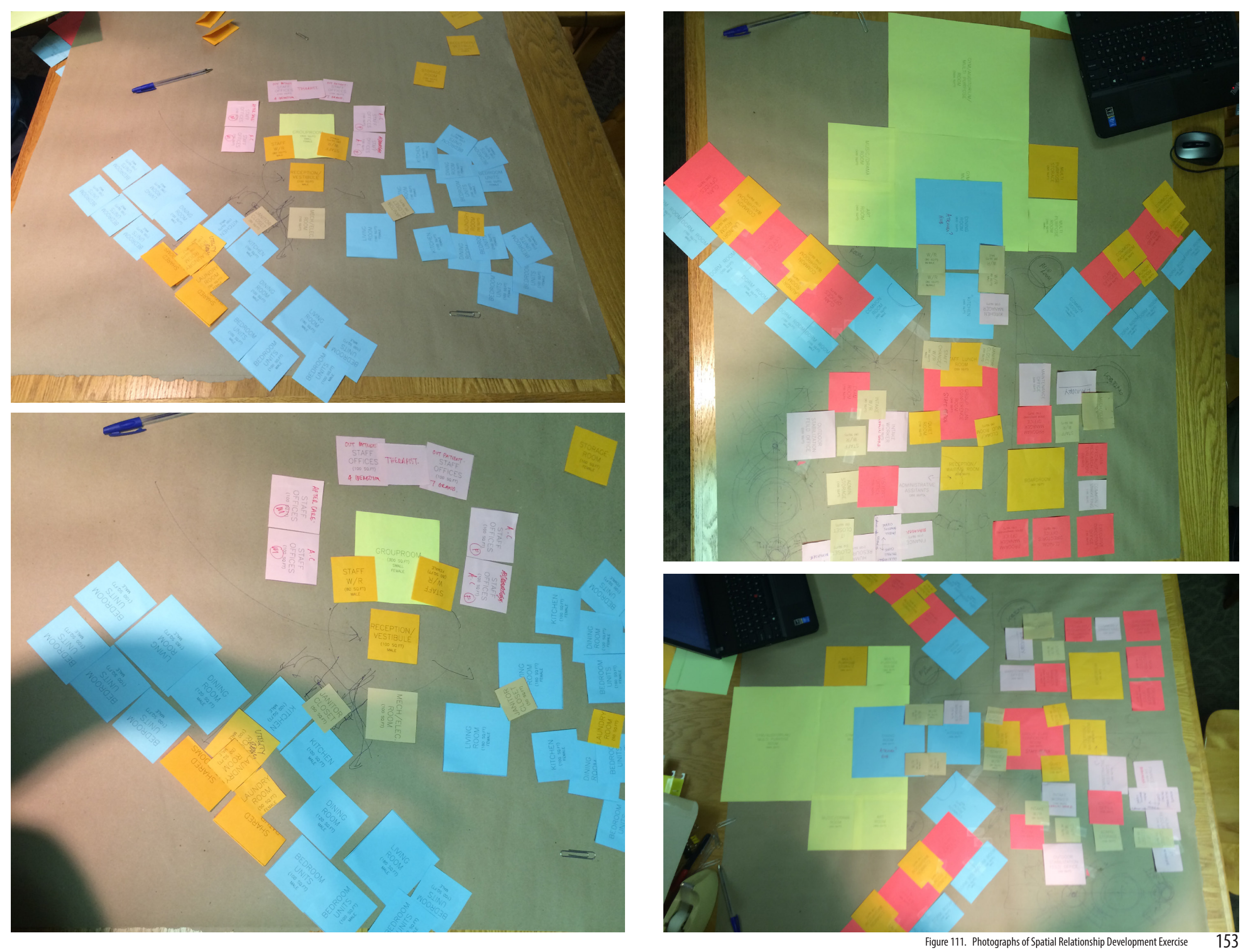

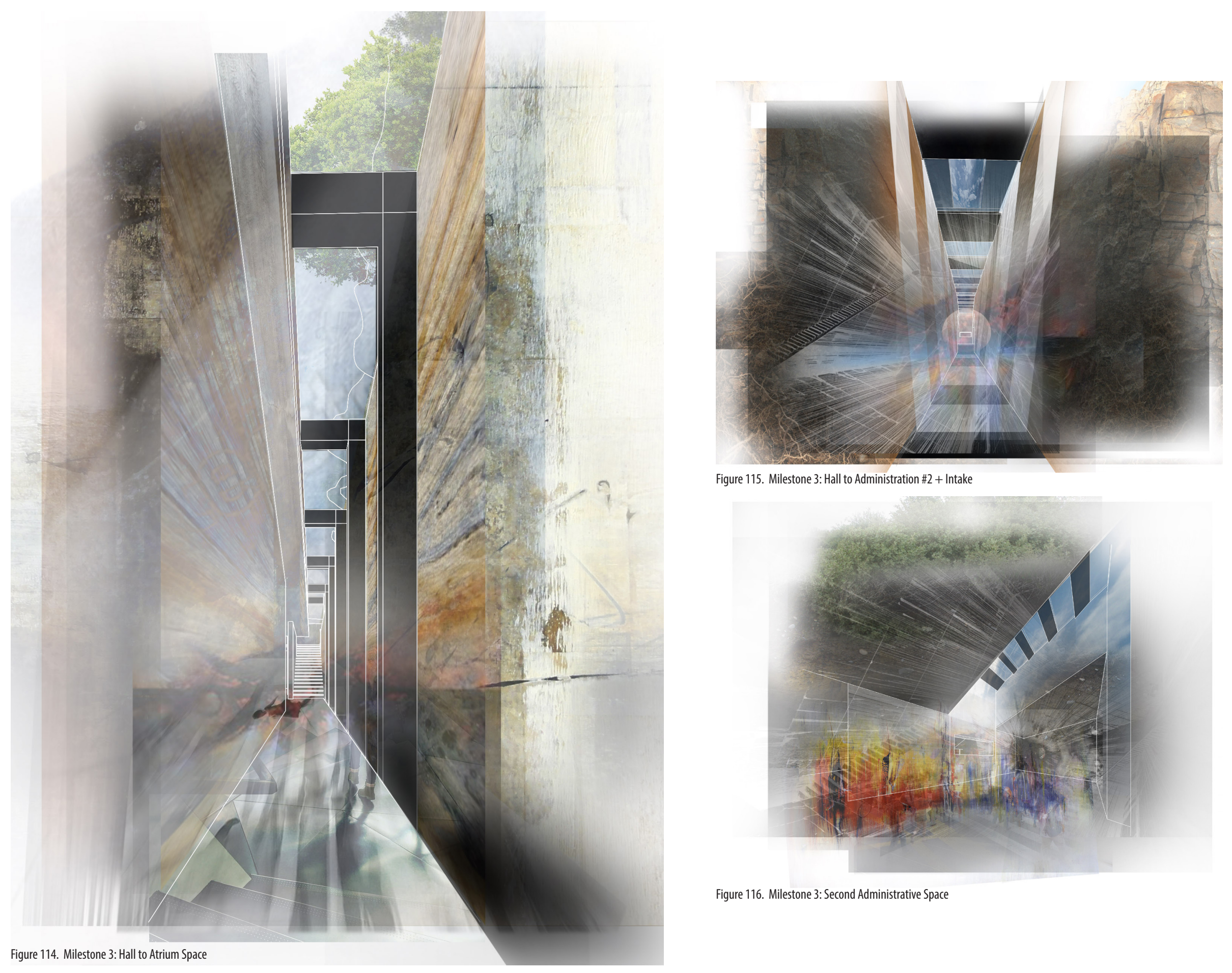

Figure 115. Milestone 3: Hall to Administration \#2 + Intake

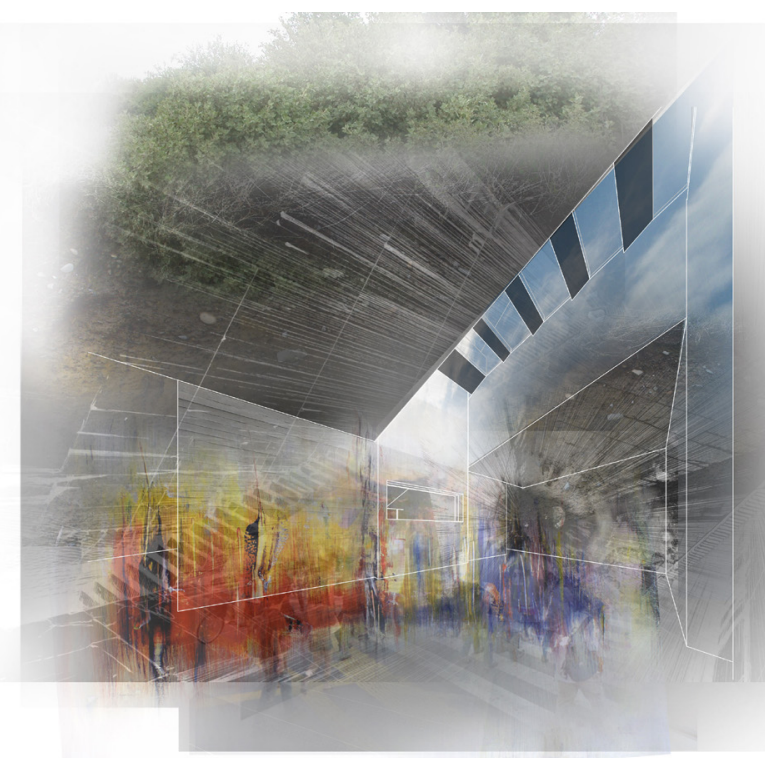

Figure 116. Milestone 3: Second Administrative Space 


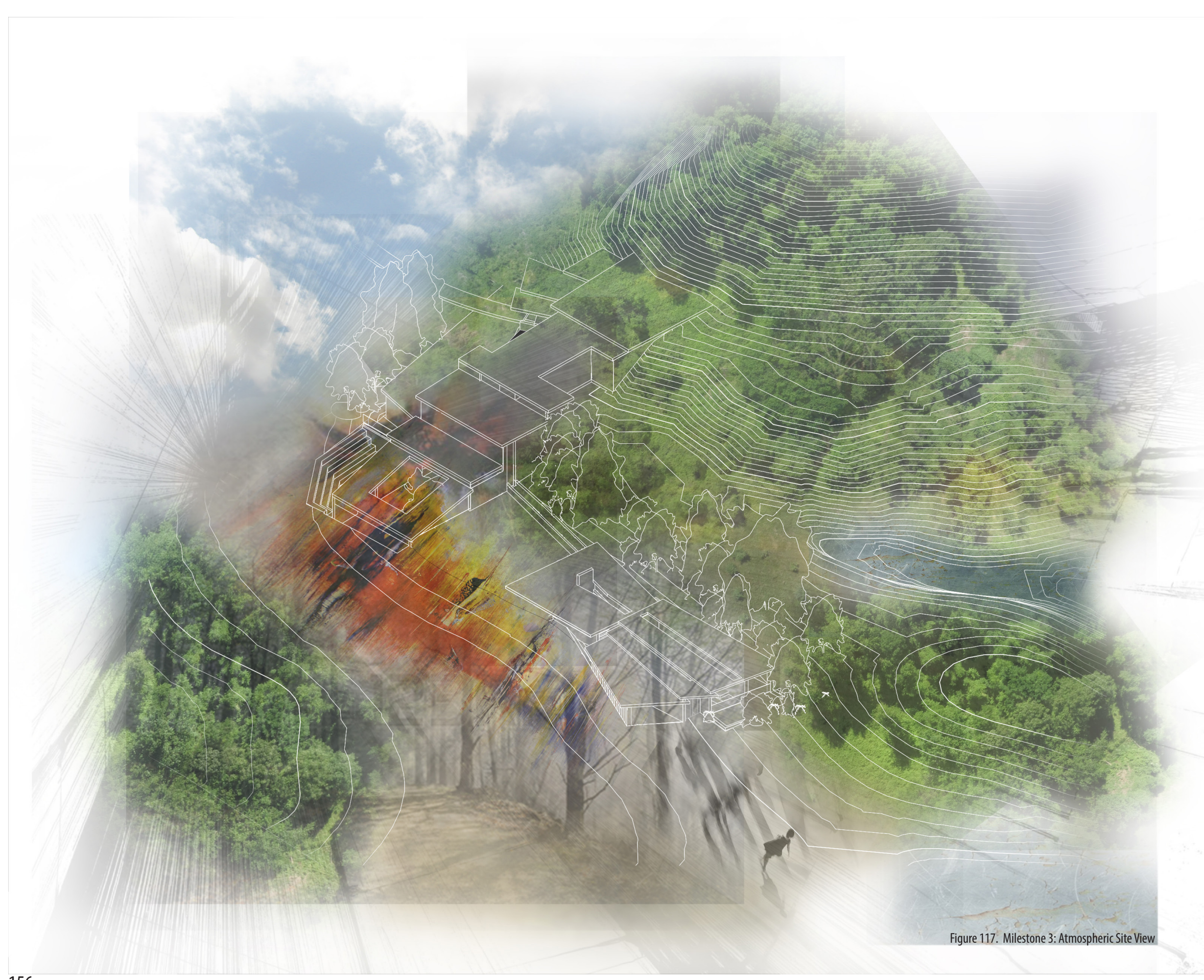




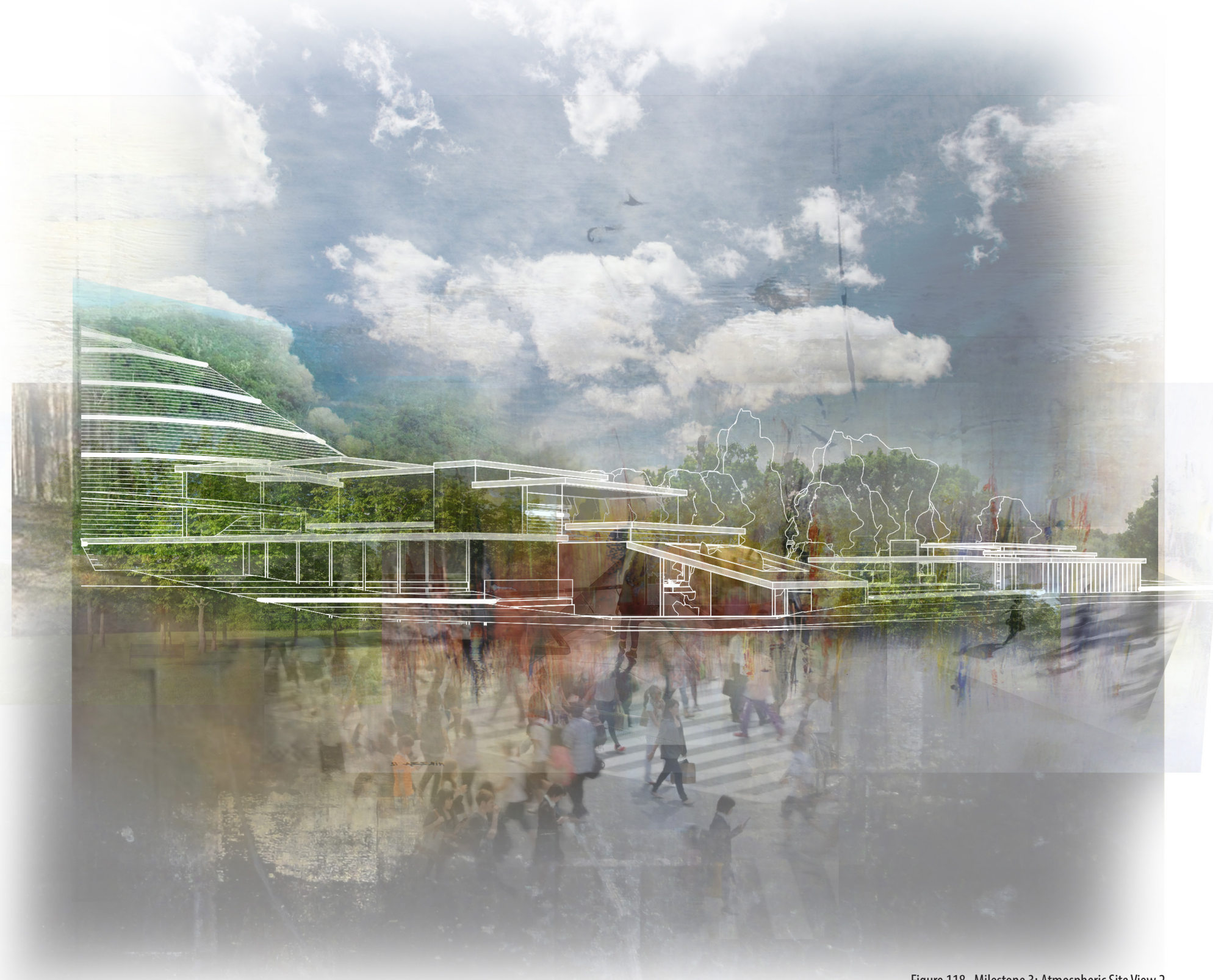

Figure 118. Milestone 3: Atmospheric Site View 2 


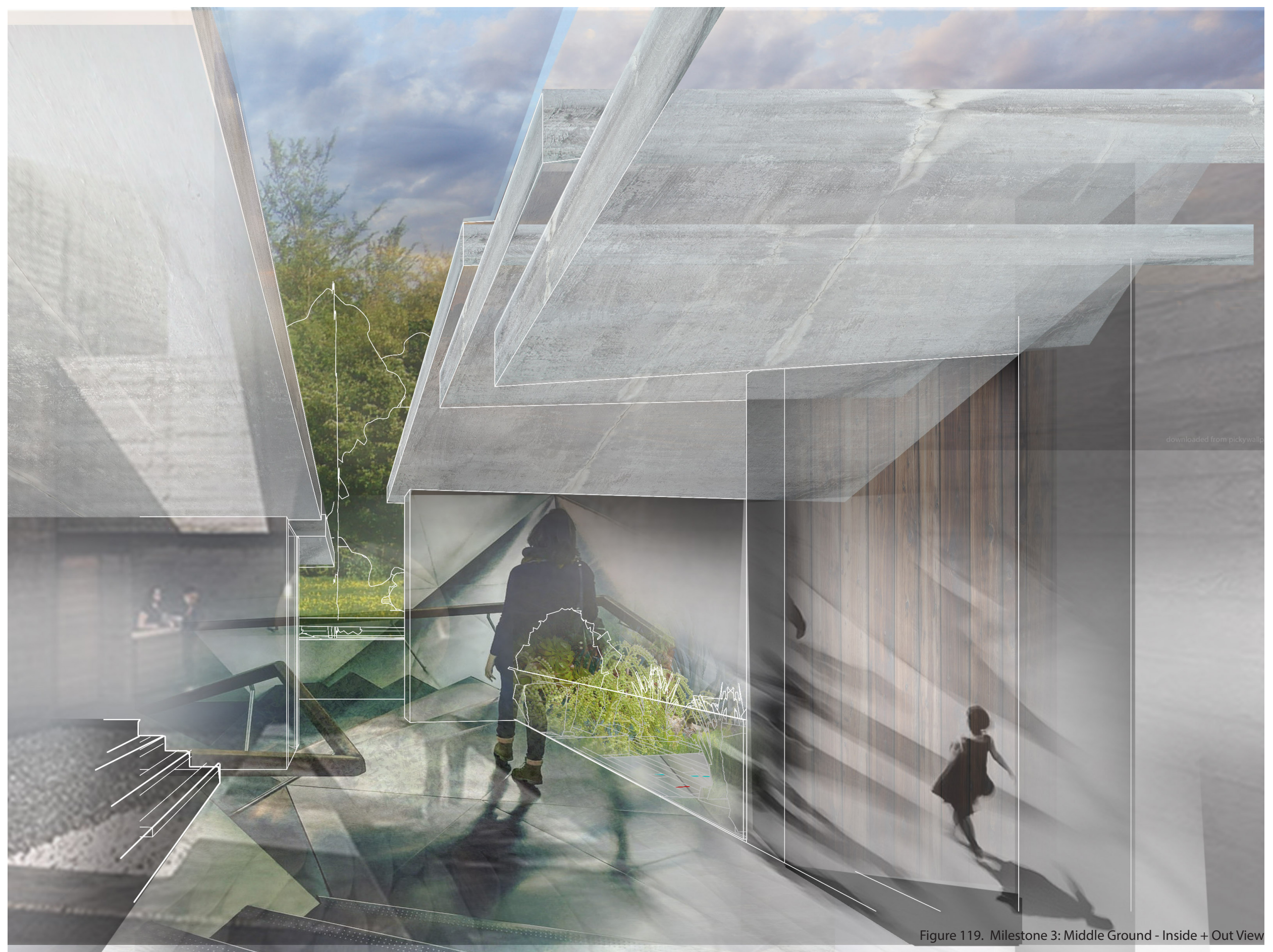




\section{RE-ENGAGING THE SPIRIT}

"Aboriginal Medicine." Aboriginal Medicine. University of Ottawa, 8 July 2009. Web.

$<$ http://www.med.uottawa.ca/sim/data/Aboriginal_Medicine_e.htm>

"Aboriginal Peoples in Canada: First Nations People, Métis and Inuit." Statistics Canada. Government of Canada, Ottawa, 23 Dec. 2015. Web. <https://www12.statcan.gc.ca/nhs-enm/2011/as-sa/99-011-x/99-011-x2011001-eng.ffm>.

Alexander, Bruce K. The Globalisation of Addiction: A Study in Poverty of the Spirit. Oxford University Press, Vancouver, BC, 2008

Alexander, Bruce. "The Rise and Fall of the Official View of Addiction." Bruce K. Alexander. Simon Fraser University, Burnbay, British Columbia, July 2014. Web. $<$ http://www.brucekalexander.com/articles-speeches/277-rise-and-fall-of-the-official-view-of-addiction-6>

Alexander, Dominic. "Ernst Fischer, The Necessity of Art: A Marxist Approach." Counterfire. University of Cambridge, 23 July 2010. Web. $<$ http://www.counterfire.org/articles/book-reviews/6012-ernst-fischer-the-necessity-of-art-a-marxist-approach>.

Altass, Angela. "Wabano Health Centre." Wabano Centre for Aboriginal Health. Award Magazine, Canada Wide Media Ltd., June 2013. Web. <http://www.wabano.com/wp-content/uploads/2012/08/Wabano-AWARD-Magazine-June-2013.pdf>.

Aristotle, Benjamin Jowett, and HW. C. Davis. Aristotle's Politics. Batoche Books, Kitchener, ON, 1999. Web. <https://socserv2.socsci.mcmaster.ca/econ/ugcm/3ll3/aristotle/Politics.pdf>.

Benton-Banai, Edward. The Mishomis Book: The Voice of the Ojibway. MNRed School House, Saint Paul, MN, 1988

Bhatt, Ritu. Rethinking Aesthetics: The Role of Body in Design. Routledge, New York, NY, 2013.

Borden, lain. Skateboarding, Space and the City: Architecture and the Body. Berg Publishing, Oxford, UK, 2001.

Borden, lain. The Urban Condition: Space, Community and Self in the Contemporary Metropolis, vol. 212, EMAP Architecture, Rotterdam, NL, 2000. Web. $<$ https://ryerson.summon.serialssolutions.com/search?s.q=+Architecture\%3A+Art+and+Science+Charles+W.+Moore\&spellcheck=true\#!/search?ho=t\&fvf=|sFullText,true,f\&l=en\&q=The\%20Urban\% 20Condition:\%20Space,\%20Community,\%20and\%20Self\%20in\%20the\%20Contemporary\%20Metropolis>.

Bozikivic, Alex. "Native Child and Family Services, by Levitt Goodman - Nomeancity." The World of Architecture, No Mean City, As Seen From Toronto. 21 Mar. 2011. Web. $<$ http://www.nomeancity.net/tour-native-child-and-family-services-by-levitt-goodman/>

Bruce, Heather E."Hoop Dancing: Literature Circles and Native American Storytelling." The English Journal, vol. 93, no. 1, 2003. Web. $<$ http://www.jstor.org.ezproxy.lib.ryerson.ca/stable/3650571?pq-origsite=summon\&seq=2\#page_scan_tab_contents>.

Buggey, Susan. “An Approach to Aboriginal Cultural Landscapes." Historic Sites and Monuments Board of Canada. Government of Canada,Ottawa, ON, Mar. 1999. Web. $<$ http://www.pc.gc.ca/docs/r/pca-acl/images/Aboriginal_Cultural_Landscapes_e.pdf>.

Burkhart Yazzie, Brian. “What Coyote and Thales can teach us: An outline of American Indian.” An outline of American Indian Epistemology in American Indian Thought: Philosophical Essays, vol. 29, Ed. Archuleta, Elizabeth. The University of Nebraska Press, Lincoln, NB, 2005, pp.15-26.

Cajete, Gregory and Leroy Little Bear. Native Science: Natural Laws of Interdependence. Clear Light Books, Santa Fe,NM, 2000.

Canada. The Truth and Reconciliation Commission of Canada. Honouring the Truth, Reconciling for the Future Summary of the Final Report of the Truth and Reconciliation Commission of Canada. The Truth and Reconciliation Commission of Canada, Ottawa, 0N, 23 July 2015. Web. <http://www.trc.ca/websites/trcinstitution/File/2015/Honouring_the_Truth_Reconciling_for_the_Future_July_23_2015.pdf>.

Canadian Community Health Survey: Mental Health, 2012." Statistics Canada. Government of Canada, 18 Sept. 2013. Web. $<$ http://www.statcan.gc.ca/daily-quotidien/130918/dq130918a-eng.htm>. 
Certeau, Michel de. The Practice of Everyday Life. University of California Press, Los Angeles, CA,1984.

Centre for Addiction and Mental Health. "Historical Chronology of CAMH's Queen Street Site." CAMH: Centre for Addiction and Mental Health. CAMH. Web.

$<$ http://www.camh.ca/en/hospital/about_camh/CAMH_redevelopment/history_of_queen_street_site/Pages/history_of_queen_street_site.aspx>.

Chansonneuve, Deborah, and Aboriginal Healing Foundation. Addictive behaviors among aboriginal people in Canada, Aboriginal Healing Foundation, Ottawa, 0N, 2007.

Chansonneuve, Deborah (2007) in Lee, Deborah. "Indigenous Knowledge Organization: A Study of Concepts, Terminology, Structure and (Mostly) Indigenous Voices." Partnership : the Canadian Journal of Library and Information Practice and Research, vol. 6, no. 1, 2011, pp.1.

Cold, Birgit. Aesthetics, Well-Being and Health: Essays within Architecture and Environmental Aesthetics. Ashgate, London, UK, 2001.

Cook, Gareth. "Why We Are Wired to Connect." Scientific American Global RSS. Scientific American Online, 22 0ct. 2013. Web. $<$ http://www.scientificamerican.com/article/why-we-are-wired-to-connect/>.

Courtwright, David. "The Prepared Mind: Marie Nyswander, Methadone Maintenance, and the Metabolic Theory of Addiction.” Addiction. Carfax Publishing, Jacksonville, Florida vol. 92, no.3, 1997, pp. 257-266.. Web. $<$ http://journals2.scholarsportal.info.ezproxy.lib.ryerson.ca/details/09652140/v92i0003/257_tpmmnmatmtoa.xml>.

Coyhis, Don, and Richard Simonelli. “The Native American Healing Experience." Substance Use \& Misuse, vol. 43, no. 12-13, 2008.

Creller, Aaron B. Making space for knowing: A Capacious Alternative to Propositional Knowledge. ProQuest Dissertations Publishing, Manoa, Hawaii, 2014.

Dapice, Ann N. “The Medicine Wheel." Journal of Transcultural Nusring. University of Ottawa Faculty of Medicine. SAGE Publications, vol. 17, no. 3, July 2006, pp. 251-260. Web. <http://www.med.uottawa.ca/sim/data/assets/documents/Aboriginal_medicine_wheel.pdf>.

Day, Christopher, and Rosie Parnell. Consensus Design: Socially Inclusive Process. Architectural Press, Burlington, MA, 2003.

Day, Christopher. Places of the Soul: Architecture and Environmental Design as a Healing Art. 2nd ed. Architectural Press, Burlington, MA,2004.

Day, Christopher, and Susan Roaf. Spirit \& Place: Healing our Environment, Healing Environment. Architectural Press, Burlington, MA,2002.

De Botton, Alain. The Architecture of Happiness. 1st American ed. McCelland and Stewart, Toronto, ON, 2006.

Diamonds, Stephen A. “Avoidance, Sobriety and Reality: The Psychology of Addiction." Psychology Today. Sussex Publishers, Feb. 2010. Web. <https://www.psychologytoday.com/blog/evil-deeds/201002/avoidance-sobriety-and-reality-the-psychology-addiction>.

Dickason, Olive P. Canada's First Nations: A History of Founding Peoples from Earliest Times. University of Oklahoma, Norman, 0K, 1992

Dumont, J. “Culture, behaviour, \& identity of the Native person”. NATI-2105: Culture, behaviour, \& identity of the Native person Laurentian University Press, Sudbury ON, 1989.

Edelman, Gerald M. Neural Darwinism: The Theory of Neuronal Group Selection. Basic Books, New York, NY, 1987.

"Facts about Mental IIIness - Canadian Mental Health Association." Canadian Mental Health Association. Canadian Mental Health Association. Web. $<$ http://www.cmha.ca/media/fast-facts-about-mental-illness/>.

Fischer, Ernst, John Berger, and Anna Bostock. The Necessity of Art. Verso, London, England 2010.

Fixico, Donald L. The American Indian Mind in a Linear World: American Indian Studies and Traditional Knowledge. Routledge, New York, NY, 1999. 
Forestry Innovation Investment "Squamish Lil'Wat Cultural Centre Case Study." Naturally Wood. Forestry Innovation Investment. Web.

$<$ <ttp://www.naturallywood.com/sites/default/files/Squamish-LilWat-Cultural-Centre-Case-Study.pdf>.

Foundations Recovery Network. “History of Rehab Facilities." Dual Diagnosis. Foundations Recovery Network. Web. <http://www.dualdiagnosis.org/drug-addiction/history-rehab-facilities/>.

Formline Architecture + Urbanism "Squamish Lil'Wat Cultural Centre." Formline Architecture + Urbanism. 2008. Web.

<http://www.formline.ca/SQUAMISH-LIL-WAT-CULTURAL-CENTRE>.

Fromm, Erich, and Ruth Nanda. Anshen. The Art of Loving. Harper \& Row, New York, NY, 1956.

"Genetics of Addiction." Addictions and Recovery. N.p., 1 Mar. 2016. Web.

$<$ http://www.addictionsandrecovery.org/is-addiction-a-disease.htm>

George, Dan, and Helmut Hirnschall. My Heart Soars. Hancock House, Saanichton, B.C., 1974

Government of Canada. "First Nations in Canada." Indigenous and Northern Affairs Canada. Government of Canada. Web.

$<$ https://www.aadnc-aandc.gc.ca/eng/1100100010002/1100100010021>.

Government of Canada. "The First Nations: The Powwow." Library and Archives Canada. Collections Canada, Ottawa, ON,08 Aug. 2012. Web.

$<$ https://www.collectionscanada.gc.ca/aboriginal-music-song/028012-2200-e.html>.

Gross, Lawrence William. Anishinaabe Ways of Knowing and Being. Routledge, New York, NY, 2016.

Harper, Douglas. "Addict." Online Etymology Dictionary. Web.

$<$ http://www.etymonline.com/index.php?term=addict>.

Hart, Michael. Seeking Mino-pimatisiwin: An Aboriginal Approach to Helping. Fernwood, Halifax, NS,2002.

Havens, F. M., Henry Coleman, and Leslie E. Keeley Co. An Open Letter : Descriptive of Dr. Keeley's method of Treatment and Cure of Drunkenness, 1891. Web. <https://babel.hathitrust.org/cgi/pt?id=dul1.ark:/13960/t57d6cr81; view=1up;seq=3>.

Heidegger, Martin. The Questions Concerning Technology and Other Essays. Harper Collins, New York, NY, 1982.

Heyman, Gene M. Addiction: A Disorder of Choice. Harvard UP, Cambridge, Mass., 2009.

Hill, (Gus) L. P. Understanding Indigenous Canadian traditional health and healing. Wilfrid Laurier University, Waterloo, 0N, 2008. Web. <http://search.proquest.com.ezproxy.lib.ryerson.ca/docview/304805019?pq-origsite=summon>

Hill, Jonathan. Weather Architecture. Routledge, New York, NY, 2012.

Hill, Johnathan. "Building a Drawing and Drawing a Building." Nordic Journal of Architectural Research, vol. 15, no. 4, 2002, pp. 15-20. Nordisk Arkitekturforskning. SINTEF Academic Press, Norway, 2013. Web. <arkitekturforskning.net/na/article/download/325/283>.

Hyde, Timothy. “Architecture, Modernity, Crisis." Journal of Architectural Education, vol. 69, no, pp. 2-3. 1, 2015.

$<$ http://journals1.scholarsportal.info.ezproxy.lib.ryerson.ca/details/10464883/v69i0001/2_amc.xml>

"Intervention to Address Intergenerational Trauma: Overcoming, Resisting and Preventing Structural Violence." University of Calgary Medicine, Calgary, AB, Winter 2012. Web. <https://www.ucalgary.ca/wethurston/files/wethurston/Report_InterventionToAddressIntergenerationalTrauma.pdf>. 
Israel, Toby. Some Place Like Home: Using Design Psychology to Create Ideal Places. Wiley, Ann Arbor, MI 2003.

Johnston, Basil. Ojibway Heritage. University of Nebraska Press, New York, NY, 1976.

Johnston, Basil. Ojibway Heritage: The ceremonies, rituals, songs, dances, prayers and legends of the Ojibway. McClelland and Stewart, Toronto, 1976.

Kirmayer, Laurence J., 1952, and Gail G. Valaskakis. Healing traditions: the mental health of aboriginal peoples in Canada. University Of British Columbia Press, Vancouver, BC 2009.

KiiskeeNtum. "Gifts from the Creator for Man's Use...The Smudging Ceremony." Aboriginal Multi-Media Society (AMMSA), vol. 16, no. 2, 1998. Web. $<$ http://go.galegroup.com.ezproxy.lib.ryerson.ca/ps/i.do?p=AONE\&u=rpu_main\&id=GALE|A30214013\&v=2.18it=r\&sid=summon\&userGroup=rpu_main\&authCount=1>

Lavallée, Lynn, et al. Journey to Healing: Aboriginal People with Addiction and Mental Health Issues: What Health, Social Service and Justice Workers Need to Know:: Centre for Addiction and Mental Health, Toronto, Canada, 2014.

Lefebvre, Henri, and Kanishka Goonewardena. Space, Difference, Everyday Life: Reading Henri Lefebvre. Routledge, New York, NY, 2008.

Lefebvre, Henri. The Production of Space, trans. Donald Nicholson-Smith, Blackwell, Oxford, UK, 1991.

Ley, David J. “The Addictive Society." Psychology Today. Sussex Publishers, 24 Aug. 2011. Web. $<$ https://www.psychologytoday.com/blog/women-who-stray/201108/the-addictive-society>.

Lee, Deborah. "Indigenous Knowledge Organization: A Study of Concepts, Terminology, Structure and (Mostly) Indigenous Voices." Partnership: the Canadian Journal of Library and Information Practice and Research, vol. 6 , no. 1, 2011, pp. 1. Web. < http://journals2.scholarsportal.info.ezproxy.lib.ryerson.ca/details/19119593/v06i0001/1_cat.xml>.

Lewis, Marc and Mark D. Griffiths Ph.D., By Adi Jaffe Ph.D., and By Suzanne Degges-White Ph.D. “Addiction." Psychology Today. Sussex Publishers. Web. $<$ https://www.psychologytoday.com/basics/addiction>.

Linebaugh, Peter. “Karl Marx, The Theft of Wood, and Working-Class Composition: A Contribution to the Current Debate." Social Justice, vol. 40, no. 1-2, 2014, pp. 137.

Linklater, Renee. Decolonizing Trauma Work: Indigenous Stories and Strategies. Fernwood Publishing, Black Point, NS, 2014.

Lown, Bernard. The Lost Art of Healing: Practicing Compassion in Medicine. Ballantine, New York, NY,1999.

Lown, Bernard. "Commodification of Health Care." Physicians for a National Health Program Newsletter. PHNP Newsletter, Spring 2007.

$<$ http://www.pnhp.org/PDF_files/spring2007newsletter_lown.pdf>.

Mancall, Peter C. Encyclopedia of Native American History. Facts On File, New York, NY, 2011.

Mander, Jerry. In the Absence of the Sacred: The Failure of Technology and the Survival of the Indian Nations. Sierra Club, San Francisco, CA, 1992.

Manitowabi, Darrel and Marjory Shawande. "The Meaning of Anishinabe Healing and Wellbeing on Manitoulin Island." Pimatisiwin: A Journal of Aboriginal and Indigenous Community Health, vol. 9.2, 2011, pp. 441-458. Web. <http://www.pimatisiwin.com/uploads/jan_20112/10ManitowabiShawande.pdf>.

Maté, Gabor. In the Realm of Hungry Ghosts: Close Encounters with Addiction. North Atlantic, Berkeley, CA, 2010.

Mate, Gabor in "Zeitgeist: Moving Forward-Natural Law." Prod. Peter Joseph. Perf. Gabor Mate. Netflix. Gentle Machines Productions, 2011. Web. <http://www.zeitgeistmovingforward.com/>.

Maudlin, Daniel, Marcel Vellinga, and Wouter Bervoets. Consuming Architecture: On the Occupation, Appropriation and Interpretation of Buildings. Routledge, New York, NY, 2014. 
McMillan, Alan D., and Eldon Yellowhorn. First Peoples in Canada. Douglas \& McIntyre, Vancouver, BC, 2004.

McNally, Michael David. Honoring Elders: Aging, Authority, and Ojibwe Religion. Columbia UP, New York, NY, 2009.

"Mental IIIness and Addictions: Facts and Statistics." Centre for Addiction and Mental Health. CAMH, 2012. Web.

$<$ http://www.camh.ca/en/hospital/about_camh/newsroom/for_reporters/Pages/addictionmentalhealthstatistics.aspx>

Metcalf, Peter. The Life of the Longhouse: An Archaeology of Ethnicity. Cambridge University Press, New York, NY, 2009. Web

$<$ http://www.ryerson.eblib.com.ezproxy.lib.ryerson.ca/patron/FullRecord.aspx?p=472017\&echo=1\&userid=ibA95MI4waOVQWqKEt|BXKAp\%2boq9h6yj\&tstamp=1470696545\&id=B04E7AA5EA065E96A FAAD98B8258815D7E5028E7>.

Mojtabai, Ramin. “Americans' Attitudes Toward Mental Health Treatment Seeking: 1990-2003." Psychiatric Services, vol. 58, no. 5, 2007, pp. 642-651. Web. <http://search.proquest.com.ezproxy.lib.ryerson.ca/docview/213083339?pq-origsite=summon>

Montgomery Sisam Architects. "Centre for Addiction and Mental Health Phase 1B." Montgomery Sisam Architects Inc. Web. $<$ http://www.montgomerysisam.com/projects/centre-addiction-and-mental-health-phase-1b>.

Montgomery Sisam Architects. "Sister of St. Margaret Smith Addiction Treatment Facility." Montgomery Sisam Architects Inc. Web. $<$ http://www.montgomerysisam.com/projects/sister-margaret-smith-addictions-treatment-centre>.

Moore, Charles W. "Architecture: Art and Science."Journal of Architectural Education (1947-1974), vol. 19, no. 4, 1965, pp 53-56. . Web. <http://www.jstor.org.ezproxy.lib.ryerson.ca/stable/1424258?pq-origsite=summon\&seq=1\#page_scan_tab_contents>.

Mussell, Bill, and Sarah Hamid-Balma, eds. "Aboriginal People." Visions Journal. Here to Help: BC Partners for Mental Health and Addiction Information, vol.5, no.1, Summer 2008, Vancouver, British Columbia, pp. 1-32. Web. <http://www.heretohelp.bc.ca/visions/aboriginal-people-vol5>.

Nabokov, Peter, and Robert Easton. Native American Architecture. Oxford University Press, New York, NY, 1989.

Native Women's Centre. “Traditional Teachings Handbook." Aboriginal Healing Outreach Program. Native Women's Centre, Aboriginal Healing \& Outreach Program, 2008. Web. <http://www.nativewomenscentre.com/files/Traditional_Teachings_Booklet.pdf>.

"Native Child and Family Services of Toronto / Levitt Goodman Architects." ArchDaily. 16 Mar. 2011. Web.

<http://www.archdaily.com/120391/native-child-and-family-services-of-toronto-levitt-goodman-architects>.

Nebelkopf, Ethan, and Mary Phillips. Healing and Mental Health for Native Americans: Speaking in Red, vol. 11, AltaMira Press, Plymouth, UK, 2004.

Norberg-Schulz, Christian. Genius Loci: Towards a Phenomenology of Architecture. Rizzoli, New York, NY, 1980.

Norton-Smith, Thomas M. The Dance of Person and Place: One Interpretation of American Indian Philosophy. State U of New York, Albany, New York, 2010.

"Ojibwe Teachings \& The 7 Grandfathers." Anishnaabeg Bimaadiziwin:An Ojibwe Peoples Resource. Web.

$<$ http://ojibweresources.weebly.com/ojibwe-teachings--the-7-grandfathers.html>.

Owen, S. (2014). "Walking in Balance: Native American Recovery Programmes". Religions, vol. 5, no. 4, 2014, pp. 1037-1049.

Pearen, Shelley J. Exploring Manitoulin. University of Toronto, Toronto, ON, 2001.

Pearson, Caryn, Teresa Janz, and Jennifer Ali. “Mental and Substance Use Disorders in Canada." Statistics Canada. Government of Canada, Ottawa, Sept. 2013. Web. <http://www.statcan.gc.ca/pub/82-003-x/2013009/article/11863-eng.htm>. 
Perez-Gomez, Alberto. “Architecture as a Performing Art- the End of the Master Builder?" Architecture: Norway. Arkitektur N Magazine, 25 May, 2015. Web. $<$ http://architecturenorway.no/questions/histories/perez-gomez-performance/>.

Pheasant, Kenny. “Ceremonies - Manidokewinan." Anishinaabemdaa. Little River Band of Ottawa Indians. Web. $<$ http://www.anishinaabemdaa.com/\#/about/ceremonies/Ceremonies>.

Rasmussen, Sandra. Addiction Treatment: Theory and Practice. SAGE Publications, London, UK, 2000.

Rodman, Margret in Milgrom, Richard. Sustaining Diversity: Participatory Design and the Production of Urban Space. York University, Toronto ON, 2003. Web. $<$ http://search.proquest.com.ezproxy.lib.ryerson.ca/docview/305290411?pq-origsite=summon>.

Ross, Rupert. Indigenous Healing: Exploring Traditional Paths. Google Play Ebook, Penguin Canada, 2014.

Sapolsky, Robert in “Zeitgeist: Moving Forward--Natural Law."Prod. Peter Joseph. Perf. Robert Sapolsky. Netflix. Gentle Machines Productions, 2011. Web. <http://www.zeitgeistmovingforward.com/>.

Saul, John Ralston. The Comeback. Penguin Books, Toronto, ON, 2014.

Schiff, Jeannette W., and William Pelech. "The Sweat Lodge Ceremony for Spiritual Healing." Journal of Religion \& Spirituality in Social Work: Social Thought, vol. 26, no. 4, 2007, pp. 71-93. Web. <http://journals1.scholarsportal.info.ezproxy.lib.ryerson.ca/pdf/15426432/v26i0004/71_tsllfsh.xml>.

Stanek, Lukasz. "Space as an Abstraction"Space, Difference, Everyday Life: Reading Henri Lefebvre edited by Kanishka GoonewardenaStefan Kipfer, Richard Milgrom, Christian Schmid, Routledge Publishing, New York, 2008, pp. 62-80. Web. <http://www.mom.arq.ufmg.br/mom/babel/textos/lefebvre_space_everyday.pdf>.

Sternberg, Esther M. Healing Spaces: The Science of Place and Well-Being. Belknap Press of Harvard University Press, Cambridge, MA, 2009.

Sunderland, Adam And Leanne C. Findlay. "Perceived Need for Mental Health Care in Canada: Results from the 2012 Canadian Community Health Survey-Mental Health." Statistics Canada Health Reports. vol. 24, no.9, Government of Canada, Ottawa, Sept. 2013. Web. <http://www.statcan.gc.ca/pub/82-003--/2013009/article/11863-eng.htm>.

Thrift, Nigel. Knowing Capitalism. Sage Publications, London, England 2005.

Thompson, Damian. The Fix: How Addiction is Invading our Lives and Taking Over Your World. Collins, London, UK, 2012.

Turner, Edith. “Life, Death, and Humor: Approaches to Storytelling in Native America." Arctic Anthropology, vol. 40, no. 2, 2000, pp. 23-29. Web. <http://www.jstor.org.ezproxy.lib.ryerson.ca/stable/40316586?pq-origsite=summon\&seq=1\#page_scan tab_contents>.

Wabano Centre for Aboriginal Health. "Our Building - Wabano." Wabano: Our Building Comments. Web. <http://www.wabano.com/about/our-building/>

West, Robert, and Ainsley Hardy. Theory of Addiction. Blackwell Pub./Addiction Press, Sussex, England, 2006.

Wilson, Kathleen J. The role of mother Earth in shaping the health of Anishinabek: A geographical exploration of culture, health and place. Queen's University, Ann Arbor, MI, 2001.

Wilson, Kathleen. “Therapeutic Landscapes and First Nations Peoples: An Exploration of Culture, Health and Place." Health and Place, vol. 9, no.2, 2003, pp. 83-93. Web. $<$ http://home.cc.umanitoba.ca/ hallmanb/files/GEOG4290-readings-pdf/wilson-2003.pdf>.

Williams-Shuker, Kimberly"An Analysis of Intravillage Longhouse Variability at the Draper Site." Paper presented at 1997 the Longhouse Conference: Inquiries into the Architecture, History and Symbolism of the Longhouse, Rochester Museum and Science Center, Rochester, NY, 1997. Web. <http://www.pitt.edu/ klwst25/draper.html>.

White, William L. Slaying the Dragon: The History of Addiction Treatment and Recovery in America. The Lighthouse Institute, Bloomington, IL, 1999. 
